\title{
EFL READING FLUENCY DEVELOPMENT AND ITS EFFECTS
}

BY

YEN THI NGOC TRAN

A thesis submitted to the Victoria University of Wellington in fulfilment of the requirements for the degree of Doctor of Philosophy in Applied Linguistics

Victoria University of Wellington 2011 


\begin{abstract}
Speed reading courses have been considered an effective method to improve learners' reading rate. Research in this area has concentrated on the effect of a speed reading course on students' speed improvement, but not on how to structure the course or the effects of speed improvement on other aspects of language and other types of reading. This thesis, in the first place, deals with the issue of scheduling a speed reading course, in terms of lesson frequency and course length, to achieve the best effect. The thesis also seeks to determine if speed development in the course leads to rate improvement in reading texts outside the course. Finally, the thesis looks at the effects of speed improvement on oral reading rate, language accuracy and language complexity. In the first of two experiments, a speed reading course was delivered to the four experimental groups, who followed the course on different scheduling. Four scoring methods were used to measure the participants' speed improvement and it was found that one group made smaller increases than the others in all scoring methods. A pre-test and a post-test for reading other types of texts were administered and the speeds on these texts by the four treatment groups were compared with those by the control group. The results demonstrated that all but one group from the treatment category outperformed the control group. The second experiment was both a replication of the first experiment in order to confirm the reliability of the first experiment's results and an expansion from the first experiment to explore other issues. It involved two control groups, one of which followed the usual English program at the university and two treatment groups, one of which received consultation sessions during the treatment. The results on speed increases within the speed reading course corroborate the findings in the first experiment. Reading rate transfer from the speed reading course to other texts was significant $(p<.001)$. Comparisons within the treatment groups and within the control groups demonstrated that the usual English program did not noticeably affect the speed increase transfer to other texts, oral reading fluency improvement, or language memory span development, but the consultation sessions substantially affected speed improvement in the course and speed improvement on other types of texts. With respect to oral reading rate the experiment found that the difference between the control groups and the treatment groups was statistically significant $(\mathrm{p}<.05)$. The relationships between reading fluency, language accuracy, and language complexity were also explored by looking at the comprehension scores and memory span results. It was found that reading fluency improvement does not
\end{abstract}


necessarily negatively affect comprehension. It, however, does not assist language accuracy development to a remarkable degree. More importantly, the experiment showed that the treatment groups considerably expanded their memory span, which implies that reading speed improvement facilitates language complexity. High correlations between speed increases in the speed reading course, reading rate improvement in other types of texts and memory span development were also found. 


\section{ACKNOWLEDGEMENTS}

I would like to express my deep gratitude to my supervisor, Paul Nation, who I believe is the most wonderful supervisor, for his valuable direction, keen insight, precious orientation, warm encouragement, and continuous support throughout this project. His enthusiasm and positive attitudes were sparkling in such a way that it helped to make my research a serious yet fun task to fulfil.

I also wish to thank my secondary supervisor, John Macalister, the head of the Linguistics and Applied Language Studies School, for foreseeing what would come along during the project right from the first days I began it. Without that, it would have been harder for me to finish the project. His prompt responses and important suggestions contributed a significant part in the thesis.

I am in debt to Sonia Millett for letting me observe her English Proficiency Program classes at the English Language Institute, Victoria University of Wellington.

I am grateful to Phan Van Tien, Nguyen Thi Tuong, Vu Thi Viet Huong, Luu Duc Hau, teachers at Vinh university in Vietnam, for letting me work with their classes while I was gathering the data for the research; and Nguyen Quynh Trang, for letting me use the computer room and helping me out with technical issues.

I wish to express my deep appreciation to Henry Lenselink, for designing the software programs, without which I would not have been able to undertake the second experiment, and for supporting me as always.

I would also like to thank the administrators, teachers, and students at both Victoria University of Wellington, New Zealand and Vinh University, Vietnam for their cooperation and help.

Finally, I would like to delicate this work to my parents and family, who have been always supporting me with love and sympathy. 


\section{TABLE OF CONTENTS}

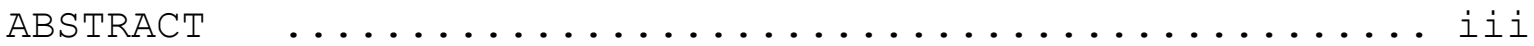

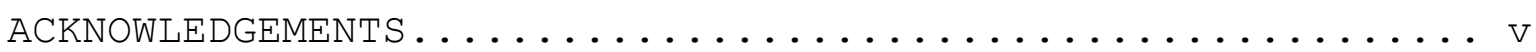

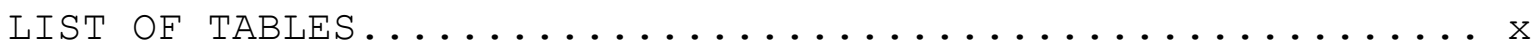

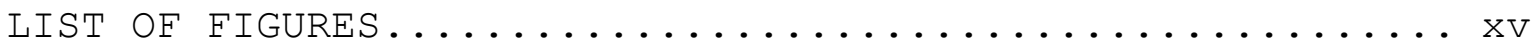

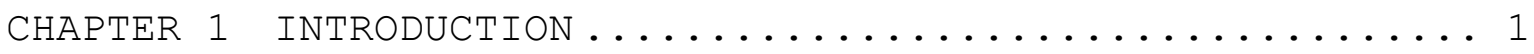

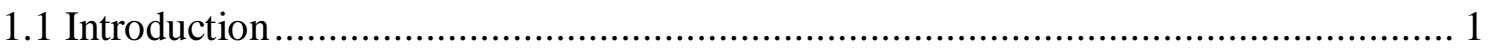

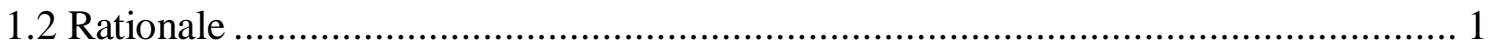

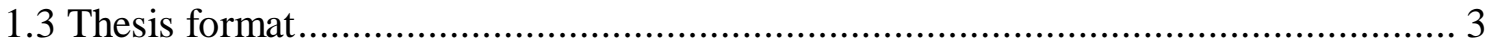

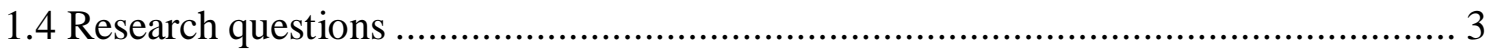

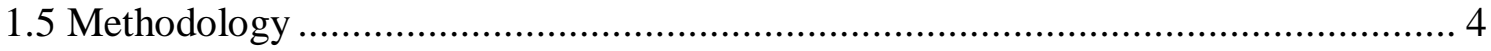

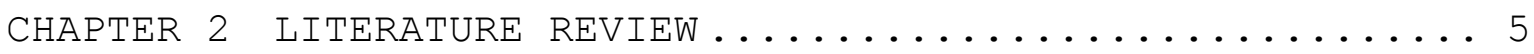

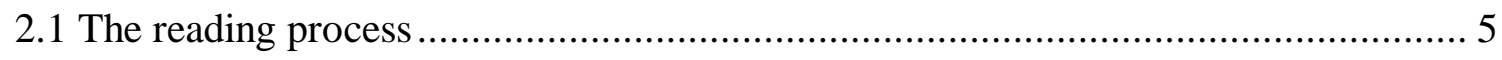

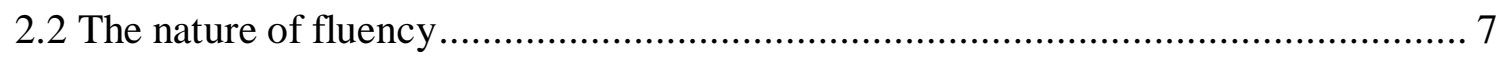

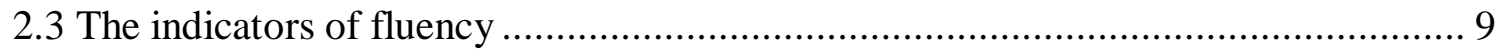

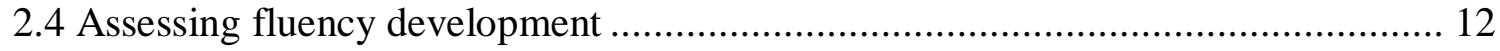

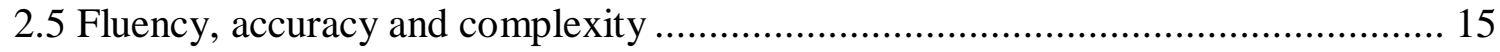

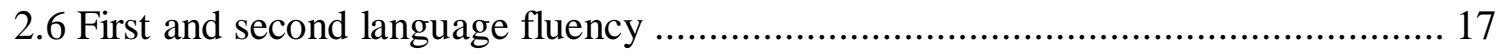

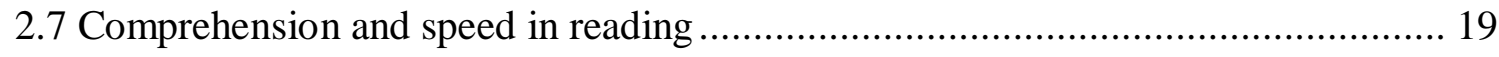

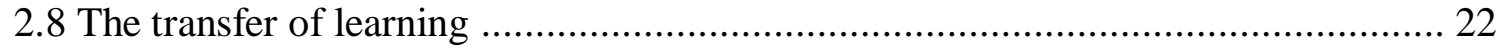

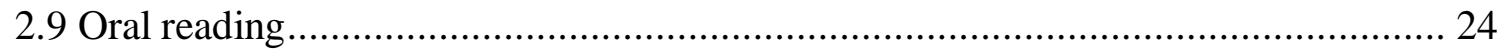

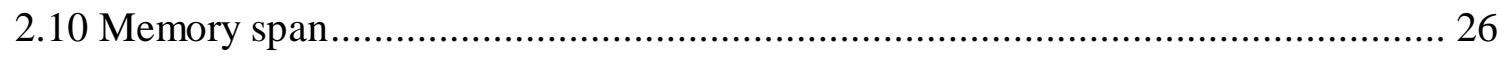

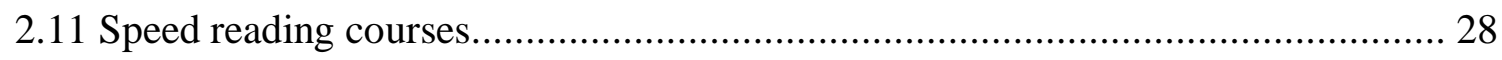

CHAPTER 3 THE FIRST EXPERIMENT .............. 32

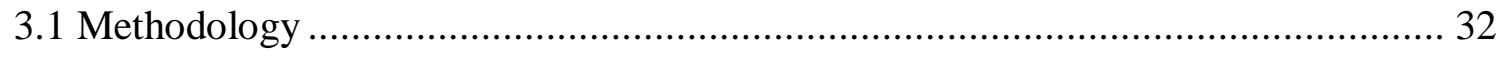

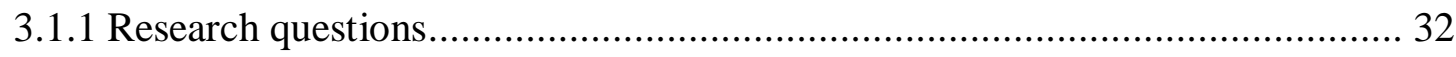

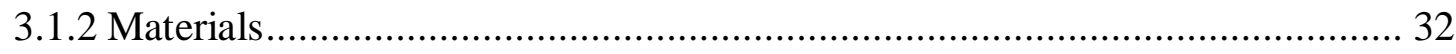

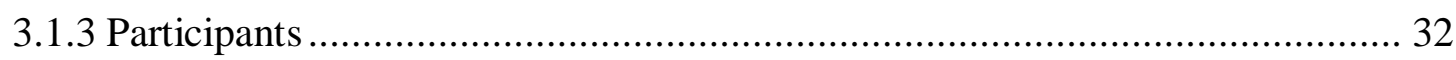


3.1.4 Procedure 33

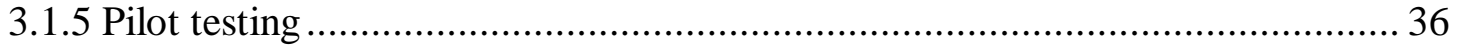

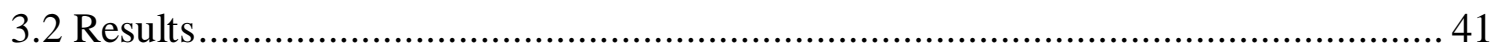

3.2.1 Speed increases in the speed reading course .......................................... 41

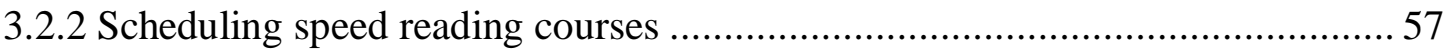

3.2.3 Speed increase transfer from the speed reading course to other types of texts .. 64

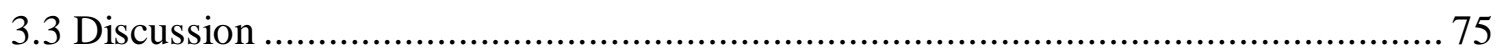

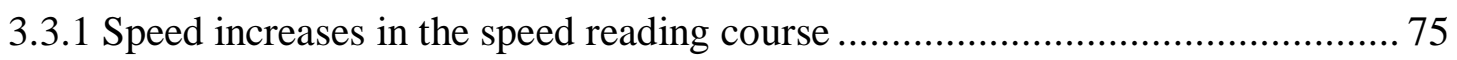

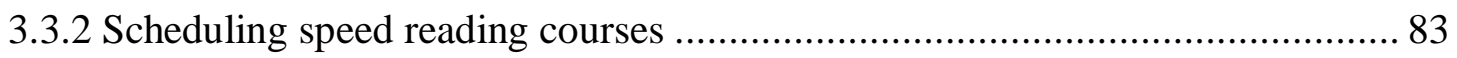

3.3.3 Speed increase transfer from the speed reading course to other types of texts .. 84

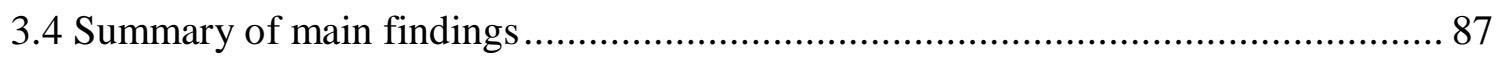

CHAPTER 4 THE SECOND EXPERIMENT $\ldots \ldots \ldots \ldots \ldots \ldots \ldots \ldots$

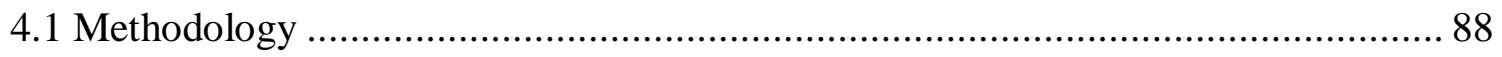

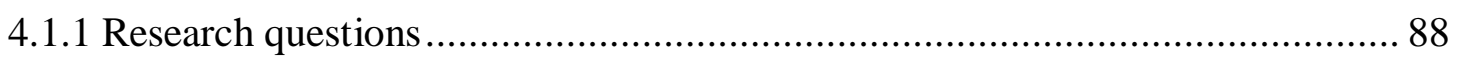

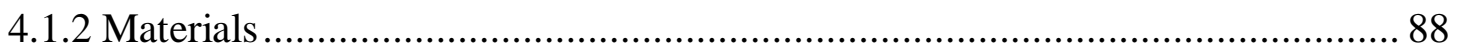

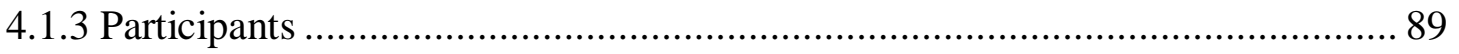

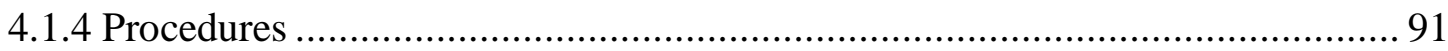

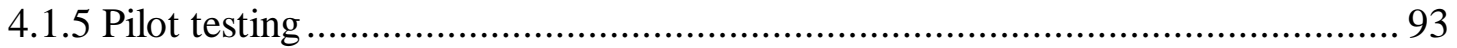

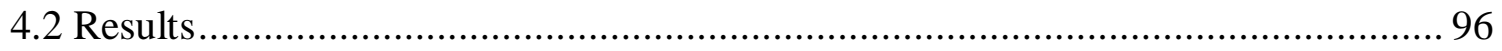

4.2.1 Speed increases in the speed reading course ............................................. 96

4.2.2 Speed increase transfer from the speed reading course to other types of texts 104

4.2.3 The effect of the speed reading course on oral reading rate .......................... 123

4.2.4 The effect of the speed reading course on language complexity ................... 129

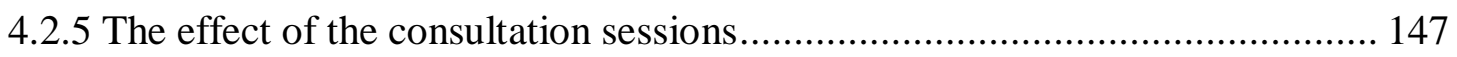

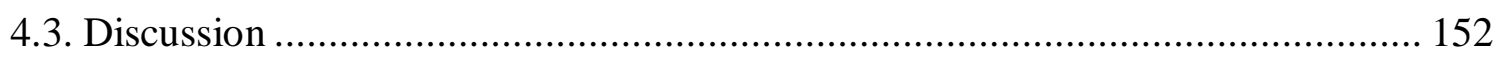

4.3.1 Speed increases in the speed reading course .......................................... 152

4.3.2 Speed increase transfer from the speed reading course to other types of texts 159 
4.3.3 The effects of the speed reading course on other aspects of language

knowledge 164

4.3.4. The effect of the consultation sessions 174

4.4 Summary of main findings

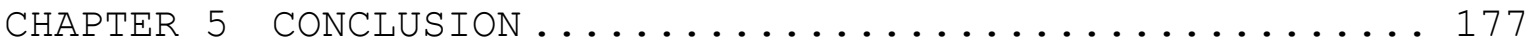

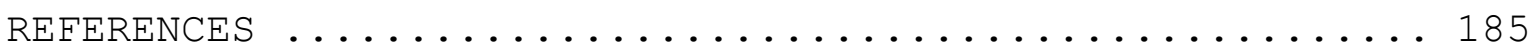

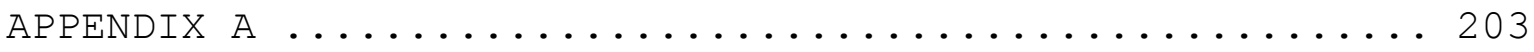

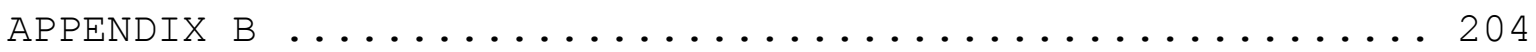

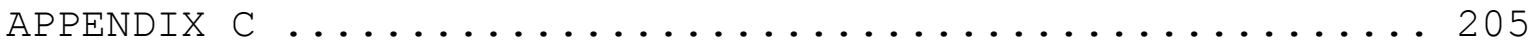

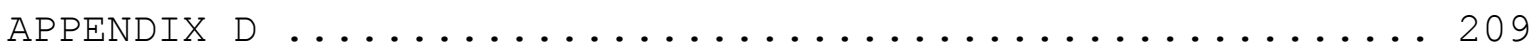

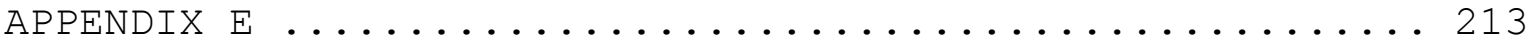

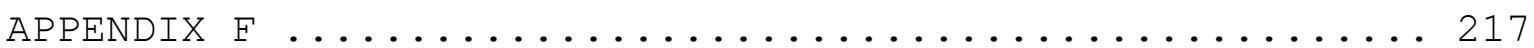

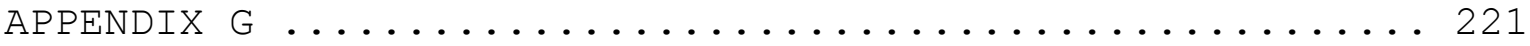

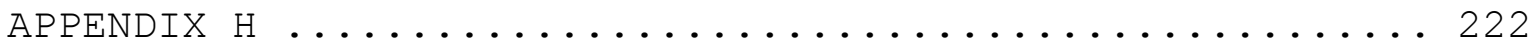

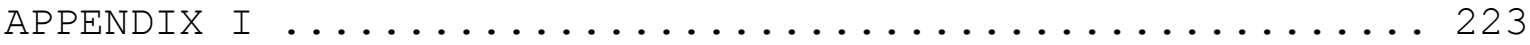

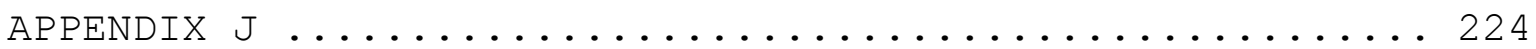

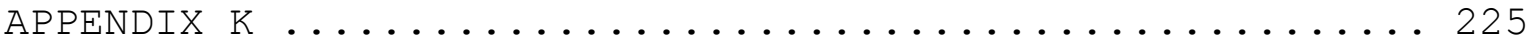

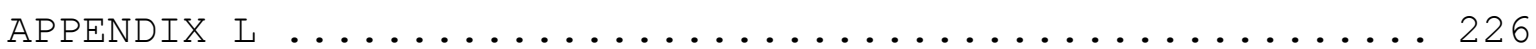

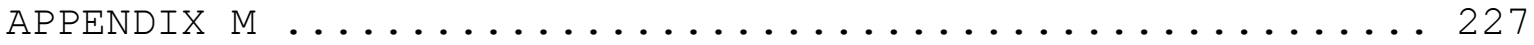

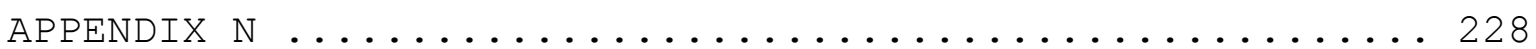

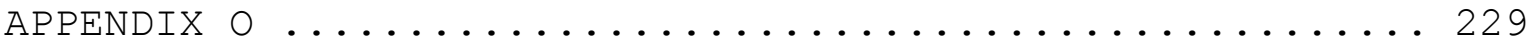

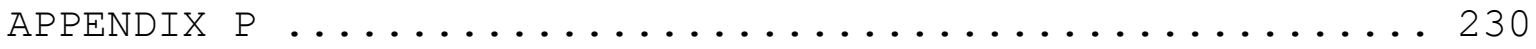

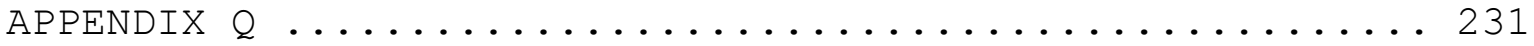

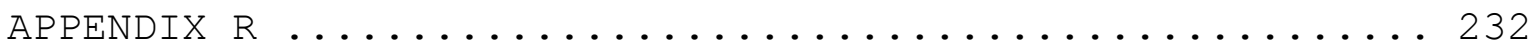

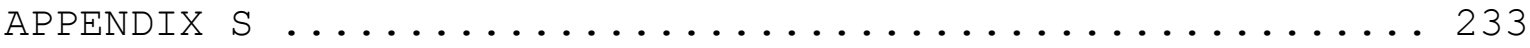

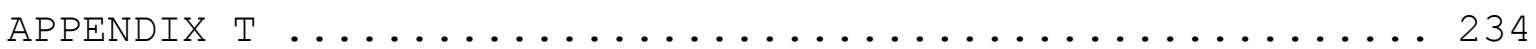

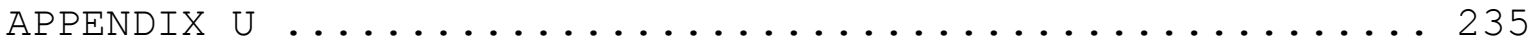

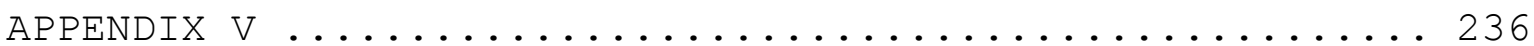

APPENDIX W 237

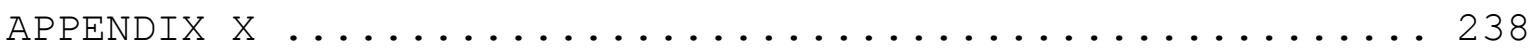




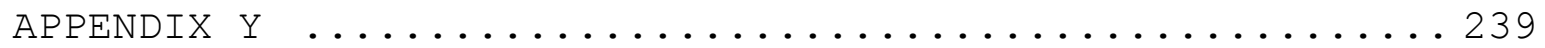




\section{LIST OF TABLES}

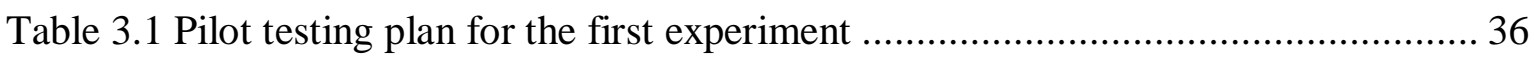

Table 3.2 Means and standard deviations of initial speeds in the course for all groups ..... 43

Table 3.3 Means and standard deviations of in-course speed increases for the treatment

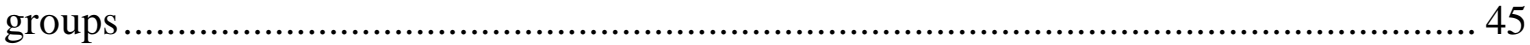

Table 3.4 Results by the participants who made no improvement .................................. 47

Table 3.5 Comparison of mean speed increases by four groups as original results and results after removing the scores by participants who made no progress

Table 3.6 Average comprehension scores on the first three texts and the last three texts, and in the three highest speed sessions, in the first half and the second half of the course

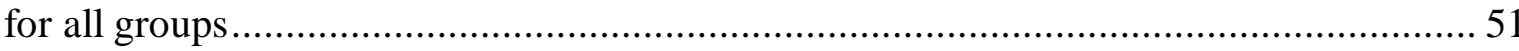

Table 3.7 Initial speeds (Ini) and final speeds (Final) in the course by all participants...... 52

Table 3.8 Numbers of participants for different change patterns 57

Table 3.9 Sessions in which each of the participants in group 1 had their three slowest and

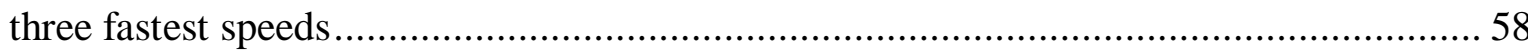

Table 3.10 Summary of the best sessions and the worst sessions for group 1 ..................59

Table 3.11 Summary of the best sessions and the worst sessions for groups 2, 3 and $4 \ldots 60$ Table 3.12 Means and standard deviations of in-course speed increases in all the four scoring methods for all treatment groups

Table 3.13 Means and standard deviations of in-course speed increases for all treatment groups when using calculations involving 16 texts

Table 3.14 Mean and standard deviations of speed increases (post-test minus pre-test) for all groups

Table 3.15 Mean and standard deviations of pre-test speed and post-test speed for all groups 65

Table 3.16 Means and standard deviations of speeds on the pre-tests and the post-tests for all groups

Table 3.17 Summary of reading speeds on the pre-tests and post-tests and speed increases for all groups

Table 3.18 Initial speed (Pre) and final speed (Post) on other texts for all participants (P) 70 Table 3.19 In-course increases (SRI) and increases on other texts (OTI) for the participants $(\mathrm{P})$ in the treatment groups 
Table 3.20 Means and standard deviations of speed increases on other types of texts for the treatment groups

Table 3.21 The four orders of texts in the pre-tests and the post-tests.

Table 3.22 Means and standard deviations of scores by four different groups following the four ways of text ordering....

Table 3.23 Speeds and average speeds in the pre-test and post-test for each of the four texts .74

Table 3.24 Frequency of the word types appearing in the speed reading course 77 Table 3.25 Numbers of word types appearing in each text of the pre-tests and post-tests and in the speed reading course .78

Table 3.26 Average of the three initial speeds for the four treatment groups .................... 80

Table 3.27 Increases made by the participants in the four treatment groups 81

Table 4.1 Brief description of what the four groups followed during the second experiment 91

Table 4.2 Pilot testing plan for the second experiment 93

Table 4.3 Means and standard deviations of in-course speed increases for the treatment groups

Table 4.4 Means and standard deviations of initial speeds and final speeds in the course for the treatment groups

Table 4.5 The percentage of participants having their slowest and fastest speeds in the four parts of the course 98

Table 4.6 Results by the participants who made no improvement in either the $20^{\text {th }}$ minus $1^{\text {st }}$ method or the average method

Table 4.7 Comparisons of groups' results with and without the negative results by participants who made no improvement in the course.

Table 4.8 Means and standard deviations of comprehension scores on the first three texts, the last three texts, in the first half and the second half of the course for the two treatment groups 101

Table 4.9 Average of the first three scores (I) and average of the last three scores (F) in the course for the participants $(\mathrm{P})$ in the two treatment groups 103

Table 4.10 Numbers of participants for different change patterns 104

Table 4.11 Means and standard deviations of speed increases on other types of texts for all groups 105 
Table 4.12 Means and standard deviations pre-test speed and post-test speed on other types of texts for all groups

Table 4.13 The slowest speeds, fastest speeds on the pre-test and post-test, the greatest progress and the worst progress for each of the four groups..... 108

Table 4.14 Numbers of participants in each group with speeds/increases in the three speed ranges in the pre-test, post-test and difference between the pre-test and post-test..... 108

Table 4.15 Means and standard deviations of initial speeds, final speeds and speed increases on other types of texts for all groups.

Table 4.16 Initial speeds (Pre) and final speeds (Post) on other types of text for all participants $(\mathrm{P})$

Table 4.17 In-course increases (SRI) and increases on other texts (OTI) by participants

(P) in the treatment groups

Table 4.18 Initial speeds, final speeds and increases on other types of texts by participants following the two orders of text administration

Table 4.19 Means and standard deviations of initial comprehension scores (Initial CS), post-test comprehension scores (Final CS), initial speeds (IS) and final speeds (FS) for three subgroups

Table 4.20 Comparison of comprehension improvement for the control groups and the treatment groups.

Table 4.21 Comparison of comprehension improvement for the control groups and the treatment groups.

Table 4.22 Reading speeds on four sections of the texts in the pre-test and post-test for all groups

Table 4.23 Speed change patterns in four sections of the texts in the pre-test and post-test for all participants

Table 4.24 Speed change patterns in two halves of the texts on the pre-test and post-test for all participants

Table 4.25 Comparison of performance on other types of texts for group C and group D122

Table 4.26 Increases (syllables per minute) in oral reading for all groups

Table 4.27 Comparisons of performance on oral reading tests using the syllables per minute calculation for all groups

Table 4.28 Comparisons of performance on oral reading tests using the words per minute calculation for all groups 124 
Table 4.29 Means and standard deviations of initial speeds and final speeds (in syllables per minute and words per minute) in oral reading for all groups

Table 4.30 Oral reading speeds (in syllables per minute) on the pre-test and post-test for the two orders of text administration

Table 4.31 Comparison of initial reading rate in the course, initial silent reading rate on other texts and initial oral reading rate for all groups 128

Table 4.32 Comparison of final reading rate in the course, final silent reading rate on other texts and final oral reading rate for all groups ................................................ 128 Table 4.33 Scoring criteria for the language memory span tests 130

Table 4.34 Increases in language memory span for all groups (tough scoring method)... 131 Table 4.35 Means and standard deviations of pre-test and post-test memory span for all groups (tough scoring method)

Table 4.36 Increases in language memory span for all groups (moderate scoring method)134 Table 4.37 Increases in language memory span for all groups (the generous scoring method)

Table 4.38 Means and standard deviations of initial scores, final scores and increases in memory span for all groups

Table 4.39 The lowest score and the highest score in the pre-test and post-test, the best progress and the worst progress in memory span for each of the four groups 136

Table 4.40 Initial scores and final scores on the memory span tests by all participants ... 137 Table 4.41 Means and standard deviations of memory span increases and in-course speed increases for three subgroups classified according to memory span increases Table 4.42 Means and standard deviations of memory span increases and speed increases on other texts for four subgroups classified according to memory span increases Table 4.43 Means and standard deviations of memory span scores for participants in each group following the two orders of text administration.

Table 4.44 Percentage of correct answers in each of the five parts of the memory span tests for all groups

Table 4.45 Numbers of participants having correct answers in each part of the test for all groups

Table 4.46 Results on the memory span tests for the control groups.

Table 4.47 Means and standard deviations of percentage of error on the pre-test and posttest and their difference for all groups 
Table 4.48 Numbers of participants with a decrease and participants with no decrease in percentage of errors on the memory span tests for all groups

Table 4.49 Comparison of decreases in error rate before and after removing unusually high or low scores for all groups

Table 4.50 Means and standard deviations of increases in the course for the two subgroups of the treatment groups..... 148

Table 4.51 Means and standard deviations of initial speeds in the course for the two subgroups.

Table 4.52 Means and standard deviations of increases, initial speeds and final speeds on other texts for the two subgroups. 150

Table 4.53 Means and standard deviations of increases, initial speeds and final speeds in oral reading for the two subgroups

Table 4.54 Means and standard deviations of increases, initial raw scores and final raw scores in memory span tests for the two subgroups.....

Table 4.55 Means and standard deviations of increases from the first three texts to the next three texts for all treatment groups in the two studies

Table 4.56 Means and standard deviations of speed increases by groups 1 and 2 and groups $\mathrm{A}$ and $\mathrm{B}$

Table 4.57 Means and standard deviations of speed increases by groups 3 and 4 and groups $\mathrm{A}$ and $\mathrm{B}$ 155

Table 4.58 Comparison of the average of the three slowest speeds and three fastest speeds for groups 3 and 4 and groups $\mathrm{A}$ and $\mathrm{B}$.

Table 4.59 Means and standard deviations of initial speeds and final speeds by groups 3 and 4 and groups $\mathrm{A}$ and $\mathrm{B}$

Table 4.60 Comparisons of increases on other types of texts and the difference between the treatment groups' increases and the control groups' increases for the two studies .... 160 Table 4.61 Comparison of initial speeds and final speeds on other types of texts for the control groups in both experiments.....

Table 4.62 Comparison of initial speeds, final speeds and increases on other types of texts by the treatment groups in both experiments.....

Table 4.63 Percentage of improved items in the memory span tests

Table 4.64 Improvement level in terms of error free sentences in the memory span tests by participants in the control groups and the treatment groups..... 170 
Table 4.65 Number of participants having a correct answer on each item of the memory span test - version A

Table 4.66 Number of participants having a correct answer on each item of memory span

test - version B

\section{LIST OF FIGURES}

Figure 3.1 Time intervals shown on the board in speed reading sessions. 34

Figure 3.2 Progress chart for participants who had a negative results comparing the second half and the first half of the course 48

Figure 3.3 Progress chart of participant 2F/no improvement 54

Figure 3.4 Progress chart of participant 2H/improvement 54

Figure 3.5 Progress chart of participant $3 \mathrm{Q} /$ gradual increase. 55

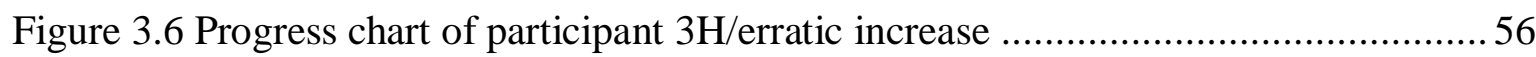

Figure 3.7 Progress chart of participant 3L/plateau increase ..........................................56

Figure 3.8 Estimated marginal means of speed increases on other texts for all groups...... 66

Figure 4.1 Progress charts by participants who had negative results in the course 99

Figure 4.2 Estimated marginal means of speed increases on other texts for all groups.... 107

Figure 4.3 Estimated marginal means of comprehension increases for all groups 117

Figure 4.4 Estimated marginal means of memory span increases for all groups 132 



\section{CHAPTER 1 INTRODUCTION}

\subsection{Introduction}

Reading fluency plays an important part in academic achievement at colleges and universities. This may explain the use of speed reading courses to help students improve their reading speed while maintaining an appropriate level of comprehension. A number of studies have shown the positive influence of a speed reading course on students' reading speed but there has not been any research on what scheduling method of a speed reading course will cause the greatest increase and what effects speed increases will have on other aspects such as oral reading, language accuracy and language complexity.

This thesis explores the effects of four different ways to schedule a speed reading course. Four groups of participants followed the speed reading course with one, two, three and four sessions a week. The results were compared to see which group gained the greatest increase. Secondly, the thesis examined the transfer of speed increase to other types of texts. Texts that were not in the speed reading course were used as pre-test and post-test for this purpose. Finally, the effects of speed increase on oral reading rate, language accuracy and language complexity were also studied. Oral reading rate was measured using a different method from the conventional ones, language accuracy was measured by comprehension questions, and language complexity was assessed by a language memory span test.

\subsection{Rationale}

According to West (1941), reading is one of the most important skills in study and daily life. Because reading ability is powerful, various researchers have attempted to investigate ways to improve students' reading ability in reading programs. Whipple (1964), for example, listed the eight criteria of a good reading program. Hoffman and Rutherford (1984) have reviewed studies on the implementation of reading programs throughout the US and concluded that there were a number of factors common among effective programs. In attempts to help teachers train their students to read better, numerous researchers such as Glock (1949), Buurman (1981), Paulson (2005) and Tinker (1946) focused on the reader's eye movements and proposed mechanical ways to count the reader's fixations or film their eye movements while they were reading. 
West (1941) believed that reading ability is powerful because it transfers from one language to another language. Therefore, if a person's reading speed in his mother language improves, it is likely that his foreign language reading rate will increase as a transfer effect. Based on this idea, several studies have investigated the transfer of reading rate improvement in mother tongue to L2 reading speed. Some influential research includes the studies by Cramer (1975), and Bismoko and Nation (1972), who found a large amount of reading speed transfer from L1 to L2. In addition, other researchers such as Elley and Mangubhai (1983) have also found that L2 reading has a role in L2 learning and gains in L2 reading rate increased over the treatment period and spread to related language skills. These findings highlight the benefits of reading speed improvement.

Techniques and methods related to the teaching reading skills process have also been taken into consideration. A great deal of research has been done to examine the benefits of retelling stories, repeated reading, speed reading courses, and extensive reading as methods to improve reading rate. For instance, Dowhower (1987) implemented repeated reading to determine its effects on children's reading speed, language accuracy, and comprehension. Susser and Robb (1990) discussed the role of extensive reading in language teaching and learning. Lituanas, Jacobs and Renandya (1999) showed that a well-conducted extensive reading program can have a significant effect on reading proficiency by conducting a study involving 60 first year students in the Philippines during which they had half of the group follow an extensive reading program while the other did not.

Speed reading courses, along with repeated reading and extensive reading, have been one popularly used method to help students increase their speed of reading. While Carver (1985) warned that increasing L1 reading speed may result in decreases in comprehension accuracy, some other researchers have maintained that speed training in one language assists reading ability in another language (Bismoko \& Nation, 1972; Bismoko \& Nation, 1974; Cramer, 1975). Chung and Nation (2006) in their investigation into the effects of a speed reading course pointed out five patterns of speed change and the degrees of reading speed increases before concluding that a speed reading course is of great help for language learners to develop their reading fluency. Macalister $(2008,2010)$ also looked at how a speed reading course could assist fluency development in reading.

Still there has not been much research directly oriented to the effect of those speed reading courses. Thus, it would be useful to determine the ideal length of a course, and more 
importantly, the effect of reading speed improvement on other types of reading outside the course, on oral reading, and on other aspects of language knowledge such as accuracy and complexity.

\subsection{Thesis format}

The thesis consists of five chapters.

Chapter 1 is the introduction, which provides a brief introduction, rationale and an overview of the thesis.

Chapter 2 is the literature review, in which previous research about the nature of reading, the nature of fluency, fluency development and assessment, first and second language fluency, language accuracy, complexity and fluency, memory span, reading comprehension, oral reading, transfer in learning, and speed reading courses will be discussed.

Chapter 3 presents the first experimental study, which aimed to scrutinize the effects of speed reading course length and frequency on reading rate improvement and the transfer of reading speed to other types of texts.

Chapter 4 deals with the second experiment, which was a replication study of the two issues in the first experiment, and was also extended in order to explore other effects of silent reading speed development on oral reading rate and language complexity.

Chapter 5 contains the discussion and conclusions.

\subsection{Research questions}

The thesis seeks to answer the following research questions:

1. How should a speed reading course be scheduled to achieve the best effect?

2. Will an increase of speed in a speed reading course transfer to other types of texts?

3. Will an increase of speed in a speed reading course transfer to oral reading?

4. Will the increase of reading rate as a result of a speed reading course be accompanied by changes in dealing with language complexity? 


\subsection{Methodology}

The main methodology used in the project was experimental. Groups of university students in Vietnam were involved in the two studies. A computer program was designed for the second experiment.

The study is intended to better inform the way teachers prepare speed reading courses and to see to what degree the benefits of fluency development extend beyond the speed reading course. 


\section{CHAPTER 2 LITERATURE REVIEW}

This chapter presents a brief review of the literature on the topics that are generally related to the research in this thesis. Previous studies on the reading process, the nature of fluency, the indicators of fluency, fluency assessment, L1 and L2 reading fluency, speed reading courses, comprehension and speed in reading, transfer theory, language fluency, accuracy and complexity, oral reading, and language memory span will be discussed.

\subsection{The reading process}

According to West (1941), reading is one of the most important skills in study and daily life. Thus, a considerable amount of literature has been published on reading. These studies investigate the nature of reading and describe reading components. The most popular theoretical perspectives in reading theory are verbal efficiency theory, schema theory, whole language theory, and rauding theory.

Verbal efficiency theory, as proposed by Perfetti (1985), tries to explain the reading process by focusing on eye fixations at fast rates. He assumed that each reader has a profile of verbal efficiency. The larger the profile, the more attentional resources are available for higher level skills, the faster the reader can read.

Schema theory (Anderson \& Pearson, 1984; Carrell \& Eisterhold, 1983) explains how people organize their knowledge using schemas or knowledge structures. Thus, it examines reading as a process for studying rather than typical reading. In other words, their subjects are people who are deliberately reading a text to learn something from it or to memorize it.

Whole language theory (Goodman, 1989; Watson, 1989) holds that reading is a natural process which has a close link with speaking, listening and writing, thus if one of these language skills develops, the others will be improved as a result. It advises educators to use a child-centred philosophy to encourage children to learn. This theory addresses normal reading but mainly deals with young readers rather than adult readers.

Rauding theory, which was proposed and developed by Carver (1977b, 1981, 1984, 1990, 1992a, 1993, 2000), focuses on normal reading by both children and adults. As this theory 
is the most relevant to the topic of this thesis, it is worthwhile providing a description of how it works.

Carver (1977b) noted that some definitions of reading are vague and general because they simply state that reading is getting meaning from printed texts. This includes a situation in which people read a text at $1000 \mathrm{wpm}$ and still get some meaning from the text suited to their purpose. However, this type of reading is unusual and does not typically happen in everyday life. Therefore in rauding theory, the term reading is used to refer to what is called normal reading, or typical reading. Some examples of this are a college student reading a text for an assignment or an adult reading a newspaper. Carver (1977a) calls this kind of reading reading ${ }^{2}$ to distinguish it from reading ${ }^{l}$, a generic term referring to the action of looking at words to get meaning. In reading ${ }^{l}$ there are five basic processes, or reading gears, as termed by Carver (1992b, p. 85): scanning, skimming, reading ${ }^{2}$, studying, and memorizing. Carver pointed out that readers shift up to the higher gears or down to the lower gears when their reading purposes change. For instance, when they do not need to understand every single sentence of the text, they usually utilize skimming. On the other hand, when they have to know the information well enough to use it for later purposes, they may shift down to studying or memorizing. However, in a typical situation, readers only operate at the third gear, reading ${ }^{2}$ or rauding. Although the term rauding in this theory involves both auding (listening) and reading, only the second dimension will be discussed in this literature review as the thesis particularly concerns fluency in reading.

According to Carver (1997), in the rauding process, readers make fixations on almost all of the words in the text and comprehend all, or most of the complete thoughts presented in the text. If readers understand less than around 75 percent of presented thoughts, they are said to have been reading, but not rauding. One of the fundamental factors for this process to occur is that the reading material must be relatively easy. If the text is at a higher level than the ability level of the reader, the rauding process is unlikely to happen. The instructions are also an important factor in that if the readers are asked to study the text carefully so that they will be able to recall the details later, perhaps they will not utilize the rauding process. These features account for the relevance of the rauding theory to this research. In the two experiments, the speed reading texts were 20 stories written within the participants' vocabulary level. The speed reading instructions informed the participants that they did not have to memorize the text for later tests, and that the 
comprehension level should be around 70 percent. The pre-test and post-test instructions asked the participants to read at the speed that they would normally read.

Carver $(1982,1983)$ found that native speakers tend to read at a constant speed of around $300 \mathrm{wpm}$, which is called the rauding rate. If readers are reading at faster or slower speeds, the process is not called rauding. Carver (1982) maintained that around $300 \mathrm{wpm}$ is the optimal rate of reading where efficiency is at its maximum. It is worth noting that rauding theory was based on research on reading English as L1. Therefore the constant rauding rate of native English people reading English texts may be different from the rauding rate of non-native English speakers reading English texts. One possible explanation for this is that adult native speakers of English already have better word recognition or automaticity than adult non-native speakers of English, thus they can save more attentional resources for comprehending. Meanwhile non-native English adults have to spend more time coping with the writing system, which slows down their speed of comprehending the text, thus may not be able to read at $300 \mathrm{wpm}$. Since this thesis concerns reading English as a foreign language, it is expected that the findings would be somehow different from the ones by Carver. However, because the mental processes of reading operate universally across languages, rauding theory is still powerful enough to serve as the underpinning of the reading process and reading speed development in this research. The thesis mainly concerns reading ${ }^{2}$ or rauding, one of the five basic processes in reading ${ }^{l}$ in that the participants read relatively easy texts with adequate accuracy of comprehension while knowing that they do not have to memorize or study the texts for later tests. The participants' reading speed during the treatment, in the pre-test and post-test will be understood as the speed of the rauding process, that is, the rate at which they read relatively easy texts and comprehend most of the presented thoughts in the text. Although it was found that rauding rate in L1 reading is constant (Carver, 1982, 1983) and speed reading courses in L1 do not help to improve this rate (Carver, 1992b), the experiments in this thesis show that a speed reading course in L2 can assist intermediate learners of English to increase their rauding rate in L2 reading.

\subsection{The nature of fluency}

Fluency plays a crucial role in proficient reading as once readers become automatic in decoding, they can devote their attention to comprehending text (Hiebert \& Fisher, 2005). Thus fluency has a close link with comprehension (Fuchs, Fuchs, \& Maxwell, 1988; 
Kuhn \& Stahl, 2003; McGlinchey \& Hixson, 2004; Oakley, 2005; Pinnell, 1995; Rasinski \& Padak, 1996; Silberglitt, Burns, Madyun, \& Lail, 2006). Furthermore, fluency is the target of the third stage in the six stages of reading ability: prereading, decoding, fluency, reading for new learning, multiple viewpoints, construction and reconstruction (Chall, 1983). During the third stage, learners practice to gain automatic word recognition and use semantic and syntactic clues in text to confirm word recognition. If learners cannot attain fluency, it is likely that they cannot reach the consequent stages of reading ability (Stahl \& Heubach, 2005). Fluency also plays a role in developing readers' confidence and motivation in that if readers become more fluent, they tend to enjoy and spend more time reading, which in turn, helps them to develop additional fluency (Oakley, 2005). Besides, fluency has an association with L1 rauding as Carver (2000) commented:

"If the term fluency is used to refer to the silent reading of relatively easy text wherein the words are recognized effortlessly at the typical reading rate of the individual while the complete thoughts in these sentences are being comprehended as they are read, then fluency and rauding are synonymous terms". (p. 5)

In this thesis, fluency implies more than what is mentioned in the quote because the research involves learners of English in a foreign language environment. Many of them may not be able to recognize English words effortlessly while comprehending most of the sentences being read. However, it can be said that this kind of fluency is the optimal goal of the language program at the university and of the treatment. Only when the participants reach the level at which they can decode words effortlessly and understand most of the thoughts presented in a text can they be said to achieve rauding. For this reason, a broader review of the literature on fluency development is necessary.

Most definitions of fluency were proposed in research on L1 reading. Studies in L2 reading commonly took the theories of $\mathrm{L} 1$ reading fluency as the underpinning. In L1 oral reading, fluency has been defined as reading aloud fast and accurately (Good \& Kaminski, 2002; Oakley, 2005; Welsch, 2006) or reading aloud with accuracy, and appropriate expression (Armbruster, Lehr, \& Osborn, 2001; Chard, Pikulski, \& McDonough, 2005; Huey, 1968; Meyer \& Felton, 1999; Rasinski, 1989; Schreiber, 1987). Appropriate expression includes such aspects as speed, phrasing, and smoothness. 
Although appropriate expression, to some extent, can show the reader's understanding of the text (Allerson \& Grabe, 1986; Pinnell, 1995; Rasinski, 2003b), fluency is integral to comprehension and the definition of fluency should include comprehension (John \& Berglund, 2006; Kuhn \& Stahl, 2003; Rasinski, Blachowicz, \& Lems, 2006; Stahl \& Heubach, 2005).

In L1 silent reading, fluency is commonly understood as the ability to read and to comprehend accurately at the same time (LaBerge \& Samuels, 1974a; Rasinski, 2000, 2003b; Rasinski, et al., 2006; Samuels, 2006). A fluent reader is a person who has "freedom from word identification problems that might hinder comprehension" (Harris \& Hodges, 1995, p. 85). This is because in order to have good reading comprehension, a reader has to be able to identify words easily and quickly (Samuels, 2002). This definition comes from automaticity theory, which holds that if a subcomponent skill becomes automatic, that means, it can be done without using many attentional resources, and the other subcomponent skills will be more likely to work effectively (Baker \& Brown, 1984; Pressley \& Afflerbach, 1995; Walczyk, 2000). Researchers also emphasize the role of smoothness and appropriate reading rate in reading fluency (Nation, 2005; Oakley, 2005).

In second and foreign language learning, fluency is defined as "the ability to speak or write a particular foreign language easily and accurately"(Pearsall, 1998, p. 707) or "making the most effective use of what skills are already known" (Nation, 1997, p. 30). In particular, reading fluency has received relatively scant attention. However, a few researchers have consistently regarded foreign reading fluency as the ability to read and comprehend a text in the foreign language at an adequate speed and two observable signals of this aspect are speed and accuracy in comprehension (Gorsuch \& Taguchi, 2008; Nation, 2005; Segalowitz, Segalowitz, \& Wood, 1998; Yamashita \& Ichikawa, 2010)

\subsection{The indicators of fluency}

Although researchers approach reading fluency from different perspectives, a consensus on the indicators of reading fluency has been established. There is popular agreement that automaticity, accuracy, and reading speed (for silent reading) or prosody (for oral reading) are the three fundamental indicators (Grabe, 2004b; Harris \& Hodges, 1995; Kuhn \& Stahl, 
2003; LaBerge \& Samuels, 1974b; Rasinski, et al., 2006; Richards, 2000; Tompkins, 2003; Worthy \& Broaddus, 2001-2002).

Automaticity is widely accepted as one of the indicators of fluency in reading. Automaticity is, in general, a term used to define the ability to complete a task without a large amount of attentional resources being used. In reading, automaticity is understood as the effortless, accurate and fast recognition of words in texts. Studies in L1 reading have shown that automaticity is a crucial component of skilled reading as it allows the reader to save cognitive resources for more complicated tasks (Schwanenflugel, et al., 2006) and influences comprehension (Adams, 1994; Just, Anderson, \& Carpenter, 1987; LaBerge \& Samuels, 1974b; Rayner \& Pollatsek, 1989). In other words, word recognition and comprehension compete for readers' attention. It is likely that readers will not be able to reserve their attention for comprehension if they have to spend too much time identifying words (LaBerge \& Samuels, 1974b; Samuels, 2002). Therefore reading instructors should help readers to "shift the blend toward automaticity by eliminating or reducing reliance on some of the controlled processes" (Segalowitz, et al., 1998, p. 54). In fact, many readers increase their reading speed but the underlying mechanisms that operate the processes are not shifting the blend toward automaticity, and it is essential for reading instruction to orient readers to restructure their underlying mechanisms in the way that helps increasing automaticity in operating the processes. Previous researchers have also considered the size of the recognition unit when discussing automaticity in reading. In many reading frameworks posited by different researchers, the term unit is referred to as the strings of letters/words or a piece of graphic material that the reader may deal with at a certain time. This relates to the principle of chunking (Miller, 1956). The overall principle of chunking is most human beings can apprehend about "seven recently learned chunks of similarly classified data" (Gobet, et al., 2001, p. 236). From the reader's perspective, the chunking principle requires them to group words into information units. In other words, they no longer process every word separately but instead process a certain number of words as one unit of information. This in turn will increase their word recognition skills. Thus "fluency development involves not just becoming faster, it also involves changing the size and nature of the basic unit that the reader is working with" (Nation, 2005, p. 25). Since assessment of the recognition unit in reading is difficult, this aspect of reading fluency has been usually neglected in previous studies. In the last two decades, there has been an increasing but still small amount of literature on automatization in L2 reading (Anderson \& Pearson, 1984; Carrell \& Eisterhold, 1983; Stanovich, 1992). Past research has found that 
among L2 university students, those who were more fluent readers also had better word recognition automaticity skills (Segalowitz, et al., 1998) and that there is a strong link between high proficiency levels and automatic word recognition in L2 (Kroll, Michael, Tokowicz, \& Dufour, 2002).

Prosody is an important indicator of fluency in oral reading. Previous research in L1 oral reading has established a set of language features that compile prosody. These features include stress or emphasis, pitch variations, intonation, pace, phrasing, and pausing (Dowhower, 1987; Rasinski, 2003a; Schreiber, 1987).

While in oral reading children's comprehension can be, to some extent, conveyed through prosody, in silent reading, there are no immediately observable clues of readers' understanding of the text. Thus many researchers suggest including comprehension accuracy as an indicator of fluency in silent reading (Gorsuch \& Taguchi, 2008; Nation, 2005; Segalowitz, et al., 1998; Yamashita \& Ichikawa, 2010). It is believed that reading faster will be meaningless if the reader comprehends little of the text. A fluent reader should be able to both read quickly and comprehend the text at the same time. Therefore, comprehension accuracy should be one of the indicators of fluency in silent reading. Some researchers have suggested a goal of at least $75 \%$ comprehension in L1 reading (Carver, 1977a, 1981, 1992b) or around 70\% accuracy in L2/FL reading (Millett, Quinn, \& Nation, 2007). In oral reading, accuracy is usually associated with decoding. It refers to "the ability to correctly generate a phonological representation of each word, either because it is part of the reader's sight-word vocabulary or by use of a more effortful decoding strategy such as sounding out the word" (Penner-Wilger, 2008, p. 1). Accuracy in decoding is usually measured by counting the number of correct words read per minute.

Silent reading speed, or silent reading rate is also popularly accepted as one of the indicators of silent reading fluency. It is generally understood as the rate of word recognition, which is the total number of words per minute a person can recognize. A considerable amount of literature has been published on this aspect. The studies on L1 reading investigated what people really do when they are reading fast, including how many fixations, saccades and regressions they make during the process, how much they can comprehend the text, how people's reading rates change and so forth. Researchers have pointed out that a normal skilled L1 reader reads at around 250-300 wpm and makes approximately 90 fixations per 100 words (Just, et al., 1987; Nation, 1997) while a normal 
speed in L1 oral reading should range from 100 to 200 wpm (Nation, 2005). Among the large volume of published studies exploring how reading rate changes in L1 reading, the most influential studies were undertaken by Carver, who examined this topic from various perspectives. In his research on the rate of reading prose, Carver (1982) claimed that there exists an optimal reading speed called rauding rate at which readers can maximize their efficiency of comprehension and that $300 \mathrm{wpm}$ is a good speed for college students to achieve the best efficiency. Although the rauding rate may vary among different people it is normally less than $400 \mathrm{wpm}$ (Carver, 1985). Some very good readers such as speed readers, professionals, college students, and people who had exceptionally high scores on tests, tend to read at around 300 to $600 \mathrm{wpm}$. For individuals, the rauding rate is approximately constant as long as the measurement is modified for word length (Carver, 1983). Thus, it is possible that teachers can predict how fast a student will read a text if they know the difficulty level of the text. This is surprising because it has been commonly thought that reading speed is affected by such factors as the purpose of reading, the difficulty of the text, and the reader's engagement level (Nell, 1988). However, it is worth noting that rauding rate in Carver's theory is not identical to the term reading speed which is commonly used by many other researchers and teachers. Besides, Carver's research examined L1 reading and thus his rauding theory may not apply in the same way in L2 reading.

Research on reading speed in L2/FL silent reading is a relatively new area. Researchers have suggested that a reasonable goal for second language learners who are reading materials with no new words should be around 250 wpm (Nation, 2005) but mention that reading speed in L2/FL is slower than in L1 (Droop \& Verhoeven, 2003; Fraser, 2007; Segalowitz, Poulsen, \& Komoda, 1991; Taguchi, Gorsuch, \& Sasamoto, 2006). Although recently L2/FL researchers and educators are focusing on methods to increase L2 and FL reading rate (Day \& Bamford, 1998; Grabe, 1991, 2004a; Silberstein, 1994), the area of reading speed in $\mathrm{L} 2 / \mathrm{FL}$ is still in its infancy.

\subsection{Assessing fluency development}

There have been various studies about how to design a good reading program to help learners develop their reading fluency. A large and growing body of literature has investigated how fluency improves and has recommended activities for fluency development. With respect to $\mathrm{L} 1$ oral reading, researchers have proposed conditions to 
improve fluency and recommended techniques and activities that can be used in the classroom or outside class to help develop children's reading fluency. Among those suggestions are using high-success texts, altering teachers' patterns of responses to reading errors (pause-prompt-praise), modeling fluent reading, encouraging free, voluntary reading, repeated reading, extended and deliberate practice, orienting student choice (Allington, 2009; Ehri, 1995; Rasinski, 1989; Stahl, Heubach, \& Cramond, 1996; Stahl \& Heubach, 2005; Welsch, 2006). Linguists and language practitioners have also explored activities to promote fluency in L2/FL reading. Some of these techniques include repeated reading, paired reading, the 4/3/2 technique, extensive reading aloud, read and look up, speed reading courses, easy extensive reading, silent repeated reading and issue logs (Day \& Bamford, 1998; Donnes, 1999; Hill, 1997; Krashen, 1995; Nation, 1997, 2005; Paran, 1996; Perfetti, Van Dyke, \& Hart, 2001; Redfield, 1999; Taguchi, Takayasu-Maass, \& Gorsuch, 2004).

Measuring reading ability in general and reading fluency in particular is important to teachers as well as educational policy makers as it provides feedback that they can use to construct their lessons or design the syllabus and set educational goals. Although the theories of reading fluency indicators have won general acceptance, there is still much controversy relating to how to assess fluency development. Even though a number of scholars have attempted to find methods to assess this aspect, these assessment discussions have generally focused on L1 oral reading rather than L1 silent reading or L2/FL reading. Past research has used a technique in which a phrase extracted from a book was exposed to students for a limited period of time and then students had to say the phrase (Huey, 1968). Another method involves small passages from an original story to measure children's oral fluency. The passages were read aloud by the teacher and the students relayed these back to their teacher to record. The method of repeating was afterwards put onto computers so that students could test themselves by first having the computer determine their zone of reading ability; second, selecting the graded passages which increase in difficulty; third, listening to a model reading already made and saved on the computer, then silently reading the passage they chose. The computer sets the target and calculates if the student has reached it or not (LaBerge \& Samuels, 1974b). Several studies also applied the curriculumbased measurement (Deno, 1985) to assess L1 oral reading fluency. This is a general outcomes measure of a student's performance in reading, writing, and spelling. In reading, accuracy is determined by dividing the number of words read correctly per minute by the total number of words read and comparing the students' performance against the target rate 
norms. Meanwhile the rate is measured by calculating the total number of words read correctly per minute and comparing the students' performance against the target rate norms.

This test allows students and teachers to do an evaluation every week instead of every month. Another method that has been used for decades to assess L1 oral reading is informal reading inventories which assume that word decoding ability is a crucial benchmark to mark a reader's improvement (Johnson, Kress, \& Pikulski, 1987). Along similar lines, some researchers developed rubrics or fluency norms to assess fluency and overall reading proficiency (Fuchs, Fuchs, Hamlett, Walz, \& Germann, 1993; Good \& Kaminski, 2002; Hasbrouck \& Tindal, 1992; Marston \& Magnusson, 1985; Rasinski, 2000; Zutell \& Rasinski, 1991).

Many studies on measuring L1 oral reading fluency have neglected comprehension until Allington (1983) called for the incorporation of comprehension in fluency assessment. He identified ways to assess comprehension. One of these methods is retelling the story, which requires readers to remember anything they can about the story. In this method, some teachers use idea units to make it easier to compare the original story and the story recalled by the reader. Recently researchers have shown increased interest in measuring reading comprehension (Daane, Campbell, Grigg, Goodman, \& Oranje, 2005; Pinnell, et al., 1995). Some of them have used a four-point scale and the results showed a strong link between fluency and reading comprehension performance (Pinnell, et al., 1995).

Recent developments in teaching and learning the reading skill have heightened the need for measuring silent reading fluency. As a result, researchers have attempted to formulate methods to measure reading rate and comprehension both for L1 silent reading (Juel \& Holmes, 1981; Mead, 1917; Vacca \& Vacca, 1999) and L2/FL silent reading (Bismoko \& Nation, 1972; 1974; Chung \& Nation, 2006; Cramer, 1975; Gorsuch \& Taguchi, 2008). Regarding reading speed, which is conventionally measured by the words per minute calculation, the one-minute reading probe and the entire text method have been used in both L1 reading research (Harris \& Sipay, 1985; Ream, 1977; Rial, 1977) and L2/FL reading research (Iwahori, 2008; Lai, 1993; Taguchi, et al., 2004). Particularly in L2/FL research, the three-minute probe and the ten-second interval method have been used (Bell, 2001; Macalister, 2008; Millett, 2005b, 2005d; Millett, et al., 2007; Nuttall, 1982; Sheu, 2003). With respect to comprehension assessment, the most popular methods to measure comprehension are true-false questions, multiple choice questions, short answer questions, 
recall tests and participant self-reports (Alderson, 1990; Gorsuch \& Taguchi, 2008; Iwahori, 2008; Lai, 1993; Paretz \& Shoham, 1990; Taguchi, et al., 2006). Typically, in a speed reading course, the learners are asked to keep a graph of their speed in words read per minute and a graph of their comprehension score on the accompanying questions. In this way, the teacher can see students' progress in reading speed and at the same time be informed about their comprehension level (Macalister, 2008; Millett, et al., 2007; Quinn \& Nation, 1974).

\subsection{Fluency, accuracy and complexity}

According to many language practitioners and researchers, L2/FL performance and competence are complex terms as they contain various components. The majority of past research has relied on three factors to describe and assess L2/FL performance and competence: fluency, accuracy, and complexity (Ellis \& Barkhuizen, 2005; Skehan, 1998). Since the 1990s, these three variables have come into focus in L2/FL learning research. It is believed that fluency, accuracy, and complexity can be used as both performance descriptors and proficiency indicators. Fluency refers to using the language with native-like rapidity, accuracy refers to being error-free, complexity refers to the ability to handle a wide range of structures and vocabulary (Wolfe-Quintero, Inagaki, \& Kim, 1998, p. 4).

Accuracy has been distinguished from fluency since the 1980s when researchers were trying to depict and measure second language oral skills. Previous research has distinguished fluency-oriented activities and accuracy-oriented activities in a language program. Fluency activities help to improve spontaneous oral linguistic production while accuracy focuses on the accurate production of language structures (Brumfit, 1984). Complexity, the third component of the triad, came into focus in the 1990s after Skehan (1998) for the first time added it to his L2 model. Since then complexity has been commonly characterized as "the extent to which the language produced in a performing task is elaborate and varied" (Ellis, 2003, p. 340) or "the scope of expanding and restructured second language knowledge" (Wolfe-Quintero, et al., 1998, p. 4). In the L2/FL acquisition literature, complexity relates itself to language tasks and language production. Some researchers also broke down the notion of complexity into two kinds: cognitive complexity and linguistic complexity (Housen, Daele, \& Pierrard, 2005; Williams \& Evans., 1998). While cognitive complexity concerns the second language 
learner and is determined by such factors related to the learners, one of which is memory span, linguistic complexity concerns the second language system. Some indicators of the learner's linguistic complexity are the variety of structures and the large stock of vocabulary.

Prior studies investigating the effect of external factors on the learner's accuracy, fluency, and complexity in language performance have proposed methods to assess the three components and explanations of how these three dimensions develop. In L1 learning, Wigglesworth (1997) confirmed that planning time provides greater advantages for high proficiency learners to make complex and fluent language production but the results were not unambiguous enough to decide whether accuracy was also developed. Conversely, Wigglesworth and Storch (2009) reported that in their research on the effect of collaborative writing on fluency, accuracy and complexity of the second language learner, accuracy was positively affected but fluency and complexity were not. In L2/FL learning, the majority of developmental measures of complexity, accuracy and fluency have been used to explore the effects of a treatment or an external factor on oral and written language production. For example, Yuan and Ellis (2003), and Mehnert (1998) examined how planning time helps learners to write better and assessed the learner's writing in three dimensions: fluency (syllables per minute (spm)), accuracy and complexity. The results showed planning time resulted in greater fluency, accuracy, and complexity. However, other authors, such as Ellis (1987) and Crookes (1989), argued that planning time affects the learner's language production in terms of complexity but did not significantly influence it in terms of accuracy. Recently Ahmadian and Tavakoli (2011) indicated that their findings showed careful planning time positively influenced complexity and accuracy but resulted in dysfluency.

Although a considerable amount of literature has been published on the association between the three aspects of language, there has not been agreement that fluency, accuracy, and complexity develop simultaneously. This experiment therefore set out with the aim to determine if development in fluency through the speed reading course leads to improvement in accuracy and complexity. 


\subsection{First and second language fluency}

There have been numerous studies on L1 reading fluency (Breznitz \& Share, 1992; Collins, 1961; Dowhower, 1987; Jones \& Lockhart, 1919; Judd \& Buswell, 1922; Kuhn \& Stahl, 2003; Perfetti, 1985; Rowell, 1976; Samuels, 2006; Stanovich, 2000) and L2 reading fluency (Arevart \& Nation, 1991; Chang, 2010; Kroll, et al., 2002; O’Brien, Segalowitz, Freed, \& Collentine, 2007; Yamashita \& Ichikawa, 2010). According to West (1941), reading ability transfers from one language to another language. Therefore, if people's reading speeds in L1 improve, it is likely that their L2 reading rate will increase as a transfer effect. Recently there has been an emerging body of literature on the relationship between L1 reading and L2 reading development. Some of those studies reported a relationship between L1 reading and L2 reading in which L2 knowledge accounted for more than $30 \%$ of the variance in L2 reading performance whereas L1 reading ability accounted only for just over $10 \%$ of the variance in L2 reading scores (Bernhardt \& Kamil, 1995). A great deal of research found that L1 reading is a dominant variable in L2 reading performance (Bossers, 1992; Brisbois, 1995; Carrell, 1991; Hacquebord, 1999; Roller, 1988). Researchers have also proposed the short-circuit hypothesis, also known as the language threshold hypothesis, which holds that learners have to reach a certain level in L2 knowledge in order to transfer their L1 reading ability to L2 reading (Clarke, 1979; Clarke, 1980) or attempted to determine the link between word recognition and comprehension in L2 reading (Levy, Abello, \& Kysynchuk, 1997). Besides, past research also found that not only L1 strategies transfer to reading L2 texts (Seng \& Hashim, 2006), but also attitudes in L1 transfer to L2 reading and this may help them reduce affective barriers and gain more confidence in L2 reading (Yamashita, 2004).

Bismoko and Nation (1972) conducted research to see whether reading practice in Indonesian as an L1 affected English as a foreign language reading speed. The subjects were two groups of students from a university in Indonesia. A control group was also set up to compare the results. The two experimental groups read two passages in Indonesian every week for ten weeks. They were asked to read two English passages as initial tests and two other English passages as final tests. The results showed that the English department students made a $75 \%$ increase in their English reading speed and the Education Department students made an increase of $72 \%$ while maintaining their comprehension levels. This allowed the two researchers to conclude that L1 reading practice transferred to $\mathrm{L} 2 / \mathrm{FL}$ reading speed. It will be interesting to see if there is a 
transfer effect from one aspect of reading to other aspects within one language, which is dealt with in this thesis.

Later Cramer (1975) carried out research among 30 fourth and fifth year secondary school students in Malaysia in order to see whether it is more efficient to give practice and training in mother tongue reading or in second language reading and which has the greater transfer to the other: mother tongue reading practice or second language reading practice. He gave the subjects, who were divided into three groups, the control group, the English medium group and the Bahasa Malaysia medium group, pre-tests in both English and Bahasa Malaysia. The English medium group then read eight practice English passages in four weeks while the Bahasa Malaysia medium group read eight Bahasa Malaysia texts over the same period. Each of the texts was accompanied by ten comprehension questions. Interestingly, the English medium group made an increase of 39\% in English reading speed and $40 \%$ in Bahasa Malaysia reading speed. The Bahasa Malaysia group increased their reading speed in Bahasa Malaysia reading by $22 \%$ but in English reading by $45 \%$. The results indicated a higher increase in L2 reading speed will be obtained if reading practice is done in L1. However, the result would have been more reliable if the students had been given more texts. As those students were studying at an English medium secondary school, it seems unclear whether the increase in their reading speed was solely the result of their reading practice of only eight texts or included the effect of the usual English program.

More recently Pitchette, Segalowitz and Connors (2003) undertook a study to investigate the relationship between L1 reading ability, L2 knowledge and L2 reading ability. The informants of the study were Bosnians, who had just moved to Quebec city, a French speaking milieu. They had already finished the Quebec government's French program and were enrolled in French courses at the time of the research. The informants were asked to do the tests twice in a period of one year so that their L1 reading ability, L2 reading ability and L2 knowledge could be assessed. The researchers used cloze tests as a means to evaluate the informants' reading ability. They provided the informants with two cloze tests in L1 and two cloze tests in L2, each of which had 40 words deleted. In order to assess the informants' L2 knowledge, the researchers utilized sections of the standard test that is used in most Quebec universities. Besides, they also asked the informants to answer a questionnaire to indicate their experience in L1 and L2. They found that both L1 reading ability and L2 knowledge have close links with L2 reading ability, but among the high level group, L1 reading ability is a significant indicator while among the low level group, 
L2 knowledge is a significant indicator. The results also indicated that the informants continued to transfer their L1 reading ability to L2 reading even though they ceased to practice L1 reading. Nevertheless, the informants who maintained L1 reading practice improved their $\mathrm{L} 2$ reading ability while non-active informants did not.

The research previously mentioned investigated the effect of reading speed development in one language on reading speed in another language. The findings may help educators to decide how much practice should be done in L1 and L2 reading in order to gain benefits for the other and to at least ensure the L2 reading improvement is accompanied by L1 reading instruction. However, far too little attention has been paid to the effects of reading practice in a language on other aspects within that language. In this thesis, the focus is on the effect of reading speed increase in an EFL course on other aspects of EFL development.

\subsection{Comprehension and speed in reading}

The nature of comprehension in reading has been explored in numerous studies. Some researchers see it as a state of having questions answered (Smith, 1978) in which readers have to find a configuration of hypotheses which offer a coherent account for the various aspects of the text (Rumelhart, 1977). In order to comprehend a text, readers modify the organisational structure of the texts for their own purposes (Calfee \& Curley, 1984). While reading they keep making predictions, or questions based on their theories about the world, and if the questions are answered while or after reading, comprehension is achieved (Smith, 1978).

A large and growing body of literature has investigated the components of comprehension. One of the main themes in the literature is the simple view of reading, which holds that comprehension can be decomposed into linguistic comprehension and reading comprehension (Dombey, 2009; Dreyert \& Katzt, 1992; Gough \& Tunmer, 1986; Hoover \& Gough, 1990). Linguistic comprehension refers to the action of using vocabulary knowledge to interpret the text and reading comprehension is the same ability, which, on the other hand, relies on printed information arriving through the eye. In order to assess linguistic comprehension, testers should ask questions about the contents of a text presented orally while to test reading comprehension, they must ask questions about a text in printed form. Some other researchers divide comprehension into two components: comprehension and interpretation (Urquhart, 1987). Comprehension 
involves what the reader utilizes according to his reading aims. Interpretation concerns the differences between people who read the same text, or within one person when reading different texts. These differences may be due to such factors as background knowledge and cultural presuppositions.

Prior studies have proposed numerous methods to predict and assess comprehension in L1. For oral reading, the compensatory encoding model (Stanovich, 1980) holds that the basic resource necessary for text comprehension is the time available. Therefore, in reading without time pressure, we cannot see the correlations between verbal efficiency and comprehension since the reader has enough time to utilize compensatory behaviours and strategies to comprehend the text. Compensatory behaviours and strategies are adjustments to help the reader overcome the inefficiency of other reading subcomponents. Apparently they take time to operate and thus add to the time needed to comprehend the text. Of the two kinds, compensatory behaviours consume less time than compensatory strategies. Consequently, when compensatory behaviours do not work effectively readers will invoke compensatory strategies. Some examples of compensatory behaviours and strategies are slow reading rate, pausing, regressive eye movement, rereading text, reading aloud, and shifting attention. While it can explain the different amounts of time different people need to read the same text, the compensatory encoding model does not apply to beginning readers. The advocates claim that it is only true for readers beyond the fourth grade. The benefit of this model is that it "accounts for the weak correlations between verbal efficiency and comprehension" that many researchers have pointed out from their tests (Walczyk, Marsiglia, Bryan, \& Naquin, 2001, p. 751). It also predicts that under reading without time pressure, the relationship between efficiency and compensatory mechanisms is negative in that the more efficient readers are at using other verbal skills, the less compensatory mechanisms they have to use. Yet compensatory encoding mechanisms fail to explain why many readers still cannot comprehend the text even though they have utilized compensatory behaviours and strategies. Furthermore, readers who have to slow down their reading rate often fail to comprehend the text since the information stored in their short-term memory has gone away by the time they manage to finish the reading unit. For silent reading, rauding theory (Carver, 1981, 1984, 1990, 1992a), on the other hand, aims to predict L1 silent reading comprehension by using a formula involving three variables: accuracy, rate and efficiency. Accuracy concerns two factors: the number of thoughts presented by the writer and the number of thoughts comprehended by the reader. In most reading contexts, 
the accuracy of comprehension is the number of comprehended thoughts in relation to the number of presented thoughts. Rate is the number of thoughts presented during a certain length of time. Efficiency of comprehension is the number of thoughts comprehended during a certain length of time. The central idea of rauding is the number of thoughts in a text that have been comprehended (comprehension level) may be predicted from a knowledge of two characteristics of the text (presented thoughts and level of difficulty), two characteristics of the reader (reading ability level and rate), and the amount of time the reader spends reading the text. Prior knowledge, prediction activities and text type do not strongly affect comprehension (Carver, 1992a).

While rauding theory takes thoughts as a measurement unit of reading rate and efficiency, numerous researchers use words to measure what they call reading speed and many of them have found evidence for a relationship between comprehension and speed. Several researchers consider speed and comprehension the constituents of reading fluency (LaBerge \& Samuels, 1974a). Although some other researchers put comprehension aside when defining reading fluency (Allington, 2009; Nation, 2005; Rasinski, 2003b), they comment that comprehension and decoding can be connected by fluency, which includes speed, and that comprehension is the optimal goal of the reading process, thus it should be given equal attention in fluency development.

While reading speed is generally thought to be associated with comprehension and past research has given insight into the relationship between these aspects, there still has been much controversy on this issue. A strong relationship between reading rate and comprehension in L1 reading has been reported in previous studies (Bowey, 2005; Fuchs, Fuchs, Hosp, \& Jenkins, 2001; Perfetti, Landi, \& Oakhill, 2005; Pinnell, et al., 1995; Stanovich, 2000). Specifically, Tan and Nicholson (1997) and Levy, Abello and Lysynchuk (Levy et al., 1997) found that poor readers benefit from rapid decoding training and suggested that in L1 children's oral reading, speed increases facilitate comprehension (Nicholson \& Tan, 1999). However, other researchers have demonstrated a weak relationship between fluency skills and reading comprehension level (Carver, 1992b; Kuhn \& Stahl, 2003). Bell, before showing that an extensive reading program can help to improve both reading speed and comprehension, pointed out that "techniques employed on speed reading courses tend to cause readers to suffer lower levels of reading comprehension" (Bell, 2001, p. 1). Another influential study on 
this aspect was done by Schwanenflugel et al. (2006), who found that comprehension was substantially affected by reading fluency and autonomy. However, this role decreases as age increases. The results indicated that once a reader has reached a fluent level, factors other than fluency affect reading comprehension.

The link between comprehension and speed in L2/FL reading has not been clearly portrayed. Past research found that speed and comprehension are not competing components in L2 performance, and that the two factors have a supporting relationship in that speed promotes accuracy in comprehension and accuracy is one of the indicators of fluency development (Alessi \& Dwyer, 2008; Segalowitz \& Segalowitz, 1993). In Chang's (2010) study, a reading activity was integrated into the usual program for 13 weeks to improve 84 college students' reading rates. Results indicated that the participants increased their reading speed by $25 \%$ and their comprehension level increased by $4 \%$. This low increase is probably due to a ceiling effect in the measurement, but it shows that speed increase does not result in a drop in comprehension.

Since a consensus on the association between speed and comprehension in both L1 and L2/FL reading has not been established, it would be helpful to put some effort into investigating the relationship between speed and comprehension in L2/FL reading by looking at the comprehension scores on other types of texts to determine if reading fluency development facilitates comprehension.

\subsection{The transfer of learning}

The term transfer has been used popularly among psychologists and linguists since the 1900s. The notion of transfer of practice was first introduced by Thorndike (1932), who said that learners can use what they have learned in a previous context to help solve problems they face in the successive contexts. His main concern was to what extent the learner can transfer knowledge from one learning task to another task and that depends on the proportion of identical elements that the two learning tasks share. Since then various researchers have attempted to delineate transfer following taxonomic and typological approaches. Different types of transfer, what actually happens in the process, the underlying concepts of each transfer type, the similarity, and nature of transferred information have been the focus of discussion in much research (Baldwin \& Ford, 1988; 
Barnett \& Ceci, 2002; Broad \& Newstrom, 1992; Brown, 1989; Butterfield, 1988; Haskel, 2000; Salomon \& Perkins, 1989; Skinner, 1938).

In the 1950s, linguistics began to apply transfer theory to language learning and put forward the notion of linguistic interference. They say that the learning of one language positively or negatively affects the learning of another language, yielding positive transfer or negative transfer (Cunningham \& Graham, 2000; Hoffenberg, 1971; Masciantonio, 1977; Nitschke, Kidd, \& Serratrice, 2010; Porter \& Duncan, 1953; Postman \& Stark, 1969). Advocates of this theory are convinced that learners with more developed native language literacy skills find it easier in acquiring literacy in a second language (Menken \& Kleyn, 2010). The transfer of L1 reading strategies and skills to L2/FL reading was also reported in a number of studies (Burt, Peyton, \& Adams, 2003; Seng \& Hashim, 2006; Yamashita, 2004).

In the last four decades, a number of researchers have shifted their focus to the transfer from the learning of one skill to the learning of another skill within one language. In an L1 study, Weaver (1979), for example, reported that the training of sentence organization skills can enable the reader's comprehending skills to a remarkable degree. Dowhower (1987) claimed that the training of repeated reading practice led to significant improvement in reading fluency, comprehension and prosody. In an L2 study, Elley and Mangubhai (1983) showed that reading English stories could facilitate related skills in English language learning. More recently Taguchi, Takayasu-Maass and Gorsuch (2004) showed that repeated reading and extensive reading assist reading competence improvement.

However, there has been little research on the transfer of reading skills from one context to another context in a foreign language. The only research we are aware of is the study by Macalister, who aimed to see if the speed improvement on simplified texts transfers to reading other texts (Macalister, 2010). He conducted the research with four intact classes in a university preparation program and concluded that participants who followed the speed reading course tended to read the authentic texts at greater speeds than they did at the start of the speed reading course. However, the study was carried out with a very small number of students ( 24 participants for the treatment and 12 for the control), thus there was not strong evidence for the speed increase transfer from the speed reading course to other types of texts. 
Thus, there is still a lack of strong evidence that reading rate improvement on one type of texts transfers to other types of texts. This study aims to give a clear answer to that question by investigating the transfer effect of a speed reading course on reading other texts. A larger sized sample was used than in Macalister's study and the control group did not do extensive reading. This was done to avoid the ambiguity of the cause of speed increases. Four texts that were not in the speed reading course were given to the participants at the beginning and the end of the treatment in order to measure their reading rates outside the speed reading course.

\subsection{Oral reading}

Oral reading used to be the fundamental mode of reading instruction in reading classes. Since the twentieth century, its popularity began to wane when silent reading started to replace oral reading as the preferred mode of reading instruction in most schools (Fuchs, et al., 2001). Many language instructors argued that silent reading was the more authentic form because in the real world it was more common than oral reading and that with silent reading but not with oral reading the rate of reading and thinking would develop (Betts, 1946; Durrell, 1940; Huey, 1968). However, other linguists and researchers claimed that the importance of oral reading should not be ignored and that it is essential to include oral reading in schools' reading programs (Postlethwaite \& Ross, 1992; Zutell \& Rasinski, 1991). Rasinski (2003b, p. 25) emphasized that through oral reading the words become more "memorable, more deeply etched into memory" than through silent reading.

Research has also focused on the relationship between L1 oral reading and silent reading. A number of authors examined what really happens when people read orally and silently. Rowell (1976), for example, reported that in her study of oral and silent reading comprehension among boys and girls at different grades, the boys' comprehension levels were higher in oral reading while the girls had no significant difference between the two modes. Juel and Holmes (1981) investigated the cognitive process in children when they do oral and silent reading. The results showed that the same process operated. If this is true, it may be inferred that when silent reading speed increases, oral reading rate will improve. In reviewing the literature, no data were found on the association between silent reading speed improvement and oral reading rate development. The thesis looks at this aspect and oral reading tests were utilized to measure the participants' speed change in oral reading before and after the treatment. 
Numerous attempts have been made to find out how to assess L1 oral reading ability. Among the various approaches to oral reading fluency assessment there is agreement that rate, accuracy, and prosody are the major indicators of oral fluency. Accuracy is the percentage of words read correctly, calculated as words correct divided by the total number of words read. Rate is simply the number of words read correctly in one minute. Prosody is assessed using a qualitative rubric, which measures such aspects as phrasing, smoothness, and pace. Based on these indicators, researchers have formulated different tests and methods such as the Peabody individual achievement test (Deno, Mirkin, \& Chiang, 1982; Dunn \& Markwardt, 1970; Markwardt, 1989) or the Stanford achievement test (August, Shanahan, \& Shanahan, 2006; Fuchs, et al., 1988) and the Gray oral reading fluency test (Wiederholt \& Bryant, 2003). Some others utilized the word meaning test (Fuchs, Tindal, \& Deno, 1984; Newton \& Bristoll, 2010), classroom teachers' holistic ratings (Parker, Hasbrouck, \& Tindal, 1992) or a combination of speed, accuracy, oral expression, and comprehension as indicators to assess oral reading fluency (Valencia, Smith, Reece, Li, \& Wixson, 2010). Several benchmarks to assess oral reading fluency have also been developed, some of which are the Dynamic Indicators of Basic Early Literacy Skills (Good \& Kaminski, 2002), Curriculum-based Measurement (Deno, 1985; Deno, et al., 1982), or the multidimensional fluency rubric (Zutell \& Rasinski, 1991).

So far little attention has been paid to oral reading in L2/FL, probably due to the lack of use of this type of reading in L2/FL learning and teaching. Thus the second experiment probably is the first study to determine if increases in silent reading speed are accompanied by increases in oral reading rate. In this experiment, only oral reading rate will be measured because prosodic indicators such as phrasing and pace can hardly be reliably assessed due to the difference between the participants' mother tongue and the English language. Accuracy (the number of words correctly read over the total number of words read in a minute) was not measured for two reasons. First, as Vietnamese learners of English have quite bad English pronunciation (Duong, 2009), it would be impossible to decide whether an incorrectly pronounced word was caused by bad pronunciation or by incorrect decoding. Second, the texts were written within the participants' vocabulary level and thus, it was expected that there were no new words in the texts. In this research, we measured the participants' rate by simply counting the total time a participant spent reading the text then converted it into the number of spm. The reason we used syllables per minute but not words per minute lies in the difference 
between the Vietnamese language and the English language. Vietnamese is not a stressed language and hence every single syllable carries an equal stress. Consequently, Vietnamese learners of English tend to bring that into English when they speak it (Hoang, 1965; Honey, 1987; Hwa-Froelich, Hodson, \& Edwards, 2002). Since the participants' English level was rather low, interference from Vietnamese is still very strong (Honey, 1987). Moreover, the fact that the two texts contain an equal number of both words and syllables will not result in any inconsistencies whether we took words or syllables as the measurement unit.

\subsection{Memory span}

The study concerns language complexity but not task complexity. It involves cognitive complexity in that it aims to explore the effects of speed reading courses on the learner's performance of a memory span task.

Past research in reading has looked primarily at working memory span, which is a common measure of short-term memory. While short-term memory is thought of as $a$ passive storage buffer, working memory span is widely defined as the mental capacity available for the simultaneous processing and storage of information, and thus a more active part of the human processing system (Daneman \& Carpenter, 1980; Just \& Carpenter, 1992). Specifically in reading, the reader's working memory stores syntactic, semantic, pragmatic information from the preceding text for later use. Because information can be lost from working memory through decay or displacement, there is a trade-off relationship between processing and storage in reading comprehension and this can be a source of individual differences in reading comprehension (Daneman \& Carpenter, 1980).

A few studies have attempted to investigate the relationship between working memory span, reading ability, and language complexity. Past research has found a causal link between working memory span and L1 reading ability, naming rate, and speech rate. Memory span, naming rate and speech rate were in a linear function to reading ability and good readers did better in all three tests than poor readers (Das \& Mishra, 1991). Researchers also found a strong relationship between working memory span and L2 performance (Caplan \& Waters, 1994; Fortkamp, 1999; Harrington \& Sawyer, 1992; Kormos \& Sáfár, 2008; Weissheimer \& Mailce, 2009; Zhang \& Feng, 1990). In Blake, 
Austin, Cannon, Lisus, and Vaughan (1994)'s study, which suggested that the ability to produce complex sentences "is constrained" by memory span, it was found that memory span is a good predictor of spontaneous language complexity. Likewise, Ramer (1977) indicated that memory abilities concurrently develop with linguistic knowledge. Along similar lines, Kemper, Kynette, Rash, O’Brien and Sprott (1989) used a digits backward test on two groups of adults and showed that adults with greater memory capacity produced more complex utterances and used more right and left branching clauses. The idea was supported by the findings that language delayed children have a shorter memory span than non-delayed children.

While reading research commonly uses reading span tasks and working memory span tasks to measure working memory, a few researchers have also attempted to use sentence memory span tests, also called language memory span tests in order to predict learners' language proficiency. Harris (1970), for example, developed a language memory test which consisted of a series of phrases or sentences of increasing length and syntactical complexity for oral repetition. He suggested a group administered method which allows the test to be done orally by dictating a series of sentences to a group of 112 students, who then wrote down the sentences after one hearing. He also reported that the results of this sentence memory span test correlated with the results on English language proficiency tests that the participants had taken at the university. Roberts \& Gibson (2002) utilised a sentence memory test which required the participants to listen to sentences containing one, two, three, four and five clauses and then answer questions about the sentence content. Although they found that the results of this test significantly correlated with the results of a reading span test, they suggested that memory for sentences is not necessarily a result of linguistic experience but rather a contribution of an independent working memory component. Recently Seung and Chapman (2004), using a sentence memory span which was auditory and carried out in connection with a speaking rate test, demonstrated that language production level accounted for a substantial portion of individual differences in sentence memory span. If these findings are reliable, a learner's language complexity can be measured by looking at sentence memory span.

This thesis is not concerned with working memory span, which is commonly discussed in reading research. Rather, the thesis deals with sentence memory span in order to predict the participants' language complexity. Therefore, the tasks the participants had to do on 
the sentence memory span tests did not require them to store and remember information while other processes are concurrently happening. The participants only had to remember the sentence and write it down without having to operate any other process. They could choose when to proceed with the next sentence once they had finished the preceding one. Unlike the other sentence memory span tests, in the second experiment, the sentence memory span tests were not done orally. Instead, the participants were allowed to read the sentences appearing on the computer screen before typing them onto the computer. This was done for several reasons. First, if the tests had required the participants to listen to the sentences and then write them down, it would have been difficult to decide if a mistake was made due to faulty listening or faulty memory span because the participants were not native English speakers. Second, because the treatment was done in reading, it would be more relevant to let the participants read rather than listen to the sentences in the tests. Third, if the participants had been asked to repeat the sentences orally, it would have been hard to decide if a mistake was caused by faulty memory span or faulty pronunciation. For these reasons, I used a memory span test on the computer for the participants to type the sentences after seeing them for a certain amount of time. The results of this experiment would be valuable to researchers who investigate the relationship between fluency development and language complexity.

\subsection{Speed reading courses}

Reading speed has been the focus of many reading courses, in which the instructors used different techniques to help learners improve their speed. Among those methods are repeated reading, extensive reading and speed reading. A few studies have shown the effect of repeated reading (Carver \& Hoffman, 1981; Dowhower, 1987; Gorsuch \& Taguchi, 2008; Herman, 1985; Samuels, 1997; Taguchi, et al., 2004) and extensive reading (Bamford, 1984; Bell, 2001; Hafiz \& Tudor, 1989; Iwahori, 2008; Leung, 2002; Lituanas, et al., 1999; Nation, 2001; Susser \& Robb, 1990) in reading ability development. There has been a growing body of literature on speed reading as one of the methods to increase reading speed. Speed reading courses can be traced from the late 1950s when a teacher named Evelyn Wood, invented a method called the Wood Method and renamed it as Reading Dynamics in 1958. Soon after that her method, which was also called speed reading, gained popularity in the United States and other English speaking countries. People were trained to use their hand as a pacer while reading to increase their ability to move their eyes smoothly across the page (Polmar, 2009). Some other reading 
techniques have also been taught and included in speed reading programs for children (Nell, 1988; Ream, 1977; Rial, 1977; Stancliffe, 2003). However, Carver (1992b) regarded training courses in speed reading in L1 as a failure in improving learners' comprehension efficiency and rauding rate (the speed at which a reader gets the most efficiency of comprehension). He also maintained that these courses may help to increase their speed by three times but will decrease their accuracy in comprehension to around one third. While Carver's warning is useful for L1 reading instructors, it should be interpreted with caution by $\mathrm{L} 2 / \mathrm{FL}$ reading instructors since the finding may not be extrapolated to L2 reading. Reading relies on two functions: word recognition and comprehending. Word recognition is something that can be trained to consume less attentional resources. The less attentional resources readers need to recognize words, the more attentional resources they will have for the controlled process of comprehending, thus the faster they read. For most adults reading their L1, word recognition is already automatic. This can explain why they do not gain many benefits from speed reading courses. By contrast, L2 learners still have to learn orthographic and morphosyntactic knowledge to automatize their word recognition (Droop \& Verhoeven, 2003; Grabe, 2009), especially if their competence in the language is limited. It takes much effort to perform the recognition process and hence leaves less resources for comprehending. As a result, the readers have to slow down their speed to maintain appropriate comprehension. In a speed reading course in L2, through practice learners' word recognition can become faster, giving them more time to concentrate on comprehending. As a result, their reading speed may increase while their comprehension is still maintained. This may be the reason why researchers have published speed reading books for EFL learners to practice increasing their reading speed.

One of the earliest books of this kind is Reading faster by Fry (1967), which contained texts written at the 2000 word level adapted from graded reading books. Each text was followed by ten comprehension questions. Finding that the texts in Fry's book were difficult for many of their learners, Quinn and Nation developed a speed reading course which was written within the 1000 word level (Quinn \& Nation, 1974). Since then speed reading courses have been regarded as one of the most effective ways to help increase students' reading rate (Chung \& Nation, 2006; Hunter, 1975; Macalister, 2008; Quinn \& Nation, 1974). Recently Millet (2005b, 2005d) wrote New Zealand speed readings for ESL learners, Book One and New Zealand speed readings for ESL learners, Book Two which are currently used in the English preparation program at 
the English Language Institute, Victoria University of Wellington, New Zealand and are freely available on the university website (Millett, 2005a, 2005c). A course of this kind usually consists of around 20 texts of equal length and difficulty level each accompanied by some comprehension questions. During the course, the students read the texts and keep a record of their reading rate and comprehension scores.

Very little was found in the literature on the question of how speed reading courses help learners to read faster and how they affect other language aspects. Several studies had addressed this issue but just within a small scope. For instance, Chung and Nation (2006) undertook a study of reading speed among 49 university students in Korea. The research aimed to answer the questions of how to determine the amount of change in reading speed, where most of the increase occurs, and the patterns of speed change. Before delivering the speed reading course, the researchers asked the students to take a vocabulary test on words in the texts, which was taken from the book Speed Reading (Quinn \& Nation, 1974). The learners read three passages per week for several weeks. The passages were accompanied by comprehension questions and there were reading speed and comprehension charts so that the learners could record their progress themselves. In order to determine the amount of change in reading speed, the researchers used three methods to calculate the participants' scores. The first was called the average scoring method, which took the average score of the last three texts minus the average score of the first three texts. The second method was called the highest minus the lowest. This calculation took the highest score minus the lowest score each participant had. For the last method, the words per minute score on the first text was taken away from the score on the last text. The results showed that a speed reading course was helpful for learners in improving their reading rate.

In a recent article, Macalister (2008) discussed whether any gains in reading speed were retained after the course finished. He also raised the question of what factors really facilitate reading rate among the students who were attending a language course as well as a speed reading course. He noted that claims of reading speed gains were based on measures taken at the start and end of the speed reading course (Bismoko \& Nation, 1972; Chung \& Nation, 2006; Cramer, 1975) and there was no evidence that these gains were maintained. Macalister also contended that the increase of reading rate shown in previous research might have been a result of a practice effect. By this, he meant after having been frequently exposed to the same type and length of texts, and the same type 
of comprehension questions, the students might know what they were expected to do. That is, the improvement is the result of task familiarity rather than a genuine fluency increase.

Macalister later found that speed increases in speed reading courses transfer to authentic texts (Macalister, 2010). However, with a small sample size, caution must be applied when interpreting the results of his study as the finding may not be repeated with a larger sample size.

Speed reading courses have been used in a number of institutions to help students learning English as a foreign or second language increase their reading speed. These courses vary in terms of scheduling. Millett et al. (2007) suggested that during a speed reading course, at least three passages should be read every week. However, they provided no evidence for this choice being better than other choices. While undertaking their study to investigate the effect of speed reading courses, Chung and Nation (2006) asked the participants to read twenty-three texts in a total of nine weeks: two texts per week in the first five weeks, three texts per week in the next three weeks, and four texts in the last week. Yet they did not mention the rationale for this scheduling method and no attempts were made to see if this schedule is more effective than other methods. Similarly, Cramer (1975) had his participants read eight practice texts over four weeks, However, the researcher did not investigate how this way of scheduling the speed reading course affected the participants' reading rate gains.

In conclusion, there is evidence that speed reading courses are effective for L2 learners, but their broader effects have not been identified. There is no research on how speed reading course should be scheduled to achieve optimal results. In this study, an experiment will be carried out to find out how many sessions per week should be held during a speed reading course to achieve optimal results.

The experiments in this thesis were designed to measure the effects of speed reading courses on reading rate improvement both in and outside the courses. They were carried out with a larger sample size and aimed to address more issues such as scheduling a speed reading course, the effects of the speed improvement on oral reading rate, language accuracy and language complexity. 


\section{CHAPTER 3 THE FIRST EXPERIMENT}

\subsection{Methodology}

\subsubsection{Research questions}

The study aimed to seek the answers for the following questions:

How should a speed reading course be scheduled to achieve optimal results?

Will the speed increase in the speed reading course transfer to other types of texts?

\subsubsection{Materials}

The texts in the speed reading course were taken from Asian and Pacific Speed Readings for ESL Learners by Millett et al. (2007). They were twenty passages written at the 1000 word level. The only words appearing in the text but not in the 1000 word list were the words that are explained in the text, titles, content words like country names and animal names. Each of the passages was 550 words long and was accompanied by ten comprehension questions. The book provides a progress chart in which participants keep records of their reading speed and comprehension scores, and an answer key.

The vocabulary test was taken from Schmitt, Schmitt and Clapham (2001). The test was changed into a bilingual test and then modified after pilot testing. This test was used to make sure the participants had reached the desired vocabulary level for the speed reading course.

The pre-test and post-test texts were taken from graded readers at the 1000 word level. There were two texts for the pre-test and two texts for the post-test. They contained around 700 words and had been modified and hence contained approximately similar numbers of total words, academic words, words at the 1000 word level, words at the 2000 word level, and off-list words.

\subsubsection{Participants}

The participants in the experiment were students at university in Vietnam. They were English major students who were in their first year at university. All of them had passed 
the university entrance examination, one component of which was an English test. They had been studying English for at least three years at high school for approximately four hours a week. The participants were following an English program that consisted of reading, speaking, listening, writing, and grammar lessons. This program occupied roughly 10 hours a week. The reading component in the program was performed in a conventional way: first, the teacher provided pre-reading activities, then the students were supposed to read the text and answer the comprehension questions. The teacher provided explanations of structures and vocabulary when necessary. The focus was on language learning rather than fluency or reading skills.

The participants were randomly divided into five groups. One group was the control group which did not follow the speed reading course. The first experimental group (hereafter named group 1) had one session of speed reading a week, and thus read only sixteen texts as the semester lasted for only sixteen weeks. The second group (hereafter named group 2) had ten weeks with two sessions a week. The third group (hereafter named group 3) and had three sessions a week and thus finished the course in seven weeks. The last group (hereafter named group 4) finished the course in five weeks with four sessions every week.

Initially group 1, group 2, group 3 and group 4 had respectively 23, 23, 24 and 21 participants. However, during the treatment, five students from group 1, four students from group 2, six students from group 3 and three students from group 4 skipped more than three reading sessions. Thus, these students' results were omitted from the analysis.

The control group initially had 28 students but finally only 22 students sat the post-test, so the analysis just included those 22 participants' results.

\subsubsection{Procedure}

Before and after the treatment, all participants sat the pre-test. Each of them was asked to read two of the four texts. The tests were administered in a way that the participants did not know their speed was being measured. The teacher asked the participants to read the texts. After one and a half minutes, the teacher asked them to mark the word in the passage they had reached. Then the participants continued to read. When they finished reading, they had to answer the ten comprehension questions that accompanied each text. The number of words read for the one and a half minute time was counted. For both pre-test and post-test, 
the participants read two different texts, so in total each participant read all four texts, two as pre-tests and two as post-tests. The four texts were delivered to the participants in the way that not all the participants read the same texts at the same time. This was to control for an order effect with the four passages. Although the four texts had been put in the Vocabulary Profiler program (Cobb; Heatley \& Nation, 1994) to make sure that they were at the same level of difficulty, this still had to be done as reading rates may be affected by the topic familiarity or general knowledge of the topic.

The four experimental groups followed the speed reading course run by the researcher. Initially, the vocabulary test was given to the four groups to make sure that they had reached the 1000 word level. During the treatment, in each of the sessions, the researcher asked the participants to read one passage in the text book, record their time, answer the comprehension questions, mark their comprehension score and mark their speed score in the progress chart. The teacher was pointing at the time written on the board, which was in five second intervals (see Figure 3.1).

Figure 3.1 Time intervals shown on the board in speed reading sessions

\begin{tabular}{|l|l|l|l|l|}
\hline 1.00 & 2.00 & 3.00 & 4.00 & 5.00 \\
1.05 & 2.05 & 3.05 & 4.05 & 5.05 \\
1.10 & 2.10 & 3.10 & 4.10 & 5.10 \\
1.15 & 2.15 & 3.15 & 4.15 & 5.15 \\
1.20 & 2.20 & 3.20 & 4.20 & 5.20 \\
1.25 & 2.25 & 3.25 & 4.25 & 5.25 \\
1.30 & 2.30 & 3.30 & 4.30 & 5.30 \\
1.35 & 2.35 & 3.35 & 4.35 & 5.35 \\
1.40 & 2.40 & 3.40 & 4.40 & 5.40 \\
1.45 & 2.45 & 3.45 & 4.45 & 5.45 \\
1.50 & 2.50 & 3.50 & 4.50 & 5.50 \\
1.55 & 2.55 & 3.55 & 4.55 & 5.55 \\
\hline
\end{tabular}

The time appeared on the board in columns beginning from 1.00 and finishing at 6.00. The time did not begin from less than one minute and more than six minutes because the texts were 550 words long and we did not expect the participants to read at a speed faster than $550 \mathrm{wpm}$ and slower than $92 \mathrm{wpm}$. However, the participants were told to indicate in the progress chart if they read faster or more slowly than the maximum or minimum speed shown by the time on the board. 
What happened during each of the sessions was as follows: The teacher wrote the time on the board before giving out the readings. The readings were put face down so that the students could not start reading it before they were told to do so. When all the students had been given a text, the teacher said "Go" and started the stop watch at the same time. The students read the text while the teacher was pointing at the time on the board. When finishing reading the text, the students looked up to the board to check the time they spent, recorded the time in the progress chart, and then answered the comprehension questions. After answering the comprehension questions, the students checked the answer key and recorded their comprehension score. Finally the students handed the teacher their texts and progress charts.

The twenty texts in the course were distributed among the participants in the way that in every session, as few students as possible were reading the same passage. This was to control for the possibility of different difficulty levels between the passages. As the time periods that the groups went through were different, the groups began the speed reading course at different points of time in such a way that they finished the course at the same time.

The following steps were taken to make sure that the treatment was properly applied. First, the researcher ran some sessions of speed reading with students from another faculty. The aim of this was for the researcher to really know what she should be doing during the treatment and to have some practice before the actual speed reading course. Second, before the speed reading course actually began, there was a training session in which the researcher explained and demonstrated the procedures to the participants, and they asked questions about how they should perform in the real sessions. Third, after two or three texts had been read, and later on during the treatment, there was the opportunity for discussion in which the participants talked about what they had been doing so that the researcher knew what had really happened and that the data were reliable. Fourth, at the beginning of the treatment, the participants were told that they must follow the instructions because they would not make any progress if they did not, and that the purpose of the progress chart was not for the researcher or their teachers to assess their English level, but for them to see their own progress. Explanations of the aims and advantages of the speed reading course were provided. Fifth, in every session, the researcher observed two or three participants to see what they did and how they did it. If there were any problems, the 
researcher talked to the participants immediately afterwards to make sure that in the next sessions, they would do what they were supposed to do. The score on that session would be tagged for later consideration. During the treatment, the researcher had a talk with some participants, and if there were anyone who did not progress at all after three or four sessions, the researcher asked them about what they had been doing and how they felt. This was done to help the researcher diagnose the problem and provide solutions.

For data collection, the researcher made two copies of the progress chart for each participant. These two copies were printed on two sheets of paper. In each session, the participants recorded their score on both copies. The researcher collected one of the copies and returned it in the next session. This way helped to avoid losing data. To gain more reliable data the researcher provided a space in the progress chart for the participants to write down their exact reading rate in every session. In addition, during the treatment, the researcher wrote a professional journal to record what she was doing. At the end of the treatment, the researcher interviewed three or four students in each class to collect feedback from the participants.

\subsubsection{Pilot testing}

Pilot testing improves the validity of a study because it makes sure that everything is working as it should. Table 3.1 lists the focuses of pilot testing in this study.

Table 3.1 Pilot testing plan for the first experiment

\begin{tabular}{|c|c|c|c|}
\hline Item & Potential problems & Pilot testing & $\begin{array}{c}\text { Number and type of } \\
\text { subjects needed }\end{array}$ \\
\hline \multirow{2}{*}{$\begin{array}{l}\text { Vocabulary } \\
\text { level test }\end{array}$} & $\begin{array}{l}\text { The vocabulary level test } \\
\text { does not properly measure } \\
\text { the amount of vocabulary } \\
\text { needed to read speed } \\
\text { reading texts. }\end{array}$ & $\begin{array}{l}\text { To see if a learner who has } \\
\text { done the vocabulary level } \\
\text { test will find out that there } \\
\text { are too many unknown } \\
\text { words in the speed reading } \\
\text { texts }\end{array}$ & $\begin{array}{l}\text { Ten and then five } \\
\text { learners of English }\end{array}$ \\
\hline & $\begin{array}{l}\text { The vocabulary test does not } \\
\text { indicate properly the } \\
\text { learners' knowledge of } \\
\text { vocabulary }\end{array}$ & $\begin{array}{l}\text { To see if a learner gets an } \\
\text { incorrect answer for the } \\
\text { vocabulary levels test just } \\
\text { because the choices are }\end{array}$ & $\begin{array}{l}\text { Five learners of } \\
\text { English }\end{array}$ \\
\hline
\end{tabular}




\begin{tabular}{|l|l|l|l|}
\hline \multicolumn{1}{|c|}{ Item } & \multicolumn{1}{|c|}{ Potential problems } & \multicolumn{1}{|c|}{ Pilot testing } & \multicolumn{1}{c|}{$\begin{array}{c}\text { Number and type of } \\
\text { subjects needed }\end{array}$} \\
\hline \multirow{3}{*}{$\begin{array}{l}\text { Pre-test and } \\
\text { Post-test texts }\end{array}$} & $\begin{array}{l}\text { The pre and post-tests for } \\
\text { reading other types of texts } \\
\text { outside the speed reading } \\
\text { course do not reflect how } \\
\text { the learners really read. }\end{array}$ & $\begin{array}{l}\text { To see how the students } \\
\text { react when they are told to } \\
\text { read the texts outside the } \\
\text { speed reading course }\end{array}$ & $\begin{array}{l}\text { Five learners of } \\
\text { English }\end{array}$ \\
\cline { 2 - 5 } Pre-test and & $\begin{array}{l}\text { The texts in pre and post } \\
\text { tests are unequal in terms of } \\
\text { difficulty and vocabulary } \\
\text { level }\end{array}$ & $\begin{array}{l}\text { To see the equality between } \\
\text { the four texts }\end{array}$ & $\begin{array}{l}\text { Five learners of } \\
\text { English }\end{array}$ \\
\cline { 2 - 5 } & $\begin{array}{l}\text { The instructions for pre and } \\
\text { post tests are not clear, or } \\
\text { not appropriate in terms of } \\
\text { getting the students to read } \\
\text { without knowing that their } \\
\text { speed is being measured but } \\
\text { knowing that the focus is on } \\
\text { meaning }\end{array}$ & $\begin{array}{l}\text { To see how the students } \\
\text { react when they are told to } \\
\text { read the texts outside the } \\
\text { speed reading course }\end{array}$ & English \\
\hline
\end{tabular}

\subsubsection{The pilot testing of vocabulary level test}

Since Millett et al. (2007) recommend that the reading texts in the speed reading course would not be appropriate for learners who had not acquired a good receptive knowledge of the first 2000 words in English, the $2^{\text {nd }} 1000$ word level test was used to choose participants for the study. Before following the speed reading course the participants were supposed to do the vocabulary level test and it was required that they correctly answered at least 27 out of 30 questions in the test. Otherwise, the texts in the speed reading course would be too difficult for them. The original test (see appendix G) was made by Schmitt et al. (2001). This test was changed into a bilingual test (see appendix $\mathrm{H}$ ) before being given to the participants.

After the ten learners had done the test, they were asked to explain why they chose a certain answer for a question. Decisions on how to modify the test in a more 
comprehensive and appropriate way were made based upon this discussion with the learners.

The results showed that some participants provided incorrect answers for item 1, item 4, item 17, and item 19. For item 1, the question asked the participants to choose among the six words birth, dust, operation, row, sport and victory to match the word in Vietnamese trò choit. This word was translated from the word game in the English version test. Three participants chose operation instead of sport and explained that they knew the word sport but in Vietnamese, this word is not usually understood as trò choii. Asking other participants whose answer was correct, we realized that they had had the correct answer because they knew all the words in the choice list and guessed the tester wanted them to choose sport, not because they thought the two words matched in meanings. Therefore, the item was then changed from trò choi to thể thao, which is a clearer choice according to all ten learners.

Regarding item 4, the participants were supposed to choose among the six words choice, crop, flesh, salary, secret, and temperature to match the word súc nóng. The two participants having wrong answers said that they understood the word temperature, but the word sức nóng should be understood as heat in English. They could explain the other words' meanings very well and thus it was likely that they had the wrong answer because the item was confusing. Other learners were also consulted before the decision to change item 4 from súc nóng to nhiệt độ was made.

With regard to item 17, three participants gave wrong answers when they were asked to choose among the six words adopt, climb, examine, pour, satisfy and surround to match the word nhin kỹ. They then said they understood all the words but they were not sure which one should be chosen because the item did not give enough information. When the new choice xem xét, nhìn kỹ, để ý was proposed, all test takers agreed that it was clearer. Consequently item 17 was modified in the proposed way.

With respect to item 19, the choice connect was meant to match the item cùng tham gia but five out of ten participants chose either inquire or recognize. They then said that they had not really known what the tester meant. Thus the words nối nhau, liên kết were used to replace the current choice, and the learners reported no confusion. 
In addition to the mentioned changes, some small changes to the other items were also made to make sure that the questions tested what the participants knew about the words but not how well they could guess what the tester wanted them to answer. After the new version (see appendix I) was produced, another five learners were asked to do the test and followed the same procedures. The results and interviews showed that the new version worked well and did not cause any confusion to the participants.

To make sure that the test agreed with the texts in the speed reading course in terms of vocabulary level, five from the first ten learners were asked to read all the 20 texts in the speed reading book. All of them said the test was not difficult and there were not too many new words for them (around three words per page in the texts). They found the texts were at a relevant level to read and practice reading at home.

\subsubsection{The pilot testing of the four texts for the pre-test and post-test}

The study aimed to test if the speed reading course resulted in a faster reading speed for reading texts which were not in the course. The participants had to do a pre-test before having the speed reading course and post-test after the course ended. In these tests, they had to read two texts and answer ten comprehension questions accompanying each text (see appendices C, D, E and F). Using four texts helped to make sure that the topic of a certain text did not have too great an effect on participants' overall speed results. However, some issues needed to be taken into consideration. First, the texts might be too difficult or too easy compared with the texts in the speed reading course, resulting in a very low or very high score on the tests. Second, the four texts might be unequally difficult distorting the results as participants reading easier texts on the pre-test and more difficult texts on the post-test would make seemingly smaller increases than participants who read more difficult texts at the beginning and easier texts at the end of the treatment. Third, there might be some other smaller problems such as the text format might appear unfamiliar, the instructions might be unclear, the comprehension questions might be too difficult or too easy, or inappropriate in terms of helping to interpret how much the readers understood the texts. Fourth, the steps performed in real test administration must be relevant so as not to lose any necessary data and thus pilot testing should be done to make sure that it would not go wrong when the study was carried out. 
First, the five learners who had read the 20 texts in the speed reading course book were asked to read all the four texts. This was done to see if the four texts were manageable in terms of vocabulary level and topic. Interviews were carried out afterwards and they showed that the texts were all at a similar difficulty level for them.

Second, the time they spent on each text was also recorded and it was shown the fastest reader spent approximately two and a half minutes on the texts and the slowest readers needed around seven minutes. Although the times they needed were different, the time amount each participant spent on the four texts differed only slightly. The biggest difference was only 20 seconds. Interviews with the readers for their comments on the text difficulty levels were also carried out. They all claimed that the texts were at the same level and they could not decide which one was easier than the others.

Third, the participants were asked to point out anything that might have made it harder for them to read the text, to understand the instructions and to answer the comprehension questions. This was done to see if there were any problems with the text format, clarity of the instructions and questions. Regarding text format, in the first version the texts were condensed into one page and thus the participants found that their concentration was not at their best as they had gotten used to reading texts that were printed in double space or at least 1.5 lines. Therefore, in the new version the texts were printed in a standard format with 1.5 line spacing and standard margins. Two participants also pointed out some spelling mistakes in the texts and in the questions. Regarding instructions, all participants said they were clear enough and they did not have any complaints. Regarding the comprehension questions, one participant said that for questions that had such things as what is correct/incorrect about...?, the word correct or incorrect should be in capital letters to help readers avoid misunderstanding. For other questions, the participants understood what the questions meant, and for the ones they had an incorrect answer, it was just because they forgot the information they read from the texts, not because the question was confusing or tricky. The materials were then modified following the comments and suggestions.

Fourth, the administration procedures were also tested to see if the proposed steps were relevant and would not distort the results. Three learners were asked to sit the trial test and then the other two were asked to do the test under the new administration procedures, which were produced according to what occurred in the first testing with the first three 
learners. With the first three learners, the researcher gave them the texts and said: "Now you have to read the text continuously until being told to stop. After reading the text you will get a list of comprehension questions and you will have to answer them." Then the researcher said "Begin" at which point the participants began to read the text. After one and a half minutes, the researcher said "Stop" and asked them to mark the word they had reached in the text. Then they continued to read to the end of the text before answering the ten comprehension questions. When one text was done, they continued with another text. The results showed that two of them answered all the comprehension questions correctly but their speeds were rather slow. The discussion afterwards showed that they had tried to slow down their speeds to remember as much as possible from the text because they had been told that they would have to answer comprehension questions. For this reason, it was decided that when administering the tests the administrators would not let the participants know that they would have to answer comprehension questions after reading the texts. Other steps would be kept the same way as they were initially designed. The new procedures were tested with the other two participants and it was shown that the change worked effectively.

\subsection{Results}

This section begins with the results from the speed reading course and how the scheduling affected the speed increases, then proceeds with the effect of the speed reading course on reading other texts.

\subsubsection{Speed increases in the speed reading course}

This section concerns the increases the treatment groups made during the speed reading course. It presents the analysis for such issues as the reading rate increases in the course, the fastest and slowest speeds, the participants with negative results, the relationship between initial speeds and final speeds and the patterns of speed change.

In order to determine the answer to each of these issues, careful consideration on what method of scoring would be the best to achieve the most reliable data was firstly made. Chung and Nation (2006) used three methods called the average scoring method, the $20^{\text {th }}$ minus $1^{\text {st }}$ scoring method, and the extreme scoring method when they did their research. The average scoring method takes the average score on the first three texts minus the 
average score on the last three texts. The $20^{\text {th }}$ minus $1^{\text {st }}$ scoring method takes the score on the $20^{\text {th }}$ text minus the score on the $1^{\text {st }}$ text. The extreme scoring method takes the highest score minus the lowest score. Another method that can be used to measure readers' reading rate improvement is the three extremes scoring method. It takes the average score on the best three texts minus the average score on the worst three texts. Each of the four methods has advantages and disadvantages and can be used for different purposes. The four methods consist of two that involve only two measurements (the $20^{\text {th }}$ minus $1^{\text {st }}$ scoring method, the extreme scoring method) and two that involve two sets of three measurements (the average scoring method, the three extremes scoring method). The advantage of those scoring two sets of three measurements is that it makes the measurement much more reliable. However, when measuring the real increases that the participants made during the entire speed reading course, the three extremes method were not used because they do not necessarily indicate the real progress through the speed reading course, although it shows what the learner might be capable of under the least favourable and most favourable condition and is thus an optimistic, probably inflated measurement.

For this, the average method was used to measure the participants' speed development. The $20^{\text {th }}$ minus $1^{\text {st }}$ method, which takes the speed on the first text minus the speed on the last text, can be used to measure reading rate change during the course in order to see how fast a participant read right from the beginning of the course and at the very end of the course. However, the problem with this scoring method is that the score on only one text is not reliable enough for an improvement, especially an improvement in reading rate, which is always changeable. There is always a possibility that on day one they did not really understand what to do and this would lower their speed and inflate the increase. Besides, reading speed fluctuates according to the purpose of reading, the mood and attitude of the reader and so forth. The speed reading course was based on self-reported results, hence some participants might have reported untrue speeds on the first day and the last day. Therefore, basing the result on the $20^{\text {th }}$ minus $1^{\text {st }}$ scoring method is not reliable enough to confirm the increase that the participants made in the speed reading course. The average scoring method takes the average speed on the last three texts minus the average speed on the first three texts. This would increase the reliability of the results because it reduces the influence not only of an inaccurate self-report but also of a particularly bad or good day for a participant. Some students may not have done well on the last text but still done well on the previous ones and some others may have read the very first text slowly because it was the first time they did speed reading. Thus including the scores on the next two texts or the 
two previous texts will increase the chances of being reliable. This method is the most conservative of all four methods.

\subsubsection{Did the participants' reading rate increase within the speed reading course?}

Precautions were also taken before using the average method. The method may yield distorted results if the initial scores of some participants were much lower or higher than the others, thus inflating their increases and/or the texts the participants read on the first days and the last days of the course were more difficult or easier than the others, thus causing the speeds on these days much to be lower and higher than the others.

To eliminate the possibility that the initial scores of some participants might have distorted their increases, the initial scores by all participants were examined to see if any participants had remarkably faster or slower speeds on the first days of the course.

Table 3.2 Means and standard deviations of initial speeds in the course for all groups

\begin{tabular}{llcccc}
\hline Measure & & Group 1 & Group 2 & Group 3 & Group 4 \\
\hline \multirow{2}{*}{ Speed on the $1^{\text {st }}$ text } & Mean & 141.16 & 136.78 & 139.61 & 126.66 \\
& SD & 38.06 & 23.59 & 30.53 & 38.11 \\
\hline \multirow{2}{*}{ Average speed on the first three texts } & Mean & 151.22 & 148.82 & 162.09 & 148.81 \\
& SD & 31.45 & 23.99 & 33.35 & 25.94 \\
\hline
\end{tabular}

As can be seen from Table 3.2, the average scores on the first text of all groups were similar with group 4 slightly lower than the others. The average scores on the first three texts of all groups were also similar but with group 3 slightly higher than the others. Group difference was only $13 \mathrm{wpm}$. This result suggests that the study was not affected by unusually high or low scores on the initial texts. Note that the average first three text scores were higher than the $1^{\text {st }}$ text score, showing that the improvement in speed was occurring with texts two and three.

The possibility that the results might have been affected by the unequal difficulty levels of the texts that participants read on the first days and the last days can be eliminated by evidence presented later in this chapter that no texts in the speed reading course were more difficult or easier than the others. Reading rate can change according to the topic and difficulty of the text, causing a possibility that the participants would have very high scores 
on the easier texts and very low scores on the more difficult texts. Therefore it would be useful to investigate the texts that the participants read and reached their three lowest and three highest scores. If there were many participants having their highest scores on a certain text, that text may be easier than the others. If it was read in one of the first sessions, the participants' speeds could have been faster than their normal ones, thus making the difference between their scores on the last and the first text smaller than it should be. If there were many participants having their lowest scores on a certain text, that text may be more difficult than the others. If some participants read this text in one of the first sessions, their speeds could have been slower than their normal ones, thus making the difference between their scores on the last and the first text bigger than it should be. As mentioned earlier, the twenty texts in the speed reading course are from the book called Asian and Pacific speed readings for ESL learners (Millett, et al., 2007). Each text is 550 words long and is accompanied by ten comprehension questions. All of the passages were written within the 1000 most frequently used words of English (West, 1953). The authors also restricted the grammar by limiting the number of relative clauses, passives and difficult time references. An examination was conducted to see how many participants read each of the 20 texts and got one of the three lowest scores and one of the three highest scores. If a text on which many participants had their speed as one of the three lowest scores but very few participants or none had their speed as one of the highest scores, it can be inferred that the text was more difficult than the other texts. Likewise, if a text on which many participants had their speed as one of the highest scores but very few participants or none had their speed as one of the lowest scores, it can be inferred that the text is easier than the others. For instance (see appendix J), 15 participants had their score on text \#1 as one of the three lowest scores and 11 had their score on this text as one of the three highest scores. This shows that text \#1 was not too difficult or too easy for the participants. Texts \#14 and \#15 had the fewest number of students who got their speed as one of the three lowest scores when reading these two texts. However, the numbers of participants who read these texts and got their speed as one of the three highest scores were not noticeably higher than others. Thus, it is not possible to state that these two texts were easier than the others. For the remaining 17 texts, the results suggested the same conclusion. None of them seemed too challenging or simple for the participants. Therefore, text effects were unlikely to have strongly affected the scoring method. It should also be remembered that different learners were reading different texts at the same time, thus randomizing any text effect. 
Given that the precautions have helped to eliminate the possibility that the results might be distorted, it can be assumed that the method will yield reliable results. Table 3.3 shows the results derived from this method.

Table 3.3 Means and standard deviations of in-course speed increases for the treatment groups

\begin{tabular}{lcccc}
\hline & Group 2 & Group 1 & Group 4 & Group 3 \\
\hline$n$ & 19 & 18 & 18 & 18 \\
\hline Mean & 37.94 & 42.94 & 53.05 & 58.27 \\
SD & 33.10 & 31.27 & 45.90 & 47.69 \\
\hline
\end{tabular}

Group 1's scores were counted by taking the average score on texts $14^{\text {th }}, 15^{\text {th }}$ and $16^{\text {th }}$ minus the average score on the first three texts. The other groups' scores were counted by taking the average score on texts $18^{\text {th }}, 19^{\text {th }}$ and $20^{\text {th }}$ minus the average score on the first three texts. Overall, the results indicated that all four groups made speed increases in the speed reading course. For example, the participants in group 1 (one text per week) made an average increase of $43 \mathrm{wpm}$. It was found that group 3 made the greatest improvement and group 4 made the second best improvement. The data indicated that group 1 and group 2 made similar average increases of $43 \mathrm{wpm}$ and $38 \mathrm{wpm}$, group 3 and group 4 made similar average increases of $58 \mathrm{wpm}$ and $53 \mathrm{wpm}$. For group 1 (see appendix L) the average reading rate on the first three texts of all the participants was $151 \mathrm{wpm}$ while the average speed on the last three texts was $194 \mathrm{wpm}$, making the total increase $43 \mathrm{wpm}$. The average scores on the first three texts and the last three texts increased from the first to the third. The first text average score was $141 \mathrm{wpm}$, the second's was $143 \mathrm{wpm}$ and the third's was $169 \mathrm{wpm}$. Likewise, the $14^{\text {th }}$ text's score was $181 \mathrm{wpm}$, the $15^{\text {th }}$ 's was $200 \mathrm{wpm}$ and the $16^{\text {th }}$ s was 202 wpm. This means the improvement that the result shows was quite consistent throughout the course, including during the first and last three sessions. Two participants had a negative result.

For group 2 (see appendix M) it was found that the participants' average reading speed on the last three texts (187 wpm) was $38 \mathrm{wpm}$ faster than that on the first three texts (149 wpm). Although the average increase this group made was smaller than that of group 1, it was quite consistent as the scores on the previous texts were higher than the scores on the next texts. The score on the first text was $137 \mathrm{wpm}$ while the score on the second text was $147 \mathrm{wpm}$ and the score on the third text was $163 \mathrm{wpm}$. Similarly, the score on the $18^{\text {th }}$ text 
was $176 \mathrm{wpm}$ while the score on the $19^{\text {th }}$ text was $188 \mathrm{wpm}$ and the score on the $20^{\text {th }}$ was 196 wpm. Two participants did not make any improvement. One of them had a 39 wpm decrease and the other had a 2 wpm decrease.

For group 3 (see appendix $\mathrm{N}$ ) their average increase was $58 \mathrm{wpm}$. The data also showed that the score on the previous text was almost always lower than the score on the next text, which shows the consistency of the participants' improvement. For the initial texts, the first text had an average of $140 \mathrm{wpm}$, the second $154 \mathrm{wpm}$, and the third $193 \mathrm{wpm}$. For the last three texts, the first text had an average of $211 \mathrm{wpm}$, the third text had an average of a bit lower score than the second text (223 wpm vs. $227 \mathrm{wpm}$ ) but still higher than the first text. Only one of the participants had a negative result.

For group 4 (see appendix O) it was shown that the participants in this group made a 53 wpm increase. This group made the same pattern of improvement as the other three groups in that their score on an earlier text was higher than their score on a later text. The average speeds on the first three texts were $127 \mathrm{wpm}, 164 \mathrm{wpm}$ and $156 \mathrm{wpm}$. The average speeds on the last three texts were 199 wpm, $201 \mathrm{wpm}$ and 205 wpm. Two participants had a negative result.

The results from the $20^{\text {th }}$ minus $1^{\text {st }}$ method, extreme method and three extremes method (see appendices $\mathrm{X}$ and $\mathrm{Y}$ ) showed the same ranking among the four groups, with group 3 making the most gain, group 4 the second, and group 1 and group 2 the least. This both enhances the validity of the results from all four groups and makes it evident that on average the participants consistently made progress during the speed reading course.

\subsubsection{Did any of the participants not gain any improvement in the speed reading} course?

A preliminary analysis of the progress charts submitted by the participants showed that there was an erratic performance by some participants, and that some participants had their highest scores in the first half of the course while their lowest scores were in the second half. Therefore we tried to look more carefully at these cases to decide if these participants had any real decrease in their reading rates. First, we examined the participants' results in the average scoring method. Second, we selected participants with negative results and 
then saw if these participants had their lowest scores in the second half and their highest scores in the first half. Finally we compared their average score of the first 10 texts (for groups 2, 3 and 4) or eight texts (for group 1) and the average of the second ten texts or eight texts (for group 1). This was done to eliminate the possibility that the participants may have coincidently been under pressure when they did the last three texts and/or the first three texts they read were easier for them. If this result was also negative, then it would be clear that these participants did not increase their reading rate. The data shown in Table 3.4 indicate that seven out of 73 students (10\%) had negative results. Three of these had minimal decreases of only 2 and $4 \mathrm{wpm}$. On the other hand, comparing the average score on the first half and the average score on the second half showed that one participant had a positive result and the other six participants' records still revealed a negative result.

Table 3.4 Results by the participants who made no improvement

\begin{tabular}{lccccccc}
\hline Measure & $1 \mathrm{~B}$ & $1 \mathrm{O}$ & $2 \mathrm{~A}$ & $2 \mathrm{~F}$ & $3 \mathrm{~B}$ & $4 \mathrm{C}$ & $4 \mathrm{~J}$ \\
\hline Average method & -2 & -19 & -2 & -39 & -4 & -23 & -25 \\
$1^{\text {st }}$ half minus $2^{\text {nd }}$ half & 2 & -12 & -4 & -15 & -8 & -7 & -8 \\
\hline
\end{tabular}

A more careful investigation into these participants' speed charts showed that participant $2 \mathrm{~F}$ had all of their three highest scores in the first half and all of their lowest scores in the second half. Participants $1 \mathrm{O}$ and $2 \mathrm{~A}$ had two of their highest scores in the first half of the course and two of their lowest scores in the second half. Participant 3B had two of the highest scores in the first half of the course. Participants $4 \mathrm{C}$ and $4 \mathrm{~J}$ had two of the highest scores in the first half and the other highest score was in the session \#11, which was just after the first half.

We also looked at progress charts of all the six participants who had negative results as compared between the average speed in the second half with the average speed in the first half of the course. The charts (see Figure 3.2) demonstrated that these participants' speeds fluctuated throughout the course but did not have an upward trend. Their speeds reached a peak in the first half but not in the second half of the course. Among these participants, participant $2 \mathrm{~F}$ had the lowest average speed among the six participants. This participant experienced a downward trend in speed, which levelled from just over $150 \mathrm{wpm}$ to 100 wpm. The other participants' speeds fluctuated around 170 wpm (participant 10), 189 wpm (participants 2A), 162 wpm (participant 3B), $162 \mathrm{wpm}$ (participant 4C), and 128 wpm (participant $4 \mathrm{~J})$. 
Figure 3.2 Progress chart for participants who had a negative results comparing the second half and the first half of the course

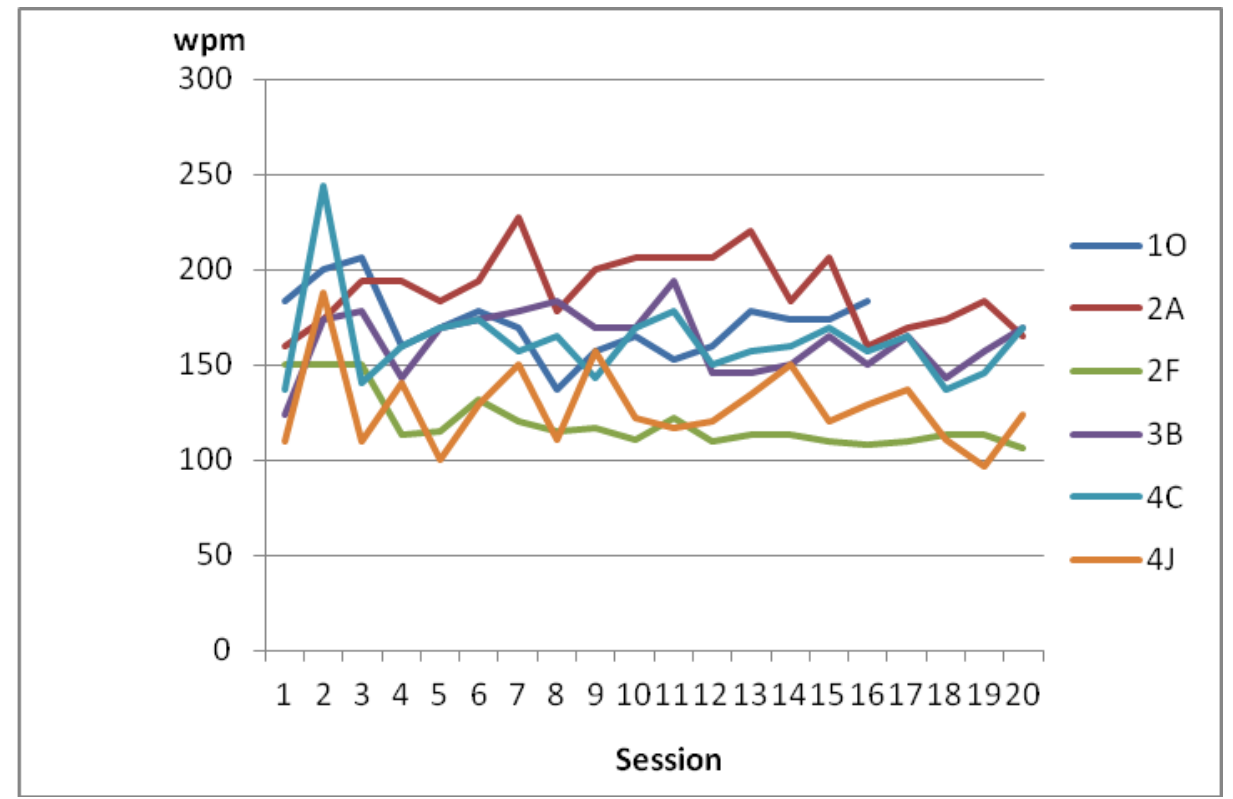

The analysis so far has made it clear that the lack of increases from these participants is consistent across the course and is not the result of the ways of calculating the score. Looking at these participants' comprehension scores may provide a possible explanation for the speed decreases they had during the course. The data for the comprehension indicated that among the six participants, only two increased their comprehension scores in the second half of the course, which might have been the reason why their speed decreased. The other four participants' comprehension scores decreased or remained the same, which indicates that they did not slow down their speeds in order to get higher comprehension scores. It is clearly worth looking at such learners carefully in future research to see why they made no progress. An unpublished study by Chung showed that by giving individual attention to such learners, all made an increase.

\subsubsection{To what extent does the decrease made by the participants who did not increase their reading rates affect the whole group results?}

As about $10 \%$ of the participants had negative results on their speed increase data, it is necessary to look at the effect that their scores had on the whole group's results to make sure that they did not distort the average score. In order to do this, these participants' scores were removed to see if there would be any noticeable difference for the groups' results. As shown in Table 3.5, group 1's new result is 4 wpm higher. Group 2's new result is 7 wpm higher. Group 3's new result is 4 wpm higher. Group 4's new result is 11 wpm 
higher. The ranking among the four groups was maintained with group 3 and group 4 having substantially bigger increases than group 1 and group 2.

The results demonstrate that the decreases that the six participants had did not have a noticeable effect on the whole group figures and confirm the progress that the four groups made during the speed reading course.

Table 3.5 Comparison of mean speed increases by four groups as original results and results after removing the scores by participants who made no progress

\begin{tabular}{llcccc}
\hline Result type & & Group 2 & Group 1 & Group 4 & Group 3 \\
\hline \multirow{2}{*}{ Original results } & Mean & 37.94 & 42.94 & 53.05 & 58.27 \\
& SD & 33.10 & 31.27 & 45.90 & 47.69 \\
\hline Results after removing & Mean & 44.87 & 47.43 & 61.98 & 61.89 \\
negative scores & SD & 26.70 & 28.02 & 38.69 & 46.48 \\
\hline
\end{tabular}

\subsubsection{How did comprehension change as the participants increase their speeds?}

Previous research has examined the effects of speed reading courses on reading rate improvement but has not explored how reading comprehension changes during the courses. Some studies in L1 speed reading courses found that increasing reading rate three times might result in a decrease in comprehension (Carver, 1992b). The goal of an ESL speed reading course is to increase reading rate while maintaining around $70 \%$ accuracy in comprehension (Millett, et al., 2007). Thus if the participants' speeds increased but their reading comprehension decreased to below $70 \%$ accuracy, it would seem that the speed improvement was meaningless. However, if we can see that the participants improved their reading rates while comprehending with $70 \%$ accuracy or more, it would be likely that their speed increases were real progress, and that speed reading courses can help readers to improve their reading rates without understanding less of the text. It is necessary to be a bit cautious about interpreting comprehension scores. The comprehension questions in the speed reading texts were designed to focus largely on the gist of the text and to be reasonably easy to answer. This was done so that there would not be difficult questions that would encourage learners to slow down to be sure of answering them. The questions were designed to encourage the learners to read faster and be successful when answering them 
so that their confidence was raised. A $70 \%$ score (seven out of 10) was considered adequate for texts read for enjoyment (Carver, 1992b).

In the present experiment, comprehension accuracy was measured by counting the number of correct answers out of the 10 multiple choice comprehension questions for each text. Two comparisons were made to determine how the participants' comprehension scores changed during the course. First, the average score on the first three texts was compared with the average score on the last three texts a participant read. Second, the average score on the first half of the course was compared with the average score on the second half of the course. An examination of the participants' comprehension scores in their three best sessions was also done to see if they reached their fastest speeds without comprehension suffering. If the data showed that in these sessions, a participant had high speeds but their comprehension was below $70 \%$ accuracy, it is not possible to say that this participant made a meaningful improvement.

A preliminary analysis of the two comparisons (see Table 3.6) indicated that all groups made an average score of at least seven out of 10 on initial texts, final texts, the first half and the second half of the course. The standard deviation was quite small. This demonstrates that they reached the goal of the course in terms of comprehension level, and that they were increasing speed while still comprehending most of the text. In addition, the data also show that for all groups except group 2, their average scores on the last three texts were slightly higher than their average scores on the first three texts, and their average scores in the second half were slightly higher than their average score on the first half. Among the 73 participants, only 15 participants had their average scores on the last three texts lower than their average scores on the first three texts, but the differences were barely noticeable ranging from 0.10 to 0.80 . The rest made their average scores on the last three texts either the same as or higher than their average scores on the first three texts. The increases ranged from 0.10 to 2.7. Although these results show that the participants' improvement in comprehension was minimal, it could still be assumed that the speed changes they made were real progress and that in speed reading courses, readers increase their speed without comprehension suffering. 
Table 3.6 Average comprehension scores on the first three texts and the last three texts, and in the three highest speed sessions, in the first half and the second half of the course for all groups

\begin{tabular}{llcccc}
\hline & & Group 1 & Group 2 & Group 3 & Group 4 \\
\hline \multirow{2}{*}{ First three texts } & Mean & 7.28 & 7.25 & 7.26 & 7.63 \\
\hline \multirow{2}{*}{ Last three texts } & SD & 0.69 & 0.80 & 1.36 & 0.84 \\
\hline \multirow{2}{*}{ First half } & Mean & 7.59 & 7.18 & 7.53 & 7.75 \\
\hline \multirow{2}{*}{ Second half } & Mean & 7.85 & 0.98 & 0.78 & 0.78 \\
\hline Three highest speed & Mean & 0.61 & 7.54 & 7.70 & 8.01 \\
sessions & Mean & 7.91 & 0.57 & 0.91 & 0.58 \\
\hline
\end{tabular}

Of all groups, group 4 always had the highest average comprehension scores, both in the first half and the second half of the course or on the first three texts and the last three texts. Group 2 always had the lowest average comprehension scores, and was the only group with a slight decrease in comprehension. Although the decrease was marginal, it might be related to the small reading speed increases they made during the course. Perhaps participants in this group were struggling with the task of keeping their comprehension at the appropriate level while having to increase their speeds.

The data showed that in their three best sessions, all groups were reading and comprehending with more than $70 \%$ accuracy (see Table 3.6) and that only 9 out of 73 participants comprehended with less than $70 \%$ accuracy in their best sessions. These results demonstrate that even when the participants read at their best speeds, most of them could still keep their comprehension level at at least $70 \%$ accuracy, thus their speed increases were meaningful and this enhances the idea that speed reading courses are meaningfully beneficial to ESL/EFL learners.

\subsubsection{How did the initial speeds relate to the final speeds?}

The participants' results are arranged from the highest average score on the three initial texts to the lowest average score and can be compared with the final speeds. In Table 3.7, the data of each individual are listed in three columns from the left to the right for code, 
initial average speed, and final average speed. For example, participant 3P had $255 \mathrm{wpm}$ as her initial average score and $305 \mathrm{wpm}$ as her final average speed. The data in the table were divided into four equally sized groups. The first group consisted of 18 participants with the highest initial speeds ranging from $255 \mathrm{wpm}$ to $169 \mathrm{wpm}$. The second group was composed of 18 participants with the initial speeds ranging from $168 \mathrm{wpm}$ to $154 \mathrm{wpm}$. The third group included 18 participants whose initial speeds ranged from $152 \mathrm{wpm}$ to 133 wpm. The fourth group were the 19 participants with initial speeds ranging from $131 \mathrm{wpm}$ to $102 \mathrm{wpm}$.

Table 3.7 Initial speeds (Ini) and final speeds (Final) in the course by all participants

\begin{tabular}{|c|c|c|c|c|c|c|c|c|c|c|c|}
\hline $\mathbf{P}$ & Ini & Final & $\mathbf{P}$ & Ini & Final & $\mathbf{P}$ & Ini & Final & $\mathbf{P}$ & Ini & Final \\
\hline $3 \mathrm{P}$ & 255 & 305 & $3 \mathrm{~L}$ & 168 & 251 & $4 \mathrm{I}$ & 152 & 162 & $1 \mathrm{~S}$ & 131 & 211 \\
\hline $4 \mathrm{~L}$ & 217 & 237 & $1 \mathrm{~K}$ & 165 & 191 & $3 \mathrm{~J}$ & 151 & 287 & $1 \mathrm{~J}$ & 131 & 161 \\
\hline $1 \mathrm{M}$ & 213 & 287 & $3 \mathrm{~W}$ & 164 & 249 & $3 \mathrm{~F}$ & 151 & 261 & $1 \mathrm{~L}$ & 130 & 213 \\
\hline $3 \mathrm{~A}$ & 198 & 200 & $2 \mathrm{D}$ & 164 & 207 & $4 \mathrm{P}$ & 150 & 198 & 1I & 129 & 185 \\
\hline 10 & 196 & 177 & $2 \mathrm{U}$ & 164 & 177 & $4 \mathrm{G}$ & 150 & 168 & 2I & 128 & 174 \\
\hline $1 \mathrm{C}$ & 193 & 213 & $2 \mathrm{~V}$ & 164 & 167 & 30 & 150 & 206 & $1 \mathrm{H}$ & 127 & 198 \\
\hline $2 \mathrm{C}$ & 189 & 228 & $4 \mathrm{~F}$ & 163 & 236 & $2 \mathrm{~F}$ & 150 & 111 & $1 \mathrm{E}$ & 127 & 165 \\
\hline $3 R$ & 188 & 288 & $2 \mathrm{~B}$ & 163 & 207 & $2 \mathrm{E}$ & 147 & 179 & $4 \mathrm{~A}$ & 123 & 186 \\
\hline $1 \mathrm{~B}$ & 183 & 181 & $2 \mathrm{~J}$ & 161 & 194 & $1 \mathrm{P}$ & 147 & 156 & $4 Q$ & 122 & 162 \\
\hline $1 \mathrm{R}$ & 182 & 216 & $3 X$ & 160 & 204 & $4 \mathrm{H}$ & 143 & 196 & $2 \mathrm{M}$ & 122 & 205 \\
\hline $3 \mathrm{U}$ & 181 & 198 & $3 B$ & 160 & 156 & $3 \mathrm{I}$ & 142 & 173 & $4 \mathrm{U}$ & 114 & 217 \\
\hline $2 \mathrm{~T}$ & 178 & 216 & $1 \mathrm{~A}$ & 158 & 194 & $2 \mathrm{P}$ & 142 & 198 & $2 \mathrm{H}$ & 112 & 175 \\
\hline 4B & 176 & 243 & $1 \mathrm{Q}$ & 157 & 234 & $2 \mathrm{R}$ & 142 & 188 & $2 \mathrm{~W}$ & 111 & 134 \\
\hline $2 \mathrm{~A}$ & 176 & 174 & $4 \mathrm{~T}$ & 156 & 221 & $4 \mathrm{O}$ & 140 & 297 & $2 \mathrm{~K}$ & 110 & 174 \\
\hline $3 \mathrm{H}$ & 175 & 182 & $4 \mathrm{M}$ & 155 & 268 & $1 \mathrm{D}$ & 139 & 221 & $1 \mathrm{~N}$ & 110 & 129 \\
\hline $4 C$ & 174 & 151 & $3 Q$ & 155 & 326 & $4 \mathrm{~J}$ & 136 & 111 & $3 \mathrm{M}$ & 108 & 146 \\
\hline $3 \mathrm{~S}$ & 172 & 213 & $4 \mathrm{R}$ & 154 & 238 & $2 \mathrm{~S}$ & 136 & 251 & $3 G$ & 107 & 131 \\
\hline \multirow[t]{3}{*}{$2 \mathrm{G}$} & 169 & 192 & $4 \mathrm{~N}$ & 154 & 217 & $3 \mathrm{~N}$ & 133 & 192 & $1 \mathrm{~F}$ & 104 & 164 \\
\hline & & & & & & & & & $4 \mathrm{~K}$ & 102 & 128 \\
\hline & 190 & 217 & & 160 & 219 & & 145 & 198 & & 118 & 171 \\
\hline
\end{tabular}

The scores in the bottom row of Table 3.7 indicates that the two groups with the higher initial speeds reached higher speeds in the final sessions of the course. The group that 
ranked the third in initial speeds also ranked the third in the final speeds. The group with the slowest initial speeds also reached the slowest speeds in the final three sessions. Interestingly the second group, whose initial average speed was $30 \mathrm{wpm}$ lower than the first group, obtained the highest final speeds with $219 \mathrm{wpm}$. It is probable therefore that not only very fast readers but any learners with an average speed from $155 \mathrm{wpm}$ can reach speeds of over $200 \mathrm{wpm}$ when reading in a foreign language.

With respect to the increases that each category of participants made, it was shown that the group with the highest initial speeds made the least improvement with an average increase of only $27 \mathrm{wpm}$. This is understandable as their initial speeds were already high. Although the other groups had different initial speeds, they made similar average increases of 59 wpm (the second group) and $53 \mathrm{wpm}$ (the third and the fourth groups). This result suggests that speed reading courses in L2/FL are beneficial for readers with low or high initial speeds. The highest initial group may be affected by a ceiling affect but in general, initial speed does not determine the amount of increase in speed during the course.

\subsubsection{What were the patterns of progress in speed?}

Although it was clear that most participants made a speed improvement during the course, it is interesting to look at how their progress was achieved. Looking at the progress charts by the participants, we found that they had different change patterns. Some progressed steadily while some others progressed with many fluctuations. Others decreased during the course or kept their speed at the same level. In order to decide which change pattern a certain participant had, we set up a few criteria to classify their graphs.

There were two main types: improvement or no improvement graphs. The no improvement graphs are the ones with the first three text scores higher than or equal to the last three texts scores and the improvement graphs are the ones with the first three text scores lower than the last three texts scores.

Figure 3.3 is an example of a no improvement graph and Figure 3.4 is an example of an improvement graph. 
Figure 3.3 Progress chart of participant 2 F/no improvement

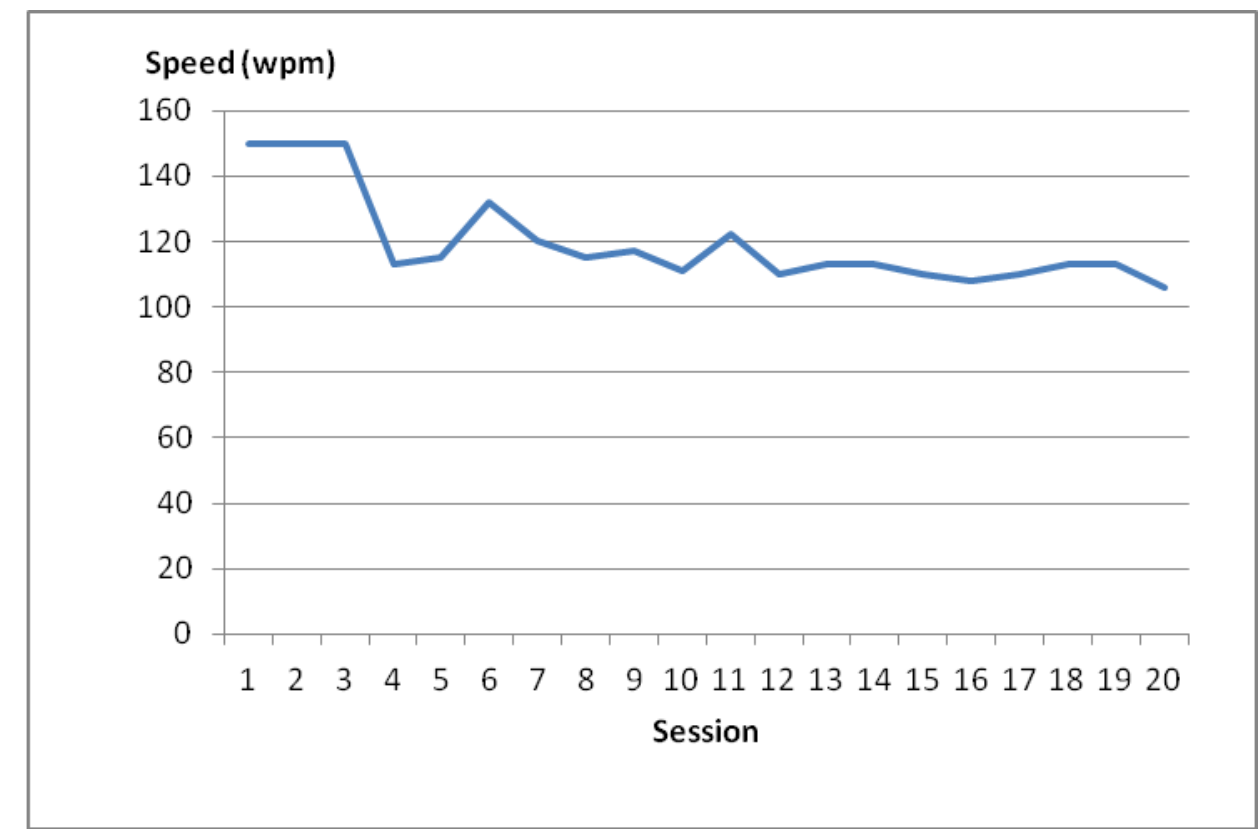

Figure 3.4 Progress chart of participant 2H/improvement

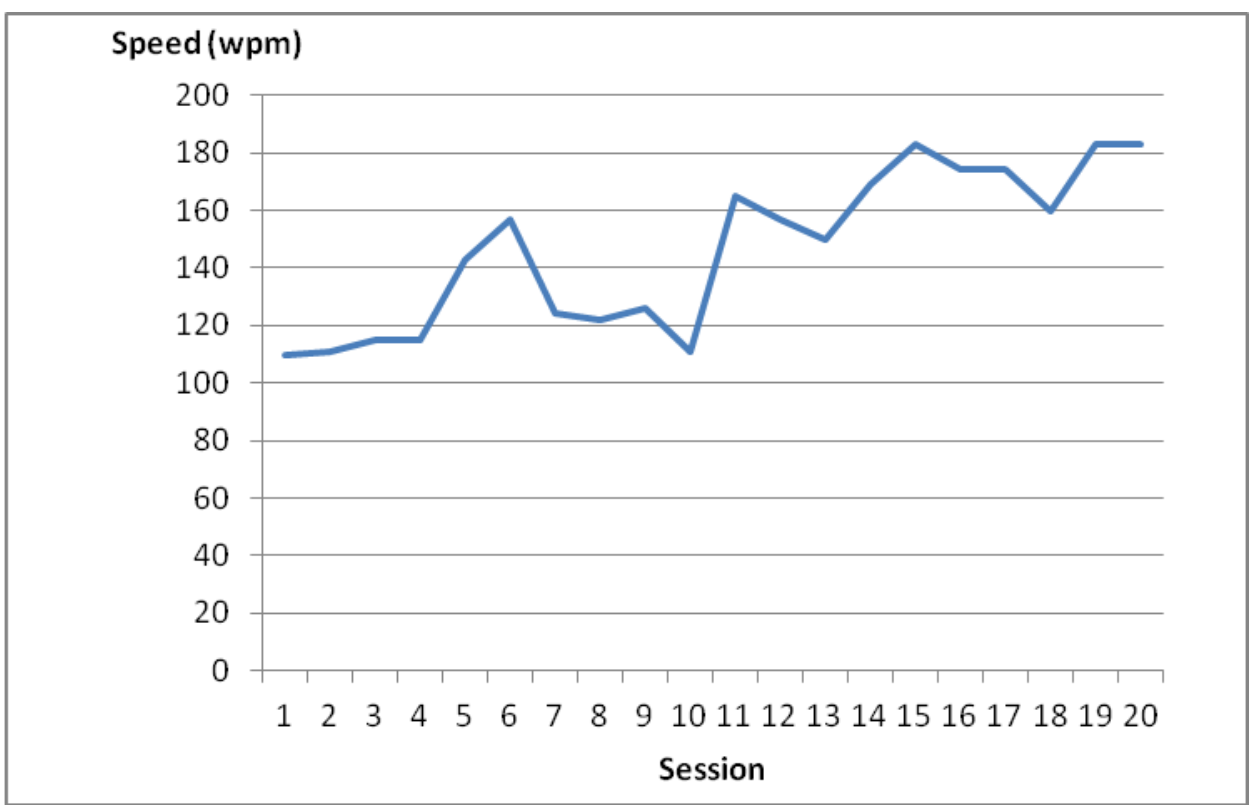

For the improvement graphs, there are four subtypes of gradual increase, erratic increase, plateau increase, and mixed increase. Chung and Nation (2006) defined these four types in their study of the effect of a speed reading course on 49 students in South Korea. Gradual increases are the ones with no more than two rises or falls of more than $70 \mathrm{wpm}$. Erratic increases are the ones with more than two rises or falls of at least $70 \mathrm{wpm}$. Plateau 
increases are the ones with at least two plateaus, each of which must consist of three successive similar scores. Similar scores means the difference between these scores is less than $10 \mathrm{wpm}$. A mixed increase pattern contains more than one of the other types.

In this study, we followed these criteria with a slight modification about plateaus. Participants' charts in this study will be considered as plateau charts if they contain at least three plateaus, each of which consist of three successive similar scores. The definition of similar scores is the same as Chung and Nation's. We defined a plateau chart in this way because there were twenty texts in the speed reading course, and if the two plateaus appeared at the two ends and fluctuations stood in the middle, the chart would not look flat enough to be called a plateau pattern. There should be another plateau somewhere else in the chart to make it more constant.

Figures 3.5, 3.6 and 3.7 illustrate an example of a gradual increase, an erratic increase and a plateau increase.

Figure 3.5 Progress chart of participant 3Q/gradual increase

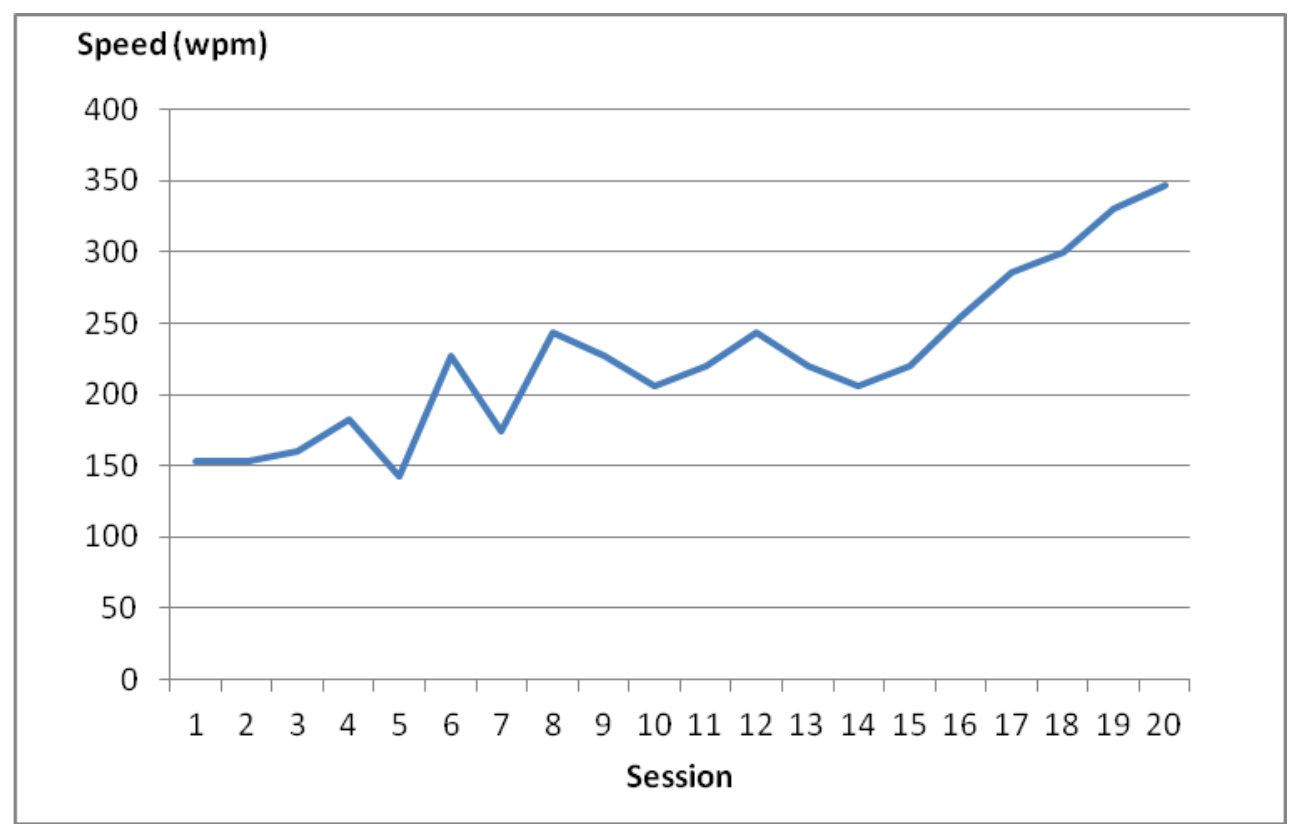




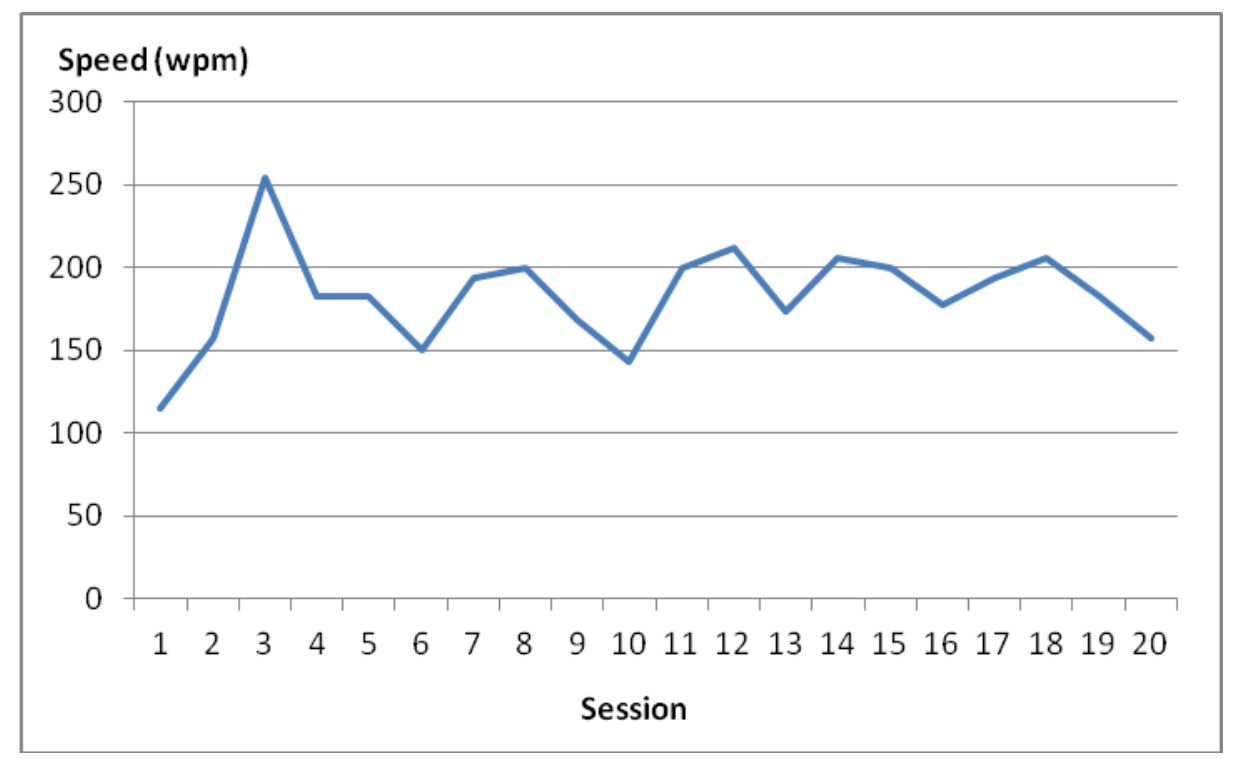

Figure 3.7 Progress chart of participant 3L/plateau increase

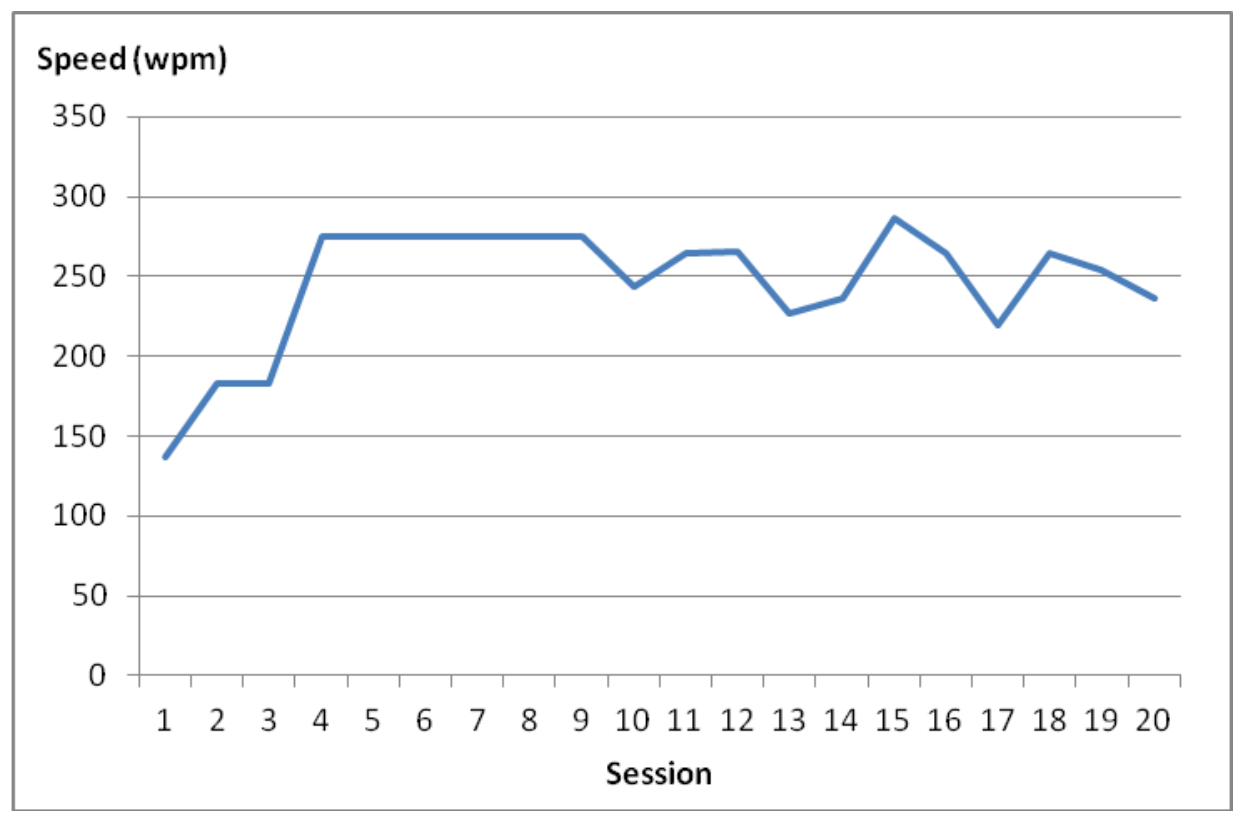

For the no improvement pattern, the average scoring method, which took the average score on the last three texts minus the average score on the first three texts, indicates that there were seven participants having a no improvement pattern. For the improvement patterns, the investigation into the participants' charts showed that none of the participants had mixed increases (see Table 3.8). Fifty-three made gradual increases. Ten participants had erratic increases and three participants made plateau increases. Hence, among the 66 participants with improvement patterns, $80 \%$ gradually increased their speeds while $20 \%$ 
had either erratic increases or plateau increases. As in Chung and Nation (2006)'s study, the gradual increase pattern was by far the predominant one.

Table 3.8 Numbers of participants for different change patterns

\begin{tabular}{lccccc}
\hline Group & No improvement & Erratic change & Plateau change & Gradual change & Mixed change \\
\hline Group1 & 2 & 3 & 0 & 13 & 0 \\
Group 2 & 2 & 2 & 2 & 13 & 0 \\
Group 3 & 1 & 3 & 1 & 13 & 0 \\
Group 4 & 2 & 2 & 0 & 14 & 0 \\
& $7(9 \%)$ & $10(14 \%)$ & $3(4 \%)$ & $53(73 \%)$ & $0(0 \%)$ \\
\hline
\end{tabular}

We have now answered the first major question regarding the speed improvement the participants made in the speed reading course. The next sections will deal with the second major question regarding what scheduling is the most effective to achieve optimal results.

\subsubsection{Scheduling speed reading courses}

In order to suggest the best scheduling method for a speed reading course to achieve optimal results, two issues need to be explored. First, it is necessary to see in which part of the course the participants had their highest scores. This will help to determine how long the course should last. Second, the results of speed increases by the four groups following the four different scheduling systems need to be compared to determine how often the sessions should be and whether duration of the course or frequency of the lessons are important.

\subsubsection{In which part of the course did the participants gain their lowest and highest scores?}

The idea behind this question was that if we could conclude that the lowest scores were in the beginning parts of the course and the highest scores were in the end part, there would be more evidence for the speed improvement made by the participants throughout the course. More importantly, it would suggest how many texts the readers should read. If the results show that many participants reached their highest scores in the first half of the course, that means it would be meaningless to continue a speed reading course beyond the 
$10^{\text {th }}$ session. To answer this question, we tried to see on which sessions of the course the participants achieved their worst and best results. To make a proper comparison between group 1 and the other three groups, we had to separate their data as group 1 had only 16 sessions while the other groups had 20 sessions. For group 1, for example, if a certain participant got his/her lowest scores in any sessions from \#1 to \#8 and the highest scores in any sessions from \#9 to \#16, it would be clearer that this participant made an increase in speed, and that the course should last until at least the $8^{\text {th }}$ session. If the highest scores were in any sessions from \#1 to \#8 but the lowest scores were in any session between \#9 and \#16, it would not be strong evidence for the participant's improvement, and it would not support the idea that the course should last beyond the $8^{\text {th }}$ session.

Table 3.9 Sessions in which each of the participants in group 1 had their three slowest and three fastest speeds

\begin{tabular}{ccccccc}
\hline Participant & Slowest & $\mathbf{2}^{\text {nd }}$ slowest & $\mathbf{3}^{\text {rd }}$ slowest & $\mathbf{3}^{\text {rd }}$ fastest & $\mathbf{2}^{\text {nd }}$ fastest & Fastest \\
\hline 1L & $\# 1$ & $\# 2$ & $\# 4$ & $\# 10$ & $\# 16$ & $\# 14$ \\
1E & $\# 1$ & $\# 2$ & $\# 5$ & $\# 13$ & $\# 15$ & $\# 16$ \\
1I & $\# 1$ & $\# 2$ & $\# 5$ & $\# 14$ & $\# 15$ & $\# 10$ \\
1C & $\# 1$ & $\# 2$ & $\# 11$ & $\# 15$ & $\# 4$ & $\# 6$ \\
1A & $\# 1$ & $\# 5$ & $\# 2$ & $\# 7$ & $\# 13$ & $\# 15$ \\
1R & $\# 1$ & $\# 8$ & $\# 2$ & $\# 14$ & $\# 16$ & $\# 9$ \\
1P & $\# 1$ & $\# 14$ & $\# 13$ & $\# 4$ & $\# 6$ & $\# 16$ \\
1Q & $\# 2$ & $\# 1$ & $\# 3$ & $\# 16$ & $\# 5$ & $\# 6$ \\
1J & $\# 2$ & $\# 1$ & $\# 8$ & $\# 16$ & $\# 3$ & $\# 11$ \\
1D & $\# 2$ & $\# 1$ & $\# 12$ & $\# 8$ & $\# 16$ & $\# 15$ \\
1F & $\# 2$ & $\# 4$ & $\# 1$ & $\# 8$ & $\# 7$ & $\# 9$ \\
1S & $\# 2$ & $\# 8$ & $\# 7$ & $\# 17$ & $\# 14$ & $\# 15$ \\
1M & $\# 2$ & $\# 14$ & $\# 5$ & $\# 7$ & $\# 16$ & $\# 15$ \\
1H & $\# 5$ & $\# 1$ & $\# 4$ & $\# 12$ & $\# 14$ & $\# 15$ \\
1K & $\# 6$ & $\# 5$ & $\# 7$ & $\# 12$ & $\# 15$ & $\# 16$ \\
1O & $\# 8$ & $\# 11$ & $\# 9$ & $\# 16$ & $\# 2$ & $\# 3$ \\
1N & $\# 10$ & $\# 4$ & $\# 2$ & $\# 13$ & $\# 9$ & $\# 15$ \\
1B & $\# 15$ & $\# 12$ & $\# 5$ & $\# 1$ & $\# 11$ & $\# 16$ \\
\hline
\end{tabular}

The worst and the best sessions of the participants in group 1 are presented in Table 3.9 and the results are summarized in Table 3.10. 
Table 3.10 Summary of the best sessions and the worst sessions for group 1

\begin{tabular}{lcccc}
\hline Measure & $\# 1$ to \#4 & $\# 5$ to \#8 & $\# 9$ to \#12 & $\# 13$ to \#16 \\
\hline Slowest speed & $72 \%$ & $17 \%$ & $11 \%$ & $0 \%$ \\
Fastest speed & $6 \%$ & $11 \%$ & $22 \%$ & $61 \%$ \\
\hline Three slowest speeds & $56 \%$ & $26 \%$ & $11 \%$ & $7 \%$ \\
Three fastest speeds & $10 \%$ & $17 \%$ & $17 \%$ & $56 \%$ \\
\hline
\end{tabular}

As shown in Table 3.9 and Table 3.10, of all the 18 participants, only $11 \%$ had the lowest scores in the second half of the course. The remaining $89 \%$ had their lowest score in the first half of the course with $72 \%$ in the first four sessions. Eighty-three percent of the participants scored the best in the second half with $61 \%$ of them had their fastest speeds in the last three sessions. Only $17 \%$ reached their best speed in the first half of the course, but they still had their lowest scores in the previous sessions. Regarding the three best scores and three worst scores, for the sake of simplicity, first we considered all 18 participants in group 1 to have 54 scores for their lowest sessions (18 participants times 3 texts) and 54 scores for their best sessions (18 participants times 3 texts). Next, we tried to see how many percent of those 54 scores were in the first part and how many were in the second part. With respect to the lowest scores, $44(82 \%)$ were in the first half with $30(56 \%)$ in the first four sessions and only 10 scores (18\%) were in the second half with six scores (11\%) reached during the \#9 to \#12 sessions and four scores (7\%) reached in the last four sessions. However, among the 10 scores reached during the second half of the course, four of them were reached by four participants $(1 \mathrm{C}, 1 \mathrm{D}, 1 \mathrm{M}$, and $1 \mathrm{~N})$ whose other two lowest scores were reached in the first half, which made their lowest score part lean toward the first half rather than the second. The other six scores were reached by three participants who had two of their lowest scores in the second half, which made their lowest score part lean towards the second half rather than the first half. Regarding the highest scores, 39 (73\%) of the 54 scores were gained in the second half of the course and the remaining $15(27 \%)$ were gained in the second half. However, of all the 15 scores gained in the second half, five scores were made by five participants $(1 \mathrm{~A}, 1 \mathrm{~J}, 1 \mathrm{D}, 1 \mathrm{M}$, and $1 \mathrm{~B})$ whose two other highest scores were in the second half, which made their highest score part lean toward the second half rather than the first half. The other 10 scores were reached by five participants $(1 \mathrm{C}, 1 \mathrm{P}, 1 \mathrm{Q}, 1 \mathrm{~F}$, and 1O) whose other two highest scores were reached in the first half. If these five participants had all three or two of the lowest scores in the second half, it would be clear that they were not making improvement. However, looking at the lowest score data, we could see that participants $1 \mathrm{C}, 1 \mathrm{Q}$ and $1 \mathrm{~F}$ had their lowest scores in the sessions 
which were completed before their highest scored sessions. Only participants 10 and $1 \mathrm{P}$ had two lowest scores in the second half and two highest scores in the first half.

This figure, together with the results in the previous parts, confirmed that most of the participants in group 1 made a predictable increase in their reading rate when taking the speed reading course.

The same preliminary analysis was carried out for the data from group 2, group 3 and group 4 and the results are presented in Table 3.11 .

Table 3.11 Summary of the best sessions and the worst sessions for groups 2, 3 and 4

\begin{tabular}{lcccc}
\hline & $\# 1$ to \#5 & $\# 6$ to \#10 & $\# 11$ to \#15 & $\# 16$ to \#20 \\
\hline Slowest speed & $86 \%$ & $7 \%$ & $2 \%$ & $5 \%$ \\
Fastest speed & $11 \%$ & $11 \%$ & $22 \%$ & $56 \%$ \\
\hline Three slowest speeds & $68 \%$ & $18 \%$ & $7 \%$ & $7 \%$ \\
Three fastest speeds & $8 \%$ & $14 \%$ & $27 \%$ & $51 \%$ \\
\hline
\end{tabular}

The results indicate that of all 55 participants in these three groups, 51 participants (93\%) had their lowest score in the first half of the course and all of them had their highest score in the sessions which came after the ones where they had their lowest scores. Among these 51 participants, 46 had their slowest speed within the first four sessions. Only four participants (7\%) had their lowest scores in the second half. These participants reached their highest score in the first half. In terms of the highest score, 43 participants (78\%) reached it in the second half of the course and the rest (22\%) reached it in the first half. With respect to the three slowest and three fastest speeds, first we considered all the 55 participants in groups 2, 3 and 4 to have 165 scores for their lowest scores (55 participants times 3 texts) and 165 scores for their highest scores. Next we tried to see if the highest ones were in the second half (from session 11 to session 20) and the lowest ones were in the first half of the course (from session 1 to session 10). The data show that 141 scores $(86 \%)$ in the lowest score group were in the first half with $68 \%$ made in the first five sessions and only $24(14 \%)$ were in the second half. However, of all the 24 scores that were in the second half, 15 scores were made by the participants whose two other lowest scores were in the first half. That means we can count these participants as the ones whose lowest scores were largely in the first half of the course rather than in the second half. 
Regarding the three highest scores, 128 scores (78\%) out of 165 highest scores were in the second half of the course. The remaining 37 scores $(22 \%)$ were in the first half. However, 17 scores out of the 37 scores made in the first half were gained by 17 different participants whose two other highest scores were in the second half, so these participants would be regarded as having their highest scores largely in the second half rather than the first half.

Taken as a whole, $80 \%$ of the participants reached their fastest speeds in the second half of the course and their slowest speeds in the first half of the course. More than half of the participants made their highest scores in the last five sessions. More than $61 \%$ of the participants in group 1 made their highest scores in their last two sessions (\#15 and \#16) and almost half of the participants in group 2, 3 and 4 made their highest scores in the last two sessions (\#19 and \#20). These results suggest that having the participants continue to read until the $16^{\text {th }}$ text for group 1 and the $20^{\text {th }}$ text for the other three groups was useful in terms of helping them to increase their reading speed. The data also indicate that most of the participants (90\%) made their three highest scores after making their lowest scores. This agrees with the idea that the highest scores were the result of improvement not erratic learner behaviour. It also demonstrates the method of calculating speed increase from taking the average of the three lowest scores away from the average of the three highest scores is largely justified.

\subsubsection{How did the four different scheduling methods affect the groups' reading speed improvement?}

The four experimental groups were scheduled in different ways for the speed reading course. Group 1 had only one session a week; group 2 had two sessions; group 3 had three sessions and group 4 had four sessions. To see which way of scheduling the speed reading course would help to achieve an optimal effect, we compared the rate changes made by each group in the course. All four methods of calculating speed change were examined. First, we looked at the difference between the highest score and the lowest score that the participants had. Second, we looked at the difference between the three highest scores and the three lowest scores. Third, we looked at the difference between the first score and the last score. Lastly, we looked at the difference between the first three scores and the last three scores for each group. As Table 3.12 shows, all four scoring methods resulted in the same ranking of the groups from lowest to highest, group 2, group 1, group 4, group 3 . The 
four methods also produced a similar ranking of each treatment, from lowest to highest average, last minus first, three extremes, and extreme.

Table 3.12 Means and standard deviations of in-course speed increases in all the four scoring methods for all treatment groups

\begin{tabular}{llcccc}
\hline Measure & & Group 2 & Group 1 & Group 4 & Group 3 \\
\hline \multirow{2}{*}{ Average method } & Mean & 37.94 & 42.94 & 53.05 & 58.27 \\
& SD & 33.10 & 31.27 & 45.90 & 47.69 \\
\hline Last minus first & Mean & 59.57 & 60.38 & 78.38 & 83.55 \\
method & SD & 44.16 & 32.85 & 52.62 & 51.64 \\
\hline Three extremes & Mean & 73.36 & 75.11 & 91.50 & 101.72 \\
method & SD & 22.68 & 26.79 & 34.70 & 52.70 \\
\hline \multirow{2}{*}{ Extreme method } & Mean & 90.26 & 95.22 & 119.55 & 142.22 \\
& SD & 31.57 & 31.84 & 40.60 & 82.15 \\
\hline
\end{tabular}

As illustrated earlier and shown in Table 3.12, when comparing the difference between the last score and the first score, we could see that group 1 and group 2 made the same increase of $60 \mathrm{wpm}$ and this increase is smaller than the increases by group 3 and group 4. Similarly, a comparison of the difference between the first three scores and the last three scores showed the same pattern with groups 1 and 2 making similar increases of $43 \mathrm{wpm}$ and $38 \mathrm{wpm}$ and groups 3 and 4 making $58 \mathrm{wpm}$ and $53 \mathrm{wpm}$. When comparing the difference between the worst score and the best score each group had, we could see that groups 1 and 2 performed about the same (increases of $95 \mathrm{wpm}$ and $90 \mathrm{wpm}$ ) but worse than groups 3 and 4 (increases of 142 wpm and 140 wpm). Likewise, comparison of the difference between the three best scores and three worst scores showed the same results with groups 1 and 2 making 75 wpm and 73 wpm increases and groups 3 and 4 making $102 \mathrm{wpm}$ and $92 \mathrm{wpm}$. In other words, the four scoring methods yielded the same pattern that groups 3 and 4 outperformed groups 1 and 2 with group 1's increase slightly smaller than group 2's and group 4's increase slightly smaller than group 3's.

Using one-way ANOVA, we tested the null hypothesis that all the mean increases of the four groups were equal. We found that the groups' mean scores were not significantly different for the average scoring method, $\mathrm{F}(3,69)=0.98, \mathrm{p}=0.406$, for the last minus first scoring method, $\mathrm{F}(3,69)=1.27, \mathrm{p}=0.277$, and for the three extremes method, $\mathrm{F}(3,69)=$ 2.61, $\mathrm{p}=0.058$. However, for the extreme method, there was a significant difference, $\mathrm{F}(3$, $69)=4.07, p=0.010$. Post hoc comparisons using Tukey HSD test indicated that the mean 
scores for group $1(M=95.22, S D=31.84)$ and group $2(M=90.26, S D=31.57)$ were significantly lower than the mean score for group $3(M=142.22, S D=82.15)$. The mean score for group $4(\mathrm{M}=119.55, \mathrm{SD}=40.60)$ was not significantly higher than the mean scores for group 1 and group 2.

Because group 1 only had one session a week and the semester only lasted for 16 weeks, we had to compare the average score on the three initial texts and the average score on the $14^{\text {th }}, 15^{\text {th }}$ and $16^{\text {th }}$ texts. This was done to make sure that the comparison was an equal one between group 1 and the other three groups. The results presented in Table 3.13 indicate that group 2 ranked the last in all four scoring methods. Group 1 made similar increases to group 3 in the two last minus first methods but smaller increases than group 3 in the two extreme methods. Group 4 made bigger increases than group 1 in all scoring methods. Group 4 made bigger increases than group 3 in the two last minus first methods but smaller increases than group 3 in the two extreme methods.

Table 3.13 Means and standard deviations of in-course speed increases for all treatment groups when using calculations involving 16 texts

\begin{tabular}{llcccc}
\hline Measure & & Group 2 & Group 1 & Group 4 & Group 3 \\
\hline \multirow{2}{*}{ Average method } & Mean & 28.37 & 42.76 & 49.05 & 40.98 \\
& SD & 33.10 & 31.27 & 45.90 & 47.69 \\
\hline Last minus first & Mean & 43.23 & 60.10 & 76.65 & 59.78 \\
method & SD & 45.22 & 32.85 & 50.07 & 49.23 \\
\hline Three extremes & Mean & 60.83 & 74.91 & 83.23 & 88.87 \\
method & SD & 21.89 & 26.79 & 28.49 & 50.37 \\
\hline \multirow{2}{*}{ Extremes method } & Mean & 82.86 & 95.04 & 112.98 & 115.06 \\
& SD & 25.52 & 31.84 & 42.37 & 54.60 \\
\hline
\end{tabular}

Taken as a whole, the data indicate that using both calculation involving 16 texts and 20 texts, groups 3 and 4 made the greatest improvement and group 2 made the least progress. Group 1 made increases more similar to group 2 than to groups 3 and 4 when using calculations involving 20 texts but they made increases more similar to groups 3 and 4 than to group 2 when using calculations involving 16 texts. Thus it might be that if group 1 had had more sessions, their average speed increase might have been bigger than just $43 \mathrm{wpm}$. This is possible because when measuring the increases for groups 2 and 3 by taking the $1^{\text {st }}$ score away from the $20^{\text {th }}$ score, their improvement was better than when measuring the increases by taking the $1^{\text {st }}$ score away from the $16^{\text {th }}$ score. Group 2 continued to increase 
their speed by 17 wpm and group 3 continued to increase their speed by 24 wpm. Although group 4 did not make any noticeable increase after the $16^{\text {th }}$ session, it can still be assumed that group 1 might have made bigger increases if they had continued the speed reading course until the $20^{\text {th }}$ session.

Overall, the results suggest that it is worth continuing the speed reading course until the $20^{\text {th }}$ session, and that the two sessions per week scheduling produces the least favourable results.

We have now answered the first two major questions regarding whether a speed increase was made during the course, and what scheduling was most effective. We will now look at the third question - does the increase made in a course transfer outside the course?

\subsubsection{Speed increase transfer from the speed reading course to other types of texts}

Before and after the treatment, all participants, including the control group, sat pre-tests and post-tests. These tests were done to see if the speed increase in a course transfers outside the course. In each test, participants had to read a passage of about 700 words and marked the word they reached after one and a half minutes before continuing to read the rest of the passage. The number of words the participants read in those one and a half minutes was counted in order to measure their reading speeds.

\subsubsection{Did the participants increase their speed when reading other types of texts?}

There was a control group who did not follow the speed reading course, but did the same pre-tests and post-tests as the four experimental groups. To measure the speed increase on other types of texts, we took the average rate on the two post-tests minus the average rate on the two pre-tests and compared the results of the four experimental groups and the control group. Table 3.14 shows the results.

As can be seen, all of the four experimental groups gained over a $50 \mathrm{wpm}$ increase in their reading rate on the texts outside the speed reading course. Group 1 and group 3 were the ones who made the best improvement with 79 wpm. Group 4 ranked the second with 72 wpm. Group 2 gained the least improvement with $58 \mathrm{wpm}$. The control group also made progress, which was much lower than groups 1,3 and 4 but very similar to group 2 . What 
is interesting in these results is the substantial increase by the control group, and the low performance of group 2, which is consistent with their progress during the speed reading course. Despite this result, the greater amount of improvement that groups 1, 3 and 4 made shows that the in-course speed increase transferred to other types of texts.

Table 3.14 Mean and standard deviations of speed increases (post-test minus pre-test) for all groups

\begin{tabular}{lccccc}
\hline & Control group & Group 1 & Group 2 & Group 3 & Group 4 \\
\hline Mean & 56.32 & 79.23 & 58.11 & 78.72 & 71.84 \\
SD & 43.25 & 32.87 & 50.64 & 47.70 & 41.98 \\
\hline
\end{tabular}

A repeated measures ANOVA was carried out on the pre-test (initial score) and post-test (final score) data. The repeated-measures factor was time (pre-test vs. post-test) and the between-subjects factor was group. The results are shown in Table 3.15 below:

Table 3.15 Mean and standard deviations of pre-test speed and post-test speed for all groups

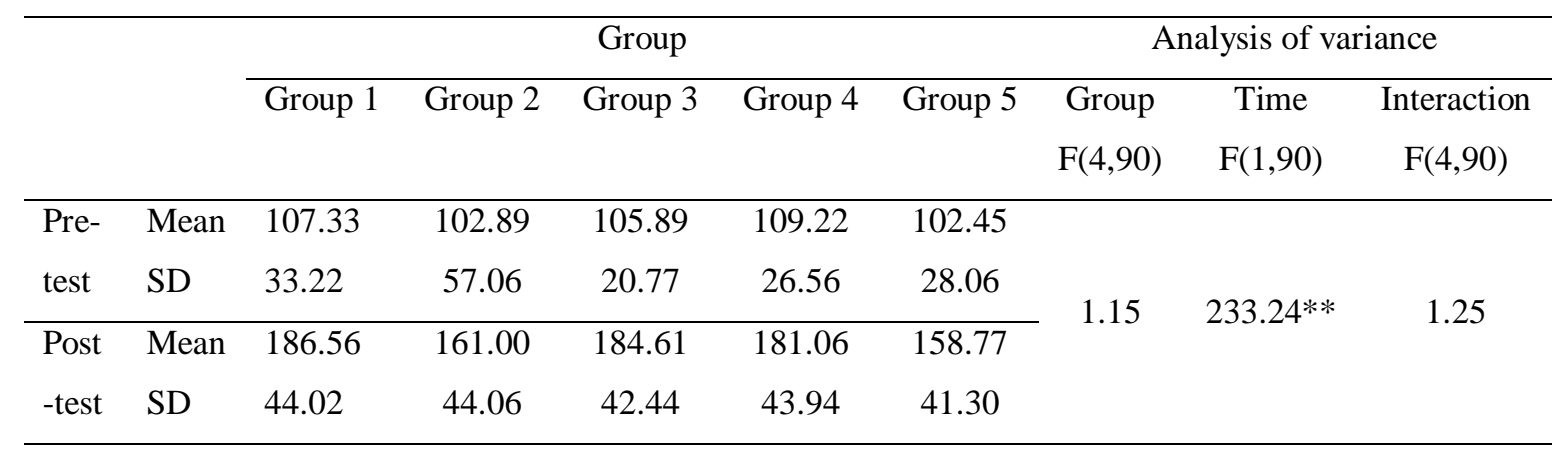

$* * \mathrm{p}<.01$.

The results showed that there was a general gain for all groups from pre-test to post-test, $\eta^{2}$ $=.722$. The overall group effect was not significant $(F(4,90)=1.15, p=.34)$. The interaction effect (group $\mathrm{x}$ time) was not significant. The treatment groups made greater mean gains than the control group but the difference was not significant, $p=.296, \eta^{2}$ $=.053$. Figure 3.8 shows the gains from pre-test to post-test of the five groups. The control group mean improvement was lower than the gains of groups 1, 2, 3 and 4 but the difference was not significant. 


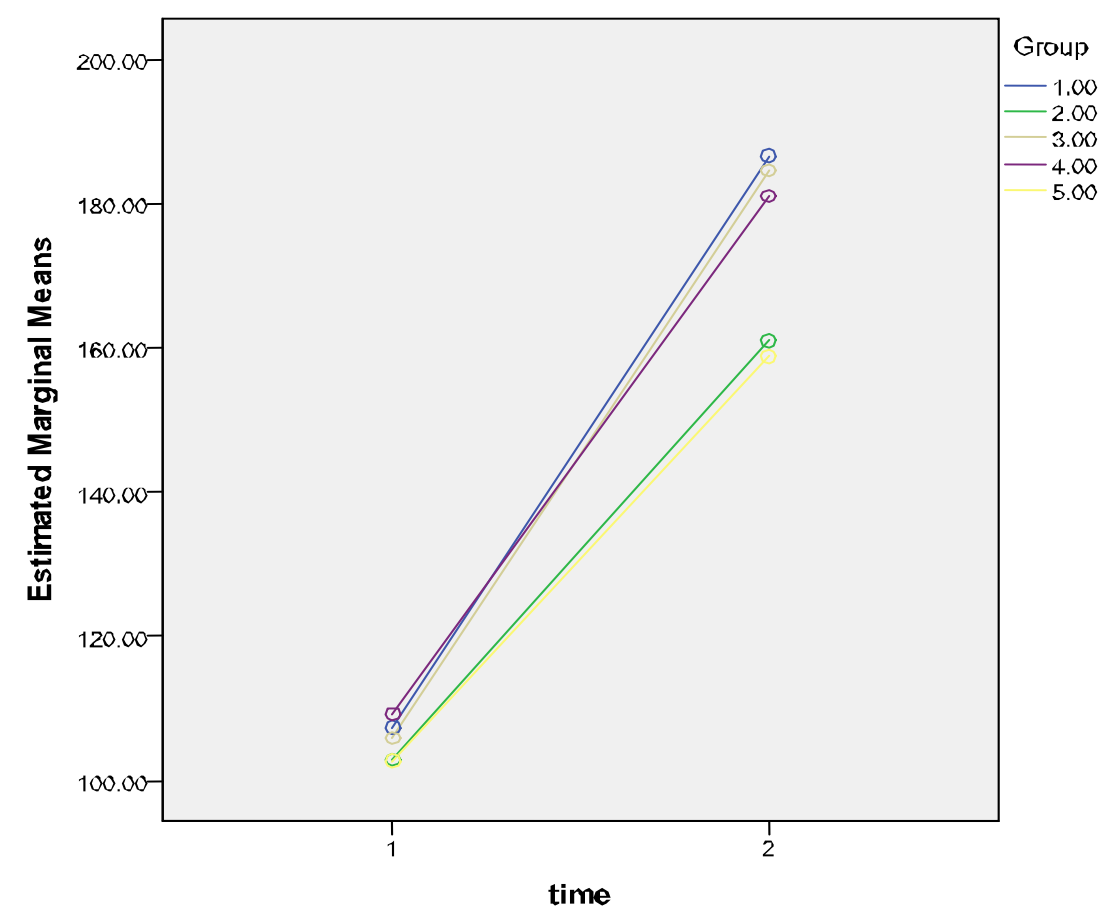

A one way ANOVA compared the gain scores (pre-test to post-test) of the five groups. The results showed the mean scores of the four groups were not significantly different, $F(4,90)$ $=1.25, \mathrm{p}=.296, \eta^{2}=.053$.

The mean gain score for group 1 speed training was $79.23(\mathrm{~N}=181, \mathrm{SD}=32.87)$. The mean gain score for group 2 speed training was $58.11(\mathrm{~N}=19, \mathrm{SD}=50.64)$. The mean gain score for group 3 was $78.72(\mathrm{~N}=18, \mathrm{SD}=47.70)$. The mean gain score for group 4 was 71.84 $(\mathrm{N}=18, \mathrm{SD}=41.98)$. The mean gain score for the control group was $56.32(\mathrm{~N}=22, \mathrm{SD}=$ 43.25).

These results suggested that although not only the four treatment groups but also the control made substantial increases in reading speed on other texts, although experimental groups 1, 3 and 4 made bigger increases than the control group. It can thus assumed that the control group might have had very good learning attitude, motivation and strategies, or that the usual English program at the university might have benefited the control group. This issue will be examined in the second study by having another control group who did not follow the speed reading course. 


\subsubsection{What were the fastest and the slowest speeds the participants had on the pre- tests and post-tests and what was the greatest increase they made?}

The aim of this question was to look at the individual participants' speeds to determine the range of speeds that participants had on the pre-tests and post-test, and to see if there were any participants making small increases just because they had unusually high speeds on the pre-tests. This analysis can also show the potential for improving speed reading on other types of texts among ESL/EFL learners. First, we looked at the average speeds of the two pre-tests and the average speeds of the two post-tests by each participant in the five groups and noted the slowest speed and the fastest speed.

Table 3.16 Means and standard deviations of speeds on the pre-tests and the post-tests for all groups

\begin{tabular}{llccccc}
\hline Test & & Control group & Group 1 & Group 2 & Group 3 & Group 4 \\
\hline \multirow{2}{*}{ Pre-test } & Mean & 102.45 & 107.33 & 102.89 & 105.89 & 109.22 \\
& SD & 28.06 & 33.22 & 57.06 & 20.77 & 26.56 \\
\hline \multirow{2}{*}{ Post-test } & Mean & 158.77 & 186.56 & 161.00 & 184.61 & 181.06 \\
& SD & 41.30 & 44.02 & 44.06 & 42.44 & 43.94 \\
\hline
\end{tabular}

Overall, the data (see Table 3.16) indicate that on the pre-tests all five groups had similar average scores ranging from $103 \mathrm{wpm}$ to $109 \mathrm{wpm}$. On the other hand, on the post-tests, their average scores greatly different with groups 1, 3 and 4 outperformed the control group and group 2, hence groups 1, 3 and 4 made the greatest increases and the control group and group 2 made the least improvement.

Table 3.17 Summary of pre-tests and post-tests speeds and speed increases for all groups

\begin{tabular}{llccccc}
\hline & Control group & Group 1 & Group 2 & Group 3 & Group 4 \\
\hline \multirow{5}{*}{ Pre-test } & Under 100 wpm & 11 & 8 & 13 & 6 & 9 \\
& From 100 to 150 wpm & 10 & 7 & 4 & 12 & 7 \\
& Over 150 wpm & 1 & 3 & 2 & 0 & 2 \\
\hline \multirow{3}{*}{ Post-test } & Ender 100 wpm & 1 & 0 & 2 & 0 & 0 \\
& From 100 to 150 wpm & 10 & 5 & 5 & 4 & 6 \\
\hline \multirow{3}{*}{ Increase $150 \mathrm{wpm}$} & From 20 to 50 wpm & 5 & 11 & 13 & 14 & 12 \\
& Onder 20 wpm & 6 & 4 & 4 & 5 & 3 \\
\hline
\end{tabular}


With respect to the initial speeds (see Table 3.16, Table 3.17, and appendix P), the lowest average speed on the pre-tests outside the speed reading course was $36 \mathrm{wpm}$, by participant OZ in the control group. The fastest average speed was $307 \mathrm{wpm}$, by participant 2T. Fortyseven out of 95 participants had the speeds under $100 \mathrm{wpm}$. Forty participants had speeds from over $100 \mathrm{wpm}$ to $150 \mathrm{wpm}$. Only eight participants had speeds over $150 \mathrm{wpm}$. The data showed that the participants in the control group had their initial scores evenly spread within the speed range for all of the participants in the research. That means their starting points were similar to those of the experimental participants and thus helped to eliminate a group bias.

With respect to the final speeds, (see Table 3.16, 3.17 and appendix P) the data showed that the fastest average speed on the post-tests ( $269 \mathrm{wpm})$ was made by participant $3 \mathrm{~L}$ and the slowest average speed on the post-tests $(75 \mathrm{wpm})$ was made by participant 2I. Compared with the average speed on the pre-tests, this result was much better. There were only three participants who had their speeds under $100 \mathrm{wpm}$. Thirty participants read at speeds from $100 \mathrm{wpm}$ to $150 \mathrm{wpm}$. Sixty-two out of 95 participants read at speeds over 150 wpm and 24 of them had their speeds over 200 wpm. However, the highest average speed on the post-tests by individual was lower than the highest average speed on the pretests (269 wpm vs. 307 wpm).

With regard to speed improvement (see Table 3.16, 3.17 and appendix Q) the data indicated that the biggest individual difference between the pre-test results and the post-test results was 168 wpm and the smallest was -47 pm. Only 14 out of 95 participants made increases less than $20 \mathrm{wpm}$. Twenty-one participants had increases ranging from $21 \mathrm{wpm}$ to $50 \mathrm{wpm}$. Sixty participants $(67 \%)$ made increases over $50 \mathrm{wpm}$. Five participants had a negative result. One of them (participant 2T) had a very high speed on the pre-tests (307 wpm) and that may be the reason why that participant's result appeared to be a big decrease.

Taken as a whole, the results demonstrate that the participants' speeds on the pre-test ranged from around 50 to $170 \mathrm{wpm}$ and their speeds on the post-test ranged from around 100 to $270 \mathrm{wpm}$. Among the participants who made no improvement, only one participant had a decrease in speed due to their unusually high speed in the pre-test. This enhances the idea that the individual scores in speeds on other types of texts were not distorted by unusually high or low scores. The data also indicated that many participants made 
increases over $20 \mathrm{wpm}$ and not only participants who started at slow speeds but also the participants who already read at high speeds could increase their speeds when reading the texts outside the course. This agrees with the results in the course. A possible explanation may be that none of them was near the ceiling of around $300 \mathrm{wpm}$ for normal reading.

\subsubsection{How do the speeds on the pre-test texts relate to the speeds on the post-test texts?}

This question was posed to establish the relationship between the initial speeds and final speeds on the other types of texts. If the data show that there is a strong relationship between the initial speeds and the final speeds, it is possible to say that the difference between the pre-test scores and post-test scores did not result from the students' not taking the tests seriously, thus confirming that the participants actually made an improvement.

The 93 participants were divided into four groups of approximately 24 according to the initial average scores on the two pre-test texts.

The results are presented in Table 3.18 with the highest initial scores in the left columns and the lowest initial scores in the right columns. The first group consisted of 23 participants, whose average scores on the pre-test were from $124 \mathrm{wpm}$ to $307 \mathrm{wpm}$. The next group were the 24 participants whose average scores on the pre-test ranged from 100 wpm to $124 \mathrm{wpm}$. The third group consisted of 24 participants whose average scores on the pre-test ranged from 83 to 100 . The last group consisted of the 24 participants whose average scores on the initial tests were from $36 \mathrm{wpm}$ to $81 \mathrm{wpm}$.

With respect to the final speeds, the first group, whose initial average speeds were the highest, achieved the best scores on the post-test with $197 \mathrm{wpm}$. The second group reached an average speed of $175 \mathrm{wpm}$ while the third group reached $164 \mathrm{wpm}$. The last group obtained the slowest final speed with only $159 \mathrm{wpm}$. It could therefore be claimed that the faster the participants read initially, the higher speeds they achieved at the end of the treatment.

On the other hand, the relationship between the initial speeds and the size of the increases was the inverse of the relationship between the initial speeds and final speeds. In other words, the better the initial speeds, the smaller the increases. The first group whose initial 
speed was the highest, made the smallest increase (48 wpm). The second group made an average increase of $63 \mathrm{wpm}$. The third group made an average increase of $73 \mathrm{wpm}$ and the last group, whose initial average speeds were the slowest, gained the greatest increase with 87 wpm.

Table 3.18 Initial speed (Pre) and final speed (Post) on other texts for all participants $(P)$

\begin{tabular}{|c|c|c|c|c|c|c|c|c|c|c|c|}
\hline $\mathbf{P}$ & Pre & Post & $\mathbf{P}$ & Pre & Post & $\mathbf{P}$ & Pre & Post & $\mathbf{P}$ & Pre & Post \\
\hline $2 \mathrm{~T}$ & 307 & 260 & $3 X$ & 124 & 158 & $3 R$ & 100 & 142 & 0AA & 81 & 151 \\
\hline $1 \mathrm{C}$ & 169 & 194 & OR & 123 & 115 & $2 \mathrm{D}$ & 98 & 153 & $1 \mathrm{H}$ & 81 & 164 \\
\hline OT & 168 & 253 & $4 \mathrm{~A}$ & 123 & 177 & $3 Q$ & 98 & 238 & $2 \mathrm{G}$ & 81 & 183 \\
\hline $1 \mathrm{R}$ & 165 & 234 & $4 \mathrm{~T}$ & 122 & 237 & $0 \mathrm{U}$ & 97 & 224 & $4 \mathrm{~K}$ & 81 & 137 \\
\hline $2 \mathrm{M}$ & 155 & 147 & $\mathrm{OF}$ & 121 & 117 & $2 \mathrm{P}$ & 97 & 118 & 1I & 80 & 130 \\
\hline $4 \mathrm{C}$ & 152 & 184 & $\mathrm{OH}$ & 121 & 171 & $4 \mathrm{O}$ & 95 & 143 & $1 \mathrm{~K}$ & 80 & 234 \\
\hline 1D & 151 & 267 & OB & 120 & 189 & $3 \mathrm{~W}$ & 94 & 262 & $1 \mathrm{~S}$ & 80 & 135 \\
\hline $4 B$ & 151 & 258 & $2 \mathrm{~F}$ & 119 & 123 & $3 \mathrm{I}$ & 93 & 179 & $2 \mathrm{~A}$ & 80 & 151 \\
\hline $4 \mathrm{P}$ & 148 & 220 & $3 \mathrm{~A}$ & 119 & 188 & $4 \mathrm{G}$ & 93 & 132 & $4 \mathrm{M}$ & 80 & 195 \\
\hline $4 Q$ & 148 & 164 & OI & 112 & 168 & $4 \mathrm{U}$ & 93 & 193 & $0 \mathrm{X}$ & 79 & 85 \\
\hline $3 \mathrm{H}$ & 146 & 169 & 10 & 111 & 208 & $0 \mathrm{~J}$ & 92 & 140 & $0 \mathrm{~V}$ & 78 & 181 \\
\hline OS & 140 & 154 & $3 \mathrm{~L}$ & 109 & 269 & $0 \mathrm{Q}$ & 92 & 110 & $3 \mathrm{M}$ & 78 & 139 \\
\hline $2 \mathrm{U}$ & 140 & 174 & $4 \mathrm{~F}$ & 109 & 219 & $1 \mathrm{E}$ & 92 & 168 & $0 \mathrm{E}$ & 77 & 147 \\
\hline $1 \mathrm{M}$ & 139 & 227 & $1 \mathrm{~A}$ & 108 & 206 & $2 \mathrm{~S}$ & 92 & 152 & $1 \mathrm{~L}$ & 77 & 191 \\
\hline $1 \mathrm{Q}$ & 133 & 206 & $3 \mathrm{~S}$ & 108 & 235 & $0 \mathrm{M}$ & 91 & 136 & $3 \mathrm{~J}$ & 77 & 161 \\
\hline $0 \mathrm{~N}$ & 132 & 158 & $1 \mathrm{~J}$ & 106 & 154 & $2 \mathrm{E}$ & 88 & 84 & $2 B$ & 75 & 191 \\
\hline $0 \mathrm{~L}$ & 129 & 141 & $3 B$ & 106 & 157 & $4 \mathrm{~N}$ & 87 & 227 & $2 \mathrm{H}$ & 73 & 168 \\
\hline 30 & 129 & 205 & $3 \mathrm{~N}$ & 106 & 152 & $4 \mathrm{~J}$ & 86 & 102 & 1B & 70 & 126 \\
\hline $3 \mathrm{U}$ & 128 & 193 & $3 G$ & 104 & 136 & $4 \mathrm{~L}$ & 86 & 177 & $3 \mathrm{~F}$ & 63 & 198 \\
\hline $4 \mathrm{H}$ & 128 & 129 & $0 \mathrm{~A}$ & 102 & 193 & $2 \mathrm{C}$ & 85 & 150 & $2 \mathrm{~W}$ & 62 & 186 \\
\hline $1 \mathrm{P}$ & 127 & 239 & $1 \mathrm{~F}$ & 102 & 133 & OD & 84 & 236 & $1 \mathrm{~N}$ & 61 & 142 \\
\hline $2 \mathrm{~J}$ & 127 & 218 & $4 \mathrm{R}$ & 101 & 223 & $0 Y$ & 84 & 137 & $2 \mathrm{~K}$ & 56 & 194 \\
\hline \multirow[t]{3}{*}{$3 \mathrm{P}$} & 124 & 142 & OC & 100 & 137 & $2 R$ & 83 & 192 & 2I & 37 & 75 \\
\hline & & & $2 \mathrm{~V}$ & 100 & 140 & $4 \mathrm{I}$ & 83 & 142 & $0 \mathrm{Z}$ & 36 & 150 \\
\hline & 149 & 197 & & 112 & 175 & & 91 & 164 & & 72 & 159 \\
\hline
\end{tabular}

Overall participants' initial speeds on other types of texts predict their final speeds and increases. 


\subsubsection{How does the increase in the speed reading course relate to the increase on reading other texts?}

Table 3.19 In-course increases (SRI) and increases on other texts (OTI) for the participants $(P)$ in the treatment groups

\begin{tabular}{cccccccccccc}
\hline P & SRI & OTI & P & SRI & OTI & P & SRI & OTI & P & SRI & OTI \\
\hline $3 \mathrm{Q}$ & 170 & 141 & $1 \mathrm{H}$ & 71 & 82 & $2 \mathrm{D}$ & 43 & 55 & $2 \mathrm{~W}$ & 23 & 125 \\
$4 \mathrm{O}$ & 157 & 48 & $4 \mathrm{~B}$ & 67 & 107 & $3 \mathrm{X}$ & 43 & 34 & $1 \mathrm{C}$ & 20 & 26 \\
$3 \mathrm{~J}$ & 136 & 85 & $4 \mathrm{~T}$ & 65 & 115 & $3 \mathrm{~S}$ & 41 & 128 & $1 \mathrm{~N}$ & 19 & 81 \\
2S & 115 & 60 & $2 \mathrm{~K}$ & 64 & 138 & $4 \mathrm{Q}$ & 40 & 16 & $4 \mathrm{G}$ & 19 & 40 \\
4M & 113 & 115 & $2 \mathrm{H}$ & 63 & 95 & $2 \mathrm{C}$ & 39 & 66 & $4 \mathrm{~L}$ & 19 & 92 \\
3F & 110 & 135 & $4 \mathrm{~A}$ & 63 & 54 & $1 \mathrm{E}$ & 38 & 76 & $3 \mathrm{U}$ & 17 & 65 \\
4U & 103 & 100 & $4 \mathrm{~N}$ & 63 & 140 & $2 \mathrm{~T}$ & 37 & -47 & $2 \mathrm{U}$ & 13 & 34 \\
$3 \mathrm{R}$ & 100 & 43 & $1 \mathrm{~F}$ & 60 & 31 & $3 \mathrm{M}$ & 37 & 61 & $4 \mathrm{I}$ & 10 & 59 \\
$3 \mathrm{~W}$ & 85 & 169 & $3 \mathrm{~N}$ & 60 & 46 & $1 \mathrm{~A}$ & 36 & 97 & $1 \mathrm{P}$ & 9 & 112 \\
$3 \mathrm{~L}$ & 84 & 160 & $1 \mathrm{I}$ & 56 & 50 & $1 \mathrm{R}$ & 34 & 69 & $3 \mathrm{H}$ & 7 & 24 \\
4R & 84 & 122 & $2 \mathrm{P}$ & 56 & 21 & $2 \mathrm{~J}$ & 33 & 91 & $2 \mathrm{~V}$ & 2 & 40 \\
1L & 83 & 114 & $3 \mathrm{O}$ & 56 & 76 & $2 \mathrm{E}$ & 32 & -4 & $3 \mathrm{~A}$ & 2 & 69 \\
2M & 83 & -8 & $4 \mathrm{H}$ & 54 & 1 & $3 \mathrm{I}$ & 31 & 86 & $1 \mathrm{~B}$ & -2 & 56 \\
1D & 82 & 117 & $3 \mathrm{P}$ & 50 & 18 & $1 \mathrm{~J}$ & 30 & 48 & $2 \mathrm{~A}$ & -2 & 71 \\
1S & 80 & 56 & $4 \mathrm{P}$ & 48 & 72 & $1 \mathrm{~K}$ & 25 & 153 & $3 \mathrm{~B}$ & -4 & 51 \\
1Q & 77 & 73 & $2 \mathrm{I}$ & 46 & 38 & $4 \mathrm{~K}$ & 25 & 56 & $1 \mathrm{O}$ & -19 & 96 \\
1M & 74 & 89 & $2 \mathrm{R}$ & 46 & 109 & $3 \mathrm{G}$ & 24 & 32 & $4 \mathrm{C}$ & -23 & 32 \\
$4 \mathrm{~F}$ & 73 & 110 & $2 \mathrm{~B}$ & 44 & 117 & $2 \mathrm{G}$ & 23 & 102 & $4 \mathrm{~J}$ & -25 & 16 \\
& & & & & & & & & $2 \mathrm{~F}$ & -39 & 4 \\
\hline & $\mathbf{1 0 1}$ & $\mathbf{9 6}$ & & $\mathbf{5 7}$ & $\mathbf{7 3}$ & & $\mathbf{3 4}$ & $\mathbf{6 2}$ & & $\mathbf{2}$ & $\mathbf{5 7}$ \\
\hline
\end{tabular}

The idea that the speed increases in the course transferred to other types of texts can be reinforced if the data show that the two types of speed improvement are in a strong relationship. In this analysis, the link between the two kinds of speed increases was examined. The in-course speed increases were measured using the average scoring method, which took the average score on the first three texts away from the average score on the last three texts. The speed increases on other types of texts were measured by taking the average score on the pre-test away from the average score on the post-test. The participants' scores were divided into four groups. The first three groups consisted of 18 participants and the last had 19 participants. 
Table 3.19 shows the increases that all participants made in the course and in the pre-tests and post-tests. The increases between the first three texts and the last three texts in the reading course were put in order from the biggest in the left columns to the smallest in the right columns. Group 1 included participants whose increases within the course ranged from 170 wpm to 73 wpm. The second group included the participants whose scores ranged from $71 \mathrm{wpm}$ to $44 \mathrm{wpm}$. The next group consisted of the participants whose scores were from $43 \mathrm{wpm}$ to $23 \mathrm{wpm}$. The last group was the one with participants whose scores were the lowest of all.

\subsubsection{Did the scheduling of the speed reading course have an effect on the increase} the participants made in reading other texts outside the course?

To answer this question, we compared the increases that the four experimental groups made between the pre-test and post-test to see which group did the best.

Table 3.20 Means and standard deviations of speed increases on other types of texts for the treatment groups

\begin{tabular}{lcccc}
\hline & Group 1 & Group 2 & Group 3 & Group 4 \\
\hline Mean & 79.23 & 58.11 & 78.72 & 71.84 \\
SD & 32.60 & 50.78 & 47.83 & 41.96 \\
\hline
\end{tabular}

The data (see Table 3.20) indicate that group 2, who had two sessions a week, had the smallest difference between the pre-test scores and the post-test scores with $58 \mathrm{wpm}$. This group was also the only group that had participants with negative results, -4 wpm, -8 wpm and $-47 \mathrm{wpm}$. This result parallels the in-course results and supports the idea that having two reading sessions per week is not the best way to schedule a speed reading course. The other three groups made similar improvement with 79 wpm for group 1 and group 3, and 72 wpm for group 4. Hence, it seemed that for these groups scheduling the speed reading course once a week, three times or four times a week did not greatly affect the increase the participants made in reading texts which were not in the course. 


\subsubsection{Did the participants get higher scores on a certain text in the pre-test and post-}

test?

There was a possibility that the texts used in the pre-tests and post-tests were not equally difficult. If this was the case, the participants who read easier texts on the pre-tests and more difficult texts on the post-tests might have made smaller increases than they would have made if the texts were equally difficult. If the data show that none of the four texts was easier or more difficult than the others, the idea that the speed increases on other texts resulted from the in-course increases will be reinforced. In order to do this, we looked for the relationship, if there was any, between a certain text in the pre-test and post-test. There were four different texts, two for the pre-test and two for the post-test. The texts are called The sinking of the Titanic, History of trade, Stock market and Work, hereafter respectively called text $\mathrm{A}$, text $\mathrm{B}$, text $\mathrm{C}$ and text $\mathrm{D}$. These texts were adapted from graded readers at the 1350 to 1500 word level and modified to make sure that were equal in difficulty and length. We also used the vocabulary program Range to check the similarity of vocabulary difficulty level. The participants read different texts as pre-test and as post-test. The administration was done in the way that the participants did not read the same texts for their pre-test and/or the post-test. This arrangement of texts controls for text difficulty and for an order effect. The arrangements followed four patterns.

Table 3.21 The four orders of texts in the pre-tests and the post-tests

\begin{tabular}{lcccc}
\hline Order & Pre-test 1 & Pre-test 2 & Post-test 1 & Post-test 2 \\
\hline First order & Text A & Text C & Text D & Text B \\
Second order & Text C & Text D & Text B & Text A \\
Third order & Text D & Text B & Text A & Text C \\
Fourth order & Text B & Text A & Text C & Text D \\
\hline
\end{tabular}

This arrangement aimed to make the texts equally delivered in the four positions in both tests. As shown in Table 3.21, the first way of ordering the texts was to have some participants read Text $\mathrm{A}$ as the first text, then text $\mathrm{C}$ as the second text in the pre-test. For the post-test, they read text D first and text B after that. Some other participants read text C and then text $\mathrm{D}$ in the pre-test and text $\mathrm{B}$ and then text $\mathrm{A}$ in the post-test, and so on. The scores gained by the participants following this kind of text arrangements are presented in Table 3.22 . 
Table 3.22 Means and standard deviations of scores by four different groups following the four ways of text ordering

\begin{tabular}{llccccc}
\hline Text order & & $1^{\text {st }}$ pre & $2^{\text {nd }}$ pre & $1^{\text {st }}$ post & $2^{\text {nd }}$ post & Increase \\
\hline The $1^{\text {st }}$ order & Mean & 104.89 & 110.20 & 167.03 & 178.24 & 66.09 \\
$(\mathrm{~A}, \mathrm{C}, \mathrm{D}, \mathrm{B})$ & SD & 39.81 & 37.10 & 37.34 & 43.22 & 45.97 \\
\hline The $2^{\text {nd }}$ order & Mean & 102.43 & 109.98 & 169.11 & 183.23 & 69.55 \\
$(\mathrm{C}, \mathrm{D}, \mathrm{B}, \mathrm{A})$ & SD & 37.23 & 41.32 & 39.03 & 57.97 & 48.66 \\
\hline The $3^{\text {rd }}$ order & Mean & 102.31 & 104.21 & 159.12 & 182.67 & 67.53 \\
$(\mathrm{D}, \mathrm{B}, \mathrm{A}, \mathrm{C})$ & SD & 31.20 & 37.58 & 39.37 & 44.64 & 36.38 \\
\hline The $4^{\text {th }}$ order & Mean & 100.46 & 105.64 & 161.57 & 185.62 & 70.59 \\
$(\mathrm{~B}, \mathrm{~A}, \mathrm{C}, \mathrm{D})$ & SD & 34.36 & 31.87 & 43.66 & 50.18 & 45.71 \\
\hline
\end{tabular}

As can be seen, on the pre-test 1 and pre-test 2, even though they read four different texts, they had similar average speeds from $100 \mathrm{wpm}$ to $109 \mathrm{wpm}$. Similarly, the data on the two post-tests showed a similar pattern. These results demonstrate that the participants' speeds were not greatly affected by the text they read.

The scores show that the participants who read text B and text $\mathrm{A}$ in the pre-test, text $\mathrm{C}$ and text $\mathrm{D}$ in the post-test had the biggest difference of $71 \mathrm{wpm}$ while the other three groups of participants had $70 \mathrm{wpm}, 68 \mathrm{wpm}$, and $66 \mathrm{wpm}$. Although the four groups read four different texts as pre-test 1, all groups had similar average speeds ranging from $100 \mathrm{wpm}$ to $105 \mathrm{wpm}$. Likewise, when reading those texts as pre-test 2, all groups had similar speeds ranging from $104 \mathrm{wpm}$ to $110 \mathrm{wpm}$.

Table 3.23 Speeds and average speeds in the pre-test and post-test for each of the four texts

\begin{tabular}{llcccccc}
\hline & & \multicolumn{3}{c}{ Pre-test } & \multicolumn{3}{c}{ Post-test } \\
\cline { 3 - 8 } & & As 1 $1^{\text {st }}$ text & As 2 ${ }^{\text {nd }}$ text & Average & As 1 ${ }^{\text {st }}$ text & As 2 ${ }^{\text {nd }}$ text & Average \\
\hline Text A & Mean & 104.12 & 105.78 & 105.02 & 159.23 & 182.69 & 171.29 \\
& SD & 30.03 & 29.15 & 29.15 & 37.45 & 35.56 & 36.25 \\
\hline Text B & Mean & 100.28 & 101.98 & 101.35 & 169.48 & 178.91 & 174.31 \\
& SD & 28.62 & 27.28 & 27.58 & 39.15 & 40.16 & 40.03 \\
\hline Text C & Mean & 102.25 & 108.68 & 106.36 & 162.09 & 183.05 & 173.15 \\
& SD & 29.03 & 29.35 & 28.89 & 38.69 & 39.15 & 39.01 \\
\hline Text D & Mean & 102.15 & 108.51 & 106.23 & 167.07 & 185.80 & 177.10 \\
& SD & 30.15 & 31.02 & 30.25 & 36.25 & 40.10 & 38.31 \\
\hline
\end{tabular}


The results on the post-test yielded the same pattern with slight differences between the four groups. The data show a slight increase in scores from pre-test 1 to pre-test 2 and from post-test 1 to post-test 2 . The average scores on each text when read as pre-test 1 , pre-test 2 , post-test 1 , post-test 2 indicate that the texts were read with equal speeds with only a minor speed difference between them (see Table 3.23).

Taken as a whole, the results demonstrate that the individual texts did not affect the speed scores. No text was noticeably easier or more difficult in any of the four possible administrations. This reinforces the idea that the speed increases the participants made on other types of texts were not due to the unequally difficult texts that they read.

\subsection{Discussion}

The first experiment set out to determine the effects of a speed reading course on reading speed improvement and its transfer to other types of texts. Another purpose of the experiment was to suggest the best scheduling for a speed reading course in order to achieve optimal results. The findings emerging from this experiment enhanced our understanding of the benefits of speed reading courses.

\subsubsection{Speed increases in the speed reading course}

In the first place, the results showed that Vietnamese EFL learners gained reading rate increases in the speed reading course. Reading speed improvement was measured using the average method, which was used by Chung and Nation (2006). The $20^{\text {th }}$ minus $1^{\text {st }}$ method was also used and it was found that the two scoring methods agreed with each other on the ranking of the group averages. The different methods, however, produced relatively different speed figures. The four experimental groups made increases from $60 \mathrm{wpm}$ to 84 wpm for the $20^{\text {th }}$ minus $1^{\text {st }}$ scoring method and increases from $38 \mathrm{wpm}$ to $58 \mathrm{wpm}$ for the average scoring method. The differences between the groups in both scoring methods are similar and the rank of each group in both methods remained the same. This supports the findings by Chung and Nation (2006) and Macalister (2008).

The participants' reading rates were further scrutinized by looking at the fastest and slowest scores they had during the speed reading course. A new method, called the three text extreme scoring method was introduced to measure the participants' amount of 
improvement in the most favourable way. This method takes the average of the three best scores minus the average of the three worst scores. The results agreed closely with the extreme scoring method, which takes the single highest score minus the lowest score. The consistency in the ranking of the four groups for both methods and this agreement with the other two scoring methods suggest all are feasible scoring methods. The agreement between the four scoring methods in ranking the groups is a partial validation of each of the methods. It can thus be assumed that each method will give reliable results for a certain purpose. Taking three scores (the average method and the three extreme method) instead of one score (the $20^{\text {th }}$ minus $1^{\text {st }}$ method and the extreme method) into the calculation is aimed at increasing reliability of the results. On the other hand, choosing between the highest minus lowest methods and the last minus first methods is the matter of being conservative or being optimistic. The last minus first methods measure what happen chronologically and make sure that the speed change is a real improvement while the highest minus lowest measure what readers can potentially do and make sure that the results are encouraging for them.

The experiment has confirmed that the participants' speed increases were real progress and that speed reading courses are useful for ESL/EFL learners. All findings related to the participants' speed improvement agreed with each other. First, all four scoring methods validate each other in terms of producing the same ranking of the groups. Second, most participants had their slowest speeds in the first half and reached their best speeds in the second half of the course. Third, the negative results of the participants who made no improvement did not affect the groups' results. Fourth, the groups' comprehension scores were kept at the appropriate level of over $70 \%$ accuracy, showing that they reading rate improvement was meaningful.

The experiment also found that participants' reading rates constantly increased during the speed course. This was done by classifying their progress charts into four categories: the gradual increase pattern, the erratic increase pattern, the plateau increase pattern and the mixed pattern. The results indicated that $80 \%$ of the participants had the gradual increase pattern and only $20 \%$ had the erratic or plateau pattern. This finding is in agreement with Chung and Nation (2006)'s findings, which showed that gradual increase pattern was by far the predominant one and that increases in speed are cumulative. 
In the present experiment, the comparison between the participants' initial speeds and their final speeds showed that not only the participants with slow initial speeds but also the participants with the fastest initial speeds benefited from the speed reading course. It was also shown that none of the participants was near the ceiling level of around $300 \mathrm{wpm}$ in normal reading. The comparison between the participants' initial speeds and their speed increases showed that initial speeds do not determine the amount of speed improvement. Both the participants with lower initial speeds and the participants with higher initial speeds made substantial increases.

The experiment found that all treatment groups made speed increases in the speed reading course. What might be the cause of speed change during a speed reading course? Previous studies have identified the change but have not looked at the causes of change. According to Nation, fluency in speaking may be caused by repetition or practice over the same task requiring similar language resources (Arevart \& Nation, 1991; Nation, 1989). It can thus be hypothesized that speed increases in speed reading courses may be caused by repetition of the vocabulary or the practice of the same tasks. Repetition of the words in speed reading texts may help learners to improve their word recognition skills. If the successive texts contain many words that already appeared many times in the previous texts, it is likely that readers will read them at faster speeds. To see if the speed improvement was caused by repetition of the words that the participants saw during the course, we examined the texts in the speed reading book. If the data provide figures of many words being repeated throughout the twenty texts in the course, it can be said that the participants could read faster because they had got acquainted with the repeated words. The results from the frequency program indicated that the texts and comprehension questions in the speed reading course book contained 1269 word types (see Table 3.24).

Table 3.24 Frequency of the word types appearing in the speed reading course

\begin{tabular}{lcccccccc}
\hline & $\begin{array}{c}>100 \\
\text { times }\end{array}$ & $\begin{array}{c}50 \text { to } 100 \\
\text { times }\end{array}$ & $\begin{array}{c}10 \text { to } 49 \\
\text { times }\end{array}$ & $\begin{array}{c}5 \text { to } 9 \\
\text { times }\end{array}$ & $\begin{array}{c}3 \text { or } 4 \\
\text { times }\end{array}$ & Twice & Once & Total \\
\hline $\begin{array}{l}\mathrm{N}^{\mathrm{o}} \text { of word } \\
\text { types }\end{array}$ & 20 & 33 & 254 & 192 & 200 & 158 & 382 & 1269 \\
\hline
\end{tabular}

Among these, 20 word types appeared over 100 times, 33 word types appeared from 50 to 100 times, 254 word types appeared from 10 to 49 times, 192 word types appeared from five to nine times, 200 appeared three or four times, 185 word types appeared only twice 
and 382 word types appeared only once. Almost half of the word types in the course appeared just once or two times and 67\% appeared less than five times. This provides evidence that speed increases were not caused by the repetition of the words in the texts.

Another way to determine the effect of repetition of the vocabulary on the participants' speed improvement is to scrutinize the texts used for the pre-test and post-test to see how many words in those texts also appeared in the speed reading course. Since it was found that speed improvement transferred to other types of texts, it is worthwhile to see if the transfer was due to the repetition of the words from the speed reading course assisting readers to read faster on the post-test. The four texts that were used in the pre-test and posttest were written at the 1350 to 1500 word level. Consequently, there might be a chance that the increases the participants made on the post-test were caused by the repetition of the words that they had already been acquainted with during the speed reading course. However, it was found that only 180 out of 719 words (25\%) in text A, 183 out of 706 words (26\%) in text B, 183 out of 710 words (26\%) in text C, and 191 out of 715 words (27\%) in text D had already been met by the participants during the speed reading course (see Table 3.25). The fact that three quarters of the different words in the text did not overlap between texts shows that overall word repetition was not the major factor affecting reading speed increase. It was therefore more likely that speed increases were achieved through practice or confidence gained from success rather than the repetition of words.

Table 3.25 Numbers of word types appearing in each text of the pre-tests and post-tests and in the speed reading course

\begin{tabular}{lcccc}
\hline & Text A & Text B & Text C & Text D \\
\hline Total number of word types & 719 & 706 & 710 & 715 \\
Number of common words & 180 & 183 & 183 & 191 \\
\hline
\end{tabular}

The repetition of words may not have been the cause of speed improvement, but the high frequency of words may have contributed to the learners' fluency development during the course. This can be examined by looking at the frequency of words in the 20 passages that the participants read. The results from the Range program showed that there were 236 words types with a frequency of 10 occurrences or higher in the course. They covered $77 \%$ of the tokens in the course. There were 412 word types with a frequency of 5 or above covering $88 \%$ of the tokens in the course. That means during the course, over three 
quarters of the words in a text could be fluently accessed. The more access the participants had to those words, the stronger lexical representations of these words the participants could develop. This supports the lexical quality hypothesis (Perfetti, 2010; Perfetti \& Hart, 2002). This theory holds that "the major source of reading ability is the knowledge a reader has about words, specific lexical representation (Perfetti, 2010, p. 298) and the practice of reading, writing, listening, and speaking promotes more high quality word representations. Thus, a skilled reader has higher quality representations for more words than a less skilled reader. It can therefore be assumed that through practice of reading with frequent access to the words types that covered more than three quarters of the tokens in the course, the participants developed more high quality word presentations, which in turn helped to increase their reading fluency.

There are, however, other possible causes of speed increases. The confidence gained from success and practice may result in a speed change. Gains resulting from success or practice can be identified by looking at the progress charts. If the chart shows many big jumps, the gain may have come from the confidence achieved by success in the previous session. If the chart shows gradual increase, the gains may have come from practicing the same task.

It was found from the preliminary analysis of the participants' charts that $80 \%$ of the participants made the gradual increase pattern. Only $20 \%$ had the erratic or plateau increase pattern. It can therefore be assumed that the confidence gained from success was not the predominant cause of speed improvement, but that many participants gradually increased their speeds thanks to practicing the same reading task during the course.

One of the most interesting findings emerging from this experiment was that although all experimental groups gained reading rate improvement from the speed reading course, it can be clearly seen that group 2, who had two sessions a week, made the least progress. Since the five groups were randomly assigned and there were no noticeable differences among the groups in terms of attitudes and motivation, it is worthwhile having a more careful look at these results and trying to pose possible explanations. In order to explain this, three questions should be considered. First, did the participants in group 2 have slower initial speeds or higher initial speeds? Second, did some of the participants in group 2 have abnormally minimal increases which made the whole group figure lower and/or some of the participants in group 1, group 3 and group 4 have extraordinarily big increases which made these group figures higher than the group 2 figure? Third, did the participants in 
group 2 have very high comprehension scores, which showed that they might have slowed down their speed in order to have more correct answers for the comprehension questions?

Slower initial speeds may show that they were at a lower level of English than the other participants and thus made less progress. Higher initial speeds may indicate that they already started with a high speed and hence did not make significant increases as compared with the others. Since abnormal results by just a few participants can have a big effect on the group's result, calculations were made to see whether the group result would be greatly changed if these participants were omitted. If an analysis of the data cannot help to provide answers to these questions, we would have to suppose that other reasons caused the difference between group 2 and the other three experimental groups.

Table 3.26 Average of the three initial speeds for the four treatment groups

\begin{tabular}{cccccccc}
\hline G1 & Initial speed & G2 & Initial speed & G3 & Initial speed & G4 & Initial speed \\
\hline $1 \mathrm{M}$ & 213 & $2 \mathrm{C}$ & 189 & $3 \mathrm{P}$ & 255 & $4 \mathrm{~L}$ & 217 \\
$1 \mathrm{O}$ & 196 & $2 \mathrm{~T}$ & 178 & $3 \mathrm{~A}$ & 198 & $4 \mathrm{~B}$ & 176 \\
$1 \mathrm{C}$ & 193 & $2 \mathrm{~A}$ & 176 & $3 \mathrm{R}$ & 188 & $4 \mathrm{C}$ & 174 \\
$1 \mathrm{~B}$ & 183 & $2 \mathrm{G}$ & 169 & $3 \mathrm{U}$ & 181 & $4 \mathrm{~F}$ & 163 \\
$1 \mathrm{R}$ & 182 & $2 \mathrm{U}$ & 164 & $3 \mathrm{H}$ & 175 & $4 \mathrm{~T}$ & 156 \\
$1 \mathrm{~K}$ & 165 & $2 \mathrm{~V}$ & 164 & $3 \mathrm{~S}$ & 172 & $4 \mathrm{M}$ & 155 \\
$1 \mathrm{~A}$ & 158 & $2 \mathrm{D}$ & 164 & $3 \mathrm{~L}$ & 168 & $4 \mathrm{R}$ & 154 \\
$1 \mathrm{Q}$ & 157 & $2 \mathrm{~B}$ & 163 & $3 \mathrm{~W}$ & 164 & $4 \mathrm{~N}$ & 154 \\
$1 \mathrm{P}$ & 147 & $2 \mathrm{~J}$ & 161 & $3 \mathrm{X}$ & 160 & $4 \mathrm{I}$ & 152 \\
$1 \mathrm{D}$ & 139 & $2 \mathrm{~F}$ & 150 & $3 \mathrm{~B}$ & 160 & $4 \mathrm{P}$ & 150 \\
$1 \mathrm{~S}$ & 131 & $2 \mathrm{E}$ & 147 & $3 \mathrm{Q}$ & 155 & $4 \mathrm{G}$ & 150 \\
$1 \mathrm{~J}$ & 131 & $2 \mathrm{P}$ & 142 & $3 \mathrm{~F}$ & 151 & $4 \mathrm{H}$ & 143 \\
$1 \mathrm{~L}$ & 130 & $2 \mathrm{R}$ & 142 & $3 \mathrm{~J}$ & 151 & $4 \mathrm{O}$ & 140 \\
$1 \mathrm{I}$ & 129 & $2 \mathrm{~S}$ & 136 & $3 \mathrm{O}$ & 150 & $4 \mathrm{~J}$ & 136 \\
$1 \mathrm{H}$ & 127 & $2 \mathrm{I}$ & 128 & $3 \mathrm{I}$ & 142 & $4 \mathrm{~A}$ & 123 \\
$1 \mathrm{E}$ & 127 & $2 \mathrm{M}$ & 122 & $3 \mathrm{~N}$ & 133 & $4 \mathrm{Q}$ & 122 \\
$1 \mathrm{~N}$ & 110 & $2 \mathrm{H}$ & 112 & $3 \mathrm{M}$ & 108 & $4 \mathrm{U}$ & 114 \\
$1 \mathrm{~F}$ & 104 & $2 \mathrm{~W}$ & 111 & $3 \mathrm{G}$ & 107 & $4 \mathrm{~K}$ & 102 \\
& & $2 \mathrm{~K}$ & 110 & & & & \\
\hline & 151 & & 149 & & 162 & & 149 \\
\hline
\end{tabular}

To see if the participants in group 2 had slower initial speeds or higher initial speeds than participants in the other three groups, we compared the initial speeds by the participants in 
group 2 and the participants in the other three groups (see Table 3.26). The table shows the average of the first three texts for the four experimental groups.

As can be seen, groups 1, 2 and 4 had similar speeds at 151 wpm, 149 wpm and 149 wpm. Only group 3 had a higher speed with $162 \mathrm{wpm}$. Although the highest speed in group 2 was lower than the highest speeds in the other three groups, it can be clearly seen that the speeds of participants in group 2 and group 4 ranged similarly.

Furthermore, if we put the initial speeds of all the participants from the highest to the lowest, the speeds of group 2 evenly ranged throughout the list. It can therefore be assumed that initial speeds were not a factor that may have affected the four group's results.

Table 3.27 Increases made by the participants in the four treatment groups

\begin{tabular}{cccccccc}
\hline G1 & Increase & G2 & Increase & G3 & Increase & G4 & Increase \\
\hline $1 \mathrm{~L}$ & 83 & $2 \mathrm{~S}$ & 115 & $3 \mathrm{Q}$ & 170 & $4 \mathrm{O}$ & 157 \\
$1 \mathrm{D}$ & 82 & $2 \mathrm{M}$ & 83 & $3 \mathrm{~J}$ & 136 & $4 \mathrm{M}$ & 113 \\
$1 \mathrm{~S}$ & 80 & $2 \mathrm{~K}$ & 64 & $3 \mathrm{~F}$ & 110 & $4 \mathrm{U}$ & 103 \\
$1 \mathrm{Q}$ & 77 & $2 \mathrm{H}$ & 63 & $3 \mathrm{R}$ & 100 & $4 \mathrm{R}$ & 84 \\
$1 \mathrm{M}$ & 74 & $2 \mathrm{P}$ & 56 & $3 \mathrm{~W}$ & 85 & $4 \mathrm{~F}$ & 73 \\
$1 \mathrm{H}$ & 71 & $2 \mathrm{I}$ & 46 & $3 \mathrm{~L}$ & 84 & $4 \mathrm{~B}$ & 67 \\
$1 \mathrm{~F}$ & 60 & $2 \mathrm{R}$ & 46 & $3 \mathrm{~N}$ & 60 & $4 \mathrm{~T}$ & 65 \\
$1 \mathrm{I}$ & 56 & $2 \mathrm{~B}$ & 44 & $3 \mathrm{O}$ & 56 & $4 \mathrm{~N}$ & 63 \\
$1 \mathrm{E}$ & 38 & $2 \mathrm{D}$ & 43 & $3 \mathrm{P}$ & 50 & $4 \mathrm{~A}$ & 63 \\
$1 \mathrm{~A}$ & 36 & $2 \mathrm{C}$ & 39 & $3 \mathrm{X}$ & 43 & $4 \mathrm{H}$ & 54 \\
$1 \mathrm{R}$ & 34 & $2 \mathrm{~T}$ & 37 & $3 \mathrm{~S}$ & 41 & $4 \mathrm{P}$ & 48 \\
$1 \mathrm{~J}$ & 30 & $2 \mathrm{~J}$ & 33 & $3 \mathrm{M}$ & 37 & $4 \mathrm{Q}$ & 40 \\
$1 \mathrm{~K}$ & 25 & $2 \mathrm{E}$ & 32 & $3 \mathrm{I}$ & 31 & $4 \mathrm{~K}$ & 25 \\
$1 \mathrm{C}$ & 20 & $2 \mathrm{G}$ & 23 & $3 \mathrm{G}$ & 24 & $4 \mathrm{~L}$ & 19 \\
$1 \mathrm{~N}$ & 19 & $2 \mathrm{~W}$ & 23 & $3 \mathrm{U}$ & 17 & $4 \mathrm{G}$ & 19 \\
$1 \mathrm{P}$ & 9 & $2 \mathrm{U}$ & 13 & $3 \mathrm{H}$ & 7 & $4 \mathrm{I}$ & 10 \\
$1 \mathrm{~B}$ & -2 & $2 \mathrm{~V}$ & 2 & $3 \mathrm{~A}$ & 2 & $4 \mathrm{C}$ & -23 \\
$1 \mathrm{O}$ & -19 & $2 \mathrm{~A}$ & -2 & $3 \mathrm{~B}$ & -4 & $4 \mathrm{~J}$ & -25 \\
& & $2 \mathrm{~F}$ & -39 & & & & \\
\hline & $\mathbf{4 3}$ & & $\mathbf{3 8}$ & & $\mathbf{5 8}$ & & $\mathbf{5 3}$ \\
\hline
\end{tabular}

To see if extreme individual scores affected the results, the increase of each participant in the four groups was examined to see if any participants' scores may have distorted the whole group figures. Table 3.27 shows that two participants in group 1, two participants in 
group 2, one participant in group 3 and two participants in group 4 had negative results. In order to see if these participants' figures distorted the whole group figures, their results were omitted. The new increases were $50 \mathrm{wpm}, 45 \mathrm{wpm}, 66 \mathrm{wpm}$, and $63 \mathrm{wpm}$ respectively for group 1, group 2, group 3, and group 4. According to these new figures, group 2 still had a 5 wpm smaller increase than group 1, and a remarkably smaller increase than groups 3 and 4 . The results also indicated that four participants in group 3 and three participants in group 4 made speed increases bigger than $100 \mathrm{wpm}$. If the three best scores from each group were omitted, the new speed increases for group 1, group 2, group 3 and group 4 were respectively 35 wpm, 29 wpm, 42 wpm and 39 wpm.

The results from the three text extreme method, which took the three highest scores minus the three lowest scores, were also examined. Omitting the three best scores and then three lowest scores in each group yielded the same pattern with group 1 and group 2 figures being similar but much smaller than group 3 and group 4 figures. Therefore, it can be concluded that the very bad or very good results of those participants did not distort the whole group figures.

To see if the participants in group 2 did not greatly increase their speed because they were reading slowly to have more correct answers for the comprehension questions, we looked at their comprehension scores and compared them with the other groups' scores. The result (see Table 3.6) showed that group 2 had the lowest comprehension scores in all measures. However, their comprehension level was always maintained at around $7.20 \%$ accuracy. This means comprehension was not a barrier for their speed increases.

In conclusion, the data drawn from all of the scoring and comparing methods show a consistent pattern that group 2 made smaller increases than the other three groups. Given that the groups were randomly assigned, the participants in group 2 were at a similar reading level to the participants in other groups, no extreme individual scores affected the group results, the participants in group 2 did not try to read more slowly than they could just to have more correct answers for the comprehension questions, it seems likely that it has to do with the scheduling. Perhaps the frequency and the duration of the speed reading course that group 2 had was not enough for them to increase their reading rates as much as the other groups. Group 2 had only two sessions per week while group 3 and group 4 had three and four sessions a week. Thus, group 2 had less intensive training than groups 3 and 4. If it is true, it can be assumed that frequency plays a strong role in producing optimal 
effects. However, even though group 2 met more frequently than group 1, group 1 still outperformed group 2. This may have been due to the difference in the course length that the two groups followed. Group 2 had reading sessions for only 10 weeks while group had them for 16 weeks. Perhaps the longer duration enabled the participants in group 1 to increase their reading rates more than the participants in group 2. However, if only course length itself decides the amount of speed increases, groups 3 and 4 would have made smaller increases than group 2 as they had the reading sessions for only 7 weeks and 5 weeks. Thus, it could only be assumed that either enough frequency or enough duration will allow speed reading courses to produce an optimal effect. Since group 2 did not have enough of either these variables, their speed improvement was the least among the four groups.

\subsubsection{Scheduling speed reading courses}

As mentioned earlier, one of the main purposes of the first experiment was to determine what is the best way to schedule a speed reading course in order to achieve the optimal effect. The results showed that groups 1, 3, and 4 outperformed group 2 in all scoring methods. This finding suggests that teachers should not use just two sessions a week in their scheduling option list. However, although it was possible to conclude that two sessions a week was a less effective choice, the lack of significant difference ( $p>.05$ in most cases) among the other groups' results has made it hard to decide which way of scheduling would be the best to achieve optimal effect. A comparison of the speed increases within the first 16 texts showed that group 3 and group 4 made greater improvement than group 1. It can be hence assumed that even if group 1 had read 20 texts, they would have still made a smaller difference than the other two groups. As a result, group 1 and group 2 can be eliminated from the consideration list. Moreover, the average of the results derived from the two ways of comparing found group 4 as the best with a 51 wpm increase and group 3 as the second best with a 49 wpm increase. Thus if one is supposed to make a decision of how to schedule the speed reading course, four times a week will be the first choice. On the other hand, the difference between the results from groups 1,3 and 4 is neither statistically nor pedagogically meaningful. Only 8 wpm (between group 3 and group 4 when comparing sixteen texts), 6 wpm (between group 1 and group 4 when comparing sixteen texts) or $5 \mathrm{wpm}$ (between group 3 and group 4 when comparing twenty texts) would not be worth changing the whole course schedule from 
having one session a week to three or four sessions a week. A teacher may choose either of these ways as long as it fits their program and timetable.

\subsubsection{Speed increase transfer from the speed reading course to other types of texts}

The experiment found that there was a large amount of increase made on other types of texts by all groups, including the control group, supporting previous research on this aspect (Macalister, 2010). The participants' speed improvement on other texts was measured using the average method, which takes the average speed on the pre-tests away from the average speed on the post-tests. The same ranking was found between speed increases in the course and speed increases on other types of texts. Groups 1, 3, and 4 outperformed group 2 on both types of texts. Particularly on the texts that were not in the course, of all the four treatment groups, groups 1 and 3 made the best progress with 79 wpm, group 4 ranked the second with 72 wpm. Group 2 made a noticeably smaller increase of only 58 wpm. All the data investigations demonstrated that these results were reliable. First, the average initial scores by all groups were similar showing that their speed change was a real improvement rather than a result of unusually low scores on the pre-tests. Second, a strong link between the participants' initial speeds and their speed increases was found. Third, the comparison of speed increases on both types of texts by all participants showed that there was also a strong relationship between the two kinds of speed improvement. Fourth, a comparison between the results by the four groups of participants who followed the four different administration arrangements showed that the four texts used in the pre-tests and post-tests were equally difficult, thus eliminating the possibility that the groups' results were distorted by a text effect or an order effect.

It was found that not only the participants whose initial speeds were low but also the participants whose initial speeds were high could make an improvement on other types of texts. This result corroborates the idea that the speed reading course is beneficial for learners at different levels of reading ability, and that none of the participants was near the ceiling level of around $300 \mathrm{wpm}$ in normal reading.

In this experiment, the control group and group 2 had similar increases in the texts outside the speed reading course. Therefore, two issues need to be considered. First, did the control group have very low initial speeds that made their differences between the pre-test and post-test bigger? Second, did some participants in the control group have very big 
increases which made the whole group figure higher and/or did some participants in group 2 have too small increases which made this group figure lower?

Regarding the initial speeds, it was found that the initial average speeds by the five groups on the pre-tests were similar, ranging from 102 wpm to 109 wpm. Group 1 and group 2 participants had slightly lower figures than the other three groups. Even if the best participant's figure of group 2 (307 wpm) was omitted, there was still no noticeable difference between the initial speeds of group 2 and the other groups. Thus, initial speeds are not a possible explanation for the transfer similarities between group 2 and the control group.

The initial and final average speeds mentioned earlier were measured by taking the average speed of the two texts each participant read in each test. It could be argued that due to the experimental design, the participants could have guessed what they should do in the second text, and thus tried to read faster than they would normally do. The consequence of this can be eliminated by taking the speed on the first text in each test as the initial speed and final speed. The results yielded from this method indicated that in the pre-test, the control group and group 2 had the lowest initial speed with $101 \mathrm{wpm}$, but the difference between these two groups and the other groups was only $5 \mathrm{wpm}$. It seems therefore that the scoring method was not the cause of the similarity between the reading rate increases in other types of texts that group 2 and the control group made.

To see if certain participants' abnormally high or low increase scores had affected the whole group figures, the increases made by individuals in the five groups were compared. Since group 2 and the control group had participants with negative results, these participants' scores may have distorted the whole group figures. If the three lowest scores were omitted from each group result, the new results would be $65 \mathrm{wpm}$ for the control group, $88 \mathrm{wpm}$ for group 1, $73 \mathrm{wpm}$ for group 2, $90 \mathrm{wpm}$ for group 3 and $84 \mathrm{wpm}$ for group 4. This made the difference between the control group and groups 1, 3 and 4 bigger. However, the difference between the control group and group 2 was still only eight wpm. If the three best scores were omitted from each group's result, the new increases would be $53 \mathrm{wpm}$ for the control group, $78 \mathrm{wpm}$ for group 1, $60 \mathrm{wpm}$ for group 2, $73 \mathrm{wpm}$ for group 3 and 74 wpm for group 4. Groups 1, 3, and 4 still outperformed the other two groups, and the difference between the control group and group 2 was still minimal. In short, it can be concluded that group 2 and the control group did not have any major difference in their 
increases even if the three best scores or three worst scores were omitted from each group's result.

To eliminate the possibility that the average scoring method may distort the real increases, other scoring methods were also used to see if there was any significant difference between the control group and group 2. One method took the first text score in the post-test minus the first text score in the pre-test. Another method took the second text score in the posttest minus the first text in the pre-test. The third method took the first text score in the pretest minus the second text score in the post-test. The fourth method took the second text score in the pre-test minus the second text score in the post-test. The results indicated that the biggest difference to emerge from these scoring methods was $12 \mathrm{wpm}$ with the bigger increase belonging to group 2 .

In conclusion, it can be said that certain high scoring or low scoring participants and the scoring method did not distort the results of the control group and group 2. Regarding group 2 and the other three experimental groups, even though group 2 had similar initial speeds as groups 1, 3, and 4, group 2 still made smaller increases. This can be the evidence for the effect of the speed reading course scheduling that the group 2 had. It remains uncertain why the control group could make similar increases to one of the treatment groups. Two possible explanations were psychological factors such as their attitudes and motivation, and the usual English program they followed. Therefore, it would be necessary to study more about this in order to see whether the usual English program helped the control group to gain speed increases.

Compared with the initial speeds on the first three texts in the course, the treatment groups' initial speeds on the other types of texts were lower. In the course, the slowest initial speed was $102 \mathrm{wpm}$. Thirty-nine out of 73 participants read at over $150 \mathrm{wpm}$. On the other hand, on the texts outside the course, the slowest speed was $37 \mathrm{wpm}$ and half of the participants read at speeds lower than $100 \mathrm{wpm}$ and only seven read at speeds over $150 \mathrm{wpm}$. The difference between the treatment groups' final speeds in the course and on the other types of texts was less noticeable than the difference between their initial speeds in the course and on the other types of texts. 


\subsection{Summary of main findings}

The first experiment seeks to determine the best way to schedule a speed reading course and the speed transfer from speed reading courses to other types of texts. The main findings suggest:

1. Within the speed reading courses, readers' reading rates increase by at least 38 wpm.

2. The speed increase in the speed reading course transfers to other types of texts and the increase on these texts can reach at least $58 \mathrm{wpm}$.

3. There was a strong relationship between rate improvement in the speed reading course and on other types of texts.

4. The initial speed is a good predictor of the increase the reader will make in the speed reading course and on other types of texts.

5. The four methods of measuring speed increases (the $20^{\text {th }}$ minus $1^{\text {st }}$ method, the average scoring method, the extreme method, and the three extremes method) agree very well in that they yielded the same group ranking in speed improvement.

6. Scheduling the speed reading course once, three times, or four times a week does not substantially affect speed increases in both the speed reading course and other types of texts.

7. Texts in the speed reading course book and other texts for the pre-test and posttest are of roughly equal difficulty level and provide results reliable enough to be used for measuring readers' reading rates.

8. The usual English program at the university may have an effect on the students' reading development. Thus, it is necessary that the second experiment examine this issue more carefully.

9. Comprehension scores in other types of texts were not collected and thus it remained unknown how comprehension changed when speed developed. The second experiment should explore this aspect. 


\section{CHAPTER 4 THE SECOND EXPERIMENT}

\subsection{Methodology}

\subsubsection{Research questions}

The second experiment was to a certain degree a replication but also an expansion of the first experiment. It repeated some procedures followed in the first experiment. A speed reading course was delivered to two experimental groups but not to two control groups. Transfer from the speed reading course to other texts was explored again but for a different purpose: to determine if the usual English program has any effect on the speed transfer from the speed reading course to other texts. Furthermore, the experiment seeks answers to the following questions:

1. Will the speed increase in the speed reading course be accompanied by a speed increase in oral reading?

2. Will the speed increase in the speed reading course contribute to language accuracy and language complexity?

\subsubsection{Materials}

The material used for the speed reading course was Asian and Pacific speed readings for ESL learners (Millett, et al., 2007). This book was also used for the first experiment and the pilot tests showed that all the texts were relatively easy for learners who have reached the $2^{\text {nd }} 1000$ word level. Besides, the first experiment found that no texts were markedly easier or more difficult than the others.

In order to investigate the transfer of speed increases from the speed reading course to other types of texts, two passages were used for the pre-test and post-tests. In the first experiment, four texts were used for this purpose. However, in the present experiment, only two from these four texts were utilized. This was because the first experiment demonstrated that the four texts were equally difficult and did not distort the results. Different calculations involving the first text or the second text or both to measure reading speeds all yielded similar results. The data of average speeds on the two texts correlated with the data of the speeds on each text. 
To determine whether speed increases in the course were accompanied by reading rate improvement and language complexity development, two memory span sets and two oral reading texts were utilized for the pre-test and post-test. The texts for the oral reading tests were written within the 1000 word level. Each text consisted of 194 words and 294 syllables. They were put in a syllabus counter program, a word counter program, a vocabulary profiler and modified so that they were equal in terms of length, vocabulary level, and syntactical complexity. Each memory span set consisted of 20 sentences that were written within the 1000 word level. The sentences were of increasing length and syntactical complexity. The two sets contained corresponding sentences that were equal in terms of vocabulary level, length, and grammatical difficulty. Language memory span can be orally administered to a group of students who are supposed to write down the sentences on a sheet of paper (Harris, 1970). However, in the present experiment, we put the sentences in a computer program, which allows the participants to read each of the sentences within a certain amount of time. The test was not orally done because that would have involved both listening skills and memory span, which would have made it more challenging to measure the participants' memory span as it would be impossible to determine if an error was caused by limited memory span or bad listening skills.

\subsubsection{Participants}

In the first experiment, it was clear that the English program had an effect on the participants' speed reading rate. The control group, who followed the same English program as the treatment group, also made a speed increase on other types of texts. Therefore, in the present experiment we set up one more control group who did not follow the English program to compare with another control group who followed the English program.

All participants were first year students at university. They had been studying English for at least three years at high school for approximately four hours a week. The participants in this experiment were put into four groups: two experimental groups, hereafter called group A and group B, and two control groups, hereafter called group C and group D. Group A and group B followed both the speeding reading course and the usual English program. Group A had consultation sessions during the course while group B did not. Group C and $\mathrm{D}$ did not follow the speed reading course. While group $\mathrm{C}$ followed the usual English program, group D followed an English course at a language centre. It was a general 
English language program, which integrated the four skills: speaking, listening, reading, and writing. The participants had about 10 hours of classes a week for four and a half months, the length of the university semester. The English program consisted of reading, speaking, listening, writing, and grammar lessons. The lessons made up around 10 hours a week.

The participants from group A, group B and group C were all English majors and came from the same department. We randomly put them into those three groups. There were at first 96 participants evenly divided into three groups of 32 participants. However, one participant from group A quit the speed reading course after the fifth session. Two participants from group B stopped at the tenth and thirteenth sessions. Four students in group $\mathrm{C}$ did not do the post-test and two quit the English program at university. Therefore, there were only 87 participants left with 31 for group A, 30 for group B and 26 for group C.

For group D, who did not follow either the English program at university or the speed reading course, we first picked 50 university students, who were following English courses at a language centre. The number was then reduced to 32 because the other 18 either were not in the same age range or did not have similar background education as the participants in the other three groups. Three participants in this group stopped their study at the language centre in the middle of the experiment, hence reducing the number of participants to 29 . The following criteria were applied with when choosing participants for group D in order to equalize participants in this group with participants in the other groups:

1. Their age range was from 19 to 23

2. They had been studying English for the same length of time as the other participants had.

3. Their background education was similar to that of the other groups.

4. They did not follow the English program that the other participants did but they followed a general English course, which lasted for the same length of time.

One of the most distinguishing features of the participants in the present study was that their academic ability was lower than those in the first study. The university went through a hard time when most good students aimed for other universities and thus the administrators had to lower the admission requirements, allowing many students with lower academic skills to enrol. Another difference between them was that the present study's participants were the first students at the university to comply with new rules. In the past, students enrolled in classes that had the same schedules for a certain fixed number 
of subjects they had to learn in each semester. However, since the university switched to the new administration allowing students to follow as many courses as they wished, many students were studying more subjects at one time and they had to move around the campus once in every two hours to find their classroom. This caused difficulty in getting the same students to stay in the one classroom to do the speed reading sessions. The students were also focused on many other subjects, which lowered their motivation for doing the speed reading. A brief description of the treatment and variables that the four groups followed is presented in Table 4.1.

Table 4.1 Brief description of what the four groups followed during the second experiment

\begin{tabular}{ccccc}
\hline $\begin{array}{c}\text { Group } \\
\text { name }\end{array}$ & $\begin{array}{c}\text { Number of } \\
\text { participants }\end{array}$ & Speed reading course & Usual English program & $\begin{array}{c}\text { English course at the } \\
\text { language centre }\end{array}$ \\
\hline A & 31 & YES & YES & NO \\
B & 30 & YES & YES & NO \\
C & 26 & NO & YES & NO \\
D & 29 & NO & NO & YES \\
\hline
\end{tabular}

\subsubsection{Procedures}

Regarding the speed reading course, the same procedures as in the first study were repeated. First, the treatment groups did the vocabulary test, and then they had three speed reading sessions every week. This scheduling was chosen because in the first study it was found that group 3 made the best speed improvement both in the speed reading course and on other types of texts.

All participants in the four groups had to sit the pre-tests and post-tests on reading other types of texts, oral reading, and language memory span. After the pre-test, the treatment groups (group A and group B) had the speed reading course while following the usual English program. During the treatment, group A received consultation sessions whereas group B did not. In the consultation sessions, the researcher talked with participants who had issues in the reading sessions and oriented them to use appropriate methods to increase their speeds. One of the control groups (group C) followed the English program at the university and the other (group D) attended an English course at a language centre.

In order to eliminate the text effect, on the pre-tests, half of the participants from each group were asked to do one set/text of the reading materials or memory span sets and the 
other half had to do the other set/text. On the post-test, the administration was the reverse of that on the pre-tests. All the tests were done on the computer. With respect to the oral reading test, the participants read the text and the computer program recorded their voice. In regard with the memory span tests, the students first read the instructions on the computer. They then saw each of the 20 sentences appearing on the screen. Each sentence appeared on the computer screen for a certain amount of time, which was enough for an average native speaker to read the sentence aloud and then to pause for two or three seconds. After the sentence disappeared, the participants had to type the sentence before moving on to the next sentence.

With respect to the tests on reading other types of texts, in the previous experiment, the pre-test and post-test to measure the speed on other types of texts was not computer-based. The following flaws were found:

+ When the administrator said 'Begin', the participants were supposed to start reading and after one and a half minutes, they were asked to stop and the researcher counted the number of words they read within that amount of time. Therefore, if any students did not start reading when required to do, their speed might have been distorted.

+ The test was administered among a big group and the text was accompanied by the comprehension questions. Consequently, the administrator could not notice if any participants ceased reading to look at the comprehension questions within the first one and a half minutes.

+ The participants were asked to circle the word they reached after one and a half minutes. Some participants may not have circled the word they reached but a word before or after that thus making the result invalid.

+ It was possible that some participants could have associated the test with the speed reading course so in the post-test, they might have cheated to get a higher score.

In the second experiment, to eliminate those flaws, we put the tests for silent reading and memory span in a computer program and used the following procedures. First, the participants were told that they would have to read a text and would see more instructions when finishing reading. Once they had already filled in their identification information, they could click the 'begin' button and start reading. They could only see the comprehension questions after they had finished reading and clicked the 'next' button. The administrator did not have to control the starting time of all the participants because the program automatically recorded the time when the participants clicked the 'next' button to 
see the comprehension questions. The researcher did not have to count the number of words that each participant read in one minute as the computer program did it automatically. During the administration, the administrator did not have to check if the participants ceased reading to read the comprehension questions since they could not see them before they finished reading.

\subsubsection{Pilot testing}

The items needed to be tested before the second experiment included the program for reading other types of texts, the program for the memory span tests, the program for the oral reading test, the oral reading texts, the memory span sets and the silent reading texts (see Table 4.2).

Table 4.2 Pilot testing plan for the second experiment

\begin{tabular}{|c|c|c|c|}
\hline Items & Potential problems & Pilot testing & $\begin{array}{l}\text { Number and type } \\
\text { of subjects needed }\end{array}$ \\
\hline \multirow[t]{2}{*}{$\begin{array}{l}\text { Memory span } \\
\text { tests }\end{array}$} & $\begin{array}{l}\text { The two sets of memory span } \\
\text { sentences might not be equally } \\
\text { difficult. }\end{array}$ & $\begin{array}{l}\text { To see if the learners could have } \\
\text { similar results on the two } \\
\text { memory span sets }\end{array}$ & $\begin{array}{l}\text { Five learners of } \\
\text { English }\end{array}$ \\
\hline & $\begin{array}{l}\text { The sets of sentences might be } \\
\text { too difficult or too easy for the } \\
\text { real participants of the } \\
\text { experiment. }\end{array}$ & $\begin{array}{l}\text { To see if there would be any } \\
\text { ceiling or floor effect caused by } \\
\text { the sets of sentences being too } \\
\text { easy or too difficult. }\end{array}$ & $\begin{array}{l}\text { Five learners of } \\
\text { English }\end{array}$ \\
\hline $\begin{array}{l}\text { Memory span } \\
\text { test program }\end{array}$ & $\begin{array}{l}\text { The program might not work } \\
\text { well or the participants might } \\
\text { find the computer tasks too } \\
\text { difficult to perform }\end{array}$ & $\begin{array}{l}\text { To see if there would be } \\
\text { technical trouble and if the } \\
\text { participants found the computer } \\
\text { tasks easy enough to perform }\end{array}$ & $\begin{array}{l}\text { Five learners of } \\
\text { English }\end{array}$ \\
\hline $\begin{array}{l}\text { Oral reading } \\
\text { texts }\end{array}$ & $\begin{array}{l}\text { The texts might not be equal in } \\
\text { terms of difficulty, vocabulary } \\
\text { level and contents }\end{array}$ & $\begin{array}{l}\text { To check the similarity of the } \\
\text { two texts }\end{array}$ & $\begin{array}{l}\text { Five learners of } \\
\text { English }\end{array}$ \\
\hline $\begin{array}{l}\text { Oral reading } \\
\text { test program }\end{array}$ & $\begin{array}{l}\text { The program might not work } \\
\text { well and the computer tasks } \\
\text { might be too difficult for the } \\
\text { participants }\end{array}$ & To see how the program worked & $\begin{array}{l}\text { Five learners of } \\
\text { English }\end{array}$ \\
\hline $\begin{array}{l}\text { Silent reading } \\
\text { test program }\end{array}$ & $\begin{array}{l}\text { The program might not work } \\
\text { well and the computer tasks } \\
\text { might be too difficult }\end{array}$ & To see how the program worked & $\begin{array}{l}\text { Five learners of } \\
\text { English }\end{array}$ \\
\hline
\end{tabular}




\subsubsection{Memory span test pilot testing}

The memory span tests were designed to test if the participants in the experiment had improved their memory span as a result of receiving the treatment. There were two sets of test items, one of which was for the pre-test and the other was for the post-test. Each participant would do one at the beginning of the study and the other at the end. Some learners did version A as the pre-test and version B as the post-test, while others did version $\mathrm{B}$ as the pre-test and version $\mathrm{A}$ as the post-test.

In order to avoid a test effect caused by one of the sets being more difficult and the other being easier, which may lead to misinterpretation of the participants' improvement, we tested the two sets with five learners of English. Because the sentences in the two sets were similar in content, we gave the five learners one set and waited for a month before we asked them to do the second set. This was done to avoid the possibility that the learners' memory about the contents in the first set would help them do the second set better. The testing showed that the two sets of memory span sentences were equal in terms of difficulty as for both sets the learners earned similar results. The data indicated there were no ceiling or floor effects. The learners gave incorrect answers and correct answers on both sets.

We also tested how the program for the memory span tests worked. The program required test takers to fill in their personal details and choose one of the two sets already shown on the screen. When they pressed the begin button, an instruction window appeared showing them what to do. The instruction told them to ask the administrator any questions if they still did not understand. Otherwise, they could click the examples button and see how the examples worked. After viewing the examples, they clicked the ready to begin button to do the real test. Each sentence appeared on the screen for a certain amount of time after which the test takers saw a blank box where they had to type the sentence they had just seen. In order to make sure no technical problems would prevent us from collecting the data, we asked two of the five learners to pilot test this program. One of them was asked to choose set $\mathrm{A}$ of the memory span sentences and the other two were asked to choose set $\mathrm{B}$. The learner who did set A had no trouble doing the test and had her results automatically saved on the computer. However, the learner who did set B could not continue the test after the nineteenth sentence. We had to consult the software programmer about that and had him repair the program. Afterwards we had the other three learners do the test on the computer with two learners doing set $\mathrm{B}$, with which the previous test taker had trouble, and the other 
doing set A. The program worked smoothly and we could get the results automatically saved on the computer and sent to our email address. The computer tasks were easy enough to perform even with the very low tech participants.

\subsubsection{Oral reading test pilot testing}

The oral reading test included two texts taken from graded readers but which were modified and checked on a vocabulary profiler to equalize the vocabulary levels, numbers of words, and familiarity of contents. We also put the texts in a syllable counter program to check if they had the same number of syllables. The word and syllable counting also was manually done to enhance the validity. The pilot testing was done to see if there would be any unusual differences between readers reading text $\mathrm{A}$ and readers reading text $\mathrm{B}$. The first time, five participants were asked to read aloud the texts while the administrator recorded their voice. The results showed that all of the participants finished text $\mathrm{B}$ in a shorter time than they spent on text A. It was found that in text A there were more full stops and commas than in text B causing the participants to make more pauses. Therefore, we modified text A to make its number of full stops and commas similar to that of text B. We then carried out the test with other five participants reading both texts and the results indicated that within one and a half minutes the participants could read similar numbers of syllables on both texts.

We also tested the recording program called Adobe Audition. After installing the program on the computer, we asked the same participants to sit and do the test again. After being given instructions, they had to perform the computer tasks themselves. All of them said afterwards that the tasks were easy and they had no problem getting the job done.

\subsubsection{Pilot testing for reading other types of texts}

The test aimed to see if the speed increases in the course transfer to other types of texts. Before and after the treatment, the participants had to sit a pre-test and post-test. In the tests participants had to read a text and then answer comprehension questions that accompanied each text. The time they spent on reading the text was recorded by the program. The texts for the tests were the ones used in the first experiment and it was shown that they were equal in terms of difficulty, vocabulary, and content. Therefore we only had to test the software program. 
The program allowed people to read the instructions carefully before they began reading the text, which was divided into four sections. The sections appeared one after another on the computer screen. This was done to explore how fast a reader reads different parts of a text. We asked five people to do the test on the computer and everything went smoothly with their results saved on the computer and sent to our email address.

\subsection{Results}

\subsubsection{Speed increases in the speed reading course}

This section looks at the results drawn from the speed reading course to see if the data from the first experiment and the second experiment are consistent. In order to do this, the participants' reading rate increases, their slowest and fastest speeds, their speed change patterns, the relationship between their initial speeds and final speeds, their comprehension scores, speed changes by participants who made no improvement were all explored to make the results as detailed as possible. In the first experiment, it was found that the average scoring method agreed very well with the other three methods and provided reliable results. Therefore, this method was used again in the present experiment.

\subsubsection{Did the participants' reading rates increase within the course?}

The data were collected from the 61 participants (group A and group B) who had the speed reading course three sessions a week. The course lasted for about seven weeks. Before and after that the participants had the pre-tests and post-tests for oral reading, memory span and reading texts that were not in the course. Group A received consultation during the speed reading course while group B did not. The consultation was provided to any participants in group A who had seemed not to do the speed reading in the ways suggested by Millett et al. (2007). A few of them were trying to slow down their speed in order to get higher scores for the comprehension questions. Some read word by word in their head while others read with their finger or pen pointing at the words. These participants were then advised not to read aloud and not to read with their finger or pen crossing the lines. They were also told that they were not expected to answer all the comprehension questions correctly.

The results (see Table 4.3) showed that for group A, who received consultation, the average increase was $57 \mathrm{wpm}$. With regard to group B, their average increase was $51 \mathrm{wpm}$. 
The data on initial scores and final scores (see Table 4.4) showed that the two groups had similar average initial scores. These results confirm the reliability of the speed improvement both groups made and suggest that although group A performed slightly better than group B, the two groups did not greatly differ in their speed improvement. There were only minor differences in these two groups' results. An examination of the results from the other three scoring methods (see appendices $\mathrm{X}$ and $\mathrm{Y}$ ) indicated that the four scoring methods agreed with each other, thus reinforcing the reliability of the four results and confirming that the participants' speed changes were a real improvement.

A comparison between the two experiments showed that both experiments found similar results.

Table 4.3 Means and standard deviations of in-course speed increases for the treatment groups

\begin{tabular}{lcc}
\hline & Group A & Group B \\
\hline$n$ & 31 & 30 \\
\hline Mean & 57.00 & 50.90 \\
SD & 40.52 & 29.91 \\
\hline
\end{tabular}

Table 4.4 Means and standard deviations of initial speeds and final speeds in the course for the treatment groups

\begin{tabular}{lllcc}
\hline & & & Group A & Group B \\
\hline \multirow{4}{*}{ Initial speeds } & Speed on the first text & Mean & 128.64 & 132.76 \\
& & SD & 29.53 & 27.24 \\
\cline { 2 - 5 } & The average speed on the first 3 texts & Mean & 131.96 & 132.36 \\
& & SD & 27.28 & 23.80 \\
\hline \multirow{3}{*}{ Final speeds } & Speed on the last text & Mean & 189.67 & 183.80 \\
& & SD & 44.11 & 39.86 \\
\cline { 2 - 5 } & The average speed on the last 3 texts & Mean & 188.90 & 183.36 \\
& & SD & 40.73 & 38.18 \\
\hline
\end{tabular}




\subsubsection{In which part of the speed reading course did the participants gain the lowest and highest score?}

This question was posed to determine where in the speed reading course the participants had their slowest speeds and highest speeds. The sessions in which the participants had their three slowest speeds and three highest speeds were examined. If the data show that most of the participants' slowest speeds were in the first half and most of their fastest speeds were in the second half, it would provide evidence that the participants made real progress during the course, and that it is worthwhile continuing to read more texts after the $10^{\text {th }}$ sessions.

As can be seen from Table 4.5, all participants had their slowest speed in the first half of the course and $89 \%$ of them had it in the first five sessions. Ninety percent of the participants reached their highest speed in the second half of the course and $70 \%$ of them reached it in the last five sessions. With regard to the three slowest and three fastest speeds, $97 \%$ of the participants had their three lowest scores in the first half of the course and $83 \%$ had their slowest speeds in the first five sessions. Ninety percent of the participants reached their three best scores in the second half of the course and $72 \%$ of them reached their three fastest speeds in the last five sessions. Among the participants who had their slowest speed(s) in the second half or their fastest speed(s) in the first half, only one participant had their fastest speed after having their slowest speed. These results corroborate the findings emerging from the first experiment and show that the participants made a real improvement and that after the $10^{\text {th }}$ text most of the participants continued to increase their speeds and the majority of them kept improving during the last five sessions. This suggests that the speed reading course was bringing about continual improvement and worth doing until the $20^{\text {th }}$ session.

Table 4.5 The percentage of participants having their slowest and fastest speeds in the four parts of the course

\begin{tabular}{lcccc}
\hline & $\# 1$ to \#5 & $\# 6$ to \#10 & $\# 11$ to \#15 & $\# 16$ to \#20 \\
\hline Slowest speed & $89 \%$ & $11 \%$ & $0 \%$ & $0 \%$ \\
Fastest speed & $3 \%$ & $7 \%$ & $20 \%$ & $70 \%$ \\
\hline Three slowest speeds & $83 \%$ & $14 \%$ & $3 \%$ & $0 \%$ \\
Three fastest speeds & $2 \%$ & $8 \%$ & $18 \%$ & $72 \%$ \\
\hline
\end{tabular}




\subsubsection{Did any participants not make any improvement?}

This section analyzes the results by participants who did not make any improvement in the course. This helps to eliminate the possibility that the groups' increases were due to a few participants with very big increases while many other participants did not make any progress.

Table 4.6 Results by the participants who made no improvement in either the $20^{\text {th }}$ minus $1^{\text {st }}$ method or the average method

\begin{tabular}{lcc}
\hline Measure & A9 & A28 \\
\hline Average method & -18 & -23 \\
\hline Average of $1^{\text {st }}$ half minus average of $2^{\text {nd }}$ half & -12 & 4 \\
\hline
\end{tabular}

Figure 4.1 Progress charts by participants who had negative results in the course

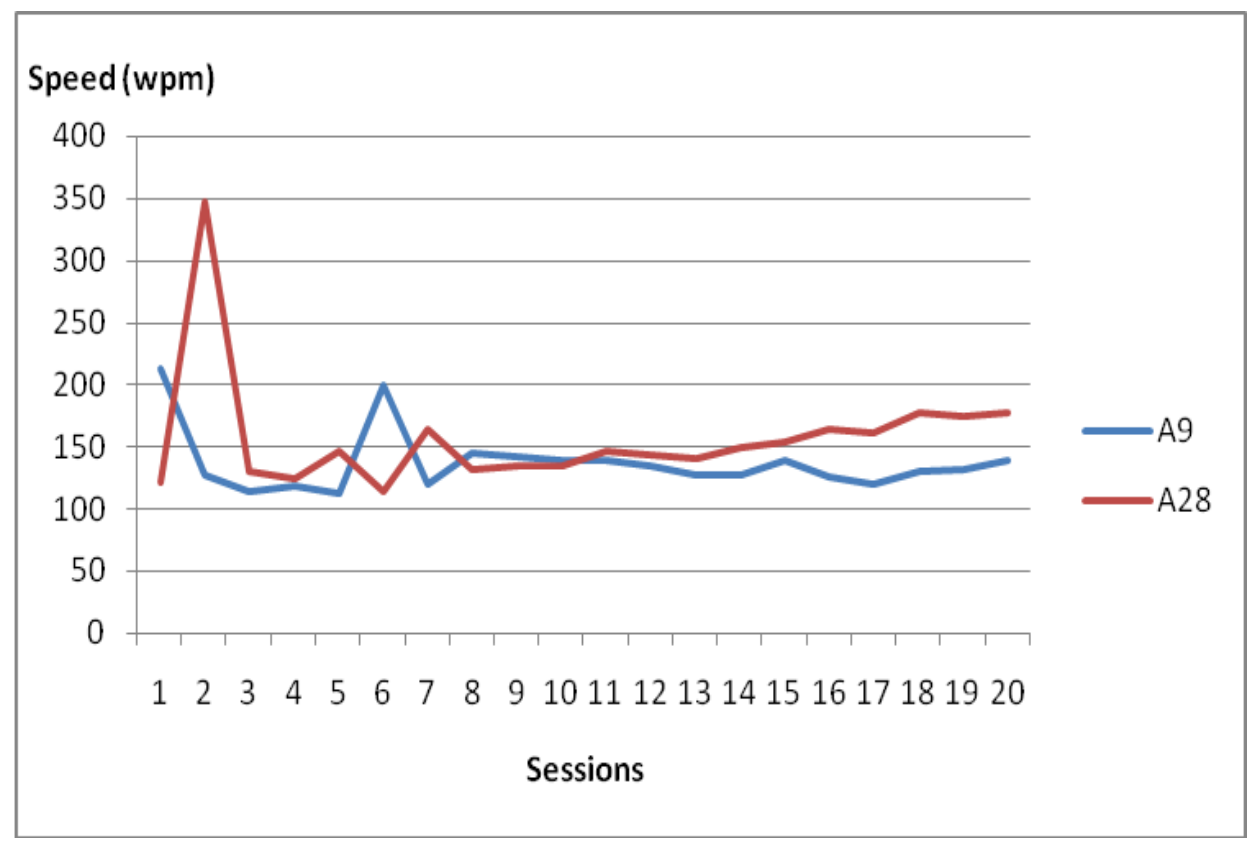

As can be seen in Table 4.6, the average scoring method demonstrated that only two participants, A9 and A28, suffered a decrease of $18 \mathrm{wpm}$ and $23 \mathrm{wpm}$. However, caution must be applied since these participants might have had better scores in earlier sessions than the last three sessions. Thus the difference between the average speeds of the first ten texts and the last ten texts was also compared. This comparison showed that only one participant (A9) had a negative result but participant A28 made an increase of $4 \mathrm{wpm}$. The progress charts of these two participants (see Figure 4.1) indicated that both of them had 
their speed peak somewhere in the first half of the course but then did not make any big increase after that.

Overall, the results demonstrated that only one participant did not make any improvement during the entire course. This agrees with the result in the first study and thus reinforces the idea that the speed reading course helped almost all participants to improve their reading speed.

\subsubsection{To what extent does the decrease made by the participants with negative results affect the group results?}

This section intends to show the reliability of the speed improvement results by the two treatment groups. Although it was apparent that both groups made increases in the speed reading course, there may be a possibility that their results were distorted by the very low figures of some participants.

Table 4.7 Comparisons of groups' results with and without the negative results by participants who made no improvement in the course

\begin{tabular}{llcc}
\hline & & Group A & Group B \\
\hline Original results & Mean & 57.00 & 50.90 \\
& SD & 40.52 & 29.91 \\
\hline Results after removing negative scores & Mean & 61.58 & 51.09 \\
& SD & 36.06 & 29.91 \\
\hline
\end{tabular}

As shown in Table 4.7, if we omit the negative results group B would have the same average increase as all participants in this group made an improvement. Group A's new result would be $62 \mathrm{wpm}$. The difference was small and the same ranking of the groups was maintained. It can thus be assumed that the negative results by the participants who made no improvement did not noticeably affect the whole group' results. This enhances the idea that the groups' results were reliable.

\subsubsection{How did comprehension change as the participants increased their speeds?}

There was a possibility that as readers increase their reading rates, their comprehension decreases. As Nation (2005) pointed out, a fast speed with little comprehension is 
meaningless. Thus it is crucial to look at the participants' comprehension scores to see if they could keep their comprehension level at around $70 \%$ and if they did not comprehend less as their reading speed improved. The participants' comprehension accuracy was measured by counting the number of correct answers they made on each of the twenty texts in the speed reading course. Two comparisons were made. First, the average score on the first three texts was compared with the average score on the last three texts. Second, the average score on the first half of the texts was compared with the average score on the second half of the texts.

Table 4.8 Means and standard deviations of comprehension scores on the first three texts, the last three texts, in the first half and the second half of the course for the two treatment groups

\begin{tabular}{llcc}
\hline Measure & & Group A & Group B \\
\hline \multirow{2}{*}{ First three texts } & Mean & 7.34 & 7.16 \\
& SD & 0.85 & 0.59 \\
\hline \multirow{2}{*}{ Last three texts } & Mean & 7.84 & 7.74 \\
& SD & 0.68 & 0.65 \\
\hline \multirow{2}{*}{ First half of the course } & Mean & 7.11 & 7.21 \\
& SD & 0.58 & 0.37 \\
\hline \multirow{2}{*}{ Second half of the course } & Mean & 7.67 & 7.44 \\
& SD & 0.45 & 0.31 \\
\hline
\end{tabular}

As can be seen in Table 4.8, both group A and group B had an average score of over seven out of 10 on the first three texts, the last three texts, the first half of the texts and the second half of the texts. Comparing the groups' average scores on the last three texts with their average score on the first three texts showed that both groups made slight increases. Comparing their average scores on the first half of the course with their average scores on the second half of the course showed the same trend. The data indicated among 61 participants, only 10 participants had their average score on the last three texts lower than their average score on the first three texts, but the decreases were minimal from 0.33 to 1.33. The rest either had the same or higher average score on the last three texts as compared to the average score on the first three texts. Note the small standard deviation showing the comprehension was generally around the desired 7 out of 10 . With regard to the difference between the first half and the second half of the texts, only 14 out of 61 participants had a negative result but the decreases were less than 0.80 . The other 47 participants made an improvement from 0.10 to 2.67 . These results show that most 
participants could keep their comprehension accuracy at the same level as they increased their speeds. This both reinforces the idea that they made real progress in reading speed and that speed reading courses can help readers to improve their speed without comprehending less.

\subsubsection{How did the initial speeds relate to the final speeds?}

This analysis intends to explore the relationship between the initial reading speeds and the increases the participants gained at the end of the course. If there is a link between the initial scores and final scores, it is possible to say that the increases were a result of learners taking the course seriously. The relation between the initial speeds and final speeds was examined by arranging the average scores of the first three texts in order from the biggest to the smallest and looking for a relationship between them and the average scores of the last three texts.

Table 4.9 presents the average of the three initial scores and the average of the three final scores for four subgroups from group A and group B. The first consisted of participants whose initial scores ranged from $138 \mathrm{wpm}$ to $177 \mathrm{wpm}$. The second consisted of participants whose initial scores ranged from $117 \mathrm{wpm}$ to $137 \mathrm{wpm}$. The third group consisted of participants whose initial scores ranged from $102 \mathrm{wpm}$ to $115 \mathrm{wpm}$. The last group consisted of participants whose scores ranged from $92 \mathrm{wpm}$ to $102 \mathrm{wpm}$.

The data showed that the first group, who had the highest initial scores, reached the highest final scores. All except one participant (A1) in this group had an average speed of less than $178 \mathrm{wpm}$ on the first three texts but reached the average speed of more than $200 \mathrm{wpm}$ on the last three texts. The fourth group, who had the lowest initial scores, had the lowest average final score. The second and third groups had different initial average scores but reached similar average final scores. With respect to the increases the participants made, the third group were the best progress makers with 91 wpm. Participants of the first group with the highest starting speeds made a slightly lower average increase with 82 wpm. Participants in the second and the fourth groups with had average increases of $68 \mathrm{wpm}$ and 67 wpm. 
Table 4.9 Average of the first three scores $(I)$ and average of the last three scores $(F)$ in the course for the participants $(P)$ in the two treatment groups

\begin{tabular}{|c|c|c|c|c|c|c|c|c|c|c|c|}
\hline $\mathbf{P}$ & I & $\mathbf{F}$ & $\mathbf{P}$ & I & $\mathbf{F}$ & $\mathbf{P}$ & $\mathbf{I}$ & $\mathbf{F}$ & $\mathbf{P}$ & I & $\mathbf{F}$ \\
\hline A24 & 177 & 271 & A10 & 137 & 198 & A9 & 115 & 186 & $\mathrm{~A} 3$ & 102 & 134 \\
\hline B4 & 175 & 223 & B17 & 135 & 237 & A17 & 113 & 167 & A26 & 102 & 165 \\
\hline A30 & 170 & 204 & B28 & 134 & 170 & B7 & 113 & 181 & A12 & 102 & 177 \\
\hline A18 & 159 & 251 & A14 & 133 & 211 & B8 & 111 & 174 & A4 & 100 & 202 \\
\hline B3 & 156 & 237 & A15 & 133 & 185 & A20 & 110 & 301 & A22 & 100 & 183 \\
\hline B13 & 151 & 218 & B9 & 132 & 202 & B26 & 110 & 171 & B19 & 98 & 176 \\
\hline B21 & 151 & 204 & B16 & 130 & 168 & A8 & 109 & 213 & B29 & 98 & 168 \\
\hline B6 & 147 & 265 & A7 & 129 & 223 & $\mathrm{~A} 2$ & 108 & 201 & B27 & 97 & 160 \\
\hline A21 & 145 & 268 & B2 & 125 & 158 & A 29 & 108 & 183 & A19 & 97 & 184 \\
\hline A31 & 144 & 231 & B23 & 123 & 211 & A5 & 108 & 176 & B1 & 96 & 234 \\
\hline B20 & 143 & 213 & B18 & 121 & 213 & B15 & 108 & 181 & B5 & 94 & 128 \\
\hline B30 & 142 & 255 & A28 & 120 & 233 & A16 & 105 & 200 & B24 & 93 & 152 \\
\hline B22 & 141 & 268 & A6 & 118 & 158 & B14 & 105 & 248 & B12 & 93 & 130 \\
\hline A27 & 141 & 233 & B11 & 118 & 187 & A11 & 104 & 229 & A23 & 92 & 126 \\
\hline \multirow[t]{2}{*}{ A1 } & 138 & 171 & B10 & 117 & 151 & A25 & 102 & 183 & B25 & 92 & 166 \\
\hline & & & & & & & & & A13 & 92 & 157 \\
\hline & 152 & 234 & & 127 & 194 & & 109 & 200 & & 97 & 165 \\
\hline & \multicolumn{3}{|c|}{ Difference: 67} & \multicolumn{3}{|c|}{ Difference: 91} & \multicolumn{3}{|c|}{ Difference: 68} \\
\hline
\end{tabular}

The results in this experiment corroborate the findings in the first experiment (see Table 3.7). First, it was again found the highest average speed on final texts a group could reach was around $220 \mathrm{wpm}$. Second, both participants with low initial speeds and participants with higher initial speeds could benefit from the speed reading course. This was because none of them were near the ceiling level of around $300 \mathrm{wpm}$. Third, it was shown that initial speeds do not determine increases in reading speed. Fourth, it was a trend that the participants with the highest initial speeds reached the highest final speeds and the participants with the lowest initial speeds had the lowest final speeds.

\subsubsection{What were the patterns of progress in speed?}

As mentioned in chapter 3, the change patterns the participants made during the speed reading course can be classified into four types: the gradual increase pattern, the erratic increase pattern, the plateau increase pattern, and the mixed increase pattern (see figures 3.5, 3.6, and 3.7 for examples of gradual increase, erratic increase and plateau increase patterns). A description of the patterns' features was also given in chapter 3. Firstly, the 
two participants whose average score on the first three texts were higher than that on the last three texts were considered as the ones who had a no improvement pattern. Then the other participants' progress charts were examined carefully and classified into one of the four types. The result is presented in Table 4.10.

Table 4.10 Numbers of participants for different change patterns

\begin{tabular}{lccccc}
\hline Group & No improvement & Erratic change & Plateau change & Gradual change & Mixed \\
\hline Group A & 2 & 1 & 3 & 25 & 0 \\
Group B & 0 & 3 & 2 & 25 & 0 \\
Total & $2(3 \%)$ & $4(7 \%)$ & $5(8 \%)$ & $50(82 \%)$ & 0 \\
\hline
\end{tabular}

The data showed that four participants (one from group A and three from group B) had the erratic increase pattern while five participants had the plateau change pattern with three from group A and two from group B. Fifty out of 61 participants (82\%) made a gradual increase. These results are similar to the results in the first experiment, thus reinforcing the idea that most participants made a gradual change during the speed reading course, and that their speed change was a real improvement through practicing, not some random learner behaviour.

So far reading speed increases in the speed reading course have been explored. The results demonstrated that almost all of the participants in the treatment groups made improvement in the course. The next section will examine the sustainability of these speed increases by looking at the speed change on other types of texts to see if speed increases transfer to other types of texts, as was found in the first experiment.

\subsubsection{Speed increase transfer from the speed reading course to other types of texts}

In the first experiment, the investigation into this issue showed that speed increases transfer to other types of texts. The four experimental groups and one control group all made increases of at least $56 \mathrm{wpm}$. Since all groups followed the usual English program at the university, it remained uncertain to what degree the increases they made were caused by the English program or the speed reading course. Therefore, in this experiment, two control groups were set up, one of which did not follow the usual English program at university. This was to see if this control group would still make progress on texts that were not in the speed reading course. This section firstly begins with an overall examination of the 
participants' speed improvement on other types of texts, then proceeds to explore the difference between treatment groups and control groups, and finally describes the relationship between the in-course increases and the increases on other types of texts.

\subsubsection{Did the participants improve their speed when reading other types of texts?}

In the present experiment, two texts were used and each participant read only one text in pre-test and the other in the post-test. Therefore, the increase they made was measured by taking the speed on the pre-test away from the speed on the post-test.

Table 4.11 Means and standard deviations of speed increases on other types of texts for all groups

\begin{tabular}{llcccc}
\hline & & \multicolumn{2}{c}{ Treatment groups } & \multicolumn{2}{c}{ Control groups } \\
\cline { 3 - 6 } & & Group A & Group B & Group C & Group D \\
\hline Individual groups & Mean & 46.16 & 50.43 & 10.46 & 19.65 \\
& SD & 27.34 & 24.28 & 29.60 & 27.37 \\
\hline Average of two treatment & Mean & \multicolumn{2}{c}{48.26} & \multicolumn{2}{c}{15.30} \\
groups and two control groups & SD & \multicolumn{2}{c}{25.76} & \multicolumn{2}{c}{28.56} \\
\hline
\end{tabular}

As shown in Table 4.11 (also see appendix T) the average increase the control groups made was $15 \mathrm{wpm}$ and the average increase the treatment groups made was $48 \mathrm{wpm}$. Group B made the greatest improvement with an average increase of $50 \mathrm{wpm}$. Group A ranked the second with an average increase of $46 \mathrm{wpm}$. Then came group D with an average increase of $20 \mathrm{wpm}$ and group $\mathrm{C}$ with an average increase of $10 \mathrm{wpm}$. The data showed that thirteen out of 116 participants had their speeds decrease by $1 \mathrm{wpm}$ to $31 \mathrm{wpm}$. The other 103 participants (89\%) had positive results from $1 \mathrm{wpm}$ to $101 \mathrm{wpm}$. More than half of the participants gained increases of at least $30 \mathrm{wpm}$ and 35 participants (30\%) made increases of at least $50 \mathrm{wpm}$. The greatest improvement was a $101 \mathrm{wpm}$ difference, made by participant D3, who was in the control group that followed an English course at the language centre. The worst result was by participant D27, who had a decrease of $31 \mathrm{wpm}$. A comparison between the participants in the control groups and the participants in the treatment groups showed that only two participants in the treatment groups (3\%) but 14 participants in the control groups $(25 \%)$ had negative results. Only three participants in the control groups $(5 \%)$ had increases of over $50 \mathrm{wpm}$ whereas more than a half of participants 
in the treatment groups $(52 \%)$ had increases of over 50 wpm. Most of the 29 participants with the biggest increases were in the treatment groups and most of the 29 participants who made the least improvement were in the control groups.

A repeated measures ANOVA was carried out on the pre-test (initial score) and post-test (final score) data. The repeated-measures factor was time (pre-test vs. post-test) and the between-subjects factor was group.

The results are shown in Table 4.12 below:

Table 4.12 Means and standard deviations pre-test speed and post-test speed on other types of texts for all groups

\begin{tabular}{|c|c|c|c|c|c|c|c|c|}
\hline & & \multicolumn{4}{|c|}{ Group } & \multicolumn{3}{|c|}{ Analysis of variance } \\
\hline & & Group A & Group B & Group C & Group D & Group & Time & Interaction \\
\hline & & & & & & $\mathrm{F}(3,112)$ & $\mathrm{F}(1,112)$ & $\mathrm{F}(3,112)$ \\
\hline \multirow[t]{2}{*}{ Pre-test } & Mean & 118.87 & 119.73 & 118.96 & 113.83 & \multirow{4}{*}{$4.36^{* *}$} & \multirow{4}{*}{$157.47 * *$} & \multirow{4}{*}{$14.88^{* *}$} \\
\hline & SD & 34.95 & 39.62 & 26.12 & 30.72 & & & \\
\hline \multirow[t]{2}{*}{ Post-test } & Mean & 165.03 & 170.17 & 129.42 & 133.48 & & & \\
\hline & SD & 36.75 & 34.62 & 20.51 & 27.19 & & & \\
\hline
\end{tabular}

$* * \mathrm{p}<.01$.

The results showed that there was a general gain for all groups from pre to post-test, $\eta^{2}$ $=.584$. There was a significant overall group effect but this is not meaningful in this context. The result of interest was the interaction (group $\mathrm{x}$ time) showing that the gains from pre-test to post-test for the two treatment groups were significantly greater than for the control groups, $\eta^{2}=.285$. As can be seen from figure 4.2 , the treatment groups made a significant improvement in reading speed, and their mean improvement was greater than the more modest gains of the control groups.

To determine the nature of the interaction effect, a one way ANOVA compared the gain scores (pre-test to post-test) of the four groups. The results showed the mean scores of the four groups were significantly different, $F(3,112)=14.88, \mathrm{p}=.000, \eta^{2}=.285$.

The mean gain score for group A speed training was $46.16(\mathrm{~N}=31, \mathrm{SD}=27.34)$. The mean gain score for Group B speed training was $50.43(\mathrm{~N}=30, \mathrm{SD}=24.28)$. The mean gain score 
for Group C control was $10.46(\mathrm{~N}=26, \mathrm{SD}=29.60)$. The mean gain score for Group $\mathrm{D}$ control was $19.65(\mathrm{~N}=29, \mathrm{SD}=27.37)$.

Figure 4.2 Estimated marginal means of speed increases on other texts for all groups

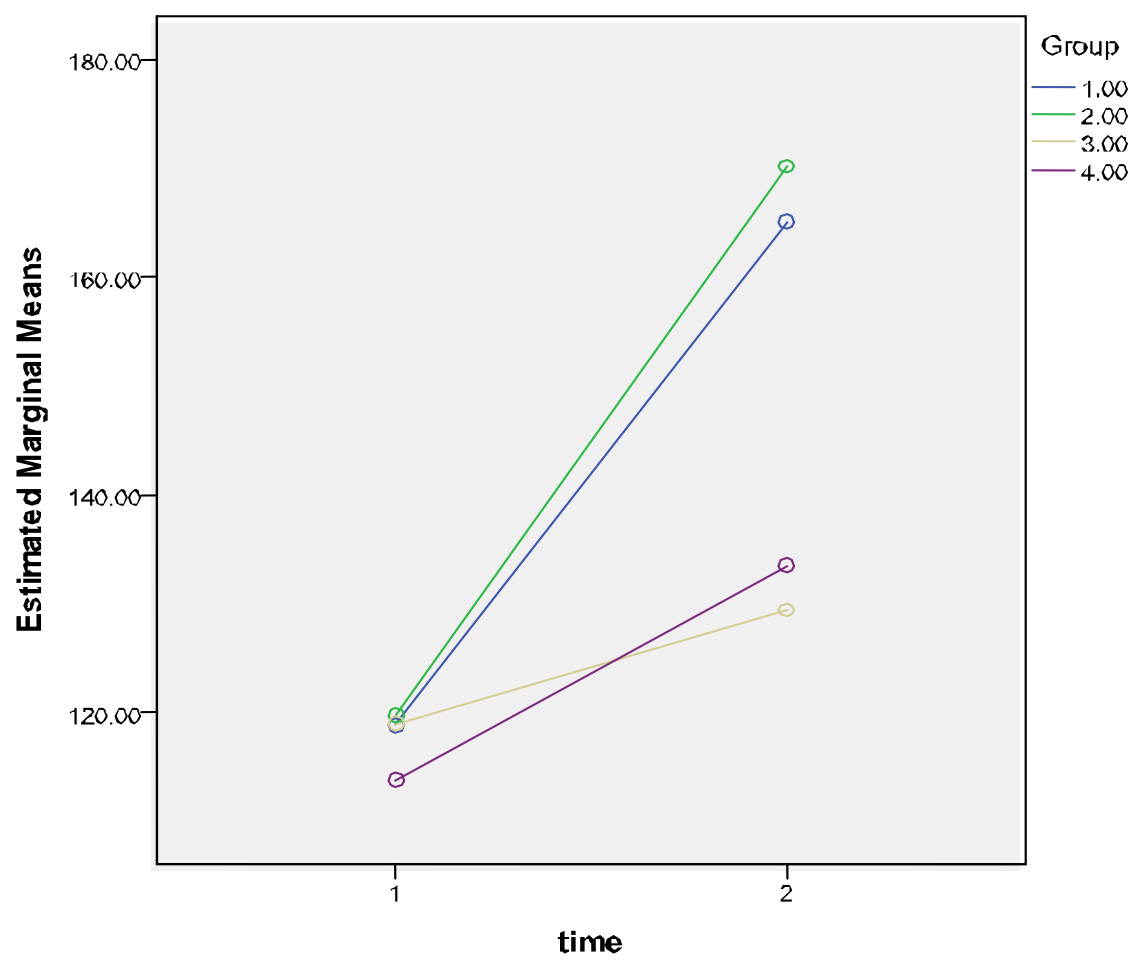

Pairwise comparisons using the Bonferroni adjustment for multiple comparisons showed a significant difference between group A and group $C(p=.000)$ and between group A and group D. $(\mathrm{p}=.002)$. There was also a significant difference between group B and group C $(\mathrm{p}=.000)$ and between group $\mathrm{B}$ and group $\mathrm{D}(\mathrm{p}=.000)$. There was no significant difference between groups $\mathrm{C}$ and $\mathrm{D}(\mathrm{p}=1.000)$.

These results agree with the findings in the first experiment thus reinforcing the idea that speed increases transfer from the course to other types of texts. The results also expanded the first experiment's findings in that significant differences between the control groups and the treatments groups were found. This makes sure that the treatment groups' achievement was due to the speed reading course.

Compared with the first experiment's participants, it can be seen that participants in this experiment made smaller increases. The difference between the best group in the first 
experiment and the best group in this experiment was $29 \mathrm{wpm}$ and the worst group in the first experiment still made a slightly bigger increase than the best group in this experiment. Increases thus may be proficiency related as the participants in the first experiment were generally of higher proficiency.

\subsubsection{What were the fastest speed and the slowest speed and what was the biggest increase?}

To eliminate the possibility that the treatment groups' increases were bigger than those of the control groups just because some participants had very fast speeds, an examination on the groups' speed ranges is necessary. This is also to see how fast the groups read on the pre-test and on the post-test and their potential for improving their speeds.

Table 4.13 The slowest speeds, fastest speeds on the pre-test and post-test, the greatest progress and the worst progress for each of the four groups

\begin{tabular}{llcccc}
\hline Measure & & Group A & Group B & Group C & Group D \\
\hline \multirow{2}{*}{ Pre-test } & Slowest speed & $49 \mathrm{wpm}$ & $46 \mathrm{wpm}$ & $67 \mathrm{wpm}$ & $71 \mathrm{wpm}$ \\
& Fastest speed & $177 \mathrm{wpm}$ & $198 \mathrm{wpm}$ & $169 \mathrm{wpm}$ & $174 \mathrm{wpm}$ \\
\hline \multirow{2}{*}{ Post-test } & Slowest speed & $104 \mathrm{wpm}$ & $104 \mathrm{wpm}$ & $95 \mathrm{wpm}$ & $81 \mathrm{wpm}$ \\
& Fastest speed & $238 \mathrm{wpm}$ & $228 \mathrm{wpm}$ & $192 \mathrm{wpm}$ & $180 \mathrm{wpm}$ \\
\hline Difference between & Worst progress & $-8 \mathrm{wpm}$ & $2 \mathrm{wpm}$ & $-22 \mathrm{wpm}$ & $-31 \mathrm{wpm}$ \\
pre-test and post-test & Best progress & $92 \mathrm{wpm}$ & $88 \mathrm{wpm}$ & $39 \mathrm{wpm}$ & $101 \mathrm{wpm}$ \\
\hline
\end{tabular}

Table 4.14 Numbers of participants in each group with speeds/increases in the three speed ranges in the pre-test, post-test and difference between the pre-test and post-test

\begin{tabular}{llcccc}
\hline Measure & Speed range & Group A & Group B & Group C & Group D \\
\hline \multirow{3}{*}{ Pre-test } & Under 100 wpm & 9 & 11 & 6 & 12 \\
& From 100 to 150 wpm & 14 & 12 & 16 & 12 \\
& Over 150 wpm & 8 & 7 & 4 & 5 \\
\hline \multirow{2}{*}{ Post-test } & Under 100 wpm & 0 & 0 & 1 & 4 \\
& From 100 to 150 wpm & 12 & 10 & 23 & 16 \\
\hline \multirow{2}{*}{ Difference between } & Over 150 wpm & 19 & 20 & 3 & 9 \\
pre-test and post-test & From 20 to 50 wpm & 10 & 10 & 16 & 15 \\
& Over 50 wpm & 16 & 16 & 0 & 3 \\
\hline
\end{tabular}


As shown in tables 4.13 and 4.14 (also see appendix U), in the pre-test, the slowest speed among all the participants was 46 by a participant in group B and the fastest speed was 198 wpm by a participant in group B. Thirty-three percent of the participants read at speeds under $100 \mathrm{wpm}$. Only $21 \%$ read at speeds over $150 \mathrm{wpm}$. On the other hand, in the posttest, the slowest speed was $81 \mathrm{wpm}$ by a participant in group D and the fastest speed was 238 wpm by a participant in group A. Only $4 \%$ of the participants read at speeds less than $100 \mathrm{wpm}$ and $44 \%$ read at speeds over $150 \mathrm{wpm}$. With regard to the increases, the best progress was 101 wpm by participant D3 and the worst progress was minus 31 wpm by participant D27. Compared with the treatment groups, the control groups made less improvement with 14 participants (25\%) having negative results and only 3 participants made increases over $50 \mathrm{wpm}$. The treatment groups outperformed the control groups in that there were only two participants having negative results. Thirty-two participants (52\%) made increases over $50 \mathrm{wpm}$. These results show that the treatment groups made greater increases, and that the two treatment groups' increases represent genuine learner progress.

\subsubsection{How do the speeds on the pre-test relate to the speeds on the post-test?}

This analysis is to compare the lowest and highest speeds in the pre-test and post-test. This will make sure that the increases the experimental groups made on other types of texts were the result of the treatment but not of calculation methods or unequal initial speeds. If the data show that the control groups and the experimental groups initially started at similar speeds but the experimental groups reached higher speeds on the post-test, the claim that they made the progress thanks to the speed reading treatment would be more convincing. Moreover, if the data show that there is a strong link between the initial speeds and final speeds, they would enhance the idea that the speed increases were real progress.

As can be seen in Table 4.15, in the pre-test, the four groups had similar average initial speeds with the highest being $120 \mathrm{wpm}$ and the lowest being $114 \mathrm{wpm}$. A comparison of all the 116 participants' results indicate that 78 participants (67\%) initially read at at least $100 \mathrm{wpm}$ or more, and $22 \%$ of them read at at least $150 \mathrm{wpm}$ and that none of the four groups started with particularly higher or lower average speeds. With regard to the posttest, there was a clear difference between the control groups and the treatment groups. A comparison of all participants' results showed that while participants in all four groups had 
their initial speeds evenly spread out in the speed range, most of the participants who had the highest scores on the post-test were in the treatment groups. The two treatment groups reached much higher average speeds on the post-test than the two control groups. Besides, among the 29 participants reaching the highest scores, only two participants were in the control groups and among the 29 participants who had the lowest scores, only four participants were from the treatment groups. Overall, the results show that all groups initially started at similar speeds but the treatment groups reached much higher speeds on the post-test. Thus, it was likely that most of the speed increases were an improvement as a result of the speed reading course.

Table 4.15 Means and standard deviations of initial speeds, final speeds and speed increases on other types of texts for all groups

\begin{tabular}{llcccc}
\hline & & Group A & Group B & Group C & Group D \\
\hline \multirow{2}{*}{ Pre-test } & Mean & 118.87 & 119.73 & 118.96 & 113.83 \\
& SD & 34.95 & 39.62 & 26.12 & 30.72 \\
\hline \multirow{2}{*}{ Post-test } & Mean & 165.03 & 170.17 & 129.42 & 133.48 \\
& SD & 36.75 & 34.62 & 20.51 & 27.19 \\
\multirow{2}{*}{ Increase } & Mean & 46.16 & 50.43 & 10.46 & 19.65 \\
& SD & 27.34 & 24.28 & 29.60 & 27.37 \\
\hline
\end{tabular}

The participants' initial speeds were also arranged in order from the biggest to the smallest and compared with their final speeds to see if participants with higher speeds on the pretest also had higher speeds on the post-test. In Table 4.16, each participant's data are presented in three columns, the first of which indicates the student, the second initial speed, and the third final speed. For example, participants B20 had an initial speed of 198 on the pre-test and a speed of $201 \mathrm{wpm}$ on the post-test. All participants were put in four groups. The first group's initial speeds ranged from 144 to $198 \mathrm{wpm}$. The second group's initial speeds ranged from 119 to $143 \mathrm{wpm}$. The third group consisted of participants whose initial speeds ranged from $93 \mathrm{wpm}$ to $118 \mathrm{wpm}$. The last group were the ones with the slowest initial speeds. It was found that there was a strong relationship between the initial speeds and final speeds. The higher average initial speed a group had, the higher average final speed that group made. Conversely, the results indicate that the higher average initial speed a group had, the smaller average increase they made. The first group with the highest average initial speed made a $22 \mathrm{wpm}$ increase. The second group made a 24 wpm increase. 
The third group ranked the next with an increase of $36 \mathrm{wpm}$. The last group made the greatest increase with $48 \mathrm{wpm}$. These findings are in agreement with the ones in the first experiment and demonstrate that the speed increases on other types of texts were real progress.

Table 4.16 Initial speeds (Pre) and final speeds (Post) on other types of text for all participants $(P)$

\begin{tabular}{|c|c|c|c|c|c|c|c|c|c|c|c|}
\hline $\mathbf{P}$ & Pre & Post & $\mathbf{P}$ & Pre & Post & $\mathbf{P}$ & Pre & Post & $\mathbf{P}$ & Pre & Post \\
\hline B20 & 198 & 201 & C6 & 143 & 122 & $\mathrm{C} 21$ & 118 & 135 & D1 & 92 & 123 \\
\hline B12 & 183 & 185 & D26 & 141 & 122 & $\mathrm{C} 26$ & 116 & 146 & A31 & 91 & 159 \\
\hline B23 & 181 & 200 & $\mathrm{C} 12$ & 138 & 138 & A20 & 114 & 186 & A16 & 90 & 177 \\
\hline A15 & 177 & 237 & B7 & 136 & 153 & B15 & 112 & 195 & $\mathrm{C} 1$ & 89 & 122 \\
\hline D27 & 174 & 143 & C9 & 135 & 127 & C15 & 112 & 125 & B9 & 87 & 161 \\
\hline A7 & 174 & 180 & $\mathrm{C} 2$ & 134 & 132 & C3 & 111 & 119 & D6 & 86 & 108 \\
\hline A13 & 173 & 194 & C8 & 134 & 164 & A17 & 111 & 178 & $\mathrm{C} 22$ & 85 & 111 \\
\hline $\mathrm{C} 16$ & 169 & 151 & D7 & 134 & 177 & D29 & 108 & 134 & C17 & 85 & 116 \\
\hline A3 & 167 & 238 & A5 & 132 & 188 & B1 & 108 & 141 & D10 & 84 & 117 \\
\hline A6 & 165 & 160 & B18 & 132 & 180 & B5 & 107 & 149 & D12 & 84 & 129 \\
\hline $\mathrm{C} 13$ & 163 & 146 & A25 & 130 & 169 & C11 & 107 & 128 & B27 & 84 & 129 \\
\hline A14 & 163 & 171 & A 21 & 130 & 189 & A27 & 107 & 161 & A1 & 83 & 137 \\
\hline B21 & 161 & 190 & A19 & 129 & 121 & C5 & 107 & 109 & B26 & 83 & 105 \\
\hline $\mathrm{C} 14$ & 160 & 143 & B14 & 129 & 184 & C19 & 106 & 137 & D3 & 79 & 180 \\
\hline D5 & 159 & 161 & $\mathrm{C} 4$ & 127 & 117 & A26 & 105 & 127 & A10 & 78 & 126 \\
\hline D28 & 158 & 162 & D19 & 127 & 125 & $\mathrm{C} 10$ & 103 & 122 & $\mathrm{D} 23$ & 76 & 84 \\
\hline A 24 & 157 & 222 & B6 & 127 & 182 & D20 & 103 & 156 & D11 & 76 & 99 \\
\hline B22 & 157 & 182 & B2 & 127 & 194 & A4 & 103 & 131 & B11 & 76 & 109 \\
\hline D13 & 157 & 171 & B13 & 126 & 177 & D9 & 102 & 137 & A28 & 76 & 168 \\
\hline B16 & 155 & 217 & D4 & 125 & 162 & A2 & 101 & 116 & A23 & 73 & 104 \\
\hline B10 & 153 & 202 & A18 & 124 & 194 & D2 & 98 & 126 & D8 & 71 & 81 \\
\hline $\mathrm{C} 23$ & 153 & 192 & D15 & 124 & 138 & B4 & 98 & 150 & D22 & 71 & 84 \\
\hline A8 & 153 & 235 & A11 & 124 & 171 & B17 & 98 & 151 & B19 & 67 & 139 \\
\hline D21 & 152 & 131 & A 29 & 123 & 146 & D18 & 97 & 155 & C20 & 67 & 100 \\
\hline B3 & 150 & 222 & C18 & 123 & 137 & A12 & 96 & 126 & A22 & 66 & 132 \\
\hline B28 & 149 & 214 & A9 & 121 & 150 & C24 & 94 & 95 & B25 & 65 & 147 \\
\hline B29 & 148 & 228 & C7 & 121 & 107 & D14 & 94 & 111 & B8 & 55 & 104 \\
\hline D17 & 145 & 149 & $\mathrm{D} 25$ & 121 & 123 & B30 & 94 & 179 & A30 & 49 & 123 \\
\hline \multirow[t]{3}{*}{ D16 } & 144 & 124 & D24 & 119 & 159 & C25 & 93 & 124 & B24 & 46 & 135 \\
\hline & 162 & 184 & & 129 & 153 & & 104 & 140 & & 76 & 124 \\
\hline & \multicolumn{3}{|c|}{ Difference: 22} & Diffe & e: 24 & & Diffe & e: 36 & & Diff & ce: 48 \\
\hline
\end{tabular}




\subsubsection{How does the in-course speed increase relate to the speed increase on other}

texts?

This analysis looks at the relationship between the speed increases in the course and the speed increases on other types of texts. If the data show that the two kinds of speed increases have a strong relationship, it is possible to say with more certainty that the increases on the other types of texts were a real transfer of speed improvement rather than just a coincidence or erratic learner behaviour. The in-course increases were measured using the average method, which took the average score on the last three texts minus the average score on the first three texts. The increases on other types of texts were measured by taking the speed on the pre-test away from the speed on the post-test.

Table 4.17 In-course increases (SRI) and increases on other texts (OTI) by participants $(P)$ in the treatment groups

\begin{tabular}{cccccccccccc}
\hline $\mathbf{P}$ & SRI & OTI & P & SRI & OTI & P & SRI & OTI & P & SRI & OTI \\
\hline A20 & 191 & 72 & B18 & 81 & 48 & A31 & 49 & 21 & B21 & 29 & 29 \\
B1 & 124 & 33 & B30 & 76 & 85 & B27 & 49 & 45 & B24 & 29 & 25 \\
B22 & 116 & 88 & A21 & 75 & 58 & A14 & 46 & 9 & B28 & 28 & 65 \\
A4 & 100 & 71 & A7 & 71 & 68 & A5 & 45 & 56 & A29 & 26 & 23 \\
B17 & 100 & 53 & B29 & 69 & 80 & B8 & 43 & 49 & B10 & 26 & 49 \\
A11 & 96 & 47 & B15 & 68 & 83 & B9 & 41 & 74 & B16 & 25 & 62 \\
A16 & 89 & 87 & A19 & 65 & 29 & B20 & 40 & 3 & B5 & 21 & 42 \\
A18 & 88 & 70 & A12 & 62 & 30 & B19 & 39 & 72 & A1 & 19 & 15 \\
B14 & 88 & 56 & A13 & 59 & 68 & B4 & 39 & 52 & A30 & 19 & 73 \\
A27 & 87 & 54 & B6 & 59 & 56 & A15 & 37 & 61 & B25 & 18 & 19 \\
A24 & 85 & 64 & A25 & 55 & 39 & B7 & 36 & 18 & B11 & 15 & 33 \\
A8 & 84 & 82 & B3 & 55 & 72 & B12 & 35 & 2 & A17 & 14 & 6 \\
B23 & 84 & 93 & A10 & 54 & 48 & A6 & 32 & 92 & A23 & 14 & 31 \\
A2 & 82 & 54 & B13 & 54 & 52 & B26 & 31 & 22 & B2 & 9 & 68 \\
A22 & 82 & 65 & A26 & 52 & 23 & A3 & 30 & 28 & A9 & -18 & -8 \\
& & & & & & & & & A28 & -23 & -6 \\
\hline
\end{tabular}

Table 4.17 compares the results for four groups of participants. The data were arranged according to the in-course increases. The first group's results are presented in the first three columns on the left with the in-course increases ranging from $82 \mathrm{wpm}$ to $191 \mathrm{wpm}$. The second group consisted of the participants with in-course increases ranging from $52 \mathrm{wpm}$ to $81 \mathrm{wpm}$. The third group's results are presented in the next three columns with their in- 
course increases ranging from $30 \mathrm{wpm}$ to $49 \mathrm{wpm}$. The last group were the participants whose in-course increases were from minus $23 \mathrm{wpm}$ to $29 \mathrm{wpm}$. The data indicate that the in-course increases highly correlated with the increases on other types of texts. The greater in-course increases a group made, the bigger increases on other texts they had. This result shows that the speed increases on other types of texts more likely resulted from the speed improvement in the course. These findings are similar to the ones found in the first experiment; hence, the results of the two experiments validate each other.

\subsubsection{Did the participants get higher scores on a certain text in the pre-test and post- test?}

The results of speed improvement transfer from the course to other types of texts may not be reliable if the texts used in the pre-test and post-test were not equally difficult. In both tests, the participants read a text and answered ten comprehension questions. The computer program recorded the time the participants spent on reading the text. Two texts were utilized for the tests. Each participant was required to read either text A or text B in the pre-test and the other text in the post-test. It was possible that certain participants might have had very big or small increases just because they read a more difficult text in the pretest and an easier text in the post-test or vice-versa. We tried to eliminate this possibility by assigning approximately half of the participants in each of the four groups to read text $\mathrm{A}$ in the pre-test and text $\mathrm{B}$ in the post-test and the other half to read text $\mathrm{B}$ in the pre-test and text $\mathrm{A}$ in the post-test. However, individuals' results might still have been distorted if the two texts were not equally difficult. Although this issue has been examined in the first experiment with the same texts, it is still worth comparing the increases by the participants who read text $\mathrm{A}$ on the pre-test and text $\mathrm{B}$ on the post-test and the increases by the participants who did the other way around to see if there was any big difference between them. Their initial speeds and final speeds were also compared.

As shown in Table 4.18, in both pre-test and post-test, no noticeable difference was found for the participants who read text $\mathrm{A}$ and the participants who read text $\mathrm{B}$. This applies to both participants in each group and participants from all four groups. For example, in group A, participants who read text A had average speeds of 111 on the pre-test and 172 wpm on the post-test. Participants who read text B had average speeds of $126 \mathrm{wpm}$ on the pre-test and $157 \mathrm{wpm}$ on the post-test. It can therefore be claimed that the texts had no 
effect on the participants' reading rate and speed improvement. This continues the validity of the result for the speed improvement on other types of texts.

Table 4.18 Initial speeds, final speeds and increases on other types of texts by participants following the two orders of text administration

\begin{tabular}{llccccc}
\hline & & Group A & Group B & Group C & Group D & All groups \\
\hline Pre-test (text A) & Mean & 111.12 & 128.51 & 123.25 & 117.43 & 119.56 \\
& SD & 22.28 & 29.67 & 23.75 & 31.81 & 27.38 \\
\cline { 2 - 7 } & Mean & 157.23 & 178.52 & 130.36 & 136.04 & 151.25 \\
Post-test (text B) & SD & 31.95 & 31.68 & 17.77 & 29.02 & 33.74 \\
\hline Pre-test (text B) & Mean & 125.68 & 111.29 & 116.38 & 110.98 & 116.37 \\
& SD & 43.28 & 46.85 & 28.70 & 30.38 & 38.18 \\
\cline { 2 - 6 } Post-test (text A) & Mean & 171.57 & 162.48 & 129.31 & 129.65 & 149.63 \\
& SD & 40.41 & 36.34 & 23.63 & 25.78 & 37.37 \\
\hline
\end{tabular}

\subsubsection{Could the participants maintain their comprehension as they increased their reading speed?}

The section explores the relationship between reading speed improvement and comprehension. It was found in both experiments that in the course, most participants could keep their comprehension accuracy at the appropriate level (around 70\% accuracy) as their reading speed improved. However, in the first experiment, no data on comprehension scores in the pre-tests and post-tests were collected. Thus, it was worthwhile examining this issue in the present experiment. If the data showed that the participants' comprehension did not decrease, it would further confirm that readers can increase their reading rate without reducing their comprehension. It would also be clearer that the increases the participants made on other types of texts were a real rauding speed improvement rather than just looking at the words without comprehending the texts. The data for this analysis were collected from the tests on other types of texts in the pre-test and post-test, in which the participants had to answer ten comprehension questions.

In the present experiment, comprehension accuracy was measured by counting the number of correct answers out of the ten comprehension questions that accompanied each text. The participants' results were classified into three types. The first group were the ones who increased their comprehension level (Increase group). The second group consisted of 
participants who kept their comprehension at the same level (Consistent group). The third group had their comprehension scores decrease (Decrease group). Table 4.19 shows the numbers of participants in each of the three groups, their initial average comprehension scores, initial average speed, final average comprehension scores, final average speeds, and the differences each group had between their initial and final figures. For instance, with respect to the increase group, their average initial comprehension score was 4.81 out of 10 and in the post-test they had an average score of 7.36, thus making an average increase of 2.55. These participants' average initial speed was $116 \mathrm{wpm}$ and they made a $44 \mathrm{wpm}$ increase in the post-test.

Table 4.19 Means and standard deviations of initial comprehension scores (Initial CS), post-test comprehension scores (Final CS), initial speeds (IS) and final speeds (FS) for three subgroups

\begin{tabular}{lclcccccc}
\hline Group & $n$ & & Initial CS & Final CS & Difference & IS & FS & Difference \\
\hline Improve & \multirow{2}{*}{ group } & Mean & 4.81 & 7.36 & 2.56 & 116.42 & 160.28 & 43.86 \\
& & SD & 1.73 & 0.91 & 1.73 & 33.75 & 36.52 & 27.39 \\
\hline Consistent & \multirow{2}{*}{24} & Mean & 6.67 & 6.67 & 0 & 129.58 & 138.67 & 9.09 \\
group & & SD & 1.81 & 1.81 & 0 & 33.37 & 29.72 & 25.82 \\
\hline Decrease & \multirow{2}{*}{20} & Mean & 6.25 & 4.6 & -1.65 & 109.12 & 131.09 & 21.97 \\
group & & SD & 1.12 & 1.39 & 0.93 & 27.23 & 25.71 & 22.63 \\
\hline
\end{tabular}

Overall, the data indicate that 72 out 116 participants increased their comprehension accuracy, 24 kept it at the same level and 20 had a decrease. The increase group had the lowest average score on the pre-test but reached the highest average score on the post-test. This group also made the greatest increase in reading speed. The consistent group had the highest average score on the pre-test but did not make any improvement on the post-test. This group made the least improvement in reading rate although their initial speed was the highest. The decrease group had a similar initial comprehension score to the consistent group, but failed to maintain it. This group made a better average increase in speed than the consistent group. These results suggest that the participants who made the greatest improvement in reading speed made the most improvement in comprehension accuracy and that for readers who start at low reading rates, success in reading at faster speeds does not cause a comprehension decrease. 
A comparison of individual participants' speeds and comprehension scores showed that among the 16 participants whose speeds decreased, only five participants had their comprehension score increase. On the other hand, among the 100 participants who made progress in reading speed, only 17 participants had their comprehension score drop, 67 participants had their comprehension score increase, and 16 participants had their comprehension score remain at the same level. These results agree with the results drawn from analysing the data at group level.

A comparison (see Table 4.20) between the control groups and treatment group showed that the treatment groups outperformed the control groups. While most of the participants in the treatment groups increased their comprehension accuracy, most of the participants in the control groups did not increase their comprehension accuracy. This result suggests two interpretations. First, the speed reading course helped the participants to maintain their comprehension while speeding up, thus most of the participants who followed the course did not have to trade comprehension for speed. Second, there may be a link between comprehension and reading speed improvement in that the participants who greatly increased their speed tended to improve their comprehension accuracy while it was less likely that participants who marginally increased their speeds would improve their comprehension accuracy.

Table 4.20 Comparison of comprehension improvement for the control groups and the treatment groups

\begin{tabular}{lcccc}
\hline & Group A & Group B & Group C & Group D \\
\hline Improve group & $27(87 \%)$ & $26(87 \%)$ & $10(39 \%)$ & $9(31 \%)$ \\
Consistent group & $2(6 \%)$ & $2(7 \%)$ & $11(42 \%)$ & $9(31 \%)$ \\
Decrease group & $2(6 \%)$ & $2(7 \%)$ & $5(19 \%)$ & $11(38 \%)$ \\
\hline
\end{tabular}

A repeated measures ANOVA was carried out on the pre-test (initial score) and post-test (final score) data. The repeated-measures factor was time (pre-test vs. post-test) and the between-subjects factor was group.

The results are shown in Table 4.21 below: 
Table 4.21 Comparison of comprehension improvement for the control groups and the treatment groups

\begin{tabular}{lllllllll}
\hline & & \multicolumn{3}{c}{ Group } & \multicolumn{3}{c}{ Analysis of variance } \\
\cline { 3 - 7 } & & Group A & Group B & Group C & Group D & $\begin{array}{c}\text { Group } \\
\mathrm{F}(3,112)\end{array}$ & $\begin{array}{c}\text { Time } \\
\mathrm{F}(1,112)\end{array}$ & $\begin{array}{c}\text { Interaction } \\
\mathrm{F}(3,112)\end{array}$ \\
\hline Pre-test & Mean & 5.10 & 5.17 & 5.50 & 6.14 & & & \\
& SD & 1.66 & 1.51 & 2.39 & 1.83 & & & \\
\hline Post-test & Mean & 6.94 & 7.20 & 6.62 & 6.17 & & & \\
& SD & 1.03 & 1.45 & 2.00 & 1.69 & & & \\
\hline$* * \mathrm{p}<.01$. & & & & & & & & \\
\hline
\end{tabular}

The results showed that there was a general gain for all groups from pre to post-test, $\eta^{2}$ $=.266$. The group effect was not significant. The interaction (group $\mathrm{x}$ time) analysis indicated that the gains from pre-test to post-test for the two treatment groups were significantly greater than for the control groups, $\eta^{2}=.126$. Figure 1 illustrates that the treatment groups made a significant improvement in comprehension while group $\mathrm{C}$ control made a smaller increase. Group D control's comprehension level almost remained the same from the pre-test to the post-test.

Figure 4.3 Estimated marginal means of comprehension increases for all groups

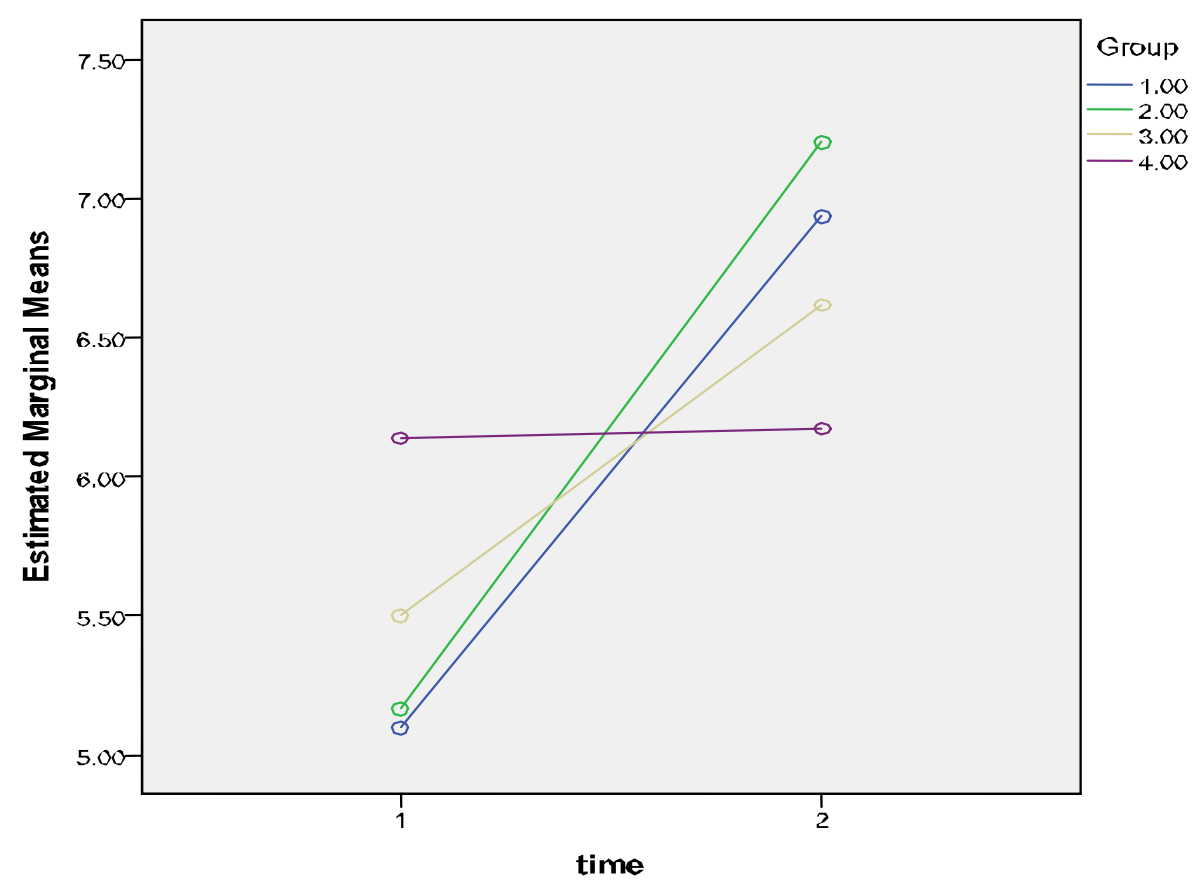


To determine the nature of the interaction effect, a one way ANOVA compared the gain scores (pre-test to post-test) of the four groups. The results showed the mean scores of the four groups were significantly different, $F(3,112)=5.38, \mathrm{p}=.002, \eta^{2}=.126$.

The mean gain score for group A comprehension increase was $1.84(\mathrm{~N}=31, \mathrm{SD}=1.95)$. The mean gain score for group B comprehension increase was $2.03(\mathrm{~N}=30, \mathrm{SD}=1.90)$. The mean gain score for group $\mathrm{C}$ control was $1.12(\mathrm{~N}=26, \mathrm{SD}=2.88)$. The mean gain score for group D control was $0.35(\mathrm{~N}=29, \mathrm{SD}=1.66)$.

Pairwise comparisons using the Bonferroni adjustment for multiple comparisons showed a significant difference between group A and group $\mathrm{D}(\mathrm{p}=.008)$ and between group $\mathrm{B}$ and group D $(\mathrm{p}=.003)$. However, there was not a significant difference between group A and group $C(p=1.000)$ and between group $B$ and group $C(p=.652)$. There was no significant difference between groups $\mathrm{C}$ and $\mathrm{D}(\mathrm{p}=.369)$.

These results suggested that the treatment groups could maintain or increase their comprehension while improving their reading speed and their gains were significantly greater than group D, who did not follow the English program at the university. The fact that the two treatment groups did not make a significantly bigger increase in comprehension than group $\mathrm{C}$, who followed the usual English program, may have something to do with the modest speed increase that this control group made. While group D made an increase of $20 \mathrm{wpm}$, group C made an increase of only $11 \mathrm{wpm}$. Perhaps without speed training, group D and group C suffered from a trade-off relationship between comprehension and speed in which a bigger increase in speed led to a smaller increase in comprehension. It was probable that group $\mathrm{C}$ could not increase their speed as much as group D because they were paying more of their attentional resources to comprehend the text.

Overall, these results suggest a positive spinoff for speed-reading training and comprehension because groups $\mathrm{A}$ and $\mathrm{B}$ were able to read the transfer texts faster than groups $\mathrm{C}$ and $\mathrm{D}$, yet still achieved similar comprehension to group $\mathrm{C}$ who were students in the same language program, and achieved greater comprehension than group D. 


\subsubsection{How did the participants' speeds change throughout a text?}

While past research has explored what really happens in readers' minds when they read, Except Nell (1988)'s finding that readers substantially decrease their speed when they are really engaged, no data were found on how the reader's speed changes throughout the text. This analysis examines the participants' speed change in the four sections of each of the texts they read in the pre-test and post-test. As mentioned earlier, each of the texts used for the tests was divided into four parts, which appeared one after each other on the computer screen. The participants were asked to read the text section by section, and after finishing each section, they clicked the "next" button to read the next one. The computer program recorded the time they spent on each section. The numbers of words in the four sections were similar at around 179 words.

Table 4.22 Reading speeds on four sections of the texts in the pre-test and post-test for all groups

\begin{tabular}{llcccccccc}
\hline & \multicolumn{3}{c}{ Pre-test } & \multicolumn{5}{c}{ Post-test } \\
\hline Group & & S1 & S2 & S3 & S4 & S1 & S2 & S3 & S4 \\
\hline \multirow{2}{*}{ Group A } & Mean & 105.35 & 101.87 & 127.03 & 140.94 & 162.45 & 155.74 & 169.55 & 171.84 \\
& SD & 51.74 & 42.28 & 57.59 & 54.78 & 43.40 & 53.58 & 37.64 & 57.11 \\
\hline \multirow{2}{*}{ Group B } & Mean & 97.07 & 11470 & 137.63 & 128.97 & 158.37 & 173.00 & 172.40 & 176.80 \\
& SD & 47.75 & 41.51 & 63.64 & 45.86 & 41.18 & 45.84 & 40.46 & 43.99 \\
\hline \multirow{2}{*}{ Group C } & Mean & 98.56 & 113.19 & 128.59 & 134.89 & 119.19 & 124.56 & 122.15 & 134.93 \\
& SD & 34.35 & 23.81 & 45.92 & 37.85 & 26.12 & 36.15 & 25.12 & 33.15 \\
\hline \multirow{2}{*}{ Group D } & Mean & 100.77 & 106.13 & 121.57 & 126.00 & 132.83 & 134.00 & 128.70 & 140.67 \\
& SD & 34.68 & 34.16 & 33.84 & 39.49 & 31.09 & 30.55 & 38.98 & 32.99 \\
\hline
\end{tabular}

Table 4.22 presents the speeds on the four sections of the texts in the pre-test and post-test for all groups. For example, on the pre-test group A had an average speed of $105 \mathrm{wpm}$ for section 1, $102 \mathrm{wpm}$ for section 2, $127 \mathrm{wpm}$ for section 3 and $141 \mathrm{wpm}$ for section 4 . On the post-test, group A had an average speed of $162 \mathrm{wpm}$ for section 1, $156 \mathrm{wpm}$ for section 2, $170 \mathrm{wpm}$ for section 3 and $172 \mathrm{wpm}$ for section 4. Overall, on both the pre-test and post-test, the data showed that the four groups followed the same trend in that their speeds on the first two sections were slower than their speeds on the last two sections. We can see a similar pattern of increases across the four sections, but for six of the eight sequences (four pre-test sequences and four post-test sequences) there was one score of the four that went against the pattern. Taken as a whole, all groups had the tendency to read faster as 
they moved through the texts. This is a bit like acceleration until a comfortable speed is reached. This suggests that texts used to measure reading speed need to be long enough for learners to reach their optimum speed.

Since the findings at group level may not be extrapolated to all participants, an examination into each participant's results was also carried out to determine how many of them had the same pattern of speed change. In order to do this, four patterns of speed change were defined: gradual decrease, gradual increase, partial pattern, and fluctuations. The gradual increase pattern is the one where the speeds on the successive sections are always faster than the speed on the previous section. The gradual decrease pattern is the one where the speeds on the successive sections are always slower than the speed on the previous section. The partial pattern contains three scores showing a decrease pattern or an increase pattern but one of the scores does not follow the pattern. The three scores showing a pattern need not be in a row. The fluctuation pattern contains both increases and decreases throughout the text. As shown in Table 4.23, in the pre-test, 28 out of 116 participants had the gradual increase pattern. These participants always had the speed on the next section higher than the speed on the previous section. Three participants had the gradual decrease pattern. Their speed on the previous part was always higher than that on the next part of the text. Fifty-one participants had the partial pattern. These participants had their speeds mainly decrease or increase but one of the four scores stood out from the pattern. Among these 51 participants, only seven had their speeds largely decrease through the text. The other 44 participants had their speeds largely increase through the text. The other 34 participants had fluctuating speeds throughout the text. In the post-test, only 10 participants had the gradual increase pattern while four other participants had the gradual decrease pattern. On the other hand, 52 participants had the partial pattern and the other 50 participants had the fluctuation pattern. Among the 52 participants with the partial pattern, only two had their speeds largely decrease. The other 50 participants had their speeds largely increase through the texts. A comparison of individual participants' speeds on the pre-test and post-test showed that only two participants had the gradual increase pattern on both tests. Eight participants had the fluctuation pattern on both tests. Nineteen participants had the partial pattern on both tests. None of the participants repeated the gradual decrease on the post-test. In total, only 29 out of 116 participants kept the same pattern on both tests. These results demonstrate that the participants were unlikely to follow the same pattern of speed change when reading a text, and that the gradual increase and gradual decrease patterns were far less dominant than the partial and fluctuation patterns. Besides, taking 
together the gradual increase and partial increase, we can see that there were more participants reading with increasing speeds than the participants reading with decreasing or fluctuating speeds through the text.

Table 4.23 Speed change patterns in four sections of the texts in the pre-test and post-test for all participants

\begin{tabular}{lcccc}
\hline & Gradual increase & Gradual decrease & Partial pattern & Fluctuations \\
\hline Pre-test & $28(24 \%)$ & $3(3 \%)$ & $51(44 \%)$ & $34(29 \%)$ \\
Post-test & $10(8.5 \%)$ & $4(3.5 \%)$ & $52(45 \%)$ & $50(43 \%)$ \\
\hline
\end{tabular}

An analysis of how the participants read the two halves of a text was also made. The results were derived from comparing the average speed on the first two sections of a text with the average speed on the second two sections of the text. In this measurement, only two speed change patterns were involved: the increase pattern and the decrease pattern. It was found in the pre-test, 97 participants had the increase pattern and 19 participants had the decrease pattern. Similarly, in the post-test, 66 participants had the increase pattern while 50 participants had the decrease pattern (see Table 4.24).

Table 4.24 Speed change patterns in two halves of the texts on the pre-test and post-test for all participants

\begin{tabular}{lcc}
\hline & Gradual increase & Gradual decrease \\
\hline Pre-test & $97(84 \%)$ & $19(16 \%)$ \\
Post-test & $66(57 \%)$ & $50(43 \%)$ \\
\hline
\end{tabular}

To sum up, it was found that although most of the participants had their reading rates fluctuate throughout the text, and there is a strong tendency that the participants read faster on the second half of the text.

\subsubsection{Did the English program affect the speed improvement on other types of texts?}

In the first experiment it remained uncertain if the English program had effects on the transfer of speed increases to other texts. The control group, who also followed the same English program at university, made an average increase of $56 \mathrm{wpm}$, which is similar to the average increase made by one of the treatment groups. Therefore in this experiment, two control groups were set up. Group C followed the usual English program while group 
D did not follow this program but attended an English course at a language centre. This was done to see if the two control groups' results would greatly differ with respect to the speed increases on other types of texts.

Table 4.25 Comparison of performance on other types of texts for group C and group D

\begin{tabular}{lccc}
\hline & & Group C & Group D \\
\hline Speed increase & Mean & 10.61 & 19.65 \\
& $\mathrm{SD}$ & 29.60 & 27.37 \\
\hline $\mathrm{N}^{\circ}$ of participants with a negative result & $9 / 26$ & $5 / 29$ \\
\hline $\mathrm{N}^{\mathrm{o}}$ of participants with increases over 50 wpm & $0 / 26$ & $3 / 29$ \\
\hline $\mathrm{N}^{\mathrm{o}}$ of participants with increases from 20 wpm to 50 wpm & $10 / 26$ & $10 / 29$ \\
\hline
\end{tabular}

As can be seen from Table 4.25, group C made an average increase of $11 \mathrm{wpm}$ while group $\mathrm{D}$ made an average increase of $20 \mathrm{wpm}$. Nine participants in group $\mathrm{C}$ and five participants in group D had negative results. Three participants in group D but none in group C had increases of over $50 \mathrm{wpm}$. The same number of participants in each group made increases from $20 \mathrm{wpm}$ to $50 \mathrm{wpm}$. A one-way ANOVA test was conducted to compare the two groups. The mean scores of the two groups were not significantly different, $F(1,53)=1.43$, $p=0.237$. It seems therefore doubtful that the English program at the university affected the participants' performance on other types of texts. This finding provides support to the idea that the speed increases on other types of texts that the participants in the two experiments made mainly resulted from the reading rate improvement the course.

So far, we have looked at the speed increases in the course and on other types of texts. The results support the idea that speed reading courses are beneficial not only in that they help learners to improve their reading rates in the course but also in that the speed improvement transfers to other types of texts. Since the speed improvement is sustainable, it is worthwhile practicing to achieve it. The results of the second experiment reported so far have been largely the result of a replication of the first experiment with some improvements in administration and measurement. They strongly confirm the results of the first experiment. The following results are from measures that were not used in the first experiment and were included in the present experiment to see the wider effects of a speed reading course. In what immediately follows, the effect, if there is any, of the in-course speed increases on oral reading rate will be explored. 


\subsubsection{The effect of the speed reading course on oral reading rate}

An important goal of the second experiment is to determine the effect of silent reading speed development on oral reading rate. As mentioned earlier, in this experiment, oral reading rate was measured by counting the number of syllables read in one minute. This section provides answers to such issues as the amount of oral reading speed improvement, the difference between the treatment groups' results and control groups' results, and the relationship between silent reading speed improvement and oral reading improvement.

\subsubsection{Did the participants' oral reading rates increase?}

The tests on oral reading speed were done on the computer. The participants were randomly assigned to read either text $\mathrm{A}$ or text $\mathrm{B}$. In order to avoid text bias, we assigned approximately half of them to read text $\mathrm{A}$ and the other half to read text $\mathrm{B}$ in the pre-test and the other way around in the post-test. The two texts were taken from graded readers and were not the same texts used to measure silent reading speed. Both texts contain 194 words and 294 syllables.

Table 4.26 Increases (syllables per minute) in oral reading for all groups

\begin{tabular}{lcccc}
\hline & Group A & Group B & Group D & Group C \\
\hline$n$ & 31 & 30 & 29 & 26 \\
Mean & 8.81 & 8.07 & 3.21 & 1.31 \\
SD & 11.99 & 11.79 & 10.10 & 11.48 \\
\hline
\end{tabular}

Table 4.27 Comparisons of performance on oral reading tests using the syllables per minute calculation for all groups

\begin{tabular}{lcccc}
\hline & Group A & Group B & Group D & Group C \\
\hline $\mathrm{N}^{\circ}$ of participants with improvement & $24(77 \%)$ & $23(77 \%)$ & $20(69 \%)$ & $15(58 \%)$ \\
\hline $\mathrm{N}^{\circ}$ of participants with increases over $20 \mathrm{spm}$ & $5(16 \%)$ & $5(17 \%)$ & $2(7 \%)$ & $2(8 \%)$ \\
\hline $\mathrm{N}^{\circ}$ of participants with no improvement & $7(23 \%)$ & $7(23 \%)$ & $9(31 \%)$ & $11(42 \%)$ \\
\hline
\end{tabular}

The data (see tables 4.26, 4.27, and appendix V) show that none of the four groups made substantial increases in oral reading rate. The best group increased their average speed by only 9 spm. Eighty-two out of 116 participants (71\%) had positive results, but among these 
progress makers, only 14 made increases over $20 \mathrm{spm}$. The rest of them made minimal increases. Thirty-four participants made no improvement.

A comparison of the two treatment groups showed that there were no striking differences between the two groups. Their average increases were similar. About $84 \%$ of group A and $77 \%$ of group B made improvement. Five participants in group A and seven participants in group B had a decrease. A comparison of the two control groups found no remarkable differences between the two groups. Their average increases were similar. Similar numbers of participants in two groups had negative results. These results suggest the usual English program and the consultation sessions did not affect the participants' oral reading rate improvement.

In order to confirm that the absence of substantial improvement in oral reading rate was not due to factors such as improper calculations, text effect, ceiling effect, unusually low scores, the data were reanalysed in various ways. First, the words per minute calculating method was used to see if the syllables per minute calculating method yielded unreliable results. Second, the participants' initial and final speeds were examined to see if the participants had reached a speed ceiling before the treatment. Third, the increases and speeds by participants who read text $\mathrm{A}$ in the pre-test and text $\mathrm{B}$ in the post-test were compared with participants who did them the other way around to see if there was a text effect. Fourth, an investigation into participants who made no improvement was made in order to see if the negative results by those participants affected the whole groups' results.

Table 4.28 Comparisons of performance on oral reading tests using the words per minute calculation for all groups

\begin{tabular}{lccccc}
\hline & & Group A & Group B & Group D & Group C \\
\hline Increase & Mean & 5.81 & 5.32 & 2.18 & 0.94 \\
& $\mathrm{SD}$ & $(7.93)$ & $(7.68)$ & $(6.60)$ & $(7.53)$ \\
\hline $\mathrm{N}^{\circ}$ of participants with improvement & & $24(77 \%)$ & $23(77 \%)$ & $20(69 \%)$ & $15(58 \%)$ \\
\hline $\mathrm{N}^{\circ}$ of participants with increases over 20 wpm & $2(6 \%)$ & $2(7 \%)$ & $1(4 \%)$ & $0(0 \%)$ \\
\hline $\mathrm{N}^{\circ}$ of participants with no improvement & & $7(23 \%)$ & $7(23 \%)$ & $9(31 \%)$ & $11(42 \%)$ \\
\hline
\end{tabular}

In the first place, to eliminate the possibility that the results were distorted by an inappropriate measuring method, we also tried measuring the participants' speed increases using the words per minute calculation. The data (see Table 4.28) showed similar patterns 
to the syllables per minute calculation method and the groups' figures were lower as there were fewer words than syllables in the texts. This result demonstrates that the calculation method is not a factor affecting the groups' results.

In order to see if the participants did not greatly improve their reading rate because they had reached the ceiling of normal oral reading before they started to receive the treatment, we looked at their initial speeds and final speeds.

Table 4.29 Means and standard deviations of initial speeds and final speeds (in syllables per minute and words per minute) in oral reading for all groups

\begin{tabular}{|c|c|c|c|c|c|c|}
\hline & & & Group A & Group B & Group D & Group C \\
\hline \multirow{4}{*}{$\begin{array}{l}\text { Initial } \\
\text { speed }\end{array}$} & spm & Mean & 170.81 & 176.87 & 174.03 & 176.73 \\
\hline & & SD & 25.03 & 28.47 & 28.09 & 26.12 \\
\hline & wpm & Mean & 112.71 & 116.71 & 114.84 & 116.62 \\
\hline & & SD & 16.51 & 18.78 & 18.54 & 17.23 \\
\hline \multirow{4}{*}{$\begin{array}{l}\text { Final } \\
\text { speed }\end{array}$} & spm & Mean & 179.61 & 184.93 & 177.34 & 178.15 \\
\hline & & SD & 27.22 & 29.68 & 25.63 & 21.51 \\
\hline & wpm & Mean & 118.52 & 122.03 & 117.02 & 117.56 \\
\hline & & SD & 17.96 & 19.59 & 16.91 & 14.19 \\
\hline
\end{tabular}

The data in Table 4.29 show that none of the groups were near the ceiling level of normal oral reading of around $200 \mathrm{wpm}$ (Meyer \& Felton, 1999). Thus it is not possible to say that the participants did not increase their oral reading rate because they were already near the ceiling level of normal reading. However, as can be seen from Table 4.29, the participants' initial speeds were in the normal range of oral reading rates, which is from $100 \mathrm{wpm}$ to 200 wpm (Meyer \& Felton, 1999), thus it was less likely that they would make big increases. In silent reading, their initial speeds were below the normal range, giving them more chances to make great increases.

A comparison between the control groups and the treatment groups indicated that group B had the same initial speed as group D. Group A had a similar speed to group C with a 3 spm difference. This shows that it was not because of lower initial speeds that the treatment groups had bigger increases than the control groups. 
Table 4.30 Oral reading speeds (in syllables per minute) on the pre-test and post-test for the two orders of text administration

\begin{tabular}{|c|c|c|c|c|c|c|}
\hline & & & Group A & Group B & Group C & Group D \\
\hline \multirow{4}{*}{ Pre-test } & \multirow{2}{*}{ Text B } & Mean & 172.23 & 175.67 & 177.76 & 175.05 \\
\hline & & SD & 29.87 & 28.15 & 33.03 & 26.28 \\
\hline & \multirow{2}{*}{ Text A } & Mean & 170.47 & 177.91 & 175.12 & 173.23 \\
\hline & & SD & 21.79 & 28.15 & 15.83 & 30.57 \\
\hline \multirow{4}{*}{$\begin{array}{l}\text { Post- } \\
\text { test }\end{array}$} & \multirow{2}{*}{ Text A } & Mean & 179.67 & 183.59 & 176.73 & 177.71 \\
\hline & & SD & 29.30 & 33.06 & 24.89 & 20.75 \\
\hline & \multirow{2}{*}{ Text B } & Mean & 179.86 & 184.56 & 178.58 & 175.40 \\
\hline & & SD & 29.87 & 30.37 & 33.03 & 26.28 \\
\hline
\end{tabular}

To eliminate the possibility that some participants had small increases because they read the easier text in the pre-test and the more difficult text in the post-test, we compared the results by the participants who read text $\mathrm{A}$ in the pre-test and text $\mathrm{B}$ in the post-test with the results by the participants who did the opposite way. The data (see Table 4.30) showed that on both pre-test and post-test, within each of the groups, the difference between the two subgroups was no more than $3 \mathrm{wpm}$. The four groups did not have the same pattern in which the subgroup who read text A always had a higher average speed than the subgroup who read text B or vice versa. By contrast, both patterns were found. For example, in the pre-test, subgroup A who read text B had a higher average speed than subgroup who read text A but subgroup B who read text B had a lower average speed than subgroup B who read text A. These results demonstrate that the texts did not produce any distorting data on the speed improvement that the participants made.

Lastly, to see if unusually low or high scores affected the whole groups' results, we examined the increases that individual participants made. It should be noted that as the biggest average increase the groups could make was $9 \mathrm{spm}$, any scores that were more than $9 \mathrm{spm}$ lower or higher than all of the other scores in the same group would be considered as abnormally low or high scores. A preliminary analysis of the individual participants' results showed that none of the participants in the four groups had abnormally high or low results. Thus, it is not possible that the treatment group's increases were affected by individual abnormal scores. 
Although the results indicated that none of the four groups made substantial increases, a comparison between the two control groups and the two treatment groups showed that the treatment groups did better than the control groups. With respect to the treatment groups, of all the 61 participants, $77 \%$ made increases from $1 \mathrm{spm}$ to $37 \mathrm{spm}$. Ten participants made increases over $20 \mathrm{spm}$. However, 12 out of 61 participants (20\%) had negative results from $-1 \mathrm{spm}$ to $-14 \mathrm{spm}$. Two participants made no change. With respect to the control groups, of all the 55 participants, only $64 \%$ had positive results ranging from $1 \mathrm{spm}$ to $22 \mathrm{spm}$. There were 17 participants $(31 \%)$ having negative results and three participants making no improvement. Compared with the treatment groups, the control groups had fewer participants with increases over $20 \mathrm{spm}$ and more participants with negative results. Using one-way ANOVA to compare the groups' mean scores, we found that the mean increases of the four groups were significantly different, $F(3,112)=2.95, p<0.001$. Post hoc comparisons using Tukey tests showed that both group $\mathrm{A}(\mathrm{M}=8.81, \mathrm{SD}=11.99)$ and group $\mathrm{B}(\mathrm{M}=8.07, \mathrm{SD}=11.79)$ had a significantly $(\mathrm{p}<.0001)$ higher mean improvement than group $\mathrm{C}(1.31, \mathrm{SD}=11.48)$ and group $\mathrm{D}(\mathrm{M}=3.21, \mathrm{SD}=11.48)$.

Taken as a whole, the experiment found that the participants, including the treatment groups did not remarkably increase their oral reading rate. However, there was a significant difference between the treatment groups and the control groups in terms of the average increases, the number of participants who made no improvement, and the number of participants with big increases. Data analysis showed that no distorting factors affected the group's results. It can thus be assumed that the treatment groups outperformed the control groups in oral reading. Given that it is a transfer to a different medium, it is quite a good result.

\subsubsection{Is there any relationship between oral reading rate and silent reading rate?}

This section aims to see if there is a link between silent reading speed and oral reading rate among EFL learners. The participants' silent reading speeds in the course and on other types of texts and their oral reading rates will be compared. Oral reading rate was measured using the words per minute calculation to make it equal to silent reading speed. Silent reading rate in the course was measured by taking the average speed on the first three and the last three texts. The results are presented in Table 4.31 and 4.32. 
Table 4.31 Comparison of initial reading rate in the course, initial silent reading rate on other texts and initial oral reading rate for all groups

\begin{tabular}{llcccc}
\hline Reading rate type & & Group A & Group B & Group C & Group D \\
\hline \multirow{2}{*}{ Reading rate in the course } & Mean & 131.96 & 132.36 & N/A & N/A \\
& SD & 27.28 & 23.80 & & \\
\hline \multirow{2}{*}{ Reading rate on other texts } & Mean & 118.87 & 119.73 & 118.96 & 113.82 \\
& SD & 34.95 & 39.62 & 26.12 & 30.72 \\
\hline \multirow{2}{*}{ Oral reading rate } & Mean & 112.71 & 116.71 & 116.62 & 114.84 \\
& SD & 16.51 & 18.78 & 17.23 & 18.54 \\
\hline
\end{tabular}

Regarding the pre-test, it can be seen from Table 4.31 that the groups' average initial speeds in the course were the fastest among the three measurements. Their oral reading rates and silent reading rates on other types of texts were similar with the silent reading rates on other types of texts being slightly faster.

Table 4.32 Comparison of final reading rate in the course, final silent reading rate on other texts and final oral reading rate for all groups

\begin{tabular}{lcccc}
\hline & Group A & Group B & Group C & Group D \\
\hline \multirow{2}{*}{ Reading rate in the course } & 188.90 & 183.36 & & \\
\hline \multirow{2}{*}{ Reading rate on other texts } & 40.73 & 38.18 & & \\
\hline \multirow{2}{*}{ Oral reading rate } & 165.03 & 170.16 & 129.42 & 133.48 \\
& 36.75 & 34.61 & 20.50 & 27.18 \\
\hline
\end{tabular}

On the other hand, in the post-test (see Table 4.32), although the groups' average final speeds in the course were still the fastest of the three categories, their average reading speeds on other types of texts were substantially faster than their oral reading rates, especially for the two treatment groups. This was because the participants made substantial increases on reading other types of texts but small increases in oral reading. These results showed a trend that the participants' oral reading rates were generally slower than their silent reading rates. Researchers have shown that normal silent reading speed is around 250-300 wpm (Just, et al., 1987) while the normal oral reading rate is around 100-200 wpm 
(Meyer \& Felton, 1999). However, it is interesting to find that in the pre-test, the participants' oral reading rates were not much slower than their silent reading rates on other types of texts.

So the speed increases in the course transfer to other types of texts, and also to oral reading. One effect of a speed reading course is to make reading rate move beyond the oral reading rate. In the next sections we will look at the effect of in-course speed increases on language complexity and accuracy.

\subsubsection{The effect of the speed reading course on language complexity}

As reading speed is highly related to fluency, and fluency is one of the three aspects in the triad of language competence and performance assessment (fluency - accuracy complexity), it is interesting to explore the relationship between reading speed and the other two aspects. The relationship between reading speed and comprehension accuracy has been examined earlier in the thesis and it was found that comprehension accuracy could be maintained as the participants improved their reading rates. In what follows, the link between reading speed and syntax accuracy and language complexity will be explored by looking at the memory span test results. The participants did a memory span test before and after the treatment. Each of the two memory span sets consist of 20 sentences of increasing complexity in grammar and length. The participants were allowed to see each of the sentences for a set time then had to type it onto the computer.

We set up a few scoring criteria to make sure the results were reliable and systematic for the 116 participants. First, the test focused on receptive language rather than productive language. That is, we aimed to see how well the readers could cope with the sentences shown to them in terms of meaning, syntax and lexis. As a result, with regard to meaning, they were supposed to repeat the exact message the sentences described. Regarding syntax, they were supposed to provide the grammatically correct forms of the original sentences. In terms of lexis, they were supposed to repeat the same words and spelling as in the original sentences.

However, as the test was done on the computer, there were a number of errors where it was difficult to decide if they were caused by just a typing mistake or incorrect lexical knowledge and/or grammatical knowledge. Therefore, we also tried to analyze the data in 
other ways to compare the results between the pre-test and post-test results for each individual. This helps to see if their language accuracy and complexity developed and if there was a trade-off between these two language aspects as Yuan and Ellis (2003) report.

Generally, the errors made by the participants can be categorized into three groups: obvious spelling errors, grammatical errors and lexis errors. Obvious spelling mistakes are the incorrect forms of words that are apparently caused by typing. One example of this is bamdinton instead of badminton. The major types of grammatical errors and lexis errors are insertion, omission and substitution. Insertion occurred when a participant added a word that was not in the original sentence. For instance, a participant wrote "Last night I finished my class early and then went for a long walk by the river.", while the original sentence was "Last night I finished my class and went for a long walk by the river". Omission means a word is missing, for example, "Have you ridden a horse?" instead of "Have you ever ridden a horse?" Substitution is changing the word forms one or another way. An example of substitution is "Her grandmother visited her and give her a big cake." instead of "Her grandmother visited her and gave her a big cake."

\section{Table 4.33 Scoring criteria for the language memory span tests}

\begin{tabular}{|c|c|c|c|c|}
\hline Error type & & Tough & Moderate & Generous \\
\hline Spelling errors & & Not accepted & Accepted & Accepted \\
\hline \multirow{2}{*}{$\begin{array}{l}\text { Grammatical } \\
\text { errors }\end{array}$} & $\begin{array}{l}\text { Errors resulting in meaning } \\
\text { change }\end{array}$ & Not accepted & Not accepted & Not accepted \\
\hline & $\begin{array}{l}\text { Errors resulting in no } \\
\text { meaning change }\end{array}$ & Not accepted & Not accepted & Accepted \\
\hline \multirow[b]{2}{*}{ Lexical errors } & $\begin{array}{l}\text { Errors resulting in meaning } \\
\text { change }\end{array}$ & Not accepted & Not accepted & Not accepted \\
\hline & $\begin{array}{l}\text { Errors resulting in no } \\
\text { meaning change }\end{array}$ & Not accepted & Not accepted & Accepted \\
\hline
\end{tabular}

Table 4.33 summarizes the scoring methods. The three scoring methods were named the tough method, the moderate method, and the generous method. For the tough method, no errors of any sort were accepted. For the moderate method, only obvious spelling mistakes were accepted. For the generous method, obvious spelling errors, grammatical errors and lexis errors were all accepted if they did not result in a meaning change. An example of a mistake resulting in a lexical meaning change is "She thought it was very interesting to listen to the talk about her brothers" instead of "She thought it was very interesting to 
listen to the talk about her friends." The generous method does not accept this mistake. An example of an error that does not result in a lexical meaning change is "Jack reads books in the library" instead of "Jack reads books at the library." The generous method accepts this mistake.

\subsubsection{Did the participants increase their language memory span?}

The participants' results on the pre-test and post-test were measured by counting the number of sentences correctly rewritten. The difference between the raw scores on the pretest and post-test indicated the amount of improvement. The highest score a participant could make on the pre-test or post-test was 20. This section concerns the increases that the four groups made on the memory span tests. The raw scores on the pre-test and post-test will be shown and discussed later.

A preliminary analysis of the data using the tough method (see Table 4.34) indicated that the average score of all participants on the pre-test was 9.5 and the average score on the post-test was 12.9. Regarding individual groups, groups A and B made a 5.45 score increase and a 4.80 score increase while groups $\mathrm{D}$ and $\mathrm{C}$ made a 1.72 score increase and 1.38 score increase. Of all 116 participants, 90 (more than three quarters) did better on the post-test and among these progress makers, 49 made increases over 5.0. Only $22 \%$ of the participants either gained the same score or had lower scores on the post-test. Ninety-five percent of the participants in groups A and B but only 58\% of the participants in groups C and D made improvement. Only $5 \%$ of the treatment groups but $42 \%$ of the control groups did not make any progress. Fifty-nine percent of the treatment groups but only $29 \%$ of the control groups made increases over 5.0.

Table 4.34 Increases in language memory span for all groups (tough scoring method)

\begin{tabular}{lccccc}
\hline & & Group A & Group B & Group D & Group C \\
\hline & Mean & 5.46 & 4.80 & 1.72 & 1.39 \\
Increases & $\mathrm{SD}$ & $(2.94)$ & $(2.68)$ & $(5.23)$ & $(4.00)$ \\
\hline $\mathrm{N}^{\mathrm{o}}$ of participants with no improvement & & $2 / 31$ & $1 / 30$ & $12 / 29$ & $11 / 26$ \\
\hline $\mathrm{N}^{\mathrm{o}}$ of participants with improvement & & $29 / 31$ & $29 / 30$ & $17 / 29$ & $15 / 26$ \\
\hline $\mathrm{N}^{0}$ of participants with increases over 5.0 & & $17 / 31$ & $16 / 30$ & $9 / 29$ & $7 / 26$ \\
\hline
\end{tabular}


A repeated measures ANOVA was carried out on the pre-test (initial score) and post-test (final score) data. The repeated-measures factor was time (pre-test vs. post-test) and the between-subjects factor was group. The results are shown in Table 4.35 below:

Table 4.35 Means and standard deviations of pre-test and post-test memory span for all groups (tough scoring method)

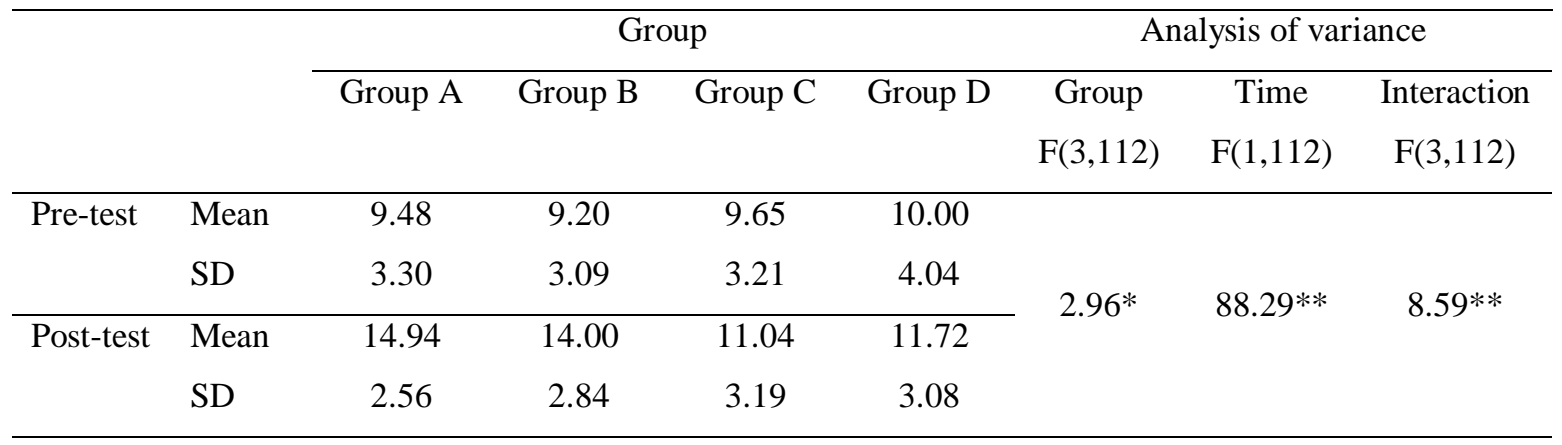

$* * \mathrm{p}<.01, * \mathrm{p}<.05$

The results indicated that there was a general gain for all groups from pre-test to post-test, $\eta^{2}=.441$. There was a large effect on the overall group, but seen in the light of this research not meaningful. The interaction (group $\mathrm{x}$ time) result data showed that the memory span gains from pre-test to post-test for the two treatment groups were significantly greater than for the control groups, $\eta^{2}=.187$. It can be clearly seen from Figure 4.4 that the treatment groups made significant gains in memory span, and their mean improvement was greater than the memory span gains of the control groups.

Figure 4.4 Estimated marginal means of memory span increases for all groups

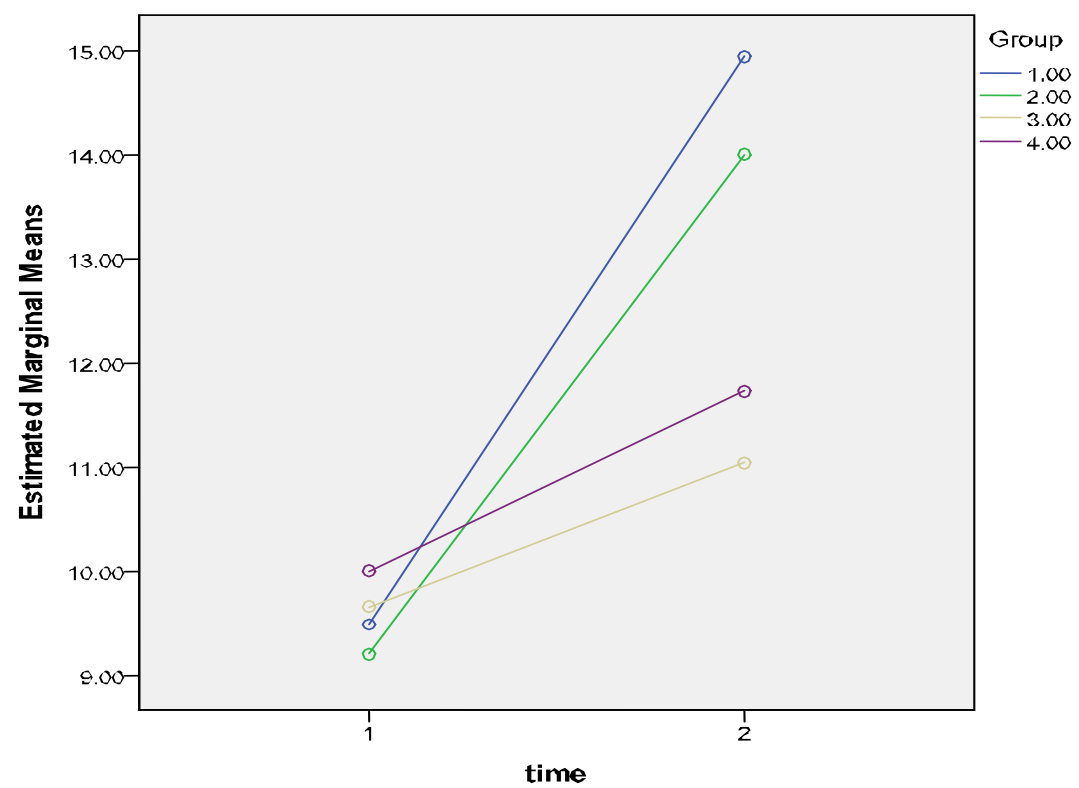


In order to determine the nature of the interaction effect, a one way ANOVA was carried out to compare the gain scores (pre-test to post-test) of the four groups. The results showed the mean scores of the four groups were significantly different, $F(3,112)=8.59, \mathrm{p}=.000$, $\eta^{2}=.187$.

The mean gain score for group A memory span development was $5.46(\mathrm{~N}=31, \mathrm{SD}=2.94)$. The mean gain score for group B speed training was $4.80(\mathrm{~N}=30, \mathrm{SD}=2.68)$. The mean gain score for group $\mathrm{C}$ control was $1.39(\mathrm{~N}=26, \mathrm{SD}=4.00)$. The mean gain score for group D control was $1.72(\mathrm{~N}=29, \mathrm{SD}=5.23)$.

Pairwise comparisons using the Bonferroni adjustment for multiple comparisons showed a significant difference between group A and group $C(p=.001)$ and between group A and group D. $(\mathrm{p}=.002)$. There was also a significant difference between group B and group C $(\mathrm{p}=.007)$ and between group $\mathrm{B}$ and group $\mathrm{D}(\mathrm{p}=.015)$. There was no significant difference between groups $\mathrm{C}$ and $\mathrm{D}(\mathrm{p}=1.000)$.

The moderate method and the generous method were also used to count the scores gained by the participants. As mentioned earlier, the moderate scoring method accepts obvious spelling mistakes and the generous scoring method accepts obvious spelling mistakes as well as lexical and grammatical mistakes that did not result in any lexical meaning change. Tables 4.34 and 4.35 show the results from these scoring methods.

According to the moderate scoring method result (see Table 4.36), the average score of all participants on the pre-test was 11.0 and the average score on the post-test was 14.1. There figures are slightly higher than the figures in the tough scoring method because of the generous criteria. Groups A and B made increases of 5.1 and 4.2. Groups D and C made increases of 1.5 and 1.3. This pattern of ranking is the same as the one from the tough scoring method. Among the 116 participants, 89 participants improved their memory span. Almost half of these participants made increases over 5.0. Twenty-seven participants made no progress. These results agree with the results in the tough scoring method. Using oneway ANOVA to compare the mean increases we found a significant difference, $\mathrm{F}(3,112)=$ 16.17, $\mathrm{p}<0.001$. Using post hoc tests (Tukey HSD) we indentified that group A $(\mathrm{M}=5.13$, $\mathrm{SD}=3.28)$ made a significantly $(\mathrm{p}<.001)$ mean improvement than group $\mathrm{C}$ and group $\mathrm{D}$. Comparisons of group B and groups C and D were significant at the $\mathrm{p}<.05$ level. 
Table 4.36 Increases in language memory span for all groups (moderate scoring method)

\begin{tabular}{lccccc}
\hline & & Group A & Group B & Group D & Group C \\
\hline \multirow{2}{*}{ Increases } & Mean & 5.13 & 4.27 & 1.59 & 1.31 \\
\hline $\mathrm{N}^{\mathrm{o}}$ of participants with no improvement & $\mathrm{SD}$ & 3.28 & 2.72 & 5.47 & 4.18 \\
\hline $\mathrm{N}^{\mathrm{o}}$ of participants with improvement & & $2 / 31$ & $2 / 30$ & $12 / 29$ & $11 / 26$ \\
\hline $\mathrm{N}^{\mathrm{o}}$ of participants with increases over 5.0 & & $29 / 31$ & $28 / 30$ & $17 / 29$ & $15 / 26$ \\
\hline
\end{tabular}

The generous scoring method (see Table 4.37) produced similar results in terms of the ranking of the groups and the numbers of participants with no improvement and participants with improvement. The average initial score by all participants was 13.2 while the average final score was 16.3. These figures are slightly higher than the figures in the moderate scoring method. Groups A and B made increases of 4.7 and 4.1. Groups C and D made increases of 1.7 and 1.6. Of all the 116 participants, 88 participants made progress and half of them made increases over 5.0. Twenty-eight made no improvement. Using oneway ANOVA to compare the four groups' mean increases we found a significant difference, $F(3,112)=14.01, p=0.006$. Post hoc comparisons (Tukey HSD) indicated that group A $(\mathrm{M}=4.71, \mathrm{SD}=3.06)$ and group $\mathrm{B}(\mathrm{M}=4.13, \mathrm{SD}=3 / 07)$ made significantly $(\mathrm{p}<.05)$ bigger increases than group $\mathrm{C}(\mathrm{M}=1.58, \mathrm{SD}=3.84)$ and group $\mathrm{D}(\mathrm{M}=1.69, \mathrm{SD}=$ 4.91). These results agree with the results in the tough scoring method and the medium scoring method.

Table 4.37 Increases in language memory span for all groups (the generous scoring method)

\begin{tabular}{llcccc}
\hline & & Group A & Group B & Group D & Group C \\
\hline \multirow{2}{*}{ Increases } & Mean & 4.71 & 4.13 & 1.69 & 1.58 \\
& $\mathrm{SD}$ & 3.06 & 3.07 & 4.91 & 3.84 \\
\hline $\mathrm{N}^{\mathrm{o}}$ of participants with no improvement & & $3 / 31$ & $4 / 30$ & $12 / 29$ & $9 / 26$ \\
\hline $\mathrm{N}^{\mathrm{o}}$ of participants with improvement & & $28 / 31$ & $26 / 30$ & $17 / 29$ & $17 / 26$ \\
\hline $\mathrm{N}^{0}$ of participants with increases over 5.0 & $17 / 31$ & $12 / 30$ & $8 / 29$ & $7 / 26$ \\
\hline
\end{tabular}

An examination of the individuals' responses to the 20 items in the pre-test and 20 items in the post-test showed that the participants were taking the test seriously. On both the pretest and post-test, there were few items that were left blank. In the pre-test, only six out of 
116 participants did not write anything for one or maximum three items. On the post-test, only five out of 116 participants did not write anything for one or maximum two items.

Taken as a whole, the data showed that there was a strong agreement among the three scoring methods and that most of the participants in the treatment groups made increases in language memory span while many of the participants in the control groups did not make progress. It seems that the speed increases in the course facilitated language memory span development.

\subsubsection{What were the best and the worst scores on the language memory span tests?}

Further analysis was done to make sure the groups' scores were not distorted by ceiling or floor effects. It was also done to see the participants' potential for developing language memory span. Since it was found that the three scoring methods agree with each other very well, in this analysis as well as the following ones, only the data in the tough scoring method were used.

The data in tables 4.38 and 4.39 show that in the pre-test the average scores of the treatment groups were slightly lower than the average scores of the control groups. However, in the post-test, the treatment groups' average scores were substantially higher than the control groups' average scores. This demonstrates that the treatment groups' increases were a real improvement and not the result of the lower average scores at the beginning of the treatment.

In the pre-test, the lowest score was 3 and the highest score was 18 by a participant in group D. Fifty-seven out of 116 participants scored 10 or more. Sixteen participants (14\%) scored 5 or less.

In the post-test, the lowest scores were around 5 and the highest scores were 19, by participants in group A and group B. Most of the participants had at least 10 correct answers and 44 participants (38\%) scored from 15 to 19 . Only three participants scored under 5 .

In both pre-test and post-test, none of the participants had zero or 20. These results demonstrate that there were no ceiling or floor effects. 
Table 4.38 Means and standard deviations of initial scores, final scores and increases in memory span for all groups

\begin{tabular}{llcccc}
\hline Test & & Group A & Group B & Group D & Group C \\
\hline \multirow{2}{*}{ Pre-test } & Mean & 9.48 & 9.20 & 10.00 & 9.65 \\
& SD & 3.30 & 3.09 & 4.04 & 3.21 \\
\hline \multirow{2}{*}{ Post-test } & Mean & 14.94 & 14.00 & 11.72 & 11.04 \\
& SD & 2.56 & 2.84 & 3.08 & 3.19 \\
\hline
\end{tabular}

Table 4.39 The lowest score and the highest score in the pre-test and post-test, the best progress and the worst progress in memory span for each of the four groups

\begin{tabular}{llcccc}
\hline & & Group A & Group B & Group D & Group C \\
\hline Pre-test & Lowest score & 3 & 3 & 3 & 3 \\
& Highest score & 17 & 15 & 15 & 18 \\
\hline Post-test & Lowest score & 7 & 4 & 5 & 5 \\
& Highest score & 19 & 19 & 18 & 17 \\
\hline Increase & Worst score & -1 & 0 & -13 & -5 \\
& Best score & 10 & 12 & 11 & 9 \\
\hline
\end{tabular}

With respect to the difference between the pre-test and post-test results, the worst progress was a decrease by 13 and the best progress was an increase by 12. Participant B2 was the best progress maker scoring only 7 on the pre-test but significantly raised it to 19 on the post-test, making an increase by $60 \%$ compared with the pre-test. Participant D5 was the worst progress maker with a decrease from 18 to 5 , resulting in a decrease by $65 \%$.

Overall, the results indicate that the tests produced no ceiling or floor effects, and that the four groups started at similar levels of memory span but the treatment groups reached higher levels in the post-test. This supports the idea that the treatment groups made a real improvement in memory span.

\subsubsection{How did the initial scores relate to the final scores?}

Comparing the initial scores and final scores can help to support the validity of the result if the data show that there is a link between them. In order to determine the relationship between the initial scores and final scores, the data of all participants were classified into four groups according to the initial scores, which were then compared with the final scores. 
In Table 4.40, the initial scores by all participants were arranged from the highest on the left to the lowest on the right. The participants were divided into four groups of 29 participants. The first group consisted of participants whose initial scores ranged from 12 to 18 . The second group were participants whose initial scores ranged from 9 to 12 . The third group consisted of participants with initial scores ranging from 8 to 11 . The last group were the participants with the initial scores ranging from 3 to 7.

Table 4.40 Initial scores and final scores on the memory span tests by all participants

\begin{tabular}{|c|c|c|c|c|c|c|c|c|c|c|c|}
\hline $\mathbf{P}$ & Initial & Final & $\mathbf{P}$ & Initial & Final & $\mathbf{P}$ & Initial & Final & $\mathbf{P}$ & Initial & Final \\
\hline D5 & 18 & 5 & B5 & 12 & 15 & A16 & 9 & 16 & B2 & 7 & 19 \\
\hline A10 & 17 & 18 & A30 & 12 & 15 & B29 & 9 & 15 & B6 & 7 & 16 \\
\hline D17 & 17 & 10 & C6 & 12 & 14 & A29 & 9 & 15 & A4 & 7 & 16 \\
\hline A12 & 16 & 18 & D6 & 12 & 12 & D1 & 9 & 15 & $\mathrm{C} 23$ & 7 & 15 \\
\hline B18 & 15 & 17 & $\mathrm{D} 20$ & 12 & 12 & B14 & 9 & 14 & A26 & 7 & 15 \\
\hline B3 & 15 & 16 & $\mathrm{C} 1$ & 12 & 11 & B16 & 9 & 14 & A18 & 7 & 13 \\
\hline C14 & 15 & 14 & D10 & 12 & 8 & A14 & 9 & 14 & D15 & 7 & 13 \\
\hline A8 & 14 & 17 & B23 & 11 & 15 & B30 & 9 & 13 & $\mathrm{C} 3$ & 7 & 12 \\
\hline D26 & 14 & 17 & A31 & 11 & 15 & A17 & 9 & 13 & B22 & 7 & 12 \\
\hline B26 & 14 & 15 & A6 & 11 & 15 & B19 & 9 & 12 & D22 & 7 & 9 \\
\hline C11 & 14 & 12 & C5 & 11 & 14 & D8 & 9 & 11 & A27 & 6 & 15 \\
\hline $\mathrm{D} 2$ & 14 & 12 & B10 & 11 & 14 & $\mathrm{C} 4$ & 9 & 8 & B24 & 6 & 14 \\
\hline A23 & 13 & 19 & B20 & 11 & 14 & $\mathrm{C} 10$ & 9 & 5 & B15 & 6 & 12 \\
\hline A19 & 13 & 18 & D4 & 11 & 13 & A21 & 8 & 17 & A15 & 5 & 15 \\
\hline D12 & 13 & 18 & $\mathrm{C} 17$ & 11 & 12 & $\mathrm{C} 15$ & 8 & 16 & A5 & 5 & 13 \\
\hline $\mathrm{C} 21$ & 13 & 17 & D13 & 11 & 12 & A28 & 8 & 16 & A7 & 5 & 11 \\
\hline A9 & 13 & 16 & D7 & 11 & 11 & A20 & 8 & 16 & $\mathrm{C} 7$ & 5 & 10 \\
\hline B4 & 13 & 15 & $\mathrm{C} 2$ & 11 & 10 & C19 & 8 & 14 & D29 & 5 & 10 \\
\hline D11 & 13 & 13 & B21 & 10 & 17 & B13 & 8 & 14 & C9 & 5 & 6 \\
\hline D18 & 13 & 13 & B9 & 10 & 16 & B17 & 8 & 14 & $\mathrm{C} 18$ & 5 & 6 \\
\hline D19 & 13 & 13 & D21 & 10 & 16 & A3 & 8 & 14 & B7 & 4 & 12 \\
\hline $\mathrm{C} 22$ & 13 & 10 & B1 & 10 & 15 & D27 & 8 & 13 & $\mathrm{D} 23$ & 3 & 14 \\
\hline $\mathrm{C} 12$ & 13 & 9 & B8 & 10 & 15 & $\mathrm{C} 20$ & 8 & 12 & D25 & 3 & 14 \\
\hline $\mathrm{C} 24$ & 13 & 9 & B11 & 10 & 15 & $\mathrm{C} 13$ & 8 & 9 & A13 & 3 & 13 \\
\hline $\mathrm{C} 25$ & 13 & 8 & A25 & 10 & 15 & D14 & 8 & 9 & $\mathrm{C} 16$ & 3 & 12 \\
\hline D3 & 13 & 6 & $\mathrm{C} 26$ & 10 & 14 & C8 & 8 & 8 & B28 & 3 & 11 \\
\hline B25 & 12 & 17 & D28 & 10 & 14 & B12 & 8 & 8 & D16 & 3 & 11 \\
\hline $\mathrm{A} 1$ & 12 & 16 & A2 & 10 & 9 & A11 & 8 & 7 & D9 & 3 & 9 \\
\hline \multirow[t]{2}{*}{ A22 } & 12 & 16 & A24 & 9 & 17 & D24 & 8 & 7 & B27 & 3 & 4 \\
\hline & 13.83 & 13.93 & & 10.83 & 13.62 & & 8.45 & 12.38 & & 5.21 & 12.14 \\
\hline
\end{tabular}


As shown in Table 4.40, the first two groups had the highest score in the post-test. The other two groups had a lower score. For the first two groups, although the difference between their average scores in the pre-test was 3.0, their average final scores were almost the same. This pattern also applies for the other two groups. Their average initial score were 8.45 and 5.21 but their average final scores were both around 12.0.

Two interpretations can be made of these results. First, even though the second group had a lower average initial score, they could reach as high an average score as the first group. Likewise, even though the fourth group had a lower average score than the third group, they could reach as high an average score as the third group. This suggests that the participants with shorter memory span could increase it to a great degree to keep up with the participants who had already had a better memory span. Second, the participants who scored higher on the pre-test tended to score higher on the post-test. This demonstrates that the difference between the participants' initial scores and final scores were real progress, not some erratic behaviour.

\subsubsection{How did the memory span increases relate to the speed increases?}

The idea that memory span developed along with speed reading improvement can be enhanced if the data show that the increases in memory span have a strong relationship with increases in reading speed improvement. This section explores the association between memory span improvement with the speed increases in the course and on other types of texts to seek more evidence for the real improvement that the participants made on memory span tests.

The relationship between memory span increases and in-course speed increases was explored by comparing the amount of each type of improvement among all participants in the treatment groups. The 61 participants in these two groups were divided into three subgroups of roughly 20 according to their memory span increases. Group 1 consisted of participants whose memory span increases ranged from 6 to 12. Group 2 consisted of participants whose memory span increases ranged from 4 to 6 . The third group consisted of participants whose memory span increases ranged from 1 to 4 . As shown in Table 4.41, the first group with the biggest average increase in memory span also achieved the best improvement in the speed reading course with a mean of $62 \mathrm{wpm}$. Similarly, the second group with the second biggest average increase in memory span ranked the second in 
reading speed improvement with a mean of $37 \mathrm{wpm}$. The third group made the least improvement both in memory span and in the course with a mean of 2.1 and $43 \mathrm{wpm}$. This result shows a trend that the greater the memory span increase one group made, the better reading speed improvement they achieved. The result supports the idea that speed improvement in the course was accompanied by development in memory span.

Table 4.41 Means and standard deviations of memory span increases and in-course speed increases for three subgroups classified according to memory span increases

\begin{tabular}{llccc}
\hline & & Subgroup 1 & Subgroup 2 & Subgroup 3 \\
\hline \multirow{2}{*}{ Memory span increase } & Mean & 8.25 & 5.27 & 2.19 \\
& SD & 1.47 & 0.70 & 1.56 \\
\hline \multirow{2}{*}{ Speed increase in the course } & Mean & 62.45 & 57.67 & 43.43 \\
& SD & 44.37 & 31.96 & 27.39 \\
\hline
\end{tabular}

The relationship between increases in memory span and increases in reading rate on other types of texts was explored by comparing the amount of the improvement in memory span and the improvement in reading rate on other types of texts. This analysis involves all 116 participants, who were categorized into four groups according to their increases in memory span. Group 1 included participants whose memory span increases ranged from 6 to 12 . Group 2 included participants whose memory span increases ranged from 4 to 6 . Group 3 consisted of participants whose memory span increases ranged from 1 to 4 . Group 4 consisted of participants who made the least improvement in memory span.

Table 4.42 Means and standard deviations of memory span increases and speed increases on other texts for four subgroups classified according to memory span increases

\begin{tabular}{llcccc}
\hline & & Subgroup 1 & Subgroup 2 & Subgroup 3 & Subgroup 4 \\
\hline Memory span increase & Mean & 8.29 & 5.15 & 2.56 & -2.3 \\
\hline \multirow{2}{*}{ Speed increase on other types of texts } & SD & 1.61 & 0.69 & 1.09 & 3.06 \\
\hline & SD & 41.34 & 36.67 & 30.32 & 24.78 \\
\hline
\end{tabular}

As can be seen from the Table 4.42, the increases in memory span agreed very well with the increases in reading speed on other types of texts. For example, group 1, who made the greatest improvement in memory span with an average increase of 8.0, also made the best improvement in reading speed on other types of texts with an average increase of $41 \mathrm{wpm}$. 
To summarize, it is clear that the groups with better improvement in other types of texts also achieved greater increases in memory span.

\subsubsection{Did either of the tests of language memory span have an effect on the participants' results?}

The groups' results of memory span increases might have been distorted if the two sets of memory span sentences were not equally difficult. The memory span tests were administered before and after the treatment. There were two versions of twenty increasingly difficult sentences. In the pre-test, approximately half of participants in each group were asked to do version A and the other half version B. In the post-test, the participants did them the other way around. There was a possibility that if one of the two versions was easier than the other, the participants who did the easier set in the pre-test might have had smaller increases and the participants who did the more difficult set might have had bigger increases than they should do if the two versions were equal. Thus this analysis aims to see if doing one set resulted in higher and lower scores, which would distort the interpretation. The scores on both versions for all individual participants in the four groups were compared. Table 4.43 presents the results for all groups in the two ways of administration. The first way was with set $\mathrm{A}$ on the pre-test and set B on the post-test and the second way was with set B on the pre-test and set A on the post-test. The data showed that the two halves of the participants had similar results. Both halves had the same average score on the pre-test and similar average scores on the post-test. Similar numbers of participants in the two halves had at least 10 correct answers in the pre-test and in the post-test.

The results for two halves of the participants in each group were also examined. It was found that there were no noticeable differences between the two halves in each group. For example, in group A, the participants who did set A on the pre-test and set B on the posttest had an average score of 9.61 on set $\mathrm{A}$ and 15.11 on set B. On the other hand, the participants who did set B on the pre-test and set A on the post-test had an average of 9.39 on set $\mathrm{B}$ and 14.89 on set $\mathrm{A}$. These results demonstrate that the two halves of participants in group A did similarly well on the two sets. Similar patterns were found among group B, group C and group D. 
Table 4.43 Means and standard deviations of memory span scores for participants in each group following the two orders of text administration

\begin{tabular}{llccccc}
\hline & & Group A & Group B & Group C & Group D & All groups \\
\hline \multirow{2}{*}{ Pre-test: set A } & Mean & 9.61 & 9.19 & 9.37 & 10.01 & 9.61 \\
& SD & 2.32 & 3.03 & 3.03 & 4.54 & 3.26 \\
\cline { 2 - 7 } Pre-test: set B & Mean & 9.39 & 9.36 & 10.03 & 9.98 & 9.67 \\
& SD & 3.63 & 3.26 & 3.46 & 3.59 & 3.56 \\
\hline \multirow{2}{*}{ Post-test: set B } & Mean & 15.11 & 14.60 & 10.71 & 10.99 & 12.95 \\
& SD & 2.99 & 2.68 & 3.72 & 3.46 & 3.71 \\
\cline { 2 - 7 } Post-test: set A & Mean & 14.89 & 13.39 & 11.39 & 12.52 & 13.20 \\
& SD & 1.87 & 2.94 & 2.66 & 2.40 & 2.78 \\
\hline
\end{tabular}

Taken as a whole, it can be seen that there was no striking difference between the results by participants who had set A and participants who had set B in either pre-test or post-test. It can therefore be assumed that the different versions of language memory span did not distort the results.

\subsubsection{With which sentences did the participants have incorrect answers?}

The idea behind this question is to see if the participants made a real improvement in their memory span or just an increase in the number of correct answers they made. Each of the two memory span sets contained 20 sentences of increasing length and grammar difficulty. The idea of the test was that if on the post-test the participants could go further in the set, it can be assumed that they developed their memory span. That is, for example, if a participant could only give correct answers for sentences from \#1 to \#9 but on the post-test, they could give correct answers for sentences from \#1 to \#15, that participant can be said to have increased their language memory span. Therefore, it is necessary to look at the order of the sentences to which the participants gave correct answers on both tests to see if the sentences on the pre-test were largely toward the beginning of the set and the sentences on the post-test were largely toward the end of the post-test. If more sentences on the posttest were largely toward the beginning while more sentences on the pre-test were largely toward the end of the set, it is not possible to say that the participants made an improvement in memory span. In order to do this, first, we divided the set of memory span sentences into five parts. Each part consisted of four sentences. Part 1 contained the easiest sentences and part 5 contained the most difficult sentences. Second, we added the total 
number of correct answers that all participants in each group had. Third, we put those sentences into the five parts and calculated the percentage for each part. For example, when adding the numbers of correct answers that the participants in group A made in the pre-test, the total was 294. Among these, 111 (38\%) were in part 1, $80(27 \%)$ were in part 2, $48(16 \%)$ in part 3, $28(10 \%)$ were in part 4, and $27(9 \%)$ were in part 5. As shown in Table 4.44, there was a decrease in the percentage of correct answers for part 1 from the pre-test to the post-test. In the pre-test, all groups had roughly $38 \%$ of correct answers in part 1 but in the post-test, this figure decreased to around $28 \%$ for the treatment groups and $33 \%$ for the control groups. Conversely, there was an increase in the percentage of correct answers for part 4 from the pre-test to the post-test. In the pre-test, the four groups had around $10 \%$ of their correct answers in part 4 , but in the post-test, they increased the figures to $17 \%$ for both the treatment groups, $14 \%$ for group $\mathrm{C}$ and $11 \%$ group $\mathrm{D}$. The treatment groups also had a higher percentage of correct answers in part 5. These results demonstrate that on the post-test, the groups reached more difficult sentences than in the pre-test.

Table 4.44 Percentage of correct answers in each of the five parts of the memory span tests for all groups

\begin{tabular}{lcccccccc}
\hline & \multicolumn{2}{c}{ Group A } & \multicolumn{2}{c}{ Group B } & \multicolumn{2}{c}{ Group C } & \multicolumn{2}{c}{ Group D } \\
\hline & Pre-test & Post-test & Pre-test & Post-test & Pre-test & Post-test & Pre-test & Post-test \\
\hline Part 1 & $38 \%$ & $27 \%$ & $37 \%$ & $28 \%$ & $38 \%$ & $33 \%$ & $37 \%$ & $33 \%$ \\
Part 2 & $27 \%$ & $23 \%$ & $29 \%$ & $23 \%$ & $26 \%$ & $28 \%$ & $28 \%$ & $26 \%$ \\
Part 3 & $16 \%$ & $20 \%$ & $18 \%$ & $19 \%$ & $20 \%$ & $21 \%$ & $17 \%$ & $21 \%$ \\
Part 4 & $10 \%$ & $17 \%$ & $11 \%$ & $17 \%$ & $10 \%$ & $14 \%$ & $9 \%$ & $11 \%$ \\
Part 5 & $9 \%$ & $15 \%$ & $5 \%$ & $13 \%$ & $6 \%$ & $5 \%$ & $9 \%$ & $9 \%$ \\
\hline
\end{tabular}

An examination of the individual participants in each group (see Table 4.45) showed that the four groups had more participants reaching the higher levelled parts on the post-test. The fact that the numbers of participants reaching lower levelled parts did not noticeably change while the number of participants reaching higher levelled parts markedly increased shows that the participants had more correct answers and these answers were for sentences in the more difficult parts of the test. Particularly for part 4, in the pre-test, only around 17 participants in each group could reach this part but in the post-test, almost all participants in the treatment groups reached this part. Similarly, in the pre-test, only around 12 
participants in each group could reach part 5, but in the post-test, that number more than doubled in the treatment groups.

Table 4.45 Numbers of participants having correct answers in each part of the test for all groups

\begin{tabular}{lcccccccc}
\hline \multicolumn{9}{c}{ Pre-test } \\
\hline & Group A & Group B & Group C & Group D & Group A & Group B & Group C & Group D \\
\hline Part 1 & 31 & 30 & 26 & 29 & 31 & 30 & 26 & 29 \\
Part 2 & 30 & 29 & 25 & 26 & 31 & 29 & 26 & 28 \\
Part 3 & 24 & 24 & 21 & 24 & 31 & 29 & 23 & 28 \\
Part 4 & 17 & 19 & 18 & 16 & 30 & 26 & 19 & 22 \\
Part 5 & 10 & 12 & 10 & 15 & 28 & 25 & 9 & 17 \\
\hline
\end{tabular}

Taken together, the results showed that on the post-test, the participants, especially the treatment groups, increased the numbers of correct answers and these answers were largely in the more difficult parts of the test. This suggests that the increases they made were a real improvement in memory span.

\subsubsection{Did the usual English program have any effects on the participants' improvement in memory span?}

In the present experiment, the two control groups did not follow the speed reading course and the difference between them was that group $\mathrm{C}$ followed the same English program at the university as the treatment groups while group D followed an English course at a language centre. Therefore it would be interesting to find out if the two control groups made different amounts of improvement in language memory span. In order to do this, the initial and final scores by participants in group $\mathrm{C}$ and participants in group $\mathrm{D}$ were compared to determine which group gained better improvement.

A preliminary analysis of the results indicated that a clear benefit of the usual English program at the university could not be identified (see Table 4.46). It can be seen that the two control groups did not greatly differ in the amounts of improvement. A one-way ANOVA showed that the two groups' mean improvement were significantly different, $\mathrm{F}(1$, $53)=0.07, p=0.078$. On average, both groups initially had similar average scores in the pre-test. For the post-test, group D's average score was marginally higher than that of 
group C. Almost the same percentage of participants (42\% in group C and $41 \%$ in group D) from the two groups had either negative results or no change and thus a similar percentage of participants in the two groups made progress. A roughly equal percentage of participants in the two groups made increases over 3.0.

Table 4.46 Results on the memory span tests for the control groups

\begin{tabular}{llcc}
\hline & & Group D & Group C \\
\hline \multirow{2}{*}{ Pre-test score } & Mean & 10.00 & 9.65 \\
& SD & 4.04 & 3.21 \\
\hline \multirow{2}{*}{ Post-test score } & Mean & 11.72 & 11.03 \\
& SD & 3.08 & 3.19 \\
\hline \multirow{5}{*}{ Increases } & Mean & 1.72 & 1.38 \\
& SD & 5.23 & 4.00 \\
& No of participants with no improvement & $12(41 \%)$ & $11(42 \%)$ \\
& No of participants with improvement & $17(59 \%)$ & $15(58 \%)$ \\
& No of participants with increases over 3.0 & $11(38 \%)$ & $9(35 \%)$ \\
\hline
\end{tabular}

These results demonstrate that the two control groups performed similarly well on the memory span test, thus suggesting that the English program at the university did not have strong effects on the language memory span tests.

\subsubsection{Did the participants improve the accuracy of their language knowledge?}

To date there has been little agreement on the relationship between language fluency and accuracy (Ano, 2004; Slee, 2008). It has been argued that when learners' language fluency increases, their language accuracy develops too (Slee, 2008). The present experiment found that fluency development helped language complexity, and that comprehension accuracy was maintained as fluency develops. Thus it would be worth examining the participants' language knowledge accuracy to see if language accuracy concurrently develops with language fluency and complexity. This was done by looking at the answers that the participants provided in the memory span tests and scrutinizing the mistakes that they made.

As mentioned earlier, certain types of mistakes were counted as acceptable in the moderate and generous scoring methods. To determine if the participants could reduce the 
percentage of errors, the results from the generous scoring method were analyzed. As obvious spelling mistakes are not related to language knowledge, the results from the moderate scoring method were excluded. We examined the participants' answers in the generous method to see if the participants made fewer acceptable mistakes in the post-test. This concerns only the sentences with mistakes. We compared the percentage of errors each participant made in the pre-test with that in the post-test. The error rate was measured by taking the percentage of errors per total number of words of the incorrect sentences. The result is presented in Table 4.47

Table 4.47 Means and standard deviations of percentage of error on the pre-test and posttest and their difference for all groups

\begin{tabular}{llcccc}
\hline Measure & & Group A & Group B & Group C & Group D \\
\hline \multirow{2}{*}{ Percentage of errors in the pre-test } & Mean & $11.26 \%$ & $15.43 \%$ & $12.81 \%$ & $11.31 \%$ \\
& SD & 4.42 & 6.10 & 8.74 & $(3.18$ \\
\hline \multirow{2}{*}{ Percentage of errors in the post-test } & Mean & $9.29 \%$ & $13.87 \%$ & 10.38 & $11.52 \%$ \\
& SD & 4.35 & 7.25 & 5.67 & 4.29 \\
\hline \multirow{2}{*}{ Decrease in percentage of errors } & Mean & $1.97 \%$ & $1.56 \%$ & $2.43 \%$ & $0.21 \%$ \\
& SD & 5.94 & 8.54 & 10.35 & 5.31 \\
\hline
\end{tabular}

Table 4.48 Numbers of participants with a decrease and participants with no decrease in percentage of errors on the memory span tests for all groups

\begin{tabular}{lccccc}
\hline & Group A & Group B & Group C & Group D \\
\hline $\mathrm{N}^{\mathrm{o}}$ of participants with a decrease & 22 & 24 & 14 & 16 \\
\hline $\mathrm{N}^{\mathrm{o}}$ of participants with no decrease & 9 & 6 & 12 & 13 \\
\hline
\end{tabular}

As shown in Table 4.47, on average, all groups had a decrease in errors. Group C did the best with a decrease of $2.43 \%$ and group D did the worst with a decrease of only $0.21 \%$. Groups A and B ranked the second and the third with a decrease of $1.97 \%$ and $1.56 \%$. The data showed that among the four groups, group B had the highest rate of errors on both pre-test and post-test. Groups A and D had the same rate on the pre-test but group A outperformed group D on the post-test. A comparison of individual participants in the four groups (see Table 4.48) showed that groups A and B had more participants with decreases in percentage of errors. Twenty-two out of 31 participants (71\%) from group A and 24 out of 30 participants $(80 \%)$ from group B made progress in accuracy. On the other hand, only 
14 out of 26 participants (54\%) from group C, and 16 out of 29 participants (55\%) from group D decreased their error percentage.

An examination of individuals' results showed that 76 participants $(66 \%)$ had decreases in error percentage. The other 40 participants (34\%) had increases from $1 \%$ to $23 \%$. The best progress maker was participant $\mathrm{C} 2$ with a decrease of $43 \%$ and the worst was participant B2 with an increase of $23 \%$. Although the data indicated that many participants made lower rates of errors on the post-test, there were very few big decreases. The only substantial decrease was made by participant C2. Most of the other participants made decreases of less than $10 \%$.

As the comparisons among the four groups' improvement on accuracy and among the individual participants showed that group $\mathrm{C}$ made the best improvement but groups $\mathrm{A}$ and B had more participants with improvement, it is necessary to check before jumping to any conclusion on how well the treatment groups did compared with the control groups. The groups' results might have been distorted by text effects, low or high initial error rates, or unusually high or low scores by certain participants. Text effects were eliminated because it had been found that the two texts were equally difficult and produced similar effects on the participants' performance. Thus we only needed to look at the groups' initial error rates and the individual participants' scores to see if these two factors affected the whole groups' results. With regard to the initial error rates, Table 4.47 indicates that group B had a higher average error rate than the control groups. It might therefore be assumed that this group had a bigger average decrease than group $\mathrm{D}$ because of its high rate on the pre-test. However, this cannot explain the fact that group $\mathrm{C}$ had a bigger decrease than group $\mathrm{B}$. Group A had the same initial rate as group D, thus it is not possible that group A's result was affected by their initial rate. Taken as a whole, initial rates did not clearly distort the groups' results. With respect to the unusually high or low scores, we examined the individual scores by all participants in the four groups to see if there were any participants with abnormally high or low figures affecting the whole groups' results. The data showed that most of the participants made increases or decreases of less than $10 \%$, thus the participants who made increases or decreases over $10 \%$ were excluded in this analysis to see if the groups' results would greatly change. Two participants from group A, two participants from group B, three participants from group $\mathrm{C}$ and two participants from group $\mathrm{D}$ were excluded in the analysis. Table 4.49 indicates that among the four groups, group C had the biggest change after removing the participants with unusually high or low scores. 
This was because group $\mathrm{C}$ had a participant with a very big decrease of $43 \%$. Groups A and B had the smallest changes. These results show that group C's big decrease was mainly thanks to the two participants who had abnormally big decreases. The two treatment groups' results were not noticeably affected by the unusually high or low scores.

Table 4.49 Comparison of decreases in error rate before and after removing unusually high or low scores for all groups

\begin{tabular}{llcccc}
\hline & & Group A & Group B & Group C & Group D \\
\hline Groups' original results & Mean & $1.97 \%$ & $1.56 \%$ & $2.43 \%$ & $0.21 \%$ \\
& SD & 5.94 & 8.54 & 10.35 & 5.31 \\
\hline Groups' results after & Mean & $2.21 \%$ & $1.48 \%$ & $0.70 \%$ & $-0.15 \%$ \\
removing abnormal results & SD & 4.74 & 3.04 & 4.02 & 4.44 \\
\hline
\end{tabular}

So far the results show that although the treatment groups did slightly better than the control groups, and that most of the participants in the treatment groups made progress, the improvement was not remarkable. This rather disappointing result may be due to the measuring method. It seems possible that the sentences that one participant had mistakes in the pre-test were longer than the ones they had in the post-test (as their language memory span was limited at the beginning of the treatment) resulting a low rate of errors. If the sentences on which the same participant made mistakes in the post-test were shorter, the rate of errors in the post-test would be higher, resulting in a minimal decrease of error commitment. These results therefore need to be interpreted with caution.

\subsubsection{The effect of the consultation sessions}

\subsubsection{Did the participants who received consultation make bigger increases than the participants who did not receive consultation?}

The consultation sessions were not given in the first experiment. In the present experiment, group A received this treatment during the speed reading course. A session was held immediately for any participant who did not increase their speeds for two successive lessons. This was carried out throughout the course until the last lesson. In the consultation sessions, the participants were advised on how to read faster, what to expect from the lessons, what they were supposed to do and not to do during the lessons. In total, 17 participants received consultation and 37 sessions were held. These 17 participants were 
the ones who at least once in the course had two successive lessons with no improvement. Among these participants, six participants had only one session and the other had more than one sessions. For group B, there were 18 participants who at least one time during the course had two successive lessons with no improvement. However, they were not given any consultation sessions. This analysis compares the results between these two subgroups of participants to see the subgroup who received the consultation did any better.

Table 4.50 Means and standard deviations of increases in the course for the two subgroups of the treatment groups

\begin{tabular}{|c|c|c|c|}
\hline Measure & & Subgroup A & Subgroup B \\
\hline \multirow{2}{*}{ Extreme method } & Mean & 110.10 & 76.87 \\
\hline & SD & 51.61 & 27.22 \\
\hline \multirow{2}{*}{ Three extremes method } & Mean & 88.97 & 64.30 \\
\hline & SD & 35.62 & 23.45 \\
\hline \multirow{2}{*}{$20^{\text {th }}$ minus $1^{\text {st }}$ method } & Mean & 65.82 & 43.94 \\
\hline & SD & 58.54 & 29.56 \\
\hline \multirow{2}{*}{ Average method } & Mean & 59.00 & 42.26 \\
\hline & SD & 49.47 & 21.13 \\
\hline \multirow{2}{*}{$1^{\text {st }}$ half minus $2^{\text {nd }}$ half } & Mean & 37.35 & 22.01 \\
\hline & SD & 25.25 & 20.07 \\
\hline
\end{tabular}

As shown in Table 4.50, subgroup A made greater increases than subgroup B in all the four scoring methods. The biggest difference was in the extreme method with $33 \mathrm{wpm}$. The smallest difference was in the average method with $17 \mathrm{wpm}$. The four scoring methods produced similar patterns and all showed that subgroup A outperformed subgroup B. A one-way ANOVA was conducted to compare the means of increases of the two subgroups. There was a significant difference between subgroup A and subgroup B in the extreme method, $F(1,33)=5.69, p=0.023$ and in the three extremes method, $F(1,33)=6.08, p=$ 0.019. In order to increase the reliability of the results, the following checks were also done. First, we measured the difference between the average of first half and the average second half in the course for each subgroup. The result indicated that subgroup A made an increase of $37 \mathrm{wpm}$ while subgroup B made an average increase of only $22 \mathrm{wpm}$. Second, we compared the initial speeds of the two subgroups to see if subgroup A had a bigger increase just because their initial speed was lower. The average scores of the first three texts were calculated and compared. This comparison can be said to provide reliable results because no participants received consultation before the third lesson, thus, eliminating the 
possibility that subgroup A had a higher initial speed because some participants in this subgroup received consultation sessions. As can be seen in Table 4.51, the two subgroups had similar the average score on the first three texts. The standard deviation scores for both subgroups were similar, showing that the participants in the two subgroups had similar ranges of speeds. This result demonstrates that subgroup A had a bigger increase not because of a low average initial speed.

Table 4.51 Means and standard deviations of initial speeds in the course for the two subgroups

\begin{tabular}{llcc}
\hline & & Subgroup A & Subgroup B \\
\hline \multirow{2}{*}{ Initial speed } & Mean & 133.23 & 134.78 \\
& SD & 29.46 & 30.93 \\
\hline \multirow{2}{*}{ Final speed } & Mean & 192.34 & 176.81 \\
& SD & 48.43 & 46.11 \\
\hline
\end{tabular}

Thirdly, we looked at the individual scores to see if the subgroups' results were affected by unusually high or low scores. This was done to eliminate the possibility that subgroup B had a smaller increase because a few participants in this subgroup had abnormally low results, which lowered the whole group's average increase. An examination into the individual increases in the average scoring method for both subgroups showed that none in subgroup B had negative results. On the other hand, two participants in subgroup A had abnormally negative results and one had an unusually big increase of $191 \mathrm{wpm}$. If we omit these scores, subgroup A would make an average increase of $61 \mathrm{wpm}$, which was $19 \mathrm{wpm}$ bigger than subgroup B's average increase. These results demonstrate that the subgroups' results were not distorted by unusually high or low scores.

Taken as a whole, it can be assumed that the consultation sessions helped the participants in group A to make greater improvement in the speed reading course. Although the difference was not statistically significant, it is pedagogically meaningful as the biggest difference was $33 \mathrm{wpm}$ and the smallest difference in the most conservative scoring method was $17 \mathrm{wpm}$. This finding supports the idea that it is worth giving consultation sessions to the participants who did not make an obvious improvement during the course. 


\subsubsection{Did the consultation sessions affect the participant's performance on reading other types of texts, oral reading, and memory span tests?}

Since it was found that speed increases in the course transferred to other types of texts, it can be hypothesized that if the consultation sessions had positive effects on speed improvement in the course, they might have affected the participants' performance on reading other texts, oral reading, and memory span tests. Therefore, it is worth comparing the results of the two subgroups to see if subgroup A performed better that subgroup B on those tests.

Table 4.52 Means and standard deviations of increases, initial speeds and final speeds on other texts for the two subgroups

\begin{tabular}{llcc}
\hline & & Subgroup A & Subgroup B \\
\hline \multirow{2}{*}{ Increase } & Mean & 51.28 & 40.35 \\
& SD & 26.91 & 26.35 \\
\hline \multirow{2}{*}{ Initial speed } & Mean & 121.12 & 119.41 \\
& SD & 27.39 & 40.49 \\
\hline \multirow{2}{*}{ Final speed } & Mean & 172.40 & 159.76 \\
& SD & 31.91 & 34.88 \\
\hline
\end{tabular}

The data in Table 4.52 indicated that subgroup A made an 11 wpm bigger increase than subgroup B. The result showed that the two subgroups had similar average speeds on the pre-test but on the post-test, subgroup A outperformed subgroup B with an average speed of $172 \mathrm{wpm}$. An examination into the individual scores indicated that the two groups did not have any participants with unusually big or small increases, thus eliminating the possibility that the groups' results were affected by abnormal scores.

Regarding the improvement in oral reading, the results (see Table 4.53) indicated that the two subgroups made the same increase. However, it can be seen that subgroup A had a higher initial speed. Although the difference between the two subgroups' initial speeds was statistically small with only $8 \mathrm{spm}$, it can be considered as substantial with respect to the improvement that the treatment groups made in oral reading. Both group A and group B made around $8 \mathrm{spm}$ on the oral tests. Thus, it can be assumed that if subgroup A had had the same initial speed as subgroup B, subgroup A's average increase would have been 8 spm bigger than subgroup B's average increase. In this situation, this is a noticeable difference. 
Table 4.53 Means and standard deviations of increases, initial speeds and final speeds in oral reading for the two subgroups

\begin{tabular}{llcc}
\hline & & Subgroup A & Subgroup B \\
\hline \multirow{2}{*}{ Increase } & Mean & 7.08 & 7.13 \\
& $\mathrm{SD}$ & 8.88 & 9.77 \\
\hline \multirow{2}{*}{ Initial speed } & Mean & 178.51 & 171.44 \\
& $\mathrm{SD}$ & 23.85 & 25.74 \\
\hline \multirow{2}{*}{ Final speed } & Mean & 185.59 & 178.57 \\
& $\mathrm{SD}$ & 24.45 & 29.19 \\
\hline
\end{tabular}

Table 4.54 Means and standard deviations of increases, initial raw scores and final raw scores in memory span tests for the two subgroups

\begin{tabular}{llcc}
\hline & & Subgroup A & Subgroup B \\
\hline \multirow{2}{*}{ Increase } & Mean & 4.83 & 4.41 \\
& $\mathrm{SD}$ & 3.01 & 3.06 \\
\hline \multirow{2}{*}{ Initial raw score } & Mean & 9.80 & 9.90 \\
& $\mathrm{SD}$ & 3.35 & 3.07 \\
\hline \multirow{2}{*}{ Final raw score } & Mean & 14.63 & 14.31 \\
& $\mathrm{SD}$ & 3.25 & 2.35 \\
\hline
\end{tabular}

Regarding memory span development, the data showed that subgroup A did slight better than subgroup B. As can be seen from Table 4.54, subgroup A made an average increase of 4.83 while subgroup B made an average increase of 4.41 . The results for initial and final raw scores indicated that subgroup A started at a similar level to subgroup B with a difference of only 0.1 , but on the post-test, subgroup A performed better reaching the score of 14.63 while subgroup B reached a 0.32 lower score. Given that the average increases by groups $\mathrm{A}$ and $\mathrm{B}$ were around 5.0, it can be said that the difference of 0.42 between subgroup A and subgroup B is small. The data also showed that two participants in subgroup A had negative results while all participants in subgroup B made an improvement. These results suggest that the consultation sessions did not have a noticeable effect on the participant's performance on the memory span test. This is understandable as the consultation sessions solely aimed to help the participants increase their reading fluency. 


\subsection{Discussion}

\subsubsection{Speed increases in the speed reading course}

The second experiment replicated the first experiment in that it also aimed to gain data from the speed reading course to see how the participants' speeds changed during the course and if reading rate improvement was made. It was found that both treatment groups made increases over $50 \mathrm{wpm}$. This is a substantial improvement in reading speed and it is encouraging to reading instructors who are considering delivering a speed reading course to their learners. The data demonstrated that the result was reliable. First, the four scoring methods agreed with each other and produced the same ranking for the two groups with group A, who received consultation sessions, always having a slightly bigger increase than group B. Second, the negative results by the participants who made no improvement did not unduly affect the whole groups' results. Third, most of the participants had their slowest speeds in the first half and fastest speeds in the second half of the course, showing that the progress occurred chronologically. Fourth, most of the participants had a gradual increase pattern, showing that their progress was caused by practice in the course rather than some erratic behaviour or on-off effect. Fifth, the participants' initial speeds and their final speeds were highly related, showing that the increases were not caused by learners not taking the course seriously. Sixth, most participants were reading with $70 \%$ accuracy of comprehension and could maintain it with a slight increase as they increased their reading speed. This shows that they were reading and comprehending the text (rauding) rather than just looking at the words without understanding the presented thoughts. These results indicate that the speed increases in the course were a real meaningful improvement.

The results in the present experiment support the findings in the first experiment in many ways. In the first place, both experiments found that most of the participants had their slowest speeds in the first half and reached their fastest scores in the second half of the course, and that many participants continued to increase their reading rates during the last three sessions. This strengthens the idea of the cumulative effect of the speed improvement during the speed reading course. It would not be worth continuing the course if the increase had been gained during the first half. Furthermore, in both experiments, most of the participants had the gradual change pattern. The data showed that $73 \%$ of the participants in the first experiment and $80 \%$ of the participants in the second experiment made steady change throughout the course. This result supports the idea that speed improvement was 
caused by confidence gained from success or by practice rather than by repetition of the words. The two experiments also agree with each other in that they both found a strong link between the participants' initial speeds and final speeds. It was a trend that the participants with higher initial speeds reached higher final speeds. In both experiments, it was found that not only the participants with lower initial speeds but also the participants with the highest initial speeds could benefit from the course. This was possible because none of the participants was near the ceiling level of around $300 \mathrm{wpm}$ for normal reading. Another issue on which the present study provided similar findings to the first study is the comprehension levels that the participants could maintain during the course. Both studies detected evidence that as they were reading the participants comprehended with around $70 \%$ accuracy and that even in the sessions where they reached their fastest speeds, their comprehension accuracy was still kept at similar levels. This result demonstrates that in a speed reading course in EFL, reading rate can increase without comprehension suffering. In short, the findings in the present experiment reinforce the findings in the first experiment and strongly support the idea that a speed reading course is very useful for EFL learners.

The effects of a speed reading course are typically measured by tracking learners' reading speed on the passages in the course. Where the last three and first three average method is used, the overall increase is calculated using six of the passages in the course. However, these six passages (the last three and the first three) also contribute to the increase in reading speed, and the averaging of each set of three results in an increase in the initial speed and a decrease in final speed, thus giving a very conservative estimate for the overall increase in the course. In this respect, the last passage minus the first passage method is a truer measure of speed increase. However it lacks reliability because of the single measurements involved. The present study did not include a control group who did not do the speed reading course but whose progress was measured by doing the first three and the last three texts. The problem with using such a group is that they would have effectively done almost one third of the speed reading course (six out of the twenty passages). However, it is possible to see how such a control group might have performed by comparing learners' speed on the first three passages with their performance on the next three passages (passages 4, 5 and 6). Table 4.55 shows the difference between the average of first three texts and the average of the next three texts for all treatment groups in the two experiments. This is a purer measure than a different control group would be because it excludes any intervening proficiency development between reading passage 3 and passage 
18 that a control group might experience. As can be seen, the difference between the average of the first three texts and the average of the next three texts was at least $11 \mathrm{wpm}$ for all groups, thus, lowering the increases that the groups would have had if we had used a different control group. This result shows that having such a control group would result in a substantial underestimate of reading speed increase, largely because of the large amount of speed increase on the six texts involved. This confirms the wisdom of not including such a control group.

Table 4.55 Means and standard deviations of increases from the first three texts to the next three texts for all treatment groups in the two studies

\begin{tabular}{lcccccc}
\hline & \multicolumn{3}{c}{ The first experiment } & \multicolumn{2}{c}{ The second experiment } \\
\hline & Group 1 & Group 2 & Group 3 & Group 4 & Group A & Group B \\
\hline Mean & 15.09 & 11.34 & 15.54 & 14.41 & 12.30 & 16.50 \\
SD & 23.52 & 17.85 & 28.75 & 19.75 & 31.54 & 24.91 \\
\hline
\end{tabular}

Which method of measuring speed increase should be used? All four methods had high levels of agreement in the present study. The two methods using initial and final scores have the highest face validity and are less likely to include abnormal and erratic behaviour. When the information is used by students, the last score minus the first is probably the best to use because it is not too conservative, and thus is better for motivation. For research, reliability is an important aspect of validity and at the very least the first three and the last three in the course need to be compared with the single first and last in the course, and preferably should be the main method for calculating increase.

Although the results in the present study corroborate the idea that speed improvement was made in the course, it should be noted that there were differences in the speed improvement by participants in the present study and participants in the first study. Since, in the first study, groups 3 and 4 made bigger increases than groups 1 and 2, and the participants in the present study had similar frequency of lessons to groups 3 and 4 , the comparisons between the treatment groups in this experiment and the treatment groups in the first experiment will be done in two ways. The first is the comparisons between groups 1 and 2 in the first experiment and groups $A$ and $B$ in the second experiment. The second is the comparisons between groups 3 and 4 in the first study and groups A and B in the second study. 
Regarding the differences between groups 1 and 2 in the first study and groups A and B in the second study, it was found that these groups made similar increases in all scoring methods except the average method (see Table 4.56). In the average scoring method, groups A and B had better results than groups 1 and 2 . As the average method is the most conservative method and it makes sure that the improvement was real progress during the course, it can therefore be assumed that groups A and B made greater improvement than groups 1 and 2.

Table 4.56 Means and standard deviations of speed increases by groups 1 and 2 and groups $A$ and $B$

\begin{tabular}{llcccc}
\hline \multirow{2}{*}{ Measure } & & \multicolumn{2}{c}{ The 1 st $^{\text {experiment }}$} & \multicolumn{2}{c}{ The $2^{\text {nd }}$ experiment } \\
\hline \multirow{2}{*}{ Average method } & Mean & 42.94 & 37.94 & 57.00 & 51.03 \\
\hline \multirow{2}{*}{$20^{\text {th }}$ minus $1^{\text {st }}$ method } & SD & 31.27 & 33.10 & 40.52 & 29.91 \\
\hline \multirow{2}{*}{ Three extremes method } & Mean & 60.38 & 59.57 & 61.03 & 51.90 \\
& SD & 32.85 & 44.16 & 48.14 & 38.44 \\
\hline \multirow{2}{*}{ Extreme method } & Mean & 75.11 & 73.36 & 80.38 & 73.16 \\
& SD & 26.79 & 22.68 & 32.99 & 30.62 \\
\hline
\end{tabular}

Table 4.57 Means and standard deviations of speed increases by groups 3 and 4 and groups $A$ and $B$

\begin{tabular}{llcccc}
\hline & & \multicolumn{2}{c}{ The $1^{\text {st }}$ experiment } & \multicolumn{2}{c}{ The $2^{\text {nd }}$ experiment } \\
\hline Measure & & Group 1 & Group 2 & Group A & Group B \\
\hline \multirow{2}{*}{ Average method } & Mean & 58.27 & 53.05 & 57.00 & 51.03 \\
\hline \multirow{2}{*}{$20^{\text {th }}$ minus $1^{\text {st }}$ method } & SD & 47.69 & 45.90 & 40.52 & 29.91 \\
\hline \multirow{2}{*}{ Three extremes method } & Mean & 83.55 & 78.38 & 61.03 & 51.90 \\
& SD & 51.64 & 52.62 & 48.14 & 38.44 \\
\hline \multirow{2}{*}{ Extreme method } & Mean & 101.72 & 91.50 & 80.38 & 73.16 \\
& Mean & 52.70 & 34.70 & 32.99 & 30.62 \\
\hline
\end{tabular}


The second comparisons between the two studies concerns the differences between groups 3 and 4 in the first study and groups A and B in the second study. The data (see Table 4.57) showed that the four groups made similar increases in the average scoring method, which suggests their amount of speed improvement during the course was similar. For the $20^{\text {th }}$ minus $1^{\text {st }}$ scoring method, extreme method, and three extremes method, noticeable differences were found, especially between group 3 and the treatment groups of the second study. Given that these groups had the same frequency of lessons, it is necessary to look at their results more carefully and try to find explanations for the differences.

Table 4.58 Comparison of the average of the three slowest speeds and three fastest speeds for groups 3 and 4 and groups $A$ and $B$

\begin{tabular}{|c|c|c|c|c|c|}
\hline & & \multicolumn{2}{|c|}{ The $1^{\text {st }}$ experiment } & \multicolumn{2}{|c|}{ The $2^{\text {nd }}$ experiment } \\
\hline & & Group 3 & Group 4 & Group A & Group B \\
\hline Average of the three & Mean & 150.22 & 134.27 & 119.77 & 121.63 \\
\hline slowest speeds & SD & 30.87 & 22.19 & 22.61 & 22.47 \\
\hline Average of the three & Mean & 251.94 & 225.77 & 200.12 & 194.96 \\
\hline fastest speeds & SD & 68.29 & 48.76 & 39.38 & 38.90 \\
\hline
\end{tabular}

In the first place, it can be seen that both of the extreme methods yielded the same pattern that groups A and B made smaller increases than groups 3 and 4. Since the big increases by groups 3 and 4 might have resulted from their very low scores of the worst sessions and the very high scores of the best sessions, it is necessary to look at their slowest speeds and fastest speeds.

The data showed that the average slowest speeds of groups 3 and 4 were higher than the average slowest speeds of groups A and B. The differences were quite big, especially between group 3 and the two groups in the present study. As shown in Table 4.58, group 3 with the highest average of slowest speeds reached the highest average of fastest speeds, then came group 4, which ranked the second for both initial and final speeds. Groups A and B had the lowest average of initial speeds and final speeds. It was also found in both experiments that the participants with higher initial speeds tended to reach higher final speeds. These results suggest that reading ability might have been the cause of the low scores that groups A and B had in their best sessions. The lower reading ability might have been a barrier for some participants in groups $\mathrm{A}$ and $\mathrm{B}$ to speed up their reading rate. There are, however, other explanations for the difference between groups 3 and 4 and groups A 
and $\mathrm{B}$ when measured using the extreme methods. The differences may be related to the bigger numbers of participants in groups $\mathrm{A}$ and $\mathrm{B}$, which increased the chance of having very marginal increases and thus lowering the whole groups' results. Groups 3 and 4 had only 18 students and the smallest increase they had was 32 wpm. On the other hand, groups A and B consisted of 31 and 30 participants and three of them had negative results, which lowered the whole groups' scores. The numbers of participants with very big increases (over $100 \mathrm{wpm}$ ) in both experiments are similar. However, the same number of them in group 3 will make its result larger than in groups A and B. Another possible explanation is that groups 3 and 4 had bigger speed fluctuations than groups A and B, hence making the whole group's results greater. This explanation is reinforced by a comparison between the results derived from the extreme method and the results derived from the three extremes method. The differences between groups 3 and 4 and groups A and $\mathrm{B}$ were narrowed when using the three extremes method. There are also human reasons for the high speeds that groups 3 and 4 reached in their best sessions. Psychological factors such as learning motivation, learning attitudes and personal factors such as academic skills and timetables can provide explanations for that. As presented earlier, groups A and B in the present experiment had lower academic skills than groups 3 and 4 in the first experiment. Moreover, they had to study more subjects during the treatment time, thus having to distribute their concentration on other courses other than the speed reading course. These obstacles might have worked as factors preventing their mind to work as effectively as groups 3 and 4 .

In the second place, the last minus first methods yielded different patterns between groups 3 and 4 and groups A and B. According to the average method, all these groups had similar results. On the other hand, according to the $20^{\text {th }}$ minus $1^{\text {st }}$ method groups A and B made smaller average increases than groups 3 and 4 . These contrasting results need to be considered through answering two questions. First, why did the two methods yield different results? Second, what could be the reasons for the big increases that groups 3 and 4 had in the $20^{\text {th }}$ minus $1^{\text {st }}$ method?

Regarding the issue relating to why the two scoring methods yielded contrasting results, the question can be answered by looking at the first three scores and the last three scores by participants in the four groups. As shown in Table 4.59, all groups' speeds did not greatly fluctuate during the last three sessions with the biggest difference between either two of these sessions being $16 \mathrm{wpm}$. However, during the first three sessions, while groups 
A and B's speeds increased slightly, groups 3 and 4's speeds substantially increased on the second and third sessions. For example, group 3's average speed was $140 \mathrm{wpm}$ in the first session but their average speed on the third session was 193 wpm, making a 53 wpm difference between the sessions. Therefore, when using the average scoring method, their speed increases were much bigger than when using the $20^{\text {th }}$ minus $1^{\text {st }}$ method.

Table 4.59 Means and standard deviations of initial speeds and final speeds by groups 3 and 4 and groups $A$ and $B$

\begin{tabular}{|c|c|c|c|c|c|}
\hline \multirow{2}{*}{ Session } & & \multicolumn{2}{|c|}{ The $1^{\text {st }}$ experiment } & \multicolumn{2}{|c|}{ The $2^{\text {nd }}$ experiment } \\
\hline & & Group 3 & Group 4 & Group A & Group B \\
\hline \multirow{3}{*}{$1^{\text {st }}$ session } & Mean & 139.61 & 126.67 & 128.65 & 132.77 \\
\hline & SD & 30.54 & 38.11 & 29.53 & 27.24 \\
\hline & Mean & 153.56 & 164.06 & 134.21 & 132.30 \\
\hline $2^{\text {nd }}$ session & SD & 34.24 & 37.29 & 48.79 & 26.65 \\
\hline \multirow{2}{*}{$3^{\text {rd }}$ session } & Mean & 193.11 & 155.72 & 133.46 & 132.53 \\
\hline & SD & 53.90 & 34.52 & 29.80 & 28.31 \\
\hline \multirow{2}{*}{$18^{\text {th }}$ session } & Mean & 211.28 & 199.33 & 185.90 & 181.47 \\
\hline & SD & 54.67 & 53.08 & 39.45 & 38.25 \\
\hline \multirow{2}{*}{$19^{\text {th }}$ session } & Mean & 226.94 & 201.28 & 191.39 & 185.31 \\
\hline & SD & 59.37 & 57.79 & 42.70 & 40.30 \\
\hline \multirow{2}{*}{$20^{\text {th }}$ session } & Mean & 223.17 & 205.06 & 189.68 & 183.80 \\
\hline & SD & 60.31 & 41.73 & 44.11 & 39.86 \\
\hline
\end{tabular}

Regarding the reasons why groups 3 and 4 made greater improvement than groups A and B in the $20^{\text {th }}$ minus $1^{\text {st }}$ method, the possibility that groups 3 and 4 had very low scores on the very first session, thus making their increases bigger can be eliminated. As can be seen in Table 4.59, groups 3 and 4 had higher initial scores than groups A and B. Thus, low initial scores were not the cause of the big increases that groups 3 and 4 made. With respect to the final speeds, group 3's standard deviation was much bigger, showing that their speed range was large whereas group A and group B's figures were much smaller, showing that these two groups' speed ranges were narrower. Thus, it can be assumed that some very good progress makers in group 3 had very fast speeds on the last session, which increased the whole group's result. However, when we omit the two participants with the speeds over $300 \mathrm{wpm}$ from group 3, the group's average increase was still bigger (209 wpm) than those of groups A and B. Besides, the numbers of participants who reached speeds over 200 
wpm in all groups were similar. Regarding group 4, this group's standard deviation was similar to groups A and B, thus it is unlikely that some unusually high scores increased the whole group's figure. Taken as a whole, the initial speeds and final speeds are not a good explanation for the speed improvement differences between groups A and B and groups 3 and 4 . Therefore, the differences between groups 3 and 4 and groups A and B can only be explained by their differences in learning attitudes, motivation, academic skills and timetables.

\subsubsection{Speed increase transfer from the speed reading course to other types of texts}

The second experiment also seeks to confirm the transfer of speed improvement to other types of texts. In the first experiment, it was found that reading speed transferred from the course and thus promoted the participants' reading rates on other types of texts. In the present experiment, the results supported all the findings in the first experiment, confirming that speed increases transferred to other types of texts. The data demonstrated that both treatment groups made substantial increases on other types of texts. Comparisons between the treatment groups and control groups were significant at the $p<0.5$ level. The reliability of this result was reinforced by some other findings. First, the treatment groups and the control groups had similar average speeds on the pre-test, showing that they started at similar levels, thus eliminating the possibility that the treatment groups made bigger increases because their initial speeds were low. Second, there was a strong relationship between the initial speeds and final speeds, showing that the participants' increases were a real improvement rather than just some erratic or dishonest behaviour. Third, it was again confirmed that the texts were equally difficult, showing that there was no text effect. Fourth, the majority of the participants increased their comprehension accuracy or kept it at the same level as they improved their reading rates, showing that their speed improvement was meaningful. Fifth, there was a strong link between in-course increases and speed increases on other types of texts, showing that the speed increases were the result of a transferring process.

Taken together considering the findings in the first study and the second study, it can be claimed that the speed increases in the course transferred to other types of texts. Except for group 2, who had a similar increase to the control group in the first study, all the other treatment groups made noticeable greater improvement on other texts than the control 
groups. However, since the control groups made increases on other types of texts, it can be argued that the treatment groups could have made improvement even if they had not received the treatment. Thus, we took a more conservative look at the groups' increases to see if taken away the amount of improvement that the control groups made, the treatment groups' results were still substantial.

Table 4.60 Comparisons of increases on other types of texts and the difference between the treatment groups' increases and the control groups' increases for the two studies

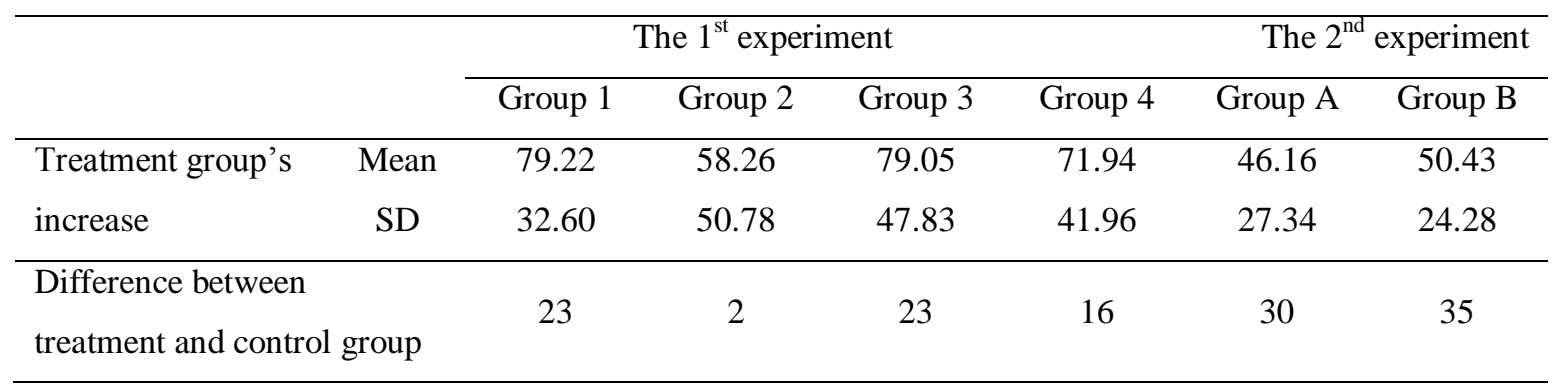

As can be seen from Table 4.60, group 1 and group 3 in the first study still made increases over $20 \mathrm{wpm}$. Group A and group B in the second study still made increases over 30 wpm. Group 4 in the first study made a slightly smaller but still noticeable increase of 16 wpm. These results show that even from the most conservative perspective, the speed reading course was still beneficial to the participants as it assisted them to increase their speeds on other types of texts by at least around $20 \mathrm{wpm}$.

One of the questions raised in the first experiment was about the effect of the English program on reading speed improvement. Thus the present experiment set out to answer this question by assigning one of the control groups not to follow the English program at the university. This was done to compare the results of the two control groups. The data showed that group C, who followed the usual English program, did not make more improvement than group D, who did not follow the program. Group C made only an average increase of $11 \mathrm{wpm}$ while group D made an average increase of $20 \mathrm{wpm}$. This result suggests that the usual English program did not remarkably affect speed change. However, the fact that both control groups in the present experiment and the control group in the first experiment made increases on other types of texts indicates that learning English in general can help learners to increase their reading rate in reading English texts. While it seemed that in the present study, the usual English program did not greatly 
increase the participants' speeds, it remains uncertain why the control group in the first study could make an average increase of $56 \mathrm{wpm}$, which is a substantial improvement. A comparison of the three groups' initial speeds (see Table 4.61) showed that the control group in the first study had an average initial speed of $102 \mathrm{wpm}$, which was around 15 wpm lower than the control groups in the second study. Even if the first study control group's average speed was as high as the second study control group, their increase was still much bigger. Thus, it is not possible to say that the first study control group had bigger increases because they had lower initial speeds. If we removed the four participants with increases over $100 \mathrm{wpm}$ from the first study control group, and if we removed the participants with negative results from the second study control group, the first study control group still had a noticeably bigger increase than the second study control group. Hence, it is not possible to say that the three control groups' results were affected by unusually high or low scores. Taken together, the difference between the first study control group and the second study control group can only be explained by the participants' schedules, learning motivation, attitudes, and academic abilities.

Table 4.61 Comparison of initial speeds and final speeds on other types of texts for the control groups in both experiments

\begin{tabular}{llccc}
\hline & & The first study & \multicolumn{2}{c}{ The second study } \\
\cline { 3 - 5 } & & Control group & Group C & Group D \\
\hline \multirow{2}{*}{ Initial speeds } & Mean & 102.68 & 118.96 & 113.82 \\
& SD & 28.06 & 26.11 & 30.72 \\
\hline \multirow{2}{*}{ Final speeds } & Mean & 158.77 & 129.42 & 133.48 \\
& SD & 41.30 & 20.50 & 27.18 \\
\hline
\end{tabular}

The second experiment found that the treatment groups made a similar increase to group 2 but noticeably smaller increases than groups 1, 3 and 4 in the first experiment (see Table 4.62). Given that the treatment groups in both experiments followed the same speed reading course, read the same passages on the tests and were all randomly assigned, it is necessary to examine this issue to see why they did not have similar increases on other types of texts. It can be seen from Table 4.62 that groups A and B had higher initial speeds than the four treatment groups in the first study. However, even if groups A and B had had the same average initial speeds as groups 1, 3 and 4, their increases would have still been smaller. Thus initial speeds were not a good explanation for the bigger increases that the treatment groups in the first study had. An examination of the individual results indicated 
that none of the participants in groups A and B made increases over $100 \mathrm{wpm}$ whereas all treatment groups in the first study had participants with increases over $100 \mathrm{wpm}$. If we removed these big figures from the groups, their new results would be similar to groups A and B's results. This suggests that the first study groups' results were affected by some unusually high figures. There are several explanations for the presence of very big increases in the first study but not in the second study. First, it is possible that the results were affected by the experimental design. Since the tests on other types of texts were manually administered in the first experiment, it was more likely that participants could associate the tests on other types of texts with the speed reading course, thus knowing what the researcher expected them to do. Conversely, the same tests were done on the computer and the software program recorded the time spent on each text, thus it was unlikely that the participants in the second experiment could figure out the relation between the tests and the speed reading course. Second, it was found that the in-course speed increases were highly related to the increases on other types of texts. As a result, it is logical that the treatment groups in the second study made smaller increases on other types of texts than the treatment groups in the second study because the first study treatment groups made greater improvement in the course than the second study treatment groups. Third, in the second study, the treatment groups might have had lower motivation, tighter schedules, and lower academic skills, all of which might have affected their progress in reading rate development.

Table 4.62 Comparison of initial speeds, final speeds and increases on other types of texts by the treatment groups in both experiments

\begin{tabular}{llcccccc}
\hline & & \multicolumn{3}{c}{ The second experiment } & \multicolumn{3}{c}{ The first experiment } \\
\cline { 3 - 8 } & & Group A & Group B & Group 1 & Group 2 & Group 3 & Group 4 \\
\hline \multirow{2}{*}{ Initial speed } & Mean & 118.87 & 119.73 & 107.33 & 102.89 & 105.88 & 109.22 \\
& SD & 34.95 & 39.61 & 33.17 & 59.17 & 30.35 & 29.45 \\
\hline \multirow{2}{*}{ Final speed } & Mean & 165.03 & 170.16 & 186.55 & 161.00 & 184.61 & 181.05 \\
& SD & 36.75 & 34.61 & 53.19 & 51.75 & 56.21 & 53.44 \\
\multirow{2}{*}{ Increase } & Mean & 46.16 & 50.43 & 79.22 & 58.26 & 79.05 & 71.94 \\
& SD & 27.34 & 24.28 & 32.60 & 50.78 & 47.83 & 41.96 \\
\hline
\end{tabular}

The present experiment expands research on the relationship between reading speed and comprehension. The findings support arguments in some previous first language studies (Bowey, 2005; Chang, 2010; Fuchs, et al., 2001; Perfetti, et al., 2005; Segalowitz \& 
Segalowitz, 1993; Stanovich, 2000). In this experiment, most participants (83\%) increased their reading rate while maintaining the same comprehension level or increasing it. Around $27 \%$ of the participants scored less on comprehension and these participants were the ones who made the least speed improvement. This supports the idea that reading faster does not necessarily degrade comprehension and that people can actually learn to increase both reading rate and comprehension at the same time. Besides, the experiment also found that the treatment groups made more improvement in comprehension than the control groups. While only around $35 \%$ of the control groups increased their comprehension accuracy, $87 \%$ in the treatment groups could increase comprehension. This result reinforces the benefits of the speed reading course in that it helped the participants not only to improve their reading rates but also to be able to increase their comprehension. Interestingly a tradeoff relationship between reading rates and comprehension level was found at the beginning of the treatment but not at the end of the treatment. In a comparison between reading rates with comprehension scores on the pre-test, there appeared to be a trend that the higher reading speed a participant had, the lower comprehension score the participants made. This can be explained by the participants' reading habits before the treatment. It might be that the participants who had more correct comprehension answers were likely to be the ones who tried to slow down to get more information from the text. On the other hand, the participants who read faster dropped their comprehension as compensatory behaviour. However, the trade-off relationship between reading speed and comprehension does not hold for the post-test when the participants had had the training in speed reading. The results from group A and group B showed that participants with the highest final speeds also reached the highest scores on comprehension. The findings highlight the effect of the speed reading course in training people to improve their reading speeds without comprehension suffering. This finding extends our understanding of the effectiveness of speed reading courses. While it is argued that in a speed reading course in L1, learners may suffer a decrease in comprehension if they increase their speeds, the current finding suggests that in a speed reading course in L2/FL, comprehension does not necessarily have to compensate for reading rate increases.

Another question examined by this research investigated how readers read throughout a text. It aims to explore how their speeds change when moving on in the text. The results showed a strong tendency for the readers to read faster in the second half of the text. Perhaps in the first half of the text, they try to slow down to obtain the general meaning of the text and get accustomed to it before allowing themselves to go any faster. This might 
be a common reading habit but it was surprising to see that the participants did not read more slowly in the last section of the text. It is commonsense that people tend to suppose that the last section contains the most important conclusion of a text and hence read it more carefully. One possible explanation is that the test was done on the computer, which prevented the participants from deciding if one section was the last part of the text, thus the participants continued to read as fast as they were doing on the previous sections. Further research needs to explore the underlying reasons why readers read more slowly at the beginning of a text and make sure the learner knows if one section is the last part of the text to derive stronger evidence for this pattern of speed change throughout the text.

\subsubsection{The effects of the speed reading course on other aspects of language knowledge}

The present experiment also investigated the influence of silent reading speed development on oral reading rate. The results indicate $77 \%$ of the treatment groups and $64 \%$ of the control groups read faster in the post-test. Although both categories made modest improvement with $8 \mathrm{spm}$ for the treatment groups and $2 \mathrm{spm}$ for the control groups, comparisons between the treatment groups and the control groups were significant at the $\mathrm{p}<.05$ level. The reliability of the result was enhanced by the examination into possible factors that might have distorted the groups' scores. First, both syllables per minute and the words per minute calculation methods were used to make sure that the results were not distorted by the scoring methods. Second, the initial and final speeds were examined to see if the groups had small increases because they already started at high speeds. The results showed that none of the participants was near the ceiling of around $200 \mathrm{wpm}$ in normal oral reading (Meyer \& Felton, 1999), thus suggesting that there was no ceiling effect. Third, the results by the participants who read text A in the pre-test and text B in the posttest were compared with the results by the participants who did them the other way around to see if there was any text effect. The data showed that the two groups did similarly well, thus confirming that the texts did not distort the groups' results. Fourth, the negative scores by participants who made no improvement were removed and the data indicated that the negative figures did not affect the groups' results. Taken together, all results suggested two implications. On the one hand, it seems that generally oral reading speed does develop along with silent reading speed, but the improvement is small. The finding has important implications for language teachers as it encourages teachers to balance the proportion of teaching productive and receptive skills in the language curriculum. Focusing on receptive skills with the hope that it will facilitate productive skills needs to be done with much more 
consideration to make sure that students are given enough chances to practice productive skills as well. On the other hand, because the treatment groups outperformed the control groups, it can be said that the speed reading course played a role in the participants' oral reading rate improvement. Since the main purpose of the speed reading course was not to help the participants to increase their oral reading speeds, and that oral reading skills largely belong to the productive dimension rather than the receptive dimension, it can be assumed that the extra effect of the speed reading course is substantial.

A comparison of average speeds in silent reading on other types of texts and oral reading demonstrated that before the treatment, the participants read at similar speeds for both oral reading and silent reading (around $118 \mathrm{wpm}$ for silent reading and $115 \mathrm{wpm}$ for oral reading). According to Meyer and Felton (1999), a good oral speed in L1 should range from around $100 \mathrm{wpm}$ to $200 \mathrm{wpm}$ but this is necessarily slower than silent reading. Therefore, it could be argued that the participants in the second experiment might have done many regressions in silent reading, which slowed down their silent reading rates. Perhaps the psychological fear that they would miss important information might have pulled them back, making them read more slowly than necessary. As a face-saving exercise, Vietnamese learners always try to avoid letting other people know that they do not understand something (Burns, 1991; Ferraro, 1994; Pham, 2010; Vang, 1999). Consequently, it seems that in silent reading they may have freely regressed and reread knowing that no one would notice it, while in oral reading they could not because they knew their voice was recorded. However, the results on the post-test found a greater difference between the participants' speeds in silent reading and oral reading (around 151 wpm for silent reading and 119 wpm for oral reading). This was because the silent reading speed improvement was substantial while the oral reading speed improvement was small. This finding, in one way, highlighted the effects of the speed reading course on silent reading speed improvement and in another way, demonstrated that participants may have learned how to avoid regressing and yet not missing important information from a text. It is also likely that they might have obtained some confidence about their reading achievement and hence dared to read faster.

Another obvious finding to emerge from this experiment is that the participants tended to read much faster in the speed reading course than in oral reading and silent reading of other types of texts. This pattern was found in both the pre-test and post-test. The difference can be explained in part by such psychological factors as pressure and anxiety. It seems 
possible that in the speed reading course, the participants were aware that their improvement was not part of the grading criteria at university and thus felt more relaxed to read. They were also told that the main goal of the course was to help them increase their reading speed but not to answer correctly all the comprehension questions. On the other hand, when reading other types of the texts and oral reading texts, they were not told anything about the aims of the tests. This may have made them feel more nervous and as a result negatively affected their speeds. This finding, while preliminary, suggests that a concentration on psychological factors may help reading instructors to achieve their goal of assisting their learners in reading faster.

In the present experiment, one of the major aims was to determine if language complexity develops concurrently with reading fluency. The participants' language complexity was assessed through the language memory span pre-test and post-test. The tests were done on the computer and the participants were supposed to repeat 20 sentences of increasing length and grammatical complexity. The memory span tests were visually but not orally done. It only involved the skill of reading the sentences, memorizing them, and retyping them. This was done to narrow the difference between the two receptive tasks and the productive tasks. A set of criteria to assess the participants' answers was formulated. This set of criteria involved three scoring methods. The tough method does not accept any mistakes. The moderate method accepts obvious spelling mistakes and the generous method accepts obvious spelling mistakes as well as lexical and grammatical mistakes that did not result in a lexical change. The strong agreement among the three scoring methods proved that the set of criteria worked well. An analysis was also performed on the reliability and validity of the memory span sets. The results provided strong evidence that the two sets were equal enough to be interchangeably used for both pre-test and post-test of memory span without causing any distorting data. The experiment therefore added to a growing but still small body of literature on assessing language memory span. Although there are second language studies of working memory span (Caplan \& Waters, 1994; Fortkamp, 1999; Harrington \& Sawyer, 1992; Kormos \& Sáfár, 2008; Weissheimer \& Mailce, 2009; Zhang \& Feng, 1990), there are few that use second language sentences (Harris, 1970; Lado, 1965; Service, 1998).

The results indicated that the three scoring methods agree with each other and produced the same ranking of the groups. Group A made the best improvement, then came group B. Group D ranked the third and group C made the least progress. It was found that the 
treatment groups outperformed the control groups. While $95 \%$ of the treatment groups made an improvement, only $58 \%$ of the control groups improved their memory span. The treatment groups had far more participants with increases over 5.0 than the control groups (59\% vs. 29\%). Almost half of the control groups did not improve their language memory span and among the ones who progressed, the improvement level was not substantial. On the other hand, only $5 \%$ of the treatment groups did not progress. The data of the best scores, the worst scores, the best increases, the worst progress, initial scores, final scores, the order of the sentences on which the participants provided correct answers, and the relationships between memory span increases and speed increases all reinforced the reliability of the result. First, the data indicated that the lowest score on the pre-test was 3.0, and on the post-test was 4.0, the highest score on the pre-test was 18.0 and on the post-test was 19.0. This shows that there was no ceiling effect or floor effect. Second, the results by the participants who did set A on the pre-test and set B on the post-test were compared and it was found that there were no noticeable differences between the two categories. Third, the average initial scores demonstrated that the four groups had similar results on the pretest, showing that their increases were not affected by their initial scores. Fourth, it was found that on the post-test, the participants could answer correctly more sentences in the more difficult parts of the test than on the pre-test. This shows that the increases made on the tests were a real improvement in memory span. Finally yet importantly, the strong relationship between the increases in the course, the speed increases on other types of texts and the increases in memory span enhances the idea that the memory span increases were a real improvement. Thus, the experiment supports findings by Yuan and Ellis (2003), who claimed that complexity develops when fluency improves.

The strong link between the three aspects: speed increases in the course, speed increases on other types of texts and memory span improvement is one of the most interesting findings of the present experiment. The data showed that the bigger increases in the course and on other types of reading a group of participants made, the greater improvement in memory span the group had. This suggests that reading fluency not only transfers from the course to other types of reading, but also is accompanied by language complexity development. Several interpretations can be made of this result. First, the strong relationship among the increases in the three aspects reinforces the reliability of the study's results. It shows that the increases in any of these aspects were not distorted by some erratic or dishonest behaviour. Second, the trend that the participants with bigger increases in one aspect also made greater improvement in the other two aspects suggests that learners' improvement 
depends on some factors that are similarly effective for any aspects of language development, thus learners who have more of those factors will improve more in any of the three aspects. Some of those factors may be high motivation, good academic skills, positive learning attitudes, and confidence. However, in order to establish this, further research is required.

The experiment yielded some interesting data about language memory span and reading speed. In the first place, the same trend was found when comparing the individual participants' initial speeds with their final speeds and when comparing the participants' initial memory span with their final memory span. When putting all the participants in four groups according to their initial speeds, it was found that the third best group could reach as high a speed as the second best group. Similarly, in memory span, the second best group could reach the same result as the best group and the fourth best group could reach as good a result as the third best group. These results suggest that the participants' reading speed improvement and memory span development do not depend on their starting levels. This is very encouraging for learners who are at lower levels of reading speeds and memory span as it holds that through practice in the course, they can actually keep up with other learners who were initially better. Another interesting finding to emerge from the present experiment is that there was no connection between memory span and reading speed, even though the increases in these two aspects are strongly related. That is, the increase in reading speed predicts the amount of improvement in memory span, but a participant's reading speed does not predict their level of memory span. If we rank the participants according to their memory span, it does not agree with the ranking of their reading speeds. To generalize, it can be hypothesised that language complexity and fluency concurrently develop but are not a good predictor of each other. However, the relationship between reading speed and memory span is an intriguing one and further studies need to be done to explore the role of memory span in the reading process, to what extent it facilitates reading rate, if it does, and how it really affects and reflects the development of language complexity and fluency.

The present study seeks to determine whether speed increases were accompanied by development of language knowledge accuracy. In the experiment, language accuracy was measured by looking at the sentences that the participants produced in the memory span tests and seeing if they contained fewer grammar mistakes than on the post-test. The error rate was measured by taking the number of errors per total number of words in the 
sentences containing the errors. It was found that the groups' error rates did not noticeably decline in the post-test. The average decrease in error percentage was only around $2 \%$ for both control groups and experimental groups. However, caution must be applied when interpreting this result. First, the results of error commitment rates may not agree with the results of memory span improvement. The number of acceptable mistakes did not always reflect the number of correct sentences each participant made. For example, in the pre-test, a participant gave seven correct answers according to the tough scoring method, and nine correct answers according to the generous scoring method. In the post-test, the participant gave 11 correct answers according to the tough scoring method and 13 correct answer according to the generous scoring method. The number of sentences with acceptable errors in the post-test was bigger (11 vs. 9), and thus increased the chance that the participant had more mistakes in the post-test. This does not mean the participant's accuracy degraded. Second, when a participant could only reach the seventh sentence in the pre-test, for example, the likelihood that the participant would make mistakes was minimized to a greater degree than when they reached the $11^{\text {th }}$ sentence in the post-test. The more they moved along the test, the longer and more complex the sentences became, giving them more chances to make mistakes. Therefore we had to examine the correspondent items in the post-test to see if the participants still made the same mistake types they did in the pretest. This can be done since the two sets of memory span contain equivalent sentences that are similar in terms of grammar, vocabulary type and length. For each participant, the items in the pre-test and post-test were compared. If the post-test list did not contain a correspondent sentence in the pre-test list, it means the participant made an improvement on that item. The number of items on which the participant made improvement per total number of items in the pre-test is called the percentage of improved items.

Table 4.63 Percentage of improved items in the memory span tests

\begin{tabular}{lccc}
\hline Percentage of improved items & Control groups & Treatment groups & Both categories \\
\hline $100 \%$ & 8 & 20 & 28 \\
From 50\% to 99\% & 19 & 21 & 40 \\
From 25\% to 49\% & 7 & 5 & 12 \\
No improved sentences & 17 & 6 & 23 \\
No acceptable errors in pre-test & 4 & 9 & 13 \\
\hline
\end{tabular}

It was shown that in the post-test, 80 out of 103 participants with acceptable errors in the pre-test had at least $25 \%$ improved items (see Table 4.63). Twenty-eight of them made no 
errors in all the corresponding items that they had errors in the pre-test. Only eight of these participants are from the control groups and the other 20 were in the treatment groups. Moreover, among the 23 participants who did not have any improved sentences, only six of them were in the treatment groups and the other 17 were in the control groups. In the first place, it appeared that many participants made accuracy development when they answered correctly the corresponding items on the post-test where they made errors in the pre-test. However, if they could avoid committing errors on the corresponding items but made errors in other sentences, it would be hard to decide their improvement level. For this reason, we also scrutinized the participants' answers to see if they had any items correctly done on the post-test but incorrectly done on the post-test. That is, if, for example, sentence \#7 on the pre-test was correctly answered but on the post-test was answered with either acceptable or unacceptable errors. We then measured the improvement level by taking the number of items that each participant answered incorrectly on the pre-test but correctly on the post-test (improved sentences) minus the number of items that the participant answered correctly on the pre-test but incorrectly on the post-test (degraded sentences). If the value is positive, it means the participants had more items improved but fewer items degraded. By that, we can say the participant made more improvement than decreasing and thus, in total, they made positive progress. The results revealed that of all the 80 participants who had improved sentences, 53 had positive results and 15 had neutral results. However, no significant difference was found between the control groups and treatment groups (see Table 4.64). As a result, it is not possible to determine whether the treated groups did better than the control group.

Table 4.64 Improvement level in terms of error free sentences in the memory span tests by participants in the control groups and the treatment groups

\begin{tabular}{lccc}
\hline Value of improvement & Control groups & Treatment groups & Both categories \\
\hline Positive & 20 & 33 & 53 \\
Neutral (zero) & 5 & 10 & 15 \\
Negative & 9 & 3 & 12 \\
No improved sentences & 17 & 6 & 23 \\
Not applicable & 4 & 9 & 13 \\
\hline
\end{tabular}

In short, findings in the experiment put us in a middle position and it provided little evidence to assert the effect of the speed reading course on language accuracy. This is in agreement with findings by Ellis (1987), Crookes (1989), and Wigglesworth (1997), who 
reported that training on other aspects (particularly planning time in those studies) affected the learner's language complexity but did not substantially promote accuracy or the results were too ambiguous to determine if accuracy was also improved. A possible explanation for this absence of development in accuracy of language knowledge is that the usual English program at the university and the English course at the language centre were generally accuracy focused, thus the accuracy effect of the speed reading course was not noticeable. By contrast, the speed reading course was fluency focused, which was new to the participants as they had not been provided this type of practice before, thus giving more chances for the participants to make substantial improvement in fluency.

The present experiment found that the memory span test worked very well and produced reliable results. Thus if appropriate revision can be done, the memory span sets can be used as a testing material for future studies. One of the adjustments that could be done on the test may relate to the increasing difficulty throughout all the items in the test. Each of the memory span sets contained 20 sentences, which were purposely designed to be of increasing difficulty in grammar and vocabulary. In order to see if any of the sentences were more difficult or easier than they were supposed to be, we examined all individual participants' responses to the items in both versions and counted the number of participants who had correct answers on each item. In order to do this, both the pre-test and post-test results were scrutinized. Although the two versions of the memory span test were designed with the aim that they contained similar items, it is still worth analyzing them separately. Thus the data were classified into two categories, one was for version $\mathrm{A}$ and the other for version $\mathrm{B}$. The results by the participants who did version $\mathrm{A}$ on the pre-test and the results by the participants who did version A on the post-test were examined. The same analysis was done for the participants who did version B. If, for example, the number of the participants who correctly answered sentence \#4 in version A was far bigger than the numbers of the participants who correctly answered sentences \#1, \#2 and \#3, it can be assumed that sentence \#4 in version A was too easy and should be modified. If sentence \#4 in both versions was found to be too easy, then the grammatical item or vocabulary level in that sentence may not be as difficult as commonly considered and changes should be made on the grammatical item or vocabulary level.

The item analysis shows that in general, the more toward the end of the test, the fewer participants could answer correctly. This trend applies for both versions. It seems from the data for both versions that item \#1 might be more difficult than items \#2 and \#3 since item 
\#1 had fewer participants than the next two items. However, it can be argued that the difference was small (only six for version A and three for version B), and that the participants might not have been accustomed to what they should do on the very first item of the test, which might have resulted in an incorrect answer. However, as can be seen in Table 4.65 and 4.66, for both versions, item \#10 seemed to be a bit too difficult compared with the three successive items that follow it. In version A, while only 60 participants could correctly answer item \#10, there were more than 70 participants having correct answers on the next three items. In version B, while only 62 participants could correctly answered item \#10, there were at least 70 participants having a correct response to this item. The data also indicated that item \#19 seemed to be too easy compared with the other three items that came before it. In version A, while around 30 participants could answer correctly items \#17 and \#18, and only 19 participants could answer correctly item \#20, 56 participants could answer correctly item \#19. In version B, while only 32 and 28 participants succeeded in items \#17 and \#18, and only 17 participants succeeded in item \#20, there were 52 participants having a correct answer to item \#19. These results suggest that item \#19 may be easier than it should be. Thus, it might be necessary to modify item \#10 making it easier and modify item \#19 making it more difficult.

Table 4.65 Number of participants having a correct answer on each item of the memory span test - version A

\begin{tabular}{cccccccccc}
\hline Item 1 & Item 2 & Item 3 & Item 4 & Item 5 & Item 6 & Item 7 & Item 8 & Item 9 & Item 10 \\
\hline 105 & 110 & 116 & 98 & 96 & 88 & 86 & 82 & 78 & 60 \\
\hline Item 11 & Item 12 & Item 13 & Item 14 & Item 15 & Item 16 & Item 17 & Item 18 & Item 19 & Item 20 \\
\hline 77 & 75 & 71 & 55 & 49 & 47 & 30 & 27 & 56 & 19 \\
\hline
\end{tabular}

Table 4.66 Number of participants having a correct answer on each item of memory span test - version $B$

\begin{tabular}{cccccccccc}
\hline Item 1 & Item 2 & Item 3 & Item 4 & Item 5 & Item 6 & Item 7 & Item 8 & Item 9 & Item 10 \\
\hline 108 & 111 & 115 & 100 & 95 & 85 & 85 & 83 & 79 & 62 \\
\hline Item 11 & Item 12 & Item 13 & Item 14 & Item 15 & Item 16 & Item 17 & Item 18 & Item 19 & Item 20 \\
\hline 76 & 78 & 70 & 54 & 48 & 43 & 32 & 28 & 52 & 17 \\
\hline
\end{tabular}

Taking a closer look at item \#10 in both versions and the individual participants' responses to the item, we found that most of the participants who had an incorrect answer to this item 
made a mistake relating to the words indicating numbers and time in the sentences. Many of them wrote 10 hours by 4 am instead of four hours by 10 am for version $\mathrm{A}$, and nine hours by $10 \mathrm{pm}$ instead of ten hours by $9 \mathrm{pm}$. Perhaps including two numbers in one sentence made it hard for the participants to remember which number went with which phrase.

Version A: I will have been running for four hours by $10 \mathrm{am}$.

Version B: They will have been working for ten hours by 9 pm.

Comparing item \#19 with its adjacent items in both versions, we found that item \#19 contained simple present verbs while the other three sentences contained past tense and past perfect tense verbs. This perhaps might have made it easier for the participants to recall item \#19 than the other three items. An examination into the participants' responses to these items showed that many participants missed out the functional words in items 17 , \#18 and \#20. This included the intensifier very, right (in right after), just (in just as), articles the, a, prepositions about, for, by, to, at, in, possessive adjectives my, his, her. While there were at least three functional words like those in each of the items 17, 18 and 20 , there was only one functional word in item \#19. The data showed that many students missed out these words in items \#17, \#18 and \#20. To conclude, in a revised version, changes should be made to the tense of the verbs and the number of functional words in item \#19.

Version A:

Item 17: We found it very hard to believe the story he told us about his brother.

Item 18: Last night I finished my class early and went for a long walk by the river.

Item 19: As soon as she comes back, I will tell her that you want to see her.

Item 20: It began to rain very hard yesterday just as we were taking his mother to the train.

\section{Version B:}

Item 17: She thought that it was very interesting to listen to the talk about her friends.

Item 18: Last year he completed his studies at school and went to a university in another city. Item 19: As long as you wait here, you will see the girl that you want to talk to.

Item 20: It started to snow very heavily yesterday right after we had parked our car in the centre. 


\subsubsection{The effect of the consultation sessions}

In the present experiment, consultation was provided to the participants in group A during the speed reading course. However, only 17 out of 31 participants in group A received the consultation. These participants would receive the consultation if they had two successive lessons with no improvement. There were 18 participants in group B who at least one time during the treatment had two successive lessons with no improvement, but these participants did not receive any consultation sessions. The effect of the consultation sessions was determined by comparing the results of the subgroup of group A and the subgroup of group B. It was found that the subgroups who were given consultation sessions outperformed the other subgroup in the speed reading course and on other types of texts. In all the four scoring methods, subgroup A made greater improvement than subgroup B and the difference was at least $17 \mathrm{wpm}$. In the extreme method, the difference was $33 \mathrm{wpm}$. This result was reinforced by the evidence that both subgroups had similar initial speeds, which means subgroup A did not have a bigger increase because they had a lower initial speed. Besides, the data showed that the subgroups' results were not distorted by unusually high or low scores. It can therefore be assumed that the consultation sessions had an effect on the participants' reading speeds during the course. With respect to the speed transfer to other types of texts, there was evidence that the subgroup who received the consultation made greater improvement than the other subgroup. The data indicated that subgroup A made an increase of $51 \mathrm{wpm}$ while subgroup B made an increase of only $40 \mathrm{wpm}$. This is a noticeable difference because it is more than $25 \%$ of the total increase that subgroup made.

Interestingly the present experiment found that in oral reading, subgroup A might have had a bigger increase if their initial speed had been the same as subgroup B's initial speed. The two subgroups made the same average increase of $7 \mathrm{spm}$. However, subgroup A's initial speed was $8 \mathrm{spm}$ higher than subgroup B's initial speed, thus, if they had had the same initial speed as subgroup B's, they might have made a difference of $8 \mathrm{spm}$ compared with subgroup B's increase. Given that the two treatment groups in the present experiment made increases of around $8 \mathrm{spm}$, it can be assumed that a difference of $8 \mathrm{spm}$ is worth mentioning. However, it can also be argued that subgroup A might not have been able to reach the final speed that they had if their initial speed had been lower. Thus, it is not convincing to say that the consultation sessions positively affected the participants' oral reading rates. 
The experiment did not detect strong evidence for the effect of the consultation on the participants' memory span development. A comparison of the two subgroups showed that subgroup A made a slightly bigger increase than subgroup B. The difference was only 0.4. This result is not surprising as the aim of the consultation was to provide the participants with advice on how to read faster. An examination into the individual participants of both groups' initial and final speeds to eliminate the possibility of a ceiling effect, floor effect, text effect, unusually high or low score effect, was also done to make sure the results were reliable. It thus seemed that the subgroup who received consultation sessions was slightly better than the other subgroup but there was not enough evidence to confirm the effects of the consultations. Further studies on this topic are therefore recommended.

\subsection{Summary of main findings}

Overall, the main findings from the second experiment are:

1. Consistencies in results of reading rate improvement among the participants during the speed reading course highlight the positive benefits of speed reading courses.

2. Consultation sessions have effects on reading rate improvement within and outside the speed reading course.

3. Speed reading can help readers to increase their fluency without degrading their comprehension level.

4. It seemed that speed increases are not accompanied by great oral reading rate improvement, but the treatment groups did outperform the control groups, and the fact that developing oral reading rate was not the aim of the course makes this modest improvement meaningful and worth mentioning.

5. Before the speed reading course Vietnamese students tended to read similarly in oral reading than silent reading, perhaps because they made more regressions in silent reading. They also tended to read faster in the second half of a text in silent reading.

6. Speed reading courses facilitate language memory span, and the relationship between reading rate and memory span is weak while the relationship between reading rate increases and memory span increases is strong.

7. There is strong evidence that fluency and complexity develop concurrently.

8. The two texts for oral reading and the two sets of memory span sentences were shown to be equal in terms of length and difficulty and thus can be interchangeably used for pre-test and post-test on oral reading rate or language memory span. 
9. The usual English program at the university did not have noticeable effects on speed improvement in the course and on other types of texts, oral reading improvement, or language memory span development. 


\section{CHAPTER 5 CONCLUSION}

This thesis examines the effects of speed reading courses on reading rate improvement in and outside the course, on oral reading rate and language complexity. In order to fulfil the purposes, two experiments were carried out among first year English major students at a university in Vietnam. The results derived from the experiments have added to our understanding of the benefits of speed reading courses and made several contributions to the current literature of second language development.

The major difference between the experiments in this thesis and previous research lies in the research questions and measuring methods. The experiments were designed to investigate a few issues that previous research had not covered. The scheduling of a speed reading course, the effect of the speed reading course on oral reading rate, language complexity and language accuracy have not been explored in any previous studies. The experimental design expanded upon earlier methodologies with new measuring methods and tests. First, the amount of in-course speed improvement was measured by a new method called the three extremes scoring method, which takes the average of three best scores minus the average of three worst scores, and it was found that this method agreed very well with the current methods. Second, memory span was measured based on a list of criteria, which was found to be reliable in producing strongly related results. Third, four texts for reading other types of texts, two texts for oral reading, and two sets of memory span sentences were also used and it was found that these materials yielded reliable results. Fourth, oral reading rate was measured using the syllables per minute method. Fifth, a computer program, which was especially designed for testing reading other types of texts and language memory span, worked smoothly and fulfilled the task of not letting the participants know that their speed was being measured. The software program worked well thus can be used for language testing in future research.

The two experiments provided additional evidence with respect to the effects of speed reading courses on reading speed. The findings lend support to speed reading research by Nation and Chung (2006), Cramer (1975), Bismoko and Nation (1972), and Macalister (2008, 2010), who showed that reading rate can be improved by a speed reading course. It was found that most participants achieved substantial increases in the course. The results were thoroughly examined from various perspectives and four measuring methods were discussed and utilized. The four scoring methods agreed with each other in terms of 
producing the same ranking of the treatment groups in each of the experiment. Large increases found from the data indicated that the best group could make an average difference of 142 wpm between their lowest and highest scores. The data of the slowest speeds, fastest speeds, and the speed change patterns strongly confirmed the findings in previous studies. The results of the two experiments also showed that it was wise not to use a control group who read the first three texts and the last three texts because that would underestimate the speed increase. The two experiments yielded findings on other issues that no research had covered before, such as the reliability of the texts in the speed reading course and the likely causes of reading speed increase within the speed reading course. A comparison of the speed progress charts collected from the participants showed that no text in the course book was too difficult or too easy for the participants. Possible explanations for the cause of speed change were also provided. Results in favour of a practice effect and confidence gained from practice and success indicated that these might have been the causes of reading speed improvement.

Although most of the participants made remarkable increases in reading rate, a few participants did not make any improvement in the course and on other types of texts. The thesis did not cover this area due to a lack of time and resources. A further study with more focus on this is therefore suggested to explore why they did not make positive progress. Perhaps interviews after the treatment and eye tracking can be helpful methods to examine this issue.

Examining speed transfer from the speed reading course to other types of texts was another important goal of this thesis. In both experiments, the sufficiency of results in favour of a positive effect confirmed that speed increases in a speed reading course transfer to other types of texts. A pre-test and post-test on reading other types of texts were administered. It was found that the experimental groups could markedly improve their reading rates. Increases of up to $85 \mathrm{wpm}$ were found and the consistency of reading speed improvement by the participants who followed different sequences of test administration showed that the four texts were appropriately designed and reliable to use. The first experiment was unable to explain the similarities in increases made by the control group and one of the treatment groups. Methods to seek the answer to this question was proposed and implemented in the second experiment. It was found that the treatment groups in the second experiment outperformed the control groups and comparison of the two categories showed a significant difference at the $\mathrm{p}<.05$ level. In both of the experiments, there was a strong 
relationship between the speed increases in the course and the speed increase on other types of texts. This reinforces the idea that the speed increase transferred from the course to other types of texts.

The relationship between reading fluency development and reading comprehension was explored in both of the experiments and similar findings were found. The results were contrasting with the findings in some previous research on the relationship between reading fluency and comprehension (Kuhn \& Stahl, 2003) but supported findings by (Chang, 2010), Segalowitz and Segalowitz (1993), Yuan and Ellis (2003), and Wigglesworth (2009). It was found that reading fluency development does not necessarily happen with a trade off in comprehension. By contrast, comprehension can be maintained or improved along with reading speed improvement. The results indicated that participants who had not been trained with speed reading tended to slow down their speed when they wanted to obtain more comprehension. As a result, their reading rate and comprehension appeared to be in a trade-off relationship. However, after being trained in speed reading, they could increase their reading speed without their comprehension declining. Many of them even improved comprehension while increasing their reading rate. This finding may be helpful for teachers and learners as it encourages learners to read faster without fearing that they will comprehend less. For a long time reading instructors have struggled with the learners' low confidence about their comprehension level, which probably plays a psychological barrier in the learning process. Thus, evidence that comprehension and reading speed are not in a trade-off relationship may help teachers and learners to be more confident to use techniques and devices to promote reading speed.

Another main topic of this thesis was how to schedule a speed reading course to achieve optimal results. The results of this investigation suggested that having two sessions a week and thus 10 weeks in total for a speed reading course would produce the least optimal effect in terms of reading speed improvement. Other ways of management such as one session a week for 20 weeks, three sessions a week for seven weeks, or four sessions a week for five weeks, yielded similar results although the groups with three sessions a week slightly outperformed the other two groups. These findings provide some useful information for teachers and administrators of speed reading courses. They can be flexibly scheduled to fit the intact English program as long as there is enough duration or high frequency. However, since this is the first study that has taken effects of scheduling speed 
reading courses on reading speed improvement into consideration, further research is necessary to further confirm the result.

This thesis also set out to determine if speed increases were accompanied by an oral reading rate improvement and language complexity and language accuracy development. The results corroborated the findings in previous research (Bowey, 2005; Crookes, 1989; Ellis, 1987; Fuchs, et al., 2001; Perfetti, et al., 2005; Segalowitz \& Segalowitz, 1993; Stanovich, 2000; Wigglesworth \& Storch, 2009; Yuan \& Ellis, 2003). Besides, a few interesting findings also emerged from analyzing the data to answer the major questions.

With regard to the effects of speed reading courses on oral reading speed, the results of the second experiment showed that silent reading rate increases were accompanied with oral reading rate increases but the improvement in oral reading rate was much smaller than the improvement in silent reading rate. A possible explanation for this may be that while the participants' initial silent reading speeds were below the floor speed in normal reading, their initial oral reading speeds were already in the normal range for oral reading. Therefore the improvement in silent reading speed was more substantial than the improvement in oral reading speed. As silent reading belongs to the receptive aspect while oral reading lends itself to both productive and receptive aspects of reading, the finding provides useful feedback for syllabus designers and teachers. It seems important for syllabus designers, language teachers, and learners, to be aware that improvement of receptive skills does not always result in development of productive skills. This calls for a balance of both productive skills oriented activities and receptive skills oriented activities in language programs. Particularly, language programs at schools and universities in Vietnam have lacked this necessary equilibrium and thus many language learners can read well but fail to communicate when needed. Perhaps Vietnamese language syllabus designers and teachers should integrate training and practice in both aspects in the language programs to make sure the learners develop their language skills in a balanced way. Although none of the four groups made substantial increases in oral reading rate, the data also showed that there was a significant difference between the treatment groups and the control groups. This highlights the benefits of the speed reading course. Since the aim of the speed reading course was to improve the participants' silent reading rates, the increases that the treatment groups made can be considered a good extra effect of the speed reading course. 
One of the most noteworthy findings to emerge from the research in this thesis was the relationship between language fluency and language complexity. The second experiment investigated this subtle link by looking at the results derived from the speed reading course, reading other types of texts and language memory span. The results demonstrated that training in speed reading promotes language memory span, that is, fluency development is accompanied by complexity improvement. The more language fluency development the participants gained, the greater memory span improvement they achieved. The most interesting finding was that reading speed increases and memory span increases are highly related. The greater the improvement in reading rate, the bigger the increase in memory span. On the other hand, it was surprising that memory span and reading speed are not a good predictor of each other. In other words, knowing individual learners' memory span does not help predict their reading rate and vice versa. These findings are consistent with those by Das and Mishra (1991), who indicated that good readers did better in memory span tests than poor readers but prediction of reading rate from memory span was weak. A pedagogical implication of these findings is syllabus designers should take advantage of fluency-oriented components, as development of fluency can facilitate language complexity. It is also worth noting that further research needs to explore the relationship between memory span and reading fluency in the inverse direction. In other words, future trials should assess the benefits, if there are any, of complexity-oriented activities in reading fluency development.

While the second experiment attested the strong relationship between reading fluency and language complexity through the memory span tests, it could not detect any evidence that reading fluency facilitates language accuracy. The memory span results revealed a minimal percentage of accuracy improvement among the participants, even for the treatment groups. While it could be argued that the measuring method might not be reliable, it is still necessary that further research be done to explore this intriguing relationship. An issue that emerged from the analysis was the seemingly contradictory findings related to accuracy in the memory span tests and in the texts that were included in the speed reading course. Whereas accuracy in the memory span tests was improved, comprehension in other types of texts outside the speed reading course was more significantly enhanced. A possible explanation may be that accuracy in comprehension of other types of texts somehow relates to receptive skills while accuracy in memory span tests is more closely related to productive skills. It was thus possible that since speed improvement is largely associated with the receptive dimension of language skills, it could more strongly enhance accuracy 
within the same dimension but not accuracy in the other dimension of language skills. Again, this finding provides useful information for language teachers and learners, who should be aware that while practice in one receptive skill may reinforce other receptive skills, productive skills might not simultaneously develop.

The results of the research add to our understanding of the role of consultation during a speed reading course. The findings showed that consultation on speed reading helps learners to make more improvement in reading rate. In the course and on other types of texts, the subgroup who received consultation outperformed the subgroup who did not receive consultation. The difference was at least $11 \mathrm{wpm}$ for the increases on other types of texts and up to $33 \mathrm{wpm}$ for the increases during the course. There was also a remarkable difference between the two subgroup's results in oral reading increases. An implication of these findings is that being aware of what they are expected to do can be very helpful for learners, thus reading instructors should make sure that their students understand what is required before starting the course, and that struggling students should be given regular encouragement and advice on how to read faster without a comprehension drop.

Several interesting findings emerged from the studies in this thesis. First, it was found that Vietnamese readers tend to read faster when they are not under pressure. Their speeds in oral reading and silent reading tests were similar while both of them were slower than in the speed reading course. This might be explained by the fact that when sitting the tests, the participants were nervous with their mind oriented to the achievement of high scores on comprehension questions that they would normally expect to see in a test at university. Conversely, when doing the speed reading, they were more relaxed as they knew the results were not included in the grading system at the university. If this is true, an implication of it would be the possibility that training on how to overcome anxiety and other psychological barriers might help readers to develop their speed to a greater degree. Another interesting finding in the second experiment is how learners tend to read a text. It was found that most participants read faster in the second half of the text. While this may be taken for granted as in the first half of a text, readers need to read slowly to be accustomed with it before they accelerate, it bears some implications for teaching and learning reading skills. Perhaps teachers can begin with spending some time training their learners how to get through the first half of the text by reading the title, introduction sentence, and so forth. Afterwards instruction on how to accelerate quickly using different reading techniques can be done to make sure the learners know what to do. The findings 
may also be useful for writers who want to make their writing easy to read. The results are surprising that the participants did not slow down in the last section of the text. This probably contrasts with a commonsense expectation that people tend to slow down their speed when they come to the last bit of the text, as the conclusion part is usually important. However, the lack of findings in favour of faster speed on the last section of a text may have been due to the experimental design. Furthermore since this is one of the first studies that examines how a reader's speed changes throughout a text, further investigation into this matter is strongly recommended.

In summary, the research in this thesis sought to determine the effects of speed reading courses on reading rate improvement within the courses, reading rate improvement on other types of texts, oral reading rate, language accuracy, and language complexity. Another aim of the research was to find the most favourable way of scheduling a speed reading course to achieve optimal results. The thesis highlighted the benefits of speed reading courses in L2/FL in several ways. In the first place, the substantial increases that the treatment groups in both experiments made reinforce the idea that a speed reading course in L2/FL can help learners to improve their reading speeds. The findings that most of the participants made gradual increases, even within the first three texts and the last three texts and that the four scoring methods agreed with each other increased the reliability of the results. Secondly, the evidence that not only the participants with higher initial speeds but also the participants with lower initial speeds could reach very high speeds at the end of the course demonstrates that a speed reading course can be beneficial for learners at different levels of reading ability. In addition, the research supports the idea that a speed reading course produces meaningful results because while increasing their speeds, the participants could maintain their comprehension at around $70 \%$ accuracy. The most optimistic finding that emerged from the research is the speed transfer from the course to other types of texts. The evidence that the treatment groups in both experiments made increases on other types of texts demonstrates that the speed improvement was sustainable, thus reinforcing the benefits of speed reading courses. Even though the control groups also gained speed increases on other types of texts, it is still worth giving speed reading courses to L2/FL learners. The reason for this is that even in the most conservative scoring method, the control groups made increases that were at least $20 \mathrm{wpm}$ less than the increases the treatment groups made. The benefits of speed reading courses were also highlighted by the evidence that the speed increases were accompanied with a slight increase in oral reading rate, and substantial improvement in memory span, which can be 
used to assess language complexity. Strong relationships were found between increases in the speed reading course, on other types of texts, and in memory span. Besides, speed reading courses can bring about psychological benefits such as positive changes in motivation, attitudes to reading, and confidence.

From a broader perspective, this thesis adds substantially to our understanding of the relationship between reading fluency, language accuracy, and language complexity. The research found that reading fluency development is accompanied by language complexity development. It also facilitates receptive language accuracy even though it does not substantially promote productive language accuracy. Besides, increases in reading fluency are a good predictor of increases in receptive language accuracy and increases in language complexity. Therefore, it can be assumed that fluency development in speaking and writing facilitates development in other aspects of language. In other words, development in one aspect of language knowledge facilitates development in other aspects of language knowledge. Even though further research is warranted to confirm some intriguing issues, the findings of the experiments do expand previous research and have noteworthy implications for language syllabus designers, language teachers and language learners, especially those are who concerned with the reading skill and speed reading courses. 


\section{REFERENCES}

Adams, M. J. (1994). Modeling the connections between word recognition and reading. In R. B. Ruddell, M. R. Ruddell \& H. Singer (Eds.), Theoretical models and processes of reading (pp. 838-863). Newark, DE: International Reading Association.

Ahmadian, M. J., \& Tavakoli, M. (2011). The effects of simultaneous use of careful online planning and task repetition on accuracy, complexity, and fluency in EFL learners' oral production. Language Teaching Research, 15(1), 35-59.

Alderson, J. C. (1990). Testing reading comprehension skills. Reading in a Foreign Language, 7(1), 465-503.

Alessi, S., \& Dwyer, A. (2008). Vocabulary assistance before and during reading. Reading in a Foreign Language, 20(2), 246-263.

Allerson, S., \& Grabe, W. (1986). Reading assessment. In F. Dubin, D. E. Eskey \& W. Grabe (Eds.), Teaching second language reading for academic purposes (pp. 161181). Massachussetts and California, USA: Addison-Wesley Publishing Company.

Allington, R. L. (1983). Fluency: The neglected reading goal. The Reading Teacher, 36, 556-561.

Allington, R. L. (2009). What really matters in fluency: Research-based practices across the curriculum. Boston: Pearson Education, Inc.

Anderson, R. C., \& Pearson, P. D. (1984). A schema-theoretic view of basic processes in reading comprehension. In P. D. Pearson (Ed.), Handbook of reading research (pp. 255-291). New York: Longman.

Ano, K. (2004). Fluency and accuracy in spoken English of Japanese high school learners. PAAL 8(1), 9-18.

Arevart, S., \& Nation, I. S. P. (1991). Fluency improvement in a second language. RELC Journal, 22(1), 84-94.

Armbruster, B. B., Lehr, F., \& Osborn, J. (2001). Put reading first: The research building blocks for teaching children to read. Kindergarten through grade 3. Washington, DC: National Institute for Literacy.

August, D., Shanahan, T., \& Shanahan, L. (2006). Developing literacy in second-language learners: Report of the national literacy panel on language minority children and youth. New York: Routledge.

Baker, L., \& Brown, A. L. (1984). Metacognitive skills and reading. In P. D. Pearson, R. Barr, M. L. Kamil \& P. Mosenthal (Eds.), Handbook of reading research (pp. 353 394). New York: Longman. 
Baldwin, T. T., \& Ford, J. K. (1988). Transfer of training: A review and directions for future research. Personnel Psychology, 41(1), 63-105.

Bamford, J. (1984). Extensive reading with graded readers. The Language Teacher, 8(4), 3-14.

Barnett, S. M., \& Ceci, S. J. (2002). When and where do we apply what we learn? A taxonomy for far transfer. Psychological Bulletin, 128, 612-637.

Bell, T. (2001). Extensive reading: Speed and comprehension. The Reading Matrix, 1(1), $1-13$.

Bernhardt, E. B., \& Kamil, M. L. (1995). Interpreting relationships between L1 and L2 reading: Consolidating the linguistic threshold and the linguistic interdependence hypotheses. Applied Linguistics, 16(1), 15-34.

Betts, E. A. (1946). Foundations of reading instruction, with emphasis on differentiated guidance. New York: American Book Company.

Bismoko, J., \& Nation, I. S. P. (1972). Reading speed and transfer of training. Publikasi Ilmu Keguruan Sastra Seni, 2(2), 3-5.

Bismoko, J., \& Nation, I. S. P. (1974). English reading speed and the mother-tongue or national language. RELC Journal, 5(1), 86-89.

Blake, J., Austin, W., Cannon, M., Lisus, A., \& Vaughan, A. (1994). The relationship between memory span and measures of imitative and spontaneous language complexity in preschool children International Journal of Behavioral Development, 17(1), 91-107.

Bossers, B. (1992). Reading in two languages: A study of reading comprehension in Dutch as a second language and in Turkish as a first language. Rottersam: Drukkerij Van Driel.

Bowey, J. (2005). Predicting individual differences in learning to read. In M. Snowling \& C. Hulme (Eds.), The science of reading. Malden, MA: Blackwell.

Breznitz, Z., \& Share, D. (1992). Effects of accelerated reading rate on memory for text. Journal of Educational Psychology, 84, 193-199.

Brisbois, J. E. (1995). Connections between first- and second-language reading. Journal of Reading Behavior, 27(4), 565-584.

Broad, M. L., \& Newstrom, J. W. (1992). Transfer of training: Action-packed strategies to ensure high payoff from training investments. New York: Addison-Wesley Publishing Company. 
Brown, A. L. (1989). Analogical learning and transfer: What develops? In S. V. A. Ortony (Ed.), Similarity and analogical reasoning. Cambridge: Cambridge University Press.

Brumfit, C. J. (1984). Communicative methodology in language teaching. Cambridge: Cambridge University Press.

Burns, R. (1991). Study and stress among first year overseas students in an Australian university. Higher Education Research and Development, 10(1), 61-77.

Burt, M., Peyton, J. K., \& Adams, R. (2003). Reading and adult English language learners: A review of the research. Washington D.C: CAL, Center for Applied Linguistics and National Center for ESL Literacy Education.

Butterfield, E. C. (1988). On solving the problem of transfer. In M. M. Gruneberg, P. E. Morris \& R. N. Skyes (Eds.), Practical aspects of memory. London: Academic.

Buurman, R. D., Roersema, T., \& Gerrissen, J. F. (1981). Eye Movements and the Perceptual Span in Reading. Reading Research Quarterly, 16(2), 227-235.

Calfee, R. C., \& Curley, R. (1984). Structures of prose in content areas. In J. Flood (Ed.), Understanding reading comprehension (pp. 161-180). Newark, DE: International Reading Association.

Caplan, D., \& Waters, G. (1994). Articulatory length and phonological similarity in span tasks: A reply to Baddeley and Andrade. Quarterly Journal of Experimental Psychology, 47A, 1055-1062.

Carrell, P. L. (1991). Second language reading: Reading ability or language proficiency? Applied Linguistics, 12, 159-179.

Carrell, P. L., \& Eisterhold, J. C. (1983). Schema theory and ESL reading pedagogy. TESOL Quarterly, 17(4), 553-573.

Carver, R. P. (1977a). Another look at rauding theory. Reading Research Quarterly, 13(1), 116-132.

Carver, R. P. (1977b). Toward a theory of reading comprehension and rauding. Reading Research Quarterly, 13(1), 8-63.

Carver, R. P. (1981). Reading comprehension and rauding theory: Thomas in Springfield.

Carver, R. P. (1982). Optimal rate of reading rose. Reading Research Quarterly, 18(1), 5688.

Carver, R. P. (1983). Is reading rate constant or flexible? Reading Research Quarterly, $18(2), 190-215$.

Carver, R. P. (1984). Rauding theory predictions of amount comprehended under purposes and speed reading conditions. Reading Research Quarterly, 19, 205-218. 
Carver, R. P. (1985). How good are some of the world's best readers? Reading Research Quarterly, 20(4), 389-419.

Carver, R. P. (1990). Predicting accuracy of comprehension from the relative difficulty of the material. Learning and individual differences, 2(4), 405-422.

Carver, R. P. (1992a). Effect of prediction activities, prior knowledge, and text type upon amount comprehended: Using rauding theory to critique schema theory research. Reading Research Quarterly, 27(2), 64-174.

Carver, R. P. (1992b). Reading Rate: Theory, research, and practical implications. Journal of Reading, 36(2), 84-95.

Carver, R. P. (1993). Merging the simple view of reading with rauding theory. Journal of Reading Behavior, 25(4), 439-455.

Carver, R. P. (1997). Reading for one second, one minute, or one year from the perspective of rauding theory Scientific Studies of Reading, 1(1), 3-43.

Carver, R. P. (2000). The causes of high and low reading achievement. New Jersey: Lawrence Erlbaum Associates.

Carver, R. P., \& Hoffman, J. V. (1981). The effect of practice through repeated reading on gain in reading ability using a computer-based instructional system. Reading Research Quarterly, 16, 374-390.

Chall, J. S. (1983). Stages of reading development. New York: Harcourt Brace.

Chang, A. C. S. (2010). The effect of a timed reading activity on EFL learners: Speed, comprehension, and perceptions. Reading in a Foreign Language, 22(2), 284-303.

Chard, D. J., Pikulski, J. J., \& McDonough, S. H. (2005). Fluency: The link between decoding and comprehension for struggling readers. In K. Lems (Ed.), Fluency instruction: Research-based best practices. New York: Guilford Press.

Chung, M., \& Nation, P. (2006). The effect of a speed reading course. English Teaching, 64(4), 181-204.

Clarke, M. A. (1979). Reading in Spanish and English: Evidence from adult ESL students. Language Learning, 29, 121-150.

Clarke, M. A. (1980). The short circuit hypothesis of ESL reading - Or when language competence interferes with reading performance. The Modern Language Journal, 64(2), 203-209.

Cobb, T. W. Vocabprofile [accessed 22 August 2010 from http://www.lextutor.ca/vp/ ] an adaptation of Heatley \& Nation's (1994) Range.

Collins, R. (1961). The comprehension of prose material by college freshmen when read silently and when read aloud. Journal of Educational Research, 52(2), 79-82. 
Cramer, S. (1975). Increasing reading speed in English or in the national language? RELC Journal, 6, 19-25.

Crookes, G. (1989). Planning and interlanguage variation. Studies in Second Language Acquisition, 11(4), 367-383.

Cunningham, T. H., \& Graham, C. R. (2000). Increasing native English vocabulary recognition through Spanish immersion: Cognate transfer from foreign to first language. Journal of Educational Psychology, 92(1), 37-49.

Daane, M. C., Campbell, J. R., Grigg, W. S., Goodman, M. J., \& Oranje, A. (2005). Fourth-grade students reading aloud: NAEP 2002 special study of oral reading (NCES 2006-469). Washington, DC: U.S. Government Printing Office.

Daneman, M. \& Carpenter, P. A. (1980). Individual differences in working memory and reading. Journal of Verbal Learning and Verbal Behavior, 19, 450-466.

Das, J. P., \& Mishra, R. K. (1991). Relation between memory span, naming time, speech rate, and reading competence. The Journal of Experimental Education, 59(2), 129139.

Day, R. R., \& Bamford, J. (1998). Extensive reading in the second language classroom. New York: Cambridge University Press.

Deno. (1985). Curriculum-based measurement: The emerging alternative. Exceptional Children, 52, 219-232.

Deno, S., Mirkin, P., \& Chiang, B. (1982). Identifying valid measures of reading. Exceptional Children, 49, 36-45.

Dombey, H. (2009). The simple view of reading. ITE English: Readings for discussion Retrieved 20 Dec 2010, from http://www.ite.org.uk/itereadings/simpleviewreading

Donnes, T. (1999). Extensive reading revisited: An interview with Richard Day and Julian Bamford. The Language Teacher, 23(7), 4-7.

Dowhower, S. L. (1987). Effects of repeated reading on second-grade transitional readers' fluency and comprehension. Reading Research Quarterly, 22(4), 389-406.

Dreyert, L. G., \& Katzt, L. (1992). An examination of "The simple view of reading". Haskins Laboratories Status Report on Speech Research.

Droop, M., \& Verhoeven, L. (2003). Language proficiency and reading ability in first- and second-language learners. Reading Research Quarterly, 38(1), 78-103.

Dunn, L. M., \& Markwardt, F. C. (1970). Peabody picture vocabulary test. Circle Pines, Minn: American Guidance Service.

Duong, N. T. (2009). Mistake or Vietnamese English. VNU Journal of Science, Foreign Languages, 25, 41-50. 
Durrell, D. D. (1940). Improvement of basic reading abilities. New York: World Book Company.

Ehri, L. C. (1995). Phases of development in learning to read words by sight. Journal of Research in Reading(18), 116-125.

Elley, W. B., \& Mangubhai, F. (1983). The impact of reading on second language learning. Reading Research Quarterly, 19(1), 53-67.

Ellis, R. (1987). Interlanguage variability in narrative discourse: Style shifting in the use of the past tense. Studies in Second Language Acquisition, 9(1), 1-19.

Ellis, R. (2003). Task-based language learning and teaching: Oxford University Press.

Ellis, R., \& Barkhuizen, G. (2005). Analysing learner language. Oxford: Oxford University Press.

Ferraro, G. (1994). The cultural dimension of international business. Englewood cliffs, NJ: Pentice Hall.

Fortkamp, M. B. M. (1999). Working memory capacity and aspects of L2 speech production. Communication and Cognition, 32, 259-296.

Fraser, C. (2007). Reading rate in L1 Mandarin Chinese and L2 English across five reading tasks. The Modern Language Journal, 91, 372-394.

Fry, E. (1967). Reading faster. Cambridge: Cambridge Univerisity Press.

Fuchs, Tindal, G., \& Deno, S. L. (1984). Methodological issues in curriculum-based reading assessment. Diagnostique, 9, 191-207.

Fuchs, L., Fuchs, D., Hosp, M., \& Jenkins, J. (2001). Oral reading fluency as an indicator of reading competence: A theoretical, empirical, and historical analysis. Scientific Studies of Reading and Writing, 5, 239-256.

Fuchs, L., Fuchs, D., \& Maxwell, L. (1988). The validity of informal reading comprehension measures. Remedial and Special Education, 9(2), 20-28.

Fuchs, L. S., Fuchs, D., Hamlett, C. L., Walz, L., \& Germann, G. (1993). Formative evaluation of academic progress: How much growth can we expect? School Psychology Review, 22, 27-48.

Glock, M. D. (1949). Effect upon eye movements and reading rate at the college level of three methods of training. Journal of Educational Psychology, 40(2), 93-106.

Gobet, F., Lane, P. C. R., Croker, S., Cheng, P. C. H., Jones, G., Oliver, I., et al. (2001). Chunking mechanisms in human learning. TRENDS in Cognitive Sciences, 5, 236243.

Good, R., \& Kaminski, R. (2002). DIBELS ${ }^{T M}$ oral reading fluency passages for first through third grades. Eugene: University of Oregon. 
Goodman, K. S. (1989). Whole language research: Foundations and development. The Elementary School Journal 90, 208-221.

Gorsuch, G., \& Taguchi, E. (2008). Repeated reading for developing reading fluency and reading comprehension: The case of EFL learners in Vietnam. System, 36(2), 253278.

Gough, P. B., \& Tunmer, W. E. (1986). Decoding, reading, and reading disability. Remedial and Special Education, 7, 6-10.

Grabe, W. (1991). Current developments in second language reading research. TESOL Quarterly, 25(3), 375-406.

Grabe, W. (2004a). Research on teaching reading. Annual Review of Applied Linguistics, 24, 44-69.

Grabe, W. (2004b). Research on teaching reading. Annual Review of Applied Linguistics 24, 44-69.

Grabe, W. (2009). Reading in a second language: Moving from theory to practice. New York: Cambridge University Press

Hacquebord, H. I. (1999). A Dutch comprehension test for identifying reading problems in L1 and L2 students. Journal of Research in Reading, 22(3), 299-303.

Hafiz, F. M., \& Tudor, I. (1989). Extensive reading and the development of language skills. ELT Journal, 43, 4-13.

Harrington, M., \& Sawyer, M. (1992). L2 working memory capacity and L2 reading skill. Studies in Second Language Acquisition, 14, 25-38.

Harris, A. J., \& Sipay, E. R. (1985). How to increase reading ability: A guide to developmental and remedial methods. White Plains, NY: Longman.

Harris, D. (1970). Report on an experimental group administered memory span test. TESOL Quarterly, 4(3), 203-213.

Harris, T. L., \& Hodges, R. E. (1995). The literacy dictionary: The vocabulary of reading and writing. Newark, DE: International Reading Association.

Hasbrouck, J. E., \& Tindal, G. (1992). Curriculum-based oral reading fluency norms for students in grades 2 through 5. Teaching Exceptional Children, 24, 41-44.

Haskel, R. E. (2000). Transfer of learning: cognition, instruction, and reasoning. San Diego, CA: Academic Press.

Heatley, A., \& Nation, P. (1994). Range. Victoria University of Wellington, NZ [Computer program, available at http://www.vuw.ac.nz/lals/.].

Herman, P. A. (1985). The effect of repeated readings on reading rate, speech pauses, and word recognition accuracy. Reading Research Quarterly, 20, 553-564. 
Hiebert, E. H., \& Fisher, C. W. (2005). A review of the National Reading Panel's studies on fluency: The role of text. The Elementary School Journal, 105(5), 443-460.

Hill, D. (1997). Survey review: Graded readers. English Language Teaching Journal, 51(1), 57-79.

Hoang, H. T. Q. (1965). A phonological contrastive study of Vietnamese and English. Texas Technological College, Texas.

Hoffenberg, R. M., et al. (1971). Evaluation of the elementary school (FLES) Latin program (No. Report: R-7202. 53).

Hoffman, J. V., \& Rutherford, W. L. (1984). Effective reading programs: A critical review of outlier studies. Reading Research Quarterly, 20(1), 79-92.

Honey, P. J. (1987). Vietnamese speakers. In M. Swan \& B. Smith (Eds.), Learner English (pp. 238-251). Cambridge: Cambridge University Press.

Hoover, W. A., \& Gough, P. B. (1990). The simple view of reading. Reading and Writing: An Interdisciplinary Journal, 2, 127-160.

Housen, A., Daele, S. V., \& Pierrard, M. (2005). Rule complexity and the effectiveness of explicit grammar instruction. In A. Housen \& M. Pierrard (Eds.), Investigations in instructed second language acquistion. Berlin: Mouton de Gruyter.

Huey, E. B. (1968). The psychology and pedagogy of reading. Washington D.C.: MIT Press.

Hunter, M. J. M. (1975). The effect of speed reading and college reading/study skills instruction on grade point average. University of Northern Colorado, Colorado.

Hwa-Froelich, D., Hodson, B. W., \& Edwards, H. T. (2002). Characteristics of Vietnamese Phonology. American Journal of Speech-Language Pathology, 11, 264-273.

Iwahori, Y. (2008). Developing reading fluency: A study of extensive reading in EFL. Reading in a Foreign Language, 20(1), 70-91.

Johns, J., \& Berglund, R. (2006). Fluency strategies and assessments. Dubuque, IA: Kendall/Hunt.

Johnson, M. S., Kress, R. A., \& Pikulski, J. J. (1987). Informal reading inventories (2nd ed.). Newark, DE: International Reading Association.

Jones, E. E., \& Lockhart, A. V. (1919). A study of oral and silent reading in the elementary schools of Evanston. School and Society, 10(225), 587-590.

Judd, C. H., \& Buswell, G. T. (1922). Silent reading: A study of the various types. Chicago: University of Chicago Press.

Juel, C., \& Holmes, B. (1981). Oral and silent reading of sentences. Reading Research Quarterly, 16(4), 545-568. 
Just, M. A., Anderson, P., \& Carpenter, P. A. (1987). The psychology of reading and language comprehension. Boston: Allyn and Bacon.

Just, M. A., \& Carpenter, P. A. (1992). A capacity theory of comprehension: Individual differences in working memory. Psychological Review, 99, 122-149.

Kemper, S., Kynette, D., Rash, S., O'Brien, K., \& Sprott, R. (1989). Life-span changes to adults language: Effects of memory and genre. Applied Psycholinguistics, 10(1), 49-66.

Kormos, J., \& Sáfár, A. (2008). Phonological short-term memory, working memory and foreign language performance in intensive language learning. Bilingualism: Language and Cognition, 11, 261-271.

Krashen, S. (1995). Free voluntary reading: Linguistic and affective arguments and some new applications. In F. Eckman, D. Highland, P. Lee, J. Mileham \& R. Weber (Eds.), Second language acquisition theory and pedagogy (pp. 187-202). Mahwah, NJ: Lawrence Erlbaum Associates.

Kroll, J., Michael, E., Tokowicz, N., \& Dufour, R. (2002). The development of lexical fluency in a second language. Second Language Research, 18, 137-171.

Kuhn, M., \& Stahl, S. (2003). Fluency: A review of development and remedial practices. Journal of Educational Psychology, 95(1), 1-21.

LaBerge, D., \& Samuels, S. J. (1974a). Basic processes in reading : perception and comprehension. New York: Erlbaum Associates.

LaBerge, D., \& Samuels, S. J. (1974b). Toward a theory of automatic information processing in reading. Cognitive Psychology, 6, 293-323.

Lado, R. (1965). Memory span as a factor in second language learning. International Review of Applied Linguistics, 3, 123-129.

Lai, F.-K. (1993). The effect of a summer reading course on reading and writing skills. System, 21, 87-100.

Levy, B. A., Abello, B. \& Lysynchuk, L. (1997). Transfer from word training to Reading in context: Gains in reading fluency and comprehension. Learning Disability Quarterly, 20 (3), 173-188.

Leung, C. Y. (2002). Extensive reading and language learning: A diary study of a beginning learner of Japanese. Reading in a Foreign Language, 14(1), 66-81.

Levy, B., Abello, B., \& Kysynchuk, L. (1997). Transfer from word training to reading in context: Gains in reading fluency and comprehension. Learning Disability Quarterly, 20, 173-188. 
Lituanas, P. M., Jacobs, G. M., \& Renandya, W. A. (1999). A study of extensive reading with remedial reading students. In Y. M. Cheah \& S. M. Ng (Eds.), Language instructional issues in Asian classrooms (pp. 89-104). Newark, DE: International Development in Asia Committee, International Reading Association.

Macalister, J. (2008). Effect of a speed reading course in an English as a second language environment. TESOLANZ Journal, 16, 23-32.

Macalister, J. (2010). Speed reading courses and their effect on reading authentic texts: A preliminary investigation. Reading in a Foreign Language 22(1), 104-116.

Markwardt, F. C. (1989). Peabody individual achievement test: PIAT-R. Circle Pines, MN: American Guidance Service.

Marston, D., \& Magnusson, D. (1985). Implementing curriculum-based measurement in special and regular education settings. Exceptional Children, 52, 266-276.

Masciantonio, R. (1977). Tangible benefits of the study of Latin: A review of research. Foreign Language Annals, 10(4), 375-382.

McGlinchey, M. T., \& Hixson, M. D. (2004). Using curriculum-based measurement to predict performance on state assessments in reading. School Psychology Review, 33, 193-203.

Mead, C. D. (1917). Results in silent versus oral reading. Journal of Educational Psychology, 8(6), 367-368.

Mehnert, U. (1998). The effects of different lengths of time for planning on second language performance. Studies in Second Language Acquisition, 20(1), 83-108.

Menken, K., \& Kleyn, T. (2010). The long-term impact of subtractive schooling in the educational experiences of secondary English language learners. International Journal of Bilingual Education and Bilingualism, 13(4), 399-417.

Meyer, M. S., \& Felton, R. H. (1999). Repeated reading to enhance fluency: Old approaches and new directions. Annals of Dyslexia, 49, 283-306.

Miller, G. A. (1956). The magical number seven, plus or minus two: Some limits on our capacity for processing information. Psychological Review, 63(2), 81-97.

Millett, S. (2005a). New Zealand speed readings for ESL learners, Book One. Retrieved 21 Sep 2009, from http://www.victoria.ac.nz/lals/staff/Publications/Bookoneall.pdf

Millett, S. (2005b). New Zealand speed readings for ESL learners, Book One. Wellington, NZ: School of Linguistics and Applied Language Studies, Victoria Unversity of Wellington.

Millett, S. (2005c). New Zealand speed readings for ESL learners, Book Two. Retrieved 21 Sep 2009, from http://www.victoria.ac.nz/lals/staff/Publications/Booltwoall.pdf 
Millett, S. (2005d). New Zealand speed readings for ESL learners, Book Two. Wellington, NZ: School of Linguistics and Applied Language Studies, Victoria University of Wellington.

Millett, S., Quinn, E., \& Nation, P. (2007). Asian and Pacific speed readings for ESL learners. Wellington: English language institute occasional publication.

Nation, P. (1989). Improving speaking fluency. System, 17(3), 377-384.

Nation, P. (1997). Developing fluency in language use. KIFL Academic Journal, 6, 30-35.

Nation, P. (2001). Planning and running an extensive reading program. NUCB Journal of Language Culture and Communication, 3(1), 1-8.

Nation, P. (2005). Reading faster. PASAA, 36, 21-38.

Nell, V. (1988). The psychology of reading for pleasure: Needs and gratifications. Reading Research Quarterly, 23(1), 6-50.

Newton, P., \& Bristoll, H. (2010). Verbal ability word meaning practice test 1. Psychometric Successive Retrieved 27 Jan 2010, from http://www.psychometric$\underline{\text { success.com }}$

Nicholson, T. \& Tan, A. (1997). Flashcards revisited: Training poor readers to read words faster improves their comprehension of text. Journal of Educational Psychology, 89 (2), 276-288.

Nicholson, T. \& Tan, A. (1999). Proficient word identification for comprehension. In G. B. Thomson and T. Nicholson (Eds.), Learning to read: Beyond phonics and whole language (pp. 150-173). New York: Teachers College Press.

Nicholson, T. \& Tan, A. (1999). Word identification processes. In G. B. Thompson \& T. Nicholson (Eds), Learning to read: Beyond phonics and whole language (pp. 150173). New York: Teachers College Press.

Nitschke, S., Kidd, E., \& Serratrice, L. (2010). First language transfer and long-term structural priming in comprehension. Language and Cognitive Processes, 25(1), 94-114.

Nuttall, C. (1982). Teaching reading skills in a foreign language. London: Heinemann Educational Books.

O'Brien, E., Segalowitz, N., Freed, B., \& Collentine, J. (2007). Phonological memory predicts second language oral fluency gains in adults. SSLA, 29, 557-582.

Oakley, G. (2005). Reading fluency as an outcome of a repertoire of interactive reading competencies: How to teach it to different types of dysfluent readers (and how ICT can help). New England Reading Association Journal, 41(1), 12-21. 
Paran, A. (1996). Reading in EFL: Facts and fictions. English Language Teaching Journal, $50(1), 25-34$.

Paretz, A. S., \& Shoham, M. (1990). Testing reading comprehension in LSP: Does topic familiarity afectt assessed difficulty and actual performance? Reading in a Foreign Language, 7(1), 447-455.

Parker, R., Hasbrouck, J. E., \& Tindal, G. (1992). Greater validity for oral reading fluency: Can miscues help? The Journal of Special Education, 25(4), 492-503.

Paulson, E. J. (2005). Viewing eye movements during reading through the lens of chaos theory: How reading is like the weather. Reading Research Quarterly, 40(3), 338358.

Pearsall, J. (Ed.) (1998) The new Oxford dictionary of English. New York: Oxford University Press.

Penner-Wilger, M. (2008). Building and Assessing Reading Fluency: Academy of READING with Oral Reading Fluency. School Specialty Retrieved 20 July 2010, from http://eps.schoolspecialty.com/downloads/researchpapers

Perfetti, C., Landi, N., \& Oakhill, J. (2005). The acquisition of reading comprehension skill. In M. Snowling \& C. Hulme (Eds.), The science of reading. Malden, MA: Blackwell.

Perfetti, C., Van Dyke, J., \& Hart, L. (2001). The psycholinguistics of basic literacy. Annual Review of Applied Linguistics, 21, 127-149.

Perfetti, C. A. (1985). Reading ability. New York: Oxford University.

Perfetti, C. A. (2010). Decoding, vocabulary and comprehension - The golden triangle of reading skill. In M. G. McKeown \& L. Kucan (Eds.), Bringing reading research to life. New York: Guilford Press.

Perfetti, C. A., \& Hart, L. (2002). The lexical quality hypothesis. In L. Verhoeven, C. Elbro \& P. Reitsma (Eds.), Precursors of functional literacy. Amsterdam: John Benjamins Publishing Company.

Pham, T. H. T. (2010). Implementing a student-centered learning approach at Vietnamese higher education institutions: Barriers under layers of casual layered analysis (CLA). Journal of Futures Studies, 15(1), 21 - 38.

Pichette, F., Segalowitz, N., \& Connors, K. (2003). Impact of maintaining L1 reading skills in L2 reading skill development in adults: Evidence from speakers of SerboCroatian learning French. The Modern Language Journal, 87(3), 391-403.

Pinnell, G. S. (1995). Reading Recovery: A Review of Research. Columbus, OH: The Ohio State University. 
Pinnell, G. S., Pikulski, J. J., Wixson, K. K., Campbell, J. R., Gough, P. B., \& Beatty, A. S. (1995). Listening to children read aloud: Oral fluency. Retrieved 7 July 2011, from http://nces.ed.gov/pubs95/web/95762.asp

Polmar, J. (2009). Brief history of speed reading. ESL teacher board Retrieved 24 July 2009, from http://www.eslteachersboard.com/cgi-bin/articles/index.pl?read=1689

Porter, L. W., \& Duncan, C. P. (1953). Negative transfer in verbal learning. Journal of Experimental Psychology, 46(1), 61-64.

Postlethwaite, T. N., \& Ross, K. N. (1992). Effective schools in reading: Implications for educational planners. Hamburg: IEA

Postman, L., \& Stark, K. (1969). Role of response availability in transfer and interference. Journal of Experimental Psychology, 79(1), 168-177.

Pressley, M., \& Afflerbach, P. (1995). Verbal protocols of reading: the nature of constructively responsive reading. Hillsdale, NJ: Lawrence Erlbaum Associates.

Quinn, \& Nation, I. S. P. (1974). Speed reading: A course for learners of English. Oxford: Oxford University Press.

Ramer, A. L. H. (1977). The development of syntactic complexity. Journal of Psycholinguistic Research, 6(2), 145-161.

Rasinski, T. V. (1989). Fluency for everyone: Incorporating fluency instruction in the classroom. The Reading Teacher, 42, 690-693.

Rasinski, T. V. (2000). Speed does matter in reading. The Reading Teacher, 54(2), 146151.

Rasinski, T. V. (2003a). Assessing reading fluency. Educational Service Material Retrieved 06 July 2009, from http://www.prel.org/products/re_/assessingfluency.htm

Rasinski, T. V. (2003b). The fluent reader: Oral reading strategies for building word recognition, fluency, and comprehension. New York: Scholastic Professional Books.

Rasinski, T. V., Blachowicz, C., \& Lems, K. (2006). Fluency Instruction. New York: Guilford Publications.

Rasinski, T. V., \& Padak, N. (1996). Five lessons to increase reading fluency. In L. Putnam (Ed.), How to become a better reading teacher (pp. 255-265). Toronto: Prentice Hall.

Rayner, K., \& Pollatsek, A. (1989). The psychology of reading. Englewood Cliffs, NJ: Prentice Hall. 
Ream, M. (1977). The Merrill Ream 10-lesson speed reading course. Mission, KS: Sheed Andrews and McMeel.

Redfield, M. (1999). Massive input through eiga shosetsu: A pilot study with Japanese learners. JALT Journal, 21(1), 51-65.

Rial, A. F. (1977). Speed reading made easy. New York: Doubleday \& Company.

Richards, M. (2000). Be a good detective: Solve the case of oral reading fluency. The Reading Teacher, 53, 534-539.

Roberts, R. \& Gibson, E. (2002). Individual differences in sentence memory. Journal of Psycholinguistic Research, 31 (6), 573-598.

Roller, C. M. (1988). Transfer of cognitive academic competence and L2 reading in a rural Zimbabwean primary school. TESOL Quarterly, 22, 303-318.

Rowell, E. H. (1976). Do elementary students read better orally or silently? The Reading Teacher, 29(4), 367-370.

Rumelhart, D. E. (1977). Toward an interactive model of reading. In S. Dornic (Ed.), Attention and Performance IV. New York: Academic Press.

Salomon, G., \& Perkins, D. N. (1989). Rocky roads to transfer: Rethinking mechanisms of a neglected phenomenon. Educational Psychologist, 24(2), 113-142.

Samuels, S. J. (1997). The method of repeated readings. The Reading Teacher, 30(5), 376381.

Samuels, S. J. (2002). Reading fluency: Its development and assessment. In A. E. Farstrup \& S. J. Samuels (Eds.), What research has to say about reading instruction (pp. 166-183). Newark, DE: International Reading Association.

Samuels, S. J. (2006). Toward a model of reading fluency. In S. J. Samuels \& A. E. Farstrup (Eds.), What research has to say about fluency instruction. Newark, DE: International Reading Association.

Schmitt, N., Schmitt, D., \& Clapham, C. (2001). Developing and exploring the behaviour of two new versions of the vocabulary levels test. Language Testing, 18(1), 55-88.

Schreiber, P. A. (1987). Prosody and structure in children's syntactic processing. In R. Horowitz \& S. J. Samuels (Eds.), Comprehending oral and written language (pp. 243-270). New York: Academic Press.

Schwanenflugel, P. J., Meisinger, E. B., Wisenbaker, J. M., Kuhn, M. R., Strauss, G. P., \& Morris, R. D. (2006). Becoming a fluent and automatic reader in the early elementary school years. Reading Research Quarterly, 41(4), 496-522. 
Segalowitz, N., Poulsen, C., \& Komoda, M. (1991). Lower level components of reading skill in higher level bilinguals: Implications for reading instruction. AILA Review, $8(1), 15-30$

Segalowitz, N., \& Segalowitz, S. (1993). Skilled performance, practice and the differentiation of speed-up from automatization effect: Evidence from second language word recognition. Applied Linguistics, 14, 369-385.

Segalowitz, S., Segalowitz, N., \& Wood, A. (1998). Assessing the development of automaticity in second language word recognition. Applied Psycholinguistics, 19, 53-67.

Seng, G. H., \& Hashim, F. (2006). Use of L1 in L2 reading comprehension among tertiary ESL learners. Reading in a Foreign Language, 18(1), 29-54.

Service, E. (1998). The effect of word length on immediate serial recall depends on phonological complexity, not articulatory duration. Quarterly Journal of Experimental Psychology, 51A, 283-304.

Seung, H.-K. \& Chapman, R. (2004). Sentence memory of individuals with Down's syndrome and typically developing children. Journal of Intellectual Disability Research, 8 (2), 160-171.

Sheu, S. P. H. (2003). Extensive reading with EFL learners at beginning level. TESL Reporter, 36, 8-26.

Silberglitt, B., Burns, M. K., Madyun, N. H., \& Lail, K. E. (2006). Relationship of reading fluency assessment data with state accountability test scores: A longitudinal comparison of grade levels. Psychology in the Schools, 43, 527-535.

Silberstein, S. (1994). Techniques and resources in teaching reading. New York: Oxford University Press.

Skehan, P. (1998). A cognitive approach to language learning. Oxford: Oxford University Press.

Skinner, B. F. (1938). The behavior of organisms. New York: Appleton-Century-Crofts.

Slee, J. M. (2008). Effects of adding fluency instruction to accuracy instruction on the reading achievement of kindergarteners at risk for failure. Carolina: ProQuest.

Smith, F. (1978). Reading. Cambridge: Cambirdge University Press.

Stahl, S. A., Heubach, K., \& Cramond, B. (1996). Fluency oriented reading instruction (No. 79). College Park, MD: National Reading Research Center.

Stahl, S. A., \& Heubach, K. M. (2005). Fluency-oriented reading instruction. Journal of Literacy Research, 37, 25-60.

Stancliffe, G. D. (2003). Speed Reading 4 Kids. The American Speed Reading Project. 
Stanovich, K. E. (1980). Toward an interactive-compensatory model of individual differences in the development of reading fluency. Reading Research Quarterly, 16, $32-71$.

Stanovich, K. E. (1992). The psychology of reading: Evolutionary and revolutionary developments. Annual Review of Applied Linguistics, 12, 3-30.

Stanovich, K. E. (2000). Progress in understanding reading. New York: Guilford.

Susser, B., \& Robb, T. N. (1990). EFL extensive reading instruction: Research and procedure. JALT Journal, 12(2), 161-185.

Taguchi, E., Gorsuch, G. J., \& Sasamoto, E. (2006). Developing second and foreign language reading fluency and its effect on comprehension: A missing link. The Reading Matrix, 6(2), 1-18.

Taguchi, E., Takayasu-Maass, M., \& Gorsuch, G. J. (2004). Developing reading fluency in EFL: How assisted repeated reading and extensive reading affect fluency development. Reading in a Foreign Language, 16(2), 70-96.

Thorndike, E. L. (1932). The fundamentals of learning. New York Teachers College Press.

Tinker, M. A. (1946). The study of eye movements in reading. Psychological Bulletin, 43, 93-120.

Tompkins, G. E. (2003). Literacy for the 21st century: Teaching reading and writing in pre-kindergarten through grade 4. Upper Saddle River, NJ: Merrill/Prentice Hall.

Urquhart, A. H. (1987). Comprehensions and interpretations. Reading in a Foreign Language, 3(2), 387-409.

Vacca, R. T., \& Vacca, J. L. (1999). Content Area Reading. New York: Harper Collins.

Valencia, S., Smith, A., Reece, A., Li, M., \& Wixson, K. (2010). Oral reading fluency assessment: Issues of construct, criterion, and consequential validity. Reading Research Quarterly, 45(3), 270-291.

Vang, C. (1999). Hmong-American students: Challenges and opportunities. In C. Park \& M. Chi (Eds.), Asian-American education: Prospects and challenges (pp. 219-236). Westport, CT: Greenwood.

Walczyk, J. J. (2000). The interplay between automatic and control processes in reading. Reading Research Quarterly, 35(4), 554-566.

Walczyk, J. J., Marsiglia, C. S., Bryan, K. S., \& Naquin, P. J. (2001). Overcoming inefficient reading skills. Journal of Educational Psychology, 93(4), 750-757.

Watson, D. (1989). Defining and describing whole language. The Elementary School Journal, 90, 130-141. 
Weaver, P. A. (1979). Improving reading comprehension: Effects of sentence organization instruction. Reading Research Quarterly, 15(1), 129-146.

Weissheimer, J., \& Mailce, M. B. (2009). Individual differences in working memory capacity and the development of L2 speech production. Issues in Applied Linguistics, 17(2), 1-20.

Welsch, R. G. (2006). Increase oral reading fluency. Intervention in School and Clinic, 41(3), 180-183.

West, M. (1941). Learning to read a foreign language. London: Longman.

West, M. (1953). A general service list of English words. London: Longman

Whipple, G. (1964). What is a good reading program? In J. H. Albert (Ed.), Reading on reading instruction. New York: David McKay Company, Inc.

Wiederholt, J. L., \& Bryant, B. R. (2003). Gray oral reading fluency test Austin, TX: ProEd.

Wigglesworth, G. (1997). An investigation of planning time and proficiency level on oral test discourse. Language Testing, 14(1), 85-106.

Wigglesworth, G., \& Storch, N. (2009). Pair versus individual writing: Effects on fluency, complexity and accuracy. Language Testing 26(3), 445-466.

Williams, J., \& Evans., J. (1998). What kind of focus and on which forms? In C. Doughty \& J. Williams (Eds.), Focus on form in classroom second language acquisition. Cambridge: Cambridge University Press.

Wolfe-Quintero, K., Inagaki, S., \& Kim, H. Y. (1998). Second language development in writing: Measures of fluency, accuracy, and complexity. University of Hawai' $\mathrm{i}$ : Second language teaching and curriculum center.

Worthy, J., \& Broaddus, K. (2001-2002). Fluency beyond the primary grades: From group performance to silent, independent reading. The Reading Teacher, 55(4), 334-343.

Yamashita, J. (2004). Reading attitudes in L1 and L2, and their influence on L2 extensive reading. Reading in a Foreign Language, 16(1), 1-19.

Yamashita, J., \& Ichikawa, S. (2010). Examining reading fluency in a foreign language: Effects of text segmentation on L2 readers. Reading in a Foreign Language, 22(2), $263-283$.

Yuan, F., \& Ellis, R. (2003). The effects of pretask planning and on-line planning on fluency, complexity, and accuracy in L2 monologic oral production. Applied Linguistics, 24, 1-27.

Zhang, W., \& Feng, L. (1990). The visual recognition and capacity of STM for Chinese disyllabic words. Acta Psychologica Sinica, 22, 383-390. 
Zutell, J., \& Rasinski, T. (1991). Training teachers to attend to their students' oral reading fluency. Theory into Practice, 30(2), 211-217. 


\section{APPENDIX A}

MEMORY SPAN TEST

\begin{tabular}{|c|c|}
\hline Set A & Set B \\
\hline This is Mary. & That is Henry. \\
\hline We like dancing. & They love cooking. \\
\hline She is reading a map. & He is watching a film. \\
\hline We ate an egg last night. & I bought a car last year. \\
\hline Have you ever ridden a horse? & Have you ever driven a train? \\
\hline I was swimming at 10 am yesterday. & She was shopping at 9 am yesterday. \\
\hline She is a teacher of English at college. & He is a teacher of Art at university. \\
\hline My friends always play tennis after class. & My brothers often play badminton after work. \\
\hline I have already lived here for five years. & They have already learnt English for five years. \\
\hline I will have been running for four hours by $10 \mathrm{am}$. & $\begin{array}{l}\text { They will have been working for } 10 \text { hours by } 9 \\
\text { pm. }\end{array}$ \\
\hline $\begin{array}{l}\text { My grandfather visited me and gave me a good } \\
\text { book. }\end{array}$ & $\begin{array}{l}\text { Her grandmother visited her and gave her a big } \\
\text { cake. }\end{array}$ \\
\hline $\begin{array}{l}\text { I went to France for business and always liked the } \\
\text { people there. }\end{array}$ & $\begin{array}{l}\text { They went to England for work and never came } \\
\text { back after that. }\end{array}$ \\
\hline John is at school, and his brother is working at home. & $\begin{array}{l}\text { Mary is at home, and her sister is studying at } \\
\text { school. }\end{array}$ \\
\hline $\begin{array}{l}\text { We plan to go to London right after we finish class } \\
\text { next week. }\end{array}$ & $\begin{array}{l}\text { They want to travel to France right before they } \\
\text { get married this year. }\end{array}$ \\
\hline $\begin{array}{l}\text { It was already late when he called to tell us he could } \\
\text { not come. }\end{array}$ & $\begin{array}{l}\text { It was very early when she called me to say she } \\
\text { got up already. }\end{array}$ \\
\hline $\begin{array}{l}\text { Jack reads books in the library, but most of his } \\
\text { friends read in their rooms. }\end{array}$ & $\begin{array}{l}\text { Peter studies English in the library but many of } \\
\text { his friends study at language centers. }\end{array}$ \\
\hline $\begin{array}{l}\text { We found it very hard to believe the story he told us } \\
\text { about his brother. }\end{array}$ & $\begin{array}{l}\text { She thought that it was very interesting to listen } \\
\text { to the talk about her friends. }\end{array}$ \\
\hline $\begin{array}{l}\text { Last night I finished my class early and went for a } \\
\text { long walk by the river. }\end{array}$ & $\begin{array}{l}\text { Last year he completed his studies at school and } \\
\text { went to a university in another city. }\end{array}$ \\
\hline $\begin{array}{l}\text { As soon as she comes back, I'll tell her that you want } \\
\text { to see her. }\end{array}$ & $\begin{array}{l}\text { As long as you wait here, you will see the girl } \\
\text { that you want to talk to. }\end{array}$ \\
\hline $\begin{array}{l}\text { It began to rain very hard yesterday just as we were } \\
\text { taking his mother to the train. }\end{array}$ & $\begin{array}{l}\text { It started to snow very heavily yesterday right } \\
\text { after we had parked our car in the centre. }\end{array}$ \\
\hline
\end{tabular}




\section{APPENDIX B}

ORAL READING TEXTS

\section{TEXT A}

Not all diamonds are turned into jewels. Actually only about twenty percent of the diamonds mined in the world ever reach the jewellers. The majority of those diamonds are not good enough because they cannot be perfectly shaped or they are badly discoloured. Many of them are black. But do not imagine that these faulty diamonds are thrown away. They are used in industry. Most of these industrial diamonds are mined in the Congo. Although they are not worth nearly as much in shillings and pence as the pure white diamonds of South Africa, their real value is much greater. It has even been claimed that the industrial diamond is one of the most important influences in our modern world. All diamonds are equally hard and it is this quality of hardness that gives the industrial diamond its special value. Metal tools, even those made with the hardest metals, wear out in time. When they are given heavy work to do their edges quickly lose their sharpness. They soon become thin and have to be repaired or replaced. But tools fitted with diamond heads, or knives coated with special diamond-filled mixtures never wear out.

\section{TEXT B}

Diamonds save manufacturers a lot of time and money. This means many more things in the shops at cheap prices. Without the diamond there would be many things that poor people could not afford. In fact diamond has played a very important part in making life easier and cheaper for countless millions of people. Engineers also make great use of the industrial diamond. Diamond drills, machines for making holes, have been used by mining engineers for a very long time. Diamond headed drills were used over a hundred years ago to drive a railway tunnel under a mountain. Now diamond cutters and polishers are used to build the great modern highways and modern airports. They are used, too, to build space ships and space instruments that must be made of very hard materials. It is doubtful if man would ever have been able to get into space at all without the help of the industrial diamond. But how are these extra hard diamond tools made? With the help of diamonds, of course. For only diamond will cut diamond. The diamond cutters of Amsterdam cut their beautiful white South African stones with Congo black diamonds. 


\section{APPENDIX C \\ TEXTS FOR READING OUTSIDE THE SPEED READING COURSE}

Text A: The sinking of the Titanic

Almost one hundred years have now passed since the Titanic sank on its first crossing. Many people assured that nothing on earth could sink this great ship. It was man's complete answer to the sea storms. It was the wonder of the world.

The Queen Elizabeth of today is 1985 feet long, but the Titanic was not much shorter. It was 852 1/2 feet long. It could carry 1,054 people in the first-class, 510 in the second-class, and 1,022 in the third-class. There were also 860 officers and men to work the ship. The powerful engines were in two rooms separated from each other by a steel wall.

The ship had six different parts, separated by steel doors. If a hole was made in its side, that part could shut off from the rest. When the steel doors were closed, the sea could not reach any other part of the ship. For this feature and for others, it was positively confirmed that the Titanic was the safest ship on the sea.

The ship was equipped with wireless, another wonder of the time. It was about ten years since Marconi had sent the first wireless signal across the Atlantic, and now numbers of ships used wireless every day. Therefore the Titanic master could call for assistance at any time. It seemed impossible that it would ever sink. But if it did, wireless signals would soon bring other ships to aid anyone in the sea.

Beautiful lights lit up the great ship. Wonderful lifts carried people up and down. The great public rooms were like those in a fine hotel. Technology had provided everything that an officer could want.

The Titanic left England in April 1912 and sailed for New York. There were rich people on board; it was considered a great honour to be allowed to sail in this so-called world wonder. It is estimated that the richest men in the ship together owned property worth $£ 120,000,000$. Mr. Thomas Andrews, the man who planned the ship, was also on board.

The night of 14th April was very cold. There was no moon, and hardly any wind. The ship captain was unhappy about the wind, because it helps sailors who are watching for 
icebergs. If the wind is blowing, the sound the waves make against icebergs can be heard. This tells the watching men to take care. But if there is no wind, there is very little noise. The ship was now in the part of the Atlantic in which icebergs cause trouble. Icebergs come from the north when the ice breaks up, and they move on the water towards the south. Ice is hard enough to cut holes in steel, and cannot easily be seen at night.

The wireless officer of the ship, J.G. Phillips, had received several signals transmitting the news that ice was not far away, and he was aware that icebergs can send big ships to the bottom of the sea. Most of these specifically important signals were submitted to the officers; but one was not processed. It was from another ship called Mesaba, reporting icebergs in front of the Titanic.

When it arrived, Phillips was working hard. Many of the travellers had sent news or orders by wireless to their friends back home. Wireless was a fairly new thing, and they were rich men. Phillips was now doing his best to finish off all this work. He was busy and therefore did not report the ice immediately. The signal lay on his table, half forgotten.

The ship's officers knew that icebergs were not far away. Although signals had been received from other ships about them, the ship continued on its course as usual. No changes were made; but two men were told to watch for icebergs. It seems to have been a clear night at first, but later it was not very easy to see far across the sea.

It was not a trend for big ships to go slowly near icebergs. This surprising fact was the result of the need to arrive at the right moment. These ships were considered as fast trains; they left at the right time, and there were expected to arrive at the right time. The shipping companies did not like the captains of ships that were late.

\section{COMPREHENSION QUESTIONS}

1. Which statement is incorrect?
A. The Titanic was believed to be the only wonder of the world.
B. The Titanic was the fastest ship of the time.
C. People believed that the Titanic could never sink.
D. The Titanic is the longest ship of all time.

\section{The Titanic}



A. is longer than the Queen Elizabeth
B. carries the fewer people in the first-class than in the second-class
C. has separated engine rooms
D. was completely made of steel

3. The Titanic was believed to be the safest ship because
A. there were 860 officers and men to work the ship
B. it has six parts
C. its parts were separated from each other by steel doors, which shut one part off from the rest
D. it had wireless

\section{Which statement is CORRECT?}
A. The Titanic was the only ship which was fitted with wireless.
B. The Titanic was the first ship to be fitted with wireless.
C. People could use lifts on the Titanic.
D. There was a fine hotel on the Titanic.

5. It is said that property worth $£ 120,000,000$ was owned by
A. the richest man in the world
B. all of the men on the Titanic
C. the richest men on the Titanic
D. all of the people on the Titanic

6. How does the wind help sailors?
A. They can see further if there is strong wind.
B. They can hear the waves against icebergs if there is strong wind.
C. They can get better signal if there is strong wind.
D. Ships can move faster if there is strong wind.

7. According to the author, ice
A. can be cut in holes.
B. can make holes in steel.
C. is easy to see when it is windy.
D. comes from the south. 
8. The Titanic received
A. no signals from other ships
B. one signal saying that there was no iceberg
C. a signal from Mesaba
D. many signals saying that icebergs can send ships to the bottom of the sea

9. The signal from a ship called Mesaba
A. was not passed on to the officers immediately
B. was neglected because the wireless officer was busy sending news back to his family in England
C. was given to the travellers
D. helped the ship's officers to slow down the ship

10. The Titanic continued on its course as usual because
A. the ship was expected to arrive at the right time
B. the ship's officers did not know about the signal
C. the officers thought that the ship is a fast train
D. The shipping companies did not like the captain 


\section{APPENDIX D \\ TEXTS FOR Reading OUTSIDE THE SPEED READING COURSE}

Text B: A short history of international trade

Trade is as old as history itself. In the beginning, people exchanged items such as food and clothes. Later, they began to use money. But international trade only became important in the fourteenth and fifteenth centuries, when many modern countries were formed.

In the seventeenth century, most governments had a very simple idea of trade. They wanted to sell as much as possible to other countries; at the same time, they wanted to buy as little as possible from other countries. This was called mercantilism, and it helped successful countries to become rich. For example, in 1651, the government of England made a new law stating that their ships controlled all the trade with countries in the British Empire. The French made a similar law.

In the eighteenth century, economists began to see disadvantages with mercantilism. Because every country was trying to sell more than it bought, countries were not working together. French and English economists told their governments that a trade agreement would be better for both countries. In 1786, France and England made an agreement. Other countries made similar agreements, and trade became easier and cheaper over the next hundred years or more.

The beginning of the twentieth century was a bad time for trade. Many countries in the world were at war between 1914 and 1918. Later, the Great Depression of the 1930s made trade difficult. Countries no longer wanted to work together - they were only interested in their own economies. This 'new mercantilism' made the Depression last longer.

In the 1940s, many countries decided that they needed to make trade agreements to help the world economy. In 1947, twenty-three countries made an agreement called GATT (General Agreement on Tariff and Trade). This aims to make it easier and cheaper for countries to buy and sell goods. Since 1947, the countries in this organization have met every few years, often in Switzerland, to talk about any problems they have with trade. The organization played a very important part in the development of world trade for fifty years. 
In 1995, GATT became the WTO (World Trade Organization). The idea of this new organization is the same as the old one - to make world trade easier and cheaper - but the WTO has more powers to solve disagreements between countries. In its first five years, the organization looked at about 200 trade disagreements.

There are many advantages to the WTO. Firstly, all the countries in the organization have to follow the same trade rules. This saves time: countries can make just one agreement instead of a lot of different ones. It also means that larger, more powerful countries cannot make it difficult for poorer countries to take part in trade. Secondly, cheaper trade means cheaper items in the shops. In the past, some countries did not want goods from other countries in their shops, so they made it very difficult and expensive for their countries to sell their goods. This was called protectionism, and it often meant higher prices. Thirdly, easier trade is considerably good for the world economy and probably means more jobs. And finally, some people say that trade agreements help to keep peace because they help countries to work together. Of course, there have been wars since GATT/WTO began, but none as large as the 1914-18 or 1939-45 World Wars.

However, some people are worried about the WTO. They argue that the organization has got too much power and does not have to explain its decisions. There are also worries about the organization and the environment. Sometimes, countries have laws against trade which damages the environment. These laws are often against the WTO rules.

Many people think that the organization is on the side of very large companies, and makes trade more difficult for small companies. For example, in the 1990s, there was a trade disagreement between the USA and the EU. The EU was paying more for bananas from poor countries because it wanted to help their economies. However, this was against the rules of the WTO. Companies in the USA wanted to sell their bananas in the EU, and because the companies were very large, they could sell bananas more cheaply than the companies in the poor countries. This is just one example of how trade agreement can make life very difficult for smaller, less powerful countries.

\section{COMPREHENSION QUESTIONS}

1. In the fourteenth and fifteenth centuries

A. International trade became easier

B. A lot of modern countries were formed 
C. Many countries were destroyed

D. There was no international trade

2. Mercantilism
A. means one country tries to buy as much as possible
B. means one country tries to sell as much as possible
C. made many countries become poor
D. was popular in the eighteenth century

3. The trade agreement between France and England
A. made it easier and cheaper to trade
B. was made in the nineteenth century
C. was suggested by the traders
D. made France and England become friends

4. Why was the beginning of the twentieth century a bad time for trade?
A. Because many countries were in the World War I
B. Because of the Great Depression
C. Both A and B
D. The author did not give reasons

5. In the passage, 'new mercantilism' means
A. Great Depression
B. World War I
C. Countries hated each other
D. Countries were just interested in their own economies

6. Which of the following statements is CORRECT?
A. GATT was first made between more than thirty countries.
B. GATT was signed in 1947.
C. GATT countries met every year.
D. GATT was in effect for about one hundred years

7. Which one the following is NOT an advantage of WTO?

A. WTO helps to keep peace. 
B. WTO promotes employment.

C. WTO makes goods cheap and easier to buy.

D. WTO helps to develop technology

\section{Protectionism}
A. helps saving time because countries can meet together and talk.
B. requires different countries to follow the same rules.
C. means one country make it difficult for other countries to sell their goods.
D. help smaller countries.

9. WTO has some disadvantages because
A. it has rules which are against environment protection.
B. it is so powerful that nobody may question its actions.
C. it provides people chances to find jobs.
D. It does not help solving trade disagreements

10. The trade disagreement between the USA and the EU is an example of
A. how WTO can help to solve trade disagreement.
B. the advantage of joining WTO.
C. how WTO makes trade difficult for smaller countries.
D. how WTO helps to develop world economy. 


\section{APPENDIX E \\ TEXTS FOR READING OUTSIDE THE SPEED READING COURSE \\ Text C: Stock markets}

Stock exchanges began in the thirteenth century. Traders used to meet in towns to buy and sell their goods. It was easier for them to use credit notes than money. In France, King Phillip the Fair decided that some rules were needed, and a group of people began to work full time to see that all the traders followed these rules. These people were first called 'stockbrokers'. In Bruges, traders used to meet outside the houses of a family called Van der Bourse. Later, the word 'Bourse' came to mean 'stock exchange'.

In the sixteenth and seventeenth centuries, other countries began to have stock exchanges. In London, a group of 150 stockbrokers had to leave the Royal Exchange because they were so noisy. They started to meet in a café called Jonathan's Coffee House. In 1773, this café became the Stock Exchange. Over the next hundred years, the London Stock Exchange was an important part of the UK economy, and lent money to new companies. But it was 200 years before the first women members were able to join the London Stock Exchange in 1971.

Stock markets usually go up when a country's economy is doing well. Of course, some companies' stocks go up or down for different reasons, but each stock exchange has an 'index' that shows how all the stocks are doing together. In Tokyo, for example, this is called the Nikkei index, and in New York, the Dow-Jones index. People watch these indexes to see how the world's businesses are doing. Since the end of the Second World War in 1945, stock markets around the world have gone up greatly because the economy of the world has got much bigger.

Usually, stock markets do not change very much in one day. But on October $19^{\text {th }} 1987$, the Dow-Jones index fell by more than 500 points. Other stock exchanges around the world also fell. People became very worried about this because of what had happened nearly sixty years earlier. In 1929, the stock markets fell quickly and suddenly in the same wayand for the next ten years the world economy was in serious trouble. That period was called the Great Depression. People lost money, lost their jobs, and lost hope in the future of business. 
Before the crash in 1929, the stock market in Wall Street was doing well - very well. People were spending money and companies were getting bigger. New companies were appearing as new inventions filled people's homes: fridges, electric lights, radios. Buying stocks in companies seemed like a good way to make money. Everybody wanted to buy stocks. So the price of stocks went up - and so people did make money. People were borrowing money to buy stocks and get rich.

But the economists at that time were worried. They knew that the stock market could not continue to go up when people were borrowing so much money. In October 1929, the market in Wall Street began to fall. As it fell, more and more people wanted to sell their stocks, so the market fell more quickly. Nobody answered the telephones at the stock exchange because it was too busy, so angry crowds came to Wall Street, trying to sell their stocks. So nobody could stop the fall.

The crash of the stock market changed the way Americans felt about money. Suddenly they did not want to buy stocks. They did not feel that their money was safe in banks either, so many people started keeping their money in boxes at home. Banks and other companies went out of business as people stopped spending. By 1933, there were 13 million people without work in the USA. Some of these people also lost their homes.

The Depression in the USA caused problems in other countries, too, because a lot of countries traded with the USA. Businesses closed and millions of people lost their jobs. Governments and economists have studied the reasons for the Wall Street Crash of 1929 and the Depression on the 1930s. Today, there are more rules in the world's stock markets about buying and selling stocks. The stock markets still go up and down, but everybody hopes there will not be another crash like the one in 1929. However, nobody can be sure that it will never happen again.

\section{COMPREHENSION QUESTIONS}

1. Stockbrokers were

A. people who were trading

B. people who broke the trade rules

C. people who checked if the traders followed the rules

D. people who worked in the office 
2. What might be the reason why the word 'Bourse' became to mean stock exchange?
A. Traders met outside of the house of the family named 'Van Der Bourse'.
B. Van Der Bourse was the first person to sell stock.
C. It was the name of the company which first sold stocks.
D. It was one of the rules set by King Phillip the Fair.

3. The first Stock Exchange in London used to be
A. The Royal Exchange
B. A restaurant
C. A company's office
D. A café

4. The first women were able to join the London Stock Exchange
A. when it lent money to new companies
B. almost 200 years after the café became the London Stock Exchange
C. almost 200 years before
D. when they had to leave the Royal Exchange

5. Nikkei and Dow-Jones are examples of
A. indexes
B. countries' economies
C. stock markets
D. stock exchanges

6. Why were people worried when the Dow-Jones index fell in 1987 ?
A. Because they were afraid that the same economic fall as in 1929 would happen again
B. Because they had been buying too much stock
C. Because they had no jobs then
D. Because other stock exchanges in the world also fell down.

7. Which statement is incorrect?
A. Before the crash in 1929, many new companies were founded.
B. The price of stock went up.
C. People borrowed money to buy stocks.
D. Many companies wanted to sell their stocks. 
8. Which statement is incorrect about what happened in the USA when the crash came?
A. People stopped selling their stocks.
B. People began to keep their money at home.
C. A lot of banks went out of business.
D. Many people lost their houses.

9. The Depression in the USA affected other countries because
A. these countries were poor.
B. these countries traded with the USA.
C. these countries tried to help the USA.
D. people from these countries buy stocks from American companies.

10. According to the author, nobody can be sure about
A. how the stock markets will affect one country's economy.
B. what people will do if there is a crash again.
C. how stock markets will change.
D. how many people will join stock markets in the future. 


\section{APPENDIX F \\ TEXTS FOR READING OUTSIDE THE SPEED READING COURSE \\ Text D: Work}

Most people want to work, but it has become difficult in today's world to find jobs for everybody. The economies of the world need to grow by approximately $4 \%$ each year just to keep the old number of jobs for people. This is not possible, and so more people are made redundant. Some people have no jobs now because machines can do the tasks of many people in a shorter time.

Also, machines do not insist on higher promotion and longer vacation. In all of the countries of the world machines are taking work from people, not only in factories but also on the farms, where one machine can incredibly do the jobs of forty people. Around the world 75,000 people a day are moving to cities, where life is already a chaos for other reasons.

As new technology become available, it is possible that more and more people will lose their jobs. Factories and farms of the future will only use machines to do the work and people to repair the machines,

Many people contend that we should try to produce less. We should try to make our lives slower and smaller. This is the only way to give meaning to our lives. Our real work is to become a real person. These are the thoughts of Professor Schumacher, who wrote the book Small is Beautiful. More and more people today assert that he is right. But others contend that there is one big problem - Professor Schumacher's ideas will only work if we reduce the number of people in the world by half. There are too many people and there is not enough work.

The most momentous problem in Today's World is the difference between rich and poor countries. The rich countries such as the US, Canada, England, France, Japan, should give help to the poor countries, so they can start their own industries. If poor countries could start their own industries then there would be more work opportunities for people.

But why do people want to work? People work because they need money to live. They need money for food and clothes and to pay for their house or apartment where they live. 
People need money for many different things and they get paid if they work. Work if very essential for everyone. It makes people feel important. It makes them feel that they are useful.

But machines can now do many things that people used to do. Technology is giving us more cars, roads and food but less work. The invention of the 'micro processor' means that we can utilise machines and computers in the smallest places. So there are even fewer people needed for work.

In Tomorrow's World the work people will do, will change. People will need to learn new things because life will be changing so fast. People will have to change their ideas about work. Perhaps school and work will be like this:

Age:

0-3 At home

3-5 Playschool

5-18 Elementary and secondary school - a general education to help people understand machinery and technology

18-25 Work

25-30 University - students will learn more when they have already worked for some years

30-40 Work - with more responsibility

40-42 Back to school - to train for a new job or to do research

42-50 Work - at the highest level of responsibility

$50 \quad$ Stop work.

If everyone knows how to do many jobs, then people can share work. In Tomorrow's World every person will choose the type of work they like best; and the organisers - the people in control of the work - will try to make the work interesting and incredible. In the next century a working week for one person could possibly look like this:

Monday Broadcaster

Tuesday Bus driver

Wednesday Pilot

Thursday Teacher

Friday Salesperson 
In Tomorrow's World work will change, People will earn money for doing many different things. There will be many new professions to keep people busy. Here are some ideas for new professions:

\begin{tabular}{|l|l|}
\hline Collector & $\begin{array}{l}\text { People will receive money to collect things, such as stamps, cards, } \\
\text { matchboxes. They will then put on shows of their work for people to } \\
\text { look at. }\end{array}$ \\
\hline Eater & People will eat food at restaurants and earn money for that. \\
\hline Story-teller & People will earn money for telling stories to audience. \\
\hline
\end{tabular}

\section{COMPREHENSION QUESTIONS}

1. If the world economies grow by $4 \%$ each year,

A. it will be possible to provide jobs for everyone.

B. it will be possible to keep the old number of jobs the same.

C. it will be easier to find a job.

D. there will be more and more jobs for people.

2. According to the author,

A. it is easy to keep the old number of jobs.

B. it is difficult to increase the world economy by $4 \%$.

C. less people are without jobs today than in the past.

D. machines can do difficult jobs that people cannot do.

3. Which statement is INCORRECT?

A. Machines are better in people in that they ask for money and holidays.

B. One machine can do the work of forty people.

C. Machines only work in factories.

D. A lot of people are moving to cities to find a job.

4. Which statement is INCORRECT?

A. More and more machines will be invented.

B. More and more people will be without work.

C. People will be only repairing machines.

D. We will produce less. 
5. Why do some people think that Professor Schumacher's ideas will not work?
A. Because there is one big problem in his ideas
B. Because there are no real people
C. Because there are too many people
D. Because he wants to reduce the number of people in the world by half

6. Which of the following is NOT a reason why work is important?
A. People earn money by working.
B. People feel important when they work.
C. People know that they are useful when they work.
D. People feel bored if they do not work.

7. Why are there fewer people needed for work?
A. Because 'micro-processor' took all of the jobs
B. Because 'micro-processor' allows us to use machines in small places
C. Because there are more and more 'micro-processor'
D. Because they have already had cars, roads and food

8. In Tomorrow's World, how much time in one's life one may spend studying?
A. about 20 years
B. about 30 years
C. about 15 years
D. about 27 years

9. Which statement is INCORRECT?
A. In Tomorrow's World, a person may do different jobs on different days of the week.
B. In Tomorrow's World, the organisers will have to make the work harder for the workers.
C. In Tomorrow's World, people can choose their work.
D. In Tomorrow's World there will be more and more professions.

10. In Tomorrow's World, a collector would be
A. A person who collect things for fun
B. A person who helps other people to collect things
C. A person who buy other people's shows
D. A person who collect things to get money 


\section{APPENDIX G}

VOCABULARY TEST

By Schmitt, Schmitt and Clapham (2001)

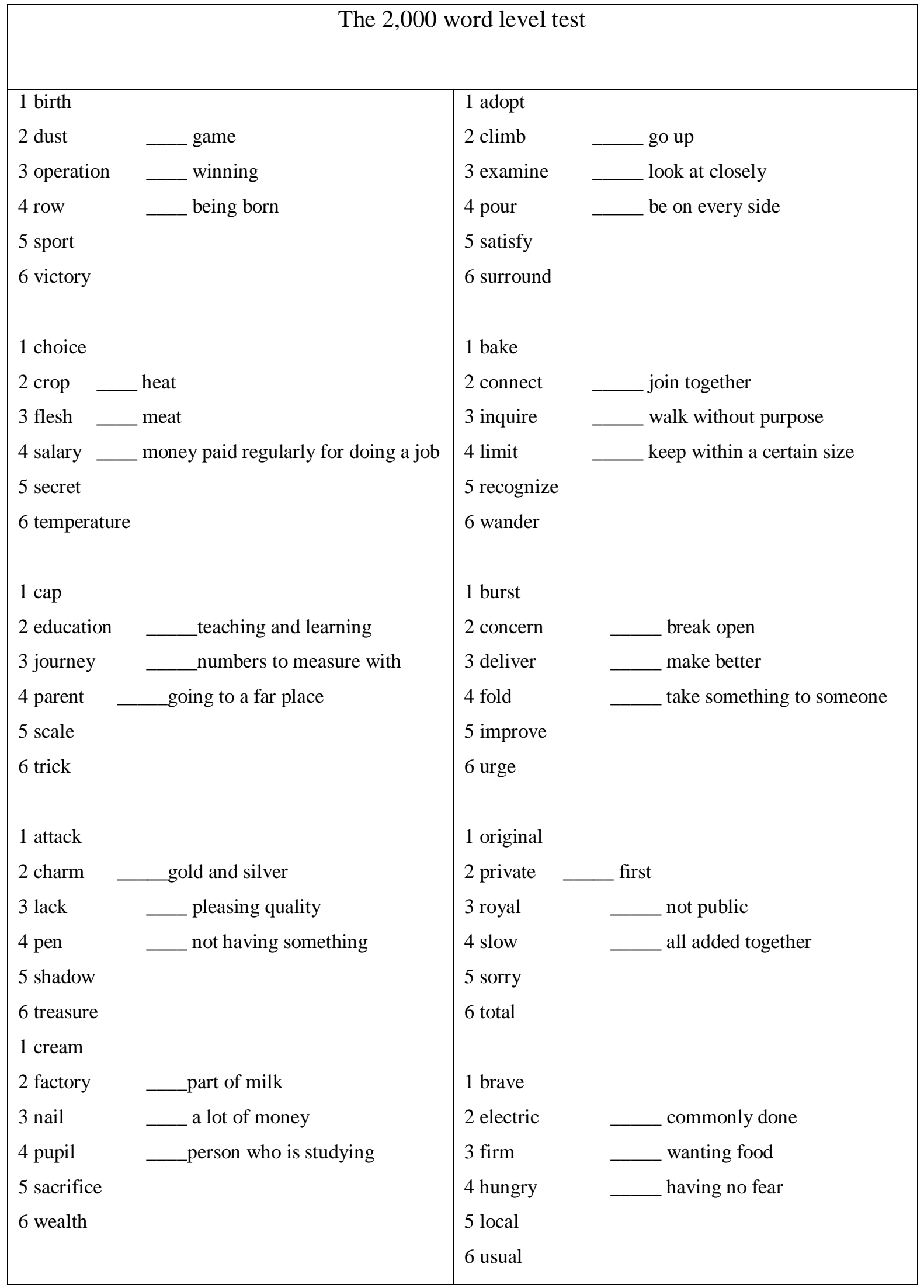




\section{APPENDIX H}

\section{BILINGUAL VOCABULARY TEST - INITIAL VERSION}

The 2,000 word level test

Instructions: Mỗi một câu hỏi có ba từ tiếng Việt bên phải và sáu từ Tiếng Anh bên trái. Với mỗi từ tiếng Việt, hãy chọn một từ tương đương trong Tiếng Anh trong sáu từ bên trái và viết số thứ tự của từ đó vào dòng kẻ ngay trước từ Tiếng Việt.

\begin{tabular}{|c|c|c|}
\hline 1 birth & & 1 adopt \\
\hline 2 dust & trò chơi & 2 climb __ tăng lên \\
\hline 3 operation & ___ chiến thắng & 3 examine _ n nì̀ kỹ \\
\hline 4 row & sinh ra & _ _ở quanh \\
\hline 5 sport & & 5 satisfy \\
\hline 6 victory & & 6 surround \\
\hline 1 choice & & 1 bake \\
\hline 2 crop & __ sức nóng & 2 connect ___ cùng tham gia \\
\hline 3 flesh & __ thịt & 3 inquire __ đi không có định hướng \\
\hline 4 salary & ___ tiền trả đều đặn cho một & 4 limit _ _ giữ ở một kích thước nhất định \\
\hline 5 secret & nghề nào đó & 5 recognize \\
\hline 6 temperature & & 6 wander \\
\hline 1 cap & & 1 burst \\
\hline 2 education & ___ dạy và học & tung ra \\
\hline 3 journey & ___ có số để đo đạc & __ làm tốt hơn \\
\hline 4 parent & __ đi đến một nơi xa & ___ đưa cho ai cái gì \\
\hline 5 scale & & 5 improve \\
\hline 6 trick & & 6 urge \\
\hline 1 attack & & 1 original \\
\hline 2 charm & - vàng và bạc & 2 private ___ đầu tiên \\
\hline 3 lack & có tính chất đáng yêu, dễ chịu & __ không có tính chất công cộng \\
\hline 4 pen & không có gì đó & __ tổng thể \\
\hline 5 shadow & & 5 sorry \\
\hline 6 treasure & & 6 total \\
\hline 1 cream & & 1 brave \\
\hline 2 factory & ___ một phần của sữa & thường thường \\
\hline 3 nail & __ nhiều tiền & __ muốn ăn \\
\hline 4 pupil & người đang học & __ không sợ hãi \\
\hline 5 sacrifice & & 5 local \\
\hline 6 wealth & & 6 usual \\
\hline
\end{tabular}




\section{APPENDIX I}

\section{BILINGUAL VOCABULARY TEST - FINAL VERSION}

\section{The 2,000 word level test}

Instructions: Mỗi một câu hỏi có ba từ tiếng Việt bên phải và sáu từ Tiếng Anh bên trái. Với mỗi từ tiếng Việt, hãy chọn một từ tương đương trong Tiếng Anh trong sáu từ bên trái và viết số thứ tự của từ đó vào dòng kẻ ngay trước từ Tiếng Việt.

\begin{tabular}{|c|c|c|}
\hline 1 birth & & 1 adopt \\
\hline 2 dust & _ thể thao & 2 climb __ tăng lên \\
\hline 3 operation & ___ chiến thắng & 3 examine _ _ _ xem xét, nhìn kỹ, để ý \\
\hline 4 row & sinh ra & __ ở quanh \\
\hline 5 sport & & 5 satisfy \\
\hline 6 victory & & 6 surround \\
\hline 1 choice & & 1 bake \\
\hline 2 crop & ___ nhiệt độ & 2 connect ___ nối nhau, liên kết \\
\hline 3 flesh & __ thit & 3 inquire ___ đi không có định hướng \\
\hline 4 salary & ____ tiền trả đều đặn cho một nghề & ___ giữ ở một kích thước nhất định \\
\hline 5 secret & nào đó & 5 recognize \\
\hline 6 temperature & & 6 wander \\
\hline 1 cap & & 1 burst \\
\hline 2 education & ___ dạy và học & ___ bung ra \\
\hline 3 journey & ___ dùng để cân/đo & _ làm tốt hơn \\
\hline 4 parent & ____ đi đến một nơi khác & ___ đưa cho ai cái gì \\
\hline 5 scale & & 5 improve \\
\hline 6 trick & & 6 urge \\
\hline 1 attack & & 1 original \\
\hline 2 charm & ___ vàng và bạc & 2 private ___ đầu tiên \\
\hline 3 lack & ___ đáng yêu, có tính chất thu hút & không có tính chất công cộng \\
\hline 4 pen & ___ không/ thiếu có gì đó & ___ tổng thể, tổng \\
\hline 5 shadow & & 5 sorry \\
\hline 6 treasure & & 6 total \\
\hline 1 cream & & 1 brave \\
\hline 2 factory & ___ một phần từ sữa & _ thường thường \\
\hline 3 nail & ___ nhiều tiền & ___ muốn ăn \\
\hline 4 pupil & người học & ___ không sợ hãi \\
\hline 5 sacrifice & & 5 local \\
\hline 6 wealth & & 6 usual \\
\hline
\end{tabular}




\section{APPENDIX J}

Number of participants who read a certain text and got one of the three lowest scores or/and one of the three highest scores in the speed reading course in the first experiment

\begin{tabular}{|c|c|c|c|c|}
\hline Texts & $\begin{array}{l}\text { Number of participants who } \\
\text { read the text and got one of the } \\
\text { three lowest scores }\end{array}$ & Percentage & $\begin{array}{l}\text { Number of participants who } \\
\text { read the text and got one of } \\
\text { the three highest scores }\end{array}$ & Percentage \\
\hline 1 & 15 & 21 & 11 & 15 \\
\hline 2 & 21 & 29 & 16 & 22 \\
\hline 3 & 11 & 15 & 14 & 19 \\
\hline 4 & 12 & 16 & 18 & 25 \\
\hline 5 & 18 & 25 & 8 & 11 \\
\hline 6 & 12 & 16 & 22 & 30 \\
\hline 7 & 14 & 19 & 28 & 38 \\
\hline 8 & 11 & 15 & 9 & 12 \\
\hline 9 & 8 & 11 & 21 & 29 \\
\hline 10 & 17 & 23 & 14 & 19 \\
\hline 11 & 13 & 18 & 24 & 33 \\
\hline 12 & 10 & 14 & 16 & 22 \\
\hline 13 & 18 & 25 & 8 & 11 \\
\hline 14 & 4 & 5 & 11 & 15 \\
\hline 15 & 5 & 7 & 15 & 21 \\
\hline 16 & 12 & 16 & 11 & 15 \\
\hline 17 & 8 & 11 & 8 & 11 \\
\hline 18 & 8 & 11 & 9 & 12 \\
\hline 19 & 13 & 18 & 6 & 8 \\
\hline 20 & 10 & 14 & 6 & 8 \\
\hline
\end{tabular}




\section{APPENDIX K}

In-course increases (wpm) in the $20^{\text {th }}$ minus $1^{\text {st }}$ scoring method for all groups in the first experiment

\begin{tabular}{|c|c|c|c|c|c|c|c|}
\hline Group 1 & Increase & Group 2 & Increase & Group 3 & Increase & Group 4 & Increase \\
\hline $1 \mathrm{Q}$ & 118 & $2 \mathrm{~S}$ & 144 & $3 \mathrm{Q}$ & 194 & $4 \mathrm{O}$ & 149 \\
\hline $1 \mathrm{D}$ & 110 & $2 \mathrm{C}$ & 120 & $3 \mathrm{~F}$ & 184 & $4 \mathrm{~F}$ & 139 \\
\hline $1 \mathrm{~L}$ & 95 & $2 \mathrm{R}$ & 113 & $3 \mathrm{~J}$ & 152 & $4 \mathrm{R}$ & 130 \\
\hline $1 \mathrm{M}$ & 94 & $2 \mathrm{P}$ & 96 & $3 \mathrm{P}$ & 130 & $4 \mathrm{U}$ & 122 \\
\hline $1 \mathrm{P}$ & 83 & $2 \mathrm{~B}$ & 90 & $3 \mathrm{R}$ & 115 & $4 \mathrm{M}$ & 120 \\
\hline $1 \mathrm{E}$ & 73 & $2 \mathrm{D}$ & 84 & $3 \mathrm{~L}$ & 99 & $4 \mathrm{H}$ & 112 \\
\hline $1 \mathrm{H}$ & 70 & $2 \mathrm{M}$ & 83 & $3 \mathrm{X}$ & 93 & $4 \mathrm{~N}$ & 110 \\
\hline $1 \mathrm{I}$ & 64 & $2 \mathrm{H}$ & 73 & $3 \mathrm{~W}$ & 75 & $4 \mathrm{~A}$ & 100 \\
\hline $1 \mathrm{~S}$ & 63 & $2 \mathrm{~J}$ & 59 & $3 \mathrm{I}$ & 64 & $4 \mathrm{~T}$ & 91 \\
\hline $1 \mathrm{R}$ & 62 & $2 \mathrm{~K}$ & 59 & $3 \mathrm{~A}$ & 57 & $4 \mathrm{P}$ & 90 \\
\hline $1 \mathrm{~F}$ & 59 & $2 \mathrm{~T}$ & 51 & $3 \mathrm{~N}$ & 57 & $4 \mathrm{~B}$ & 77 \\
\hline $1 \mathrm{~J}$ & 59 & $2 \mathrm{E}$ & 43 & $3 \mathrm{~B}$ & 45 & $4 \mathrm{I}$ & 64 \\
\hline $1 \mathrm{~K}$ & 43 & $2 \mathrm{~V}$ & 34 & $3 \mathrm{M}$ & 43 & $4 \mathrm{Q}$ & 64 \\
\hline $1 \mathrm{~A}$ & 30 & $2 \mathrm{G}$ & 33 & $3 \mathrm{H}$ & 42 & $4 \mathrm{C}$ & 32 \\
\hline $1 \mathrm{C}$ & 23 & $2 \mathrm{I}$ & 32 & $3 \mathrm{O}$ & 41 & $4 \mathrm{G}$ & 32 \\
\hline $1 \mathrm{~B}$ & 21 & $2 \mathrm{U}$ & 28 & $3 \mathrm{U}$ & 41 & $4 \mathrm{~J}$ & 14 \\
\hline $1 \mathrm{~N}$ & 20 & $2 \mathrm{~A}$ & 23 & $3 \mathrm{G}$ & 40 & $4 \mathrm{~K}$ & 14 \\
\hline $1 \mathrm{O}$ & 0 & $2 \mathrm{~W}$ & 11 & $3 \mathrm{~S}$ & 32 & $4 \mathrm{~L}$ & -49 \\
\hline & & $2 \mathrm{~F}$ & -44 & & & & \\
\hline & $\mathbf{6 0}$ & & $\mathbf{6 0}$ & & $\mathbf{8 4}$ & & $\mathbf{7 8}$ \\
\hline
\end{tabular}




\section{APPENDIX L}

Scores on initial and final texts, average scores of the first three texts (A 1-3) and the last three texts (A 14-16) for group 1 in the first experiment

\begin{tabular}{|l|c|c|c|c|c|c|c|c|c|}
\hline P & 1st text & 2nd text & 3rd text & 14th text & 15 th text & 16 th text & A 1-3 & A 14-16 & D \\
\hline 1L & 111 & 126 & 153 & 227 & 206 & 206 & 130 & 213 & 83 \\
\hline 1D & 134 & 105 & 178 & 165 & 254 & 244 & 139 & 221 & 82 \\
\hline 1S & 137 & 110 & 146 & 212 & 220 & 200 & 131 & 211 & 80 \\
\hline 1Q & 146 & 143 & 183 & 212 & 227 & 264 & 157 & 234 & 77 \\
\hline 1M & 220 & 200 & 220 & 200 & 347 & 314 & 213 & 287 & 74 \\
\hline 1H & 113 & 122 & 146 & 200 & 212 & 183 & 127 & 198 & 71 \\
\hline 1F & 101 & 100 & 110 & 178 & 153 & 160 & 104 & 164 & 60 \\
\hline 1I & 110 & 134 & 143 & 188 & 194 & 174 & 129 & 185 & 56 \\
\hline 1E & 110 & 113 & 157 & 143 & 169 & 183 & 127 & 165 & 38 \\
\hline 1A & 153 & 157 & 165 & 200 & 200 & 183 & 158 & 194 & 36 \\
\hline 1R & 165 & 174 & 206 & 220 & 200 & 227 & 182 & 216 & 34 \\
\hline 1J & 110 & 108 & 174 & 157 & 157 & 169 & 131 & 161 & 30 \\
\hline 1K & 157 & 174 & 165 & 178 & 194 & 200 & 165 & 191 & 25 \\
\hline 1C & 183 & 183 & 212 & 188 & 244 & 206 & 193 & 213 & 20 \\
\hline 1N & 91 & 108 & 132 & 111 & 165 & 111 & 110 & 129 & 19 \\
\hline 1P & 111 & 160 & 169 & 134 & 140 & 194 & 147 & 156 & 9 \\
\hline 1B & 206 & 165 & 178 & 174 & 143 & 227 & 183 & 181 & -2 \\
\hline 1O & 183 & 200 & 206 & 174 & 174 & 183 & 196 & 177 & -19 \\
\hline & $\mathbf{1 4 1}$ & $\mathbf{1 4 3}$ & $\mathbf{1 6 9}$ & $\mathbf{1 8 1}$ & $\mathbf{2 0 0}$ & $\mathbf{2 0 2}$ & $\mathbf{1 5 1}$ & $\mathbf{1 9 4}$ & $\mathbf{4 3}$ \\
\hline
\end{tabular}




\section{APPENDIX M}

Scores on initial and final texts, average scores of the first three texts (A 1-3) and the last three texts (A 18-20) for group 2 in the first experiment

\begin{tabular}{|c|c|c|c|c|c|c|c|c|c|}
\hline $\mathrm{P}$ & 1 st text & 2nd text & 3rd text & 18th text & 19th text & 20th text & A $1-3$ & A $18-20$ & $\mathrm{D}$ \\
\hline $2 \mathrm{~S}$ & 110 & 137 & 160 & 244 & 254 & 254 & 136 & 251 & 115 \\
\hline $2 \mathrm{M}$ & 111 & 146 & 110 & 194 & 227 & 194 & 122 & 205 & 83 \\
\hline $2 \mathrm{~K}$ & 115 & 92 & 122 & 178 & 169 & 174 & 110 & 174 & 64 \\
\hline $2 \mathrm{H}$ & 110 & 111 & 115 & 160 & 183 & 183 & 112 & 175 & 63 \\
\hline $2 \mathrm{P}$ & 110 & 137 & 178 & 188 & 200 & 206 & 142 & 198 & 56 \\
\hline 2I & 188 & 98 & 98 & 134 & 169 & 220 & 128 & 174 & 46 \\
\hline $2 \mathrm{R}$ & 111 & 120 & 194 & 174 & 165 & 224 & 142 & 188 & 46 \\
\hline $2 B$ & 137 & 169 & 183 & 200 & 194 & 227 & 163 & 207 & 44 \\
\hline $2 \mathrm{D}$ & 143 & 183 & 165 & 188 & 206 & 227 & 164 & 207 & 43 \\
\hline $2 \mathrm{C}$ & 124 & 200 & 244 & 220 & 220 & 244 & 189 & 228 & 39 \\
\hline $2 \mathrm{~T}$ & 169 & 183 & 183 & 227 & 200 & 220 & 178 & 216 & 37 \\
\hline $2 \mathrm{~J}$ & 153 & 165 & 165 & 169 & 200 & 212 & 161 & 194 & 33 \\
\hline $2 \mathrm{E}$ & 122 & 140 & 178 & 165 & 206 & 165 & 147 & 179 & 32 \\
\hline $2 \mathrm{G}$ & 150 & 174 & 183 & 174 & 220 & 183 & 169 & 192 & 23 \\
\hline $2 \mathrm{~W}$ & 126 & 106 & 101 & 140 & 124 & 137 & 111 & 134 & 23 \\
\hline $2 \mathrm{U}$ & 150 & 160 & 183 & 165 & 188 & 178 & 164 & 177 & 13 \\
\hline $2 \mathrm{~V}$ & 160 & 150 & 183 & 137 & 169 & 194 & 164 & 167 & 2 \\
\hline $2 \mathrm{~A}$ & 160 & 174 & 194 & 174 & 165 & 183 & 176 & 174 & -2 \\
\hline $2 \mathrm{~F}$ & 150 & 150 & 150 & 113 & 113 & 106 & 150 & 111 & -39 \\
\hline & 137 & 147 & 163 & 176 & 188 & 196 & 149 & 187 & 38 \\
\hline
\end{tabular}




\section{APPENDIX N}

Scores on initial and final texts, average scores of the first three texts (A 1-3) and the last three texts (A 18-20) for group 3 in the first experiment

\begin{tabular}{|c|c|c|c|c|c|c|c|c|c|}
\hline $\mathrm{P}$ & 1st text & 2nd text & 3rd text & 18th text & 19th text & 20th text & A 1-3 & A 18-20 & D \\
\hline 3Q & 153 & 153 & 160 & 300 & 330 & 347 & 155 & 326 & 170 \\
\hline 3J & 134 & 106 & 212 & 275 & 300 & 286 & 151 & 287 & 136 \\
\hline 3F & 91 & 151 & 212 & 254 & 254 & 275 & 151 & 261 & 110 \\
\hline 3R & 160 & 183 & 220 & 275 & 314 & 275 & 188 & 288 & 100 \\
\hline 3W & 169 & 157 & 165 & 227 & 275 & 244 & 164 & 249 & 85 \\
\hline 3L & 137 & 183 & 183 & 264 & 254 & 236 & 168 & 251 & 84 \\
\hline 3N & 126 & 132 & 140 & 194 & 200 & 183 & 133 & 192 & 60 \\
\hline 3O & 165 & 124 & 160 & 200 & 212 & 206 & 150 & 206 & 56 \\
\hline 3P & 200 & 236 & 330 & 286 & 300 & 330 & 255 & 305 & 50 \\
\hline 3X & 134 & 153 & 194 & 178 & 206 & 227 & 160 & 204 & 43 \\
\hline 3S & 188 & 140 & 188 & 200 & 220 & 220 & 172 & 213 & 41 \\
\hline 3M & 110 & 98 & 117 & 150 & 134 & 153 & 108 & 146 & 37 \\
\hline 3I & 105 & 137 & 183 & 137 & 212 & 169 & 142 & 173 & 31 \\
\hline 3G & 100 & 110 & 111 & 120 & 134 & 140 & 107 & 131 & 24 \\
\hline 3U & 165 & 183 & 194 & 194 & 194 & 206 & 181 & 198 & 17 \\
\hline 3H & 115 & 157 & 254 & 206 & 183 & 157 & 175 & 182 & 7 \\
\hline 3A & 137 & 183 & 275 & 200 & 206 & 194 & 198 & 200 & 2 \\
\hline 3B & 124 & 178 & 178 & 143 & 157 & 169 & 160 & 156 & -4 \\
\hline & $\mathbf{1 4 0}$ & $\mathbf{1 5 4}$ & $\mathbf{1 9 3}$ & $\mathbf{2 1 1}$ & $\mathbf{2 2 7}$ & $\mathbf{2 2 3}$ & $\mathbf{1 6 2}$ & $\mathbf{2 2 0}$ & $\mathbf{5 8}$ \\
\hline
\end{tabular}




\section{APPENDIX O}

Scores on initial and final texts, average scores of the first three texts (A 1-3) and the last three texts (A 18-20) for group 4 in the first experiment

\begin{tabular}{|c|c|c|c|c|c|c|c|c|c|}
\hline $\mathrm{P}$ & $1 \mathrm{st}$ text & 2nd text & 3rd text & 18th text & 19th text & 20th text & A $1-3$ & A $18-20$ & D \\
\hline 40 & 115 & 146 & 160 & 314 & 314 & 264 & 140 & 297 & 157 \\
\hline $4 \mathrm{M}$ & 134 & 165 & 165 & 275 & 275 & 254 & 155 & 268 & 113 \\
\hline $4 \mathrm{U}$ & 105 & 137 & 100 & 188 & 236 & 227 & 114 & 217 & 103 \\
\hline $4 \mathrm{R}$ & 124 & 126 & 212 & 206 & 254 & 254 & 154 & 238 & 84 \\
\hline $4 \mathrm{~F}$ & 105 & 183 & 200 & 227 & 236 & 244 & 163 & 236 & 73 \\
\hline 4B & 150 & 227 & 150 & 275 & 227 & 227 & 176 & 243 & 67 \\
\hline $4 \mathrm{~T}$ & 129 & 169 & 169 & 206 & 236 & 220 & 156 & 221 & 65 \\
\hline $4 N$ & 117 & 150 & 194 & 212 & 212 & 227 & 154 & 217 & 63 \\
\hline $4 \mathrm{~A}$ & 100 & 122 & 146 & 188 & 169 & 200 & 123 & 186 & 63 \\
\hline $4 \mathrm{H}$ & 108 & 183 & 137 & 169 & 200 & 220 & 143 & 196 & 54 \\
\hline $4 \mathrm{P}$ & 110 & 183 & 157 & 200 & 194 & 200 & 150 & 198 & 48 \\
\hline $4 Q$ & 110 & 124 & 132 & 174 & 137 & 174 & 122 & 162 & 40 \\
\hline $4 \mathrm{~K}$ & 110 & 106 & 91 & 122 & 137 & 124 & 102 & 128 & 25 \\
\hline $4 \mathrm{~L}$ & 269 & 183 & 200 & 236 & 254 & 220 & 217 & 237 & 19 \\
\hline $4 \mathrm{G}$ & 137 & 129 & 183 & 183 & 153 & 169 & 150 & 168 & 19 \\
\hline $4 \mathrm{I}$ & 110 & 188 & 157 & 165 & 146 & 174 & 152 & 162 & 10 \\
\hline $4 \mathrm{C}$ & 137 & 244 & 140 & 137 & 146 & 169 & 174 & 151 & -23 \\
\hline $4 \mathrm{~J}$ & 110 & 188 & 110 & 111 & 97 & 124 & 136 & 111 & -25 \\
\hline & 127 & 164 & 156 & 199 & 201 & 205 & 149 & 202 & 53 \\
\hline
\end{tabular}




\section{APPENDIX P}

Initial speed (SP) and final speed (FS) on other types of texts for all participants in the first experiment

\begin{tabular}{|c|c|c|c|c|c|c|c|c|c|c|c|c|c|c|}
\hline P & IS & FS & P & IS & FS & P & IS & FS & P & IS & FS & P & IS & FS \\
\hline 0A & 102 & 193 & $1 \mathrm{~A}$ & 108 & 206 & $2 \mathrm{~A}$ & 80 & 151 & $3 \mathrm{~A}$ & 119 & 188 & $4 \mathrm{~A}$ & 123 & 177 \\
\hline 0AA & 81 & 151 & $1 \mathrm{~B}$ & 70 & 126 & $2 \mathrm{~B}$ & 75 & 191 & $3 \mathrm{~B}$ & 106 & 157 & $4 \mathrm{~B}$ & 151 & 258 \\
\hline 0B & 120 & 189 & $1 \mathrm{C}$ & 169 & 194 & $2 \mathrm{C}$ & 85 & 150 & $3 \mathrm{~F}$ & 63 & 198 & $4 \mathrm{C}$ & 152 & 184 \\
\hline 0C & 100 & 137 & $1 \mathrm{D}$ & 151 & 267 & $2 \mathrm{D}$ & 98 & 153 & $3 \mathrm{G}$ & 104 & 136 & $4 \mathrm{~F}$ & 109 & 219 \\
\hline 0D & 84 & 236 & $1 \mathrm{E}$ & 92 & 168 & $2 \mathrm{E}$ & 88 & 84 & $3 \mathrm{H}$ & 146 & 169 & $4 \mathrm{G}$ & 93 & 132 \\
\hline 0E & 77 & 147 & $1 \mathrm{~F}$ & 102 & 133 & $2 \mathrm{~F}$ & 119 & 123 & $3 \mathrm{I}$ & 93 & 179 & $4 \mathrm{H}$ & 128 & 129 \\
\hline 0F & 121 & 117 & $1 \mathrm{H}$ & 81 & 164 & $2 \mathrm{G}$ & 81 & 183 & $3 \mathrm{~J}$ & 77 & 161 & $4 \mathrm{I}$ & 83 & 142 \\
\hline 0H & 121 & 171 & $1 \mathrm{I}$ & 80 & 130 & $2 \mathrm{H}$ & 73 & 168 & $3 \mathrm{~L}$ & 109 & 269 & $4 \mathrm{~J}$ & 86 & 102 \\
\hline 0I & 112 & 168 & $1 \mathrm{~J}$ & 106 & 154 & $2 \mathrm{I}$ & 37 & 75 & $3 \mathrm{M}$ & 78 & 139 & $4 \mathrm{~K}$ & 81 & 137 \\
\hline 0J & 92 & 140 & $1 \mathrm{~K}$ & 80 & 234 & $2 \mathrm{~J}$ & 127 & 218 & $3 \mathrm{~N}$ & 106 & 152 & $4 \mathrm{~L}$ & 86 & 177 \\
\hline 0L & 129 & 141 & $1 \mathrm{~L}$ & 77 & 191 & $2 \mathrm{~K}$ & 56 & 194 & $3 \mathrm{O}$ & 129 & 205 & $4 \mathrm{M}$ & 80 & 195 \\
\hline 0M & 91 & 136 & $1 \mathrm{M}$ & 139 & 227 & $2 \mathrm{M}$ & 155 & 147 & $3 \mathrm{P}$ & 124 & 142 & $4 \mathrm{~N}$ & 87 & 227 \\
\hline 0N & 132 & 158 & $1 \mathrm{~N}$ & 61 & 142 & $2 \mathrm{P}$ & 97 & 118 & $3 \mathrm{Q}$ & 98 & 238 & $4 \mathrm{O}$ & 95 & 143 \\
\hline 0Q & 92 & 110 & $1 \mathrm{O}$ & 111 & 208 & $2 \mathrm{R}$ & 83 & 192 & $3 \mathrm{R}$ & 100 & 142 & $4 \mathrm{P}$ & 148 & 220 \\
\hline 0R & 123 & 115 & $1 \mathrm{P}$ & 127 & 239 & $2 \mathrm{~S}$ & 92 & 152 & $3 \mathrm{~S}$ & 108 & 235 & $4 \mathrm{Q}$ & 148 & 164 \\
\hline 0S & 140 & 154 & $1 \mathrm{Q}$ & 133 & 206 & $2 \mathrm{~T}$ & 307 & 260 & $3 \mathrm{U}$ & 128 & 193 & $4 \mathrm{R}$ & 101 & 223 \\
\hline 0T & 168 & 253 & $1 \mathrm{R}$ & 165 & 234 & $2 \mathrm{U}$ & 140 & 174 & $3 \mathrm{~W}$ & 94 & 262 & $4 \mathrm{~T}$ & 122 & 237 \\
\hline 0U & 97 & 224 & $1 \mathrm{~S}$ & 80 & 135 & $2 \mathrm{~V}$ & 100 & 140 & $3 \mathrm{X}$ & 124 & 158 & $4 \mathrm{U}$ & 93 & 193 \\
\hline 0V & 78 & 181 & & & & $2 \mathrm{~W}$ & 62 & 186 & & & & & & \\
\hline 0X & 79 & 85 & & & & & & & & & & & & \\
\hline 0Y & 84 & 137 & & & & & & & & & & & & \\
\hline 0Z & 36 & 150 & & & & & & & & & & & & \\
\hline
\end{tabular}




\section{APPENDIX Q}

Speed increases (SI) on other types of texts for all participants in the first experiment

\begin{tabular}{|c|c|c|c|c|c|c|c|c|c|}
\hline$P$ & SI & $\mathrm{P}$ & SI & $P$ & SI & $P$ & SI & $P$ & SI \\
\hline OR & -8 & $1 \mathrm{C}$ & 25 & $2 \mathrm{~T}$ & -47 & $3 P$ & 18 & $4 \mathrm{H}$ & 1 \\
\hline $0 \mathrm{~F}$ & -4 & $1 \mathrm{~F}$ & 31 & $2 \mathrm{M}$ & -8 & $3 \mathrm{H}$ & 23 & $4 \mathrm{~J}$ & 16 \\
\hline $0 \mathrm{X}$ & 6 & $1 \mathrm{~J}$ & 48 & $2 \mathrm{E}$ & \begin{tabular}{l|}
-4 \\
\end{tabular} & $3 \mathrm{G}$ & 32 & $4 \mathrm{Q}$ & 16 \\
\hline $0 \mathrm{~L}$ & 12 & 1I & 50 & $2 \mathrm{~F}$ & 4 & $3 X$ & 34 & $4 \mathrm{C}$ & 32 \\
\hline $0 \mathrm{~S}$ & 14 & $1 \mathrm{~S}$ & 55 & $2 \mathrm{P}$ & 21 & $3 R$ & 42 & $4 \mathrm{G}$ & 39 \\
\hline $0 \mathrm{Q}$ & 18 & 1B & 56 & $2 \mathrm{U}$ & 34 & $3 \mathrm{~N}$ & 46 & 40 & 48 \\
\hline $0 \mathrm{~N}$ & 26 & $1 \mathrm{R}$ & 69 & 2I & 38 & $3 \mathrm{~B}$ & 51 & $4 \mathrm{~A}$ & 54 \\
\hline $0 \mathrm{C}$ & 37 & $1 \mathrm{Q}$ & 73 & $2 \mathrm{~V}$ & 40 & $3 \mathrm{M}$ & 61 & $4 \mathrm{~K}$ & 56 \\
\hline $0 \mathrm{M}$ & 45 & $1 \mathrm{E}$ & 76 & $2 \mathrm{D}$ & 55 & $3 \mathrm{U}$ & 65 & 4I & 59 \\
\hline $0 \mathrm{~J}$ & 48 & $1 \mathrm{~N}$ & 81 & $2 \mathrm{~S}$ & 60 & $3 \mathrm{~A}$ & 69 & $4 \mathrm{P}$ & 72 \\
\hline $0 \mathrm{H}$ & 50 & $1 \mathrm{H}$ & 83 & $2 \mathrm{C}$ & 65 & 30 & 76 & $4 \mathrm{~L}$ & 91 \\
\hline $0 \mathrm{Y}$ & 53 & $1 \mathrm{M}$ & 88 & $2 \mathrm{~A}$ & 71 & $3 \mathrm{~J}$ & 84 & $4 \mathrm{U}$ & 100 \\
\hline OI & 56 & 10 & 97 & $2 \mathrm{~J}$ & 91 & 3I & 86 & $4 \mathrm{~B}$ & 107 \\
\hline OB & 69 & $1 \mathrm{~A}$ & 98 & $2 \mathrm{H}$ & 95 & $3 \mathrm{~S}$ & 127 & $4 \mathrm{~F}$ & 110 \\
\hline 0AA & 70 & $1 \mathrm{P}$ & 112 & $2 \mathrm{G}$ & 102 & $3 \mathrm{~F}$ & 135 & $4 \mathrm{M}$ & 115 \\
\hline $0 \mathrm{E}$ & 70 & $1 \mathrm{~L}$ & 114 & $2 \mathrm{R}$ & 109 & $3 \mathrm{Q}$ & 140 & $4 \mathrm{~T}$ & 115 \\
\hline OT & 85 & 1D & 116 & $2 \mathrm{~B}$ & 116 & $3 \mathrm{~L}$ & 160 & $4 \mathrm{R}$ & 122 \\
\hline $0 \mathrm{~A}$ & 91 & $1 \mathrm{~K}$ & 154 & $2 \mathrm{~W}$ & 124 & $3 \mathrm{~W}$ & 168 & $4 \mathrm{~N}$ & 140 \\
\hline $0 \mathrm{~V}$ & 103 & & & $2 \mathrm{~K}$ & 138 & & & & \\
\hline $0 \mathrm{Z}$ & 114 & & & & & & & & \\
\hline $0 \mathrm{U}$ & 127 & & & & & & & & \\
\hline OD & 152 & & & & & & & & \\
\hline
\end{tabular}




\section{APPENDIX R}

The first score, the last score, the average of the first three scores, the average of the last three scores in the speed reading course by the two treatment groups in the second experiment

\begin{tabular}{|c|c|c|c|c|c|c|c|c|c|}
\hline $\mathrm{P}$ & 1st & $20^{\text {th }}$ & $\begin{array}{c}\text { First } 3 \\
\text { texts }\end{array}$ & $\begin{array}{c}\text { Last } 3 \\
\text { texts }\end{array}$ & $\mathrm{P}$ & $1 \mathrm{st}$ & $20^{\text {th }}$ & $\begin{array}{l}1^{\text {st }} 3 \\
\text { texts }\end{array}$ & $\begin{array}{c}\text { Last } 3 \\
\text { texts }\end{array}$ \\
\hline A1 & 150 & 170 & 148 & 167 & B1 & 94 & 245 & 105 & 229 \\
\hline A10 & 150 & 194 & 141 & 194 & B10 & 118 & 141 & 117 & 142 \\
\hline A11 & 104 & 275 & 130 & 226 & B11 & 138 & 157 & 140 & 155 \\
\hline A12 & 104 & 174 & 110 & 172 & B12 & 93 & 132 & 93 & 128 \\
\hline A13 & 92 & 150 & 92 & 151 & B13 & 147 & 228 & 164 & 218 \\
\hline A14 & 125 & 174 & 144 & 189 & B14 & 144 & 183 & 127 & 214 \\
\hline A15 & 122 & 183 & 148 & 185 & B15 & 108 & 174 & 112 & 180 \\
\hline A16 & 92 & 189 & 109 & 198 & B16 & 108 & 147 & 130 & 155 \\
\hline A17 & 157 & 157 & 143 & 157 & B17 & 127 & 254 & 136 & 237 \\
\hline A18 & 154 & 245 & 160 & 248 & B18 & 114 & 213 & 132 & 213 \\
\hline A19 & 99 & 165 & 109 & 174 & B19 & 135 & 154 & 121 & 160 \\
\hline $\mathrm{A} 2$ & 103 & $\begin{array}{l}189 \\
\end{array}$ & 108 & 191 & B2 & 147 & 161 & 148 & 157 \\
\hline A20 & 110 & 300 & 110 & 301 & B20 & 138 & 183 & 149 & 189 \\
\hline A21 & 174 & 264 & 161 & 236 & B21 & 154 & 183 & 158 & 187 \\
\hline A22 & 94 & 189 & 100 & 182 & B22 & 165 & 275 & 152 & 268 \\
\hline A23 & 110 & 132 & 104 & 117 & B23 & 110 & 200 & 125 & 209 \\
\hline A24 & 165 & 275 & 186 & 271 & B24 & 92 & 127 & 102 & 131 \\
\hline A25 & 127 & 170 & 123 & 178 & B25 & 157 & 141 & 124 & 142 \\
\hline A26 & 103 & 165 & 108 & 160 & B26 & 174 & 183 & 133 & 165 \\
\hline A27 & 150 & 236 & 147 & 233 & B27 & 97 & 144 & 99 & 148 \\
\hline A28 & 122 & 178 & 200 & 177 & B28 & 130 & 161 & 134 & 163 \\
\hline A29 & 103 & 150 & 120 & 146 & B29 & 99 & 170 & 98 & 167 \\
\hline A3 & 110 & 138 & 104 & 133 & B3 & 174 & 206 & 165 & 221 \\
\hline A30 & 165 & 200 & 181 & 200 & B30 & 150 & 236 & 160 & 236 \\
\hline A31 & 161 & 183 & 152 & 201 & B4 & 174 & 228 & 184 & 223 \\
\hline A4 & 112 & 206 & 102 & 202 & B5 & 110 & 125 & 100 & 121 \\
\hline A5 & 108 & 135 & 119 & 164 & B6 & 138 & 220 & 161 & 220 \\
\hline A6 & 118 & 150 & 118 & 150 & B7 & 170 & 178 & 136 & 172 \\
\hline A7 & 147 & 200 & 137 & 209 & B8 & 108 & 165 & 111 & 155 \\
\hline A8 & 144 & 206 & 126 & 211 & B9 & 170 & 200 & 155 & 196 \\
\hline A9 & 213 & 138 & 151 & 133 & & & & & \\
\hline
\end{tabular}




\section{APPENDIX S}

The slowest (SS) and fastest speeds (FS), the average of the three slowest (ASS) and the three fastest speeds (AFS) in the course for the treatment groups in the second experiment

\begin{tabular}{|c|c|c|c|c|c|c|c|c|c|c|c|c|c|}
\hline$P$ & ASS & AFS & D & SS & FS & D & $\mathrm{P}$ & ASS & AFS & D & SS & FS & D \\
\hline A1 & 138 & 171 & 33 & 132 & 174 & 42 & B1 & 96 & 234 & 137 & 92 & 245 & 153 \\
\hline $\mathrm{A} 10$ & $\begin{array}{ll}137 \\
\end{array}$ & 198 & 61 & 118 & 200 & 82 & $\mathrm{~B} 10$ & 117 & 151 & 34 & 116 & 154 & 38 \\
\hline A11 & 104 & 229 & 126 & 97 & 275 & 178 & B11 & 118 & 187 & 69 & 116 & 200 & 84 \\
\hline $\mathrm{A} 12$ & 102 & 177 & 75 & 93 & 178 & 85 & B12 & 93 & 130 & 37 & 92 & 132 & 40 \\
\hline A13 & 92 & 157 & 65 & 92 & 161 & 69 & $\mathrm{~B} 13$ & 151 & 218 & 67 & 147 & 228 & 81 \\
\hline A14 & 133 & 211 & 78 & 125 & 220 & 95 & B14 & 105 & 248 & 143 & 92 & 275 & 183 \\
\hline A15 & 133 & 185 & 52 & 122 & 189 & 67 & B15 & 108 & 181 & 73 & 108 & 183 & 75 \\
\hline A16 & 105 & 200 & 95 & 92 & 206 & 114 & B16 & 130 & 168 & 38 & 108 & 170 & 62 \\
\hline A17 & 113 & 167 & 53 & 108 & 165 & 57 & B17 & 135 & 237 & 101 & 127 & 254 & 127 \\
\hline A18 & 159 & 251 & 92 & 154 & 254 & 100 & B18 & 121 & 213 & 92 & 114 & 213 & 99 \\
\hline A19 & 97 & 184 & 87 & 97 & 194 & 97 & B19 & 98 & 176 & 78 & 94 & 183 & 89 \\
\hline $\mathrm{A} 2$ & 108 & 201 & 93 & 102 & 220 & 118 & B2 & 125 & 158 & 33 & 106 & 161 & 55 \\
\hline A20 & 110 & 301 & 191 & 110 & 315 & 205 & B20 & 143 & 213 & 70 & 138 & 228 & 90 \\
\hline A21 & 145 & 268 & 123 & 132 & 275 & 143 & B21 & 151 & 204 & 53 & 154 & 206 & 52 \\
\hline A22 & 100 & 183 & 84 & 94 & 189 & 95 & B22 & 141 & 268 & 127 & 130 & 275 & 145 \\
\hline A23 & 92 & 126 & 34 & 92 & 132 & 40 & B23 & 123 & 211 & 87 & 110 & 220 & 110 \\
\hline A24 & 177 & 271 & 94 & 165 & 275 & 110 & B24 & 93 & 152 & 58 & 92 & 170 & 78 \\
\hline A25 & 102 & 183 & 80 & 92 & 200 & 108 & B25 & 92 & 166 & 73 & 92 & 183 & 91 \\
\hline A26 & 102 & 165 & 63 & 99 & 170 & 71 & B26 & 110 & 171 & 62 & 103 & 183 & 80 \\
\hline A27 & 141 & 233 & 93 & 125 & 236 & 111 & B27 & 97 & 160 & 63 & 92 & 174 & 82 \\
\hline A28 & 120 & 233 & 113 & 114 & 348 & 234 & $\mathrm{~B} 28$ & 134 & 170 & 35 & 130 & 178 & 48 \\
\hline A29 & 108 & 183 & 75 & 103 & 183 & 80 & B29 & 98 & 168 & 71 & 94 & 170 & 76 \\
\hline $\mathrm{A} 3$ & 102 & 134 & 32 & 99 & 138 & 39 & B3 & 156 & 237 & 81 & 144 & 254 & 110 \\
\hline A30 & 170 & 204 & 34 & 165 & 206 & 41 & B30 & 142 & 255 & 112 & 127 & 264 & 137 \\
\hline A31 & 144 & 231 & 87 & 144 & 236 & 92 & B4 & 175 & 223 & 47 & 174 & 228 & 54 \\
\hline A4 & 100 & 202 & 102 & 93 & 206 & 113 & B5 & 94 & 128 & 34 & 92 & 127 & 35 \\
\hline A5 & 108 & 176 & 68 & 104 & 183 & 79 & B6 & 147 & 265 & 118 & 138 & 275 & 137 \\
\hline A6 & 118 & 158 & 40 & 112 & 161 & 49 & B7 & 113 & 181 & 69 & 108 & 183 & 75 \\
\hline A7 & 129 & 223 & 94 & 122 & 220 & 98 & B8 & 111 & 174 & 63 & 108 & 178 & 70 \\
\hline A8 & 109 & 213 & 104 & 103 & 220 & 117 & B9 & 132 & 202 & 70 & 127 & 206 & 79 \\
\hline A9 & 115 & 186 & 71 & 114 & 213 & 99 & & & & & & & \\
\hline
\end{tabular}




\section{APPENDIX T}

Speed increases on other types of texts for all groups in the second experiment

\begin{tabular}{|c|c|c|c|c|c|c|c|}
\hline Group A & Increase & Group B & Increase & Group C & Increase & Group D & Increase \\
\hline A19 & -8 & B12 & 2 & C6 & -22 & D27 & -31 \\
\hline A6 & -6 & B20 & 3 & C16 & -18 & D21 & -21 \\
\hline A7 & 6 & B7 & 18 & $\mathrm{C} 13$ & -17 & D16 & -20 \\
\hline A14 & 9 & B23 & 19 & C14 & -17 & D26 & -19 \\
\hline A2 & 15 & B26 & 22 & C7 & -14 & D19 & -2 \\
\hline A13 & 21 & B22 & 25 & $\mathrm{C} 4$ & -10 & D25 & 2 \\
\hline A26 & 23 & B21 & 29 & C9 & -8 & D5 & 3 \\
\hline A29 & 23 & B1 & 33 & $\mathrm{C} 2$ & -2 & D17 & 4 \\
\hline A4 & 28 & B11 & 33 & $\mathrm{C} 12$ & -1 & $\mathrm{D} 28$ & 5 \\
\hline A9 & 29 & B5 & 42 & C24 & 1 & D23 & 8 \\
\hline A12 & 30 & B27 & 45 & $\mathrm{C} 5$ & 3 & D8 & 10 \\
\hline A23 & 31 & B18 & 48 & $\mathrm{C} 3$ & 8 & D22 & 13 \\
\hline A25 & 39 & B10 & 49 & $\mathrm{C} 15$ & 13 & D13 & 15 \\
\hline A11 & 47 & B8 & 49 & $\mathrm{C} 18$ & 15 & D15 & 15 \\
\hline A10 & 48 & B13 & 52 & $\mathrm{C} 21$ & 18 & D14 & 17 \\
\hline A1 & 54 & B4 & 52 & $\mathrm{C} 10$ & 19 & D6 & 21 \\
\hline A27 & 54 & B17 & 53 & C11 & 21 & D11 & 24 \\
\hline A5 & 56 & B14 & 56 & $\mathrm{C} 22$ & 26 & D29 & 26 \\
\hline A21 & 58 & B6 & 56 & $\mathrm{C} 26$ & 30 & D2 & 28 \\
\hline A15 & 61 & B16 & 62 & $\mathrm{C} 8$ & 30 & D1 & 31 \\
\hline A24 & 64 & B28 & 65 & C19 & 31 & D10 & 33 \\
\hline A22 & 65 & B2 & 68 & C17 & 32 & D9 & 35 \\
\hline A17 & 68 & B19 & 72 & $\mathrm{C} 25$ & 32 & D4 & 37 \\
\hline A31 & 68 & B3 & 72 & $\mathrm{C} 1$ & 33 & D24 & 41 \\
\hline A18 & 70 & B9 & 74 & $\mathrm{C} 20$ & 34 & D7 & 44 \\
\hline A3 & 71 & B29 & 80 & $\mathrm{C} 23$ & 39 & D12 & 45 \\
\hline $\mathrm{A} 20$ & 72 & B15 & 83 & & & D20 & 53 \\
\hline A30 & 73 & B25 & 83 & & & D18 & 59 \\
\hline A8 & 82 & B30 & 85 & & & D3 & 101 \\
\hline A16 & 87 & B24 & 88 & & & & \\
\hline A28 & 92 & & & & & & \\
\hline
\end{tabular}




\section{APPENDIX U}

Initial speed (Initial) and final speed (Final) on other types of texts for all groups in the second experiment

\begin{tabular}{|c|c|c|c|c|c|c|c|c|c|c|c|}
\hline $\mathrm{P}$ & Initial & Final & $\mathrm{P}$ & Initial & Final & $\mathrm{P}$ & Initial & Final & $\mathrm{P}$ & Initial & Final \\
\hline A30 & 49 & 123 & B24 & 46 & 135 & $\mathrm{C} 5$ & 67 & $\begin{array}{ll}109 \\
\end{array}$ & D22 & 71 & 84 \\
\hline A22 & 66 & 132 & B8 & 55 & 104 & C6 & 85 & 122 & D8 & 71 & 81 \\
\hline A23 & 73 & 104 & B25 & 65 & 147 & C9 & 85 & 127 & D11 & 76 & 99 \\
\hline A28 & 76 & 168 & B19 & 67 & 139 & $\mathrm{C} 1$ & 89 & 122 & D23 & 76 & 84 \\
\hline A10 & 78 & 126 & B11 & 76 & 109 & $\mathrm{C} 21$ & 93 & 135 & D3 & 79 & 180 \\
\hline A1 & 83 & 137 & B26 & 83 & 105 & $\mathrm{C} 20$ & 94 & 100 & D10 & 84 & 117 \\
\hline A16 & 90 & 177 & B27 & 84 & 129 & C8 & 103 & 164 & D12 & 84 & 129 \\
\hline A31 & 91 & 159 & B9 & 87 & 161 & $\mathrm{C} 4$ & 106 & 117 & D6 & 86 & 108 \\
\hline A12 & 96 & 126 & B30 & 94 & 179 & C11 & 107 & 128 & D1 & 92 & 123 \\
\hline A2 & 101 & 116 & B17 & 98 & 151 & C14 & 107 & 143 & D14 & 94 & 111 \\
\hline A4 & 103 & 131 & B4 & 98 & 150 & C10 & 111 & 122 & D18 & 97 & 155 \\
\hline A26 & 105 & 127 & B5 & 107 & 149 & C17 & 112 & 116 & D2 & 98 & 126 \\
\hline A27 & 107 & 161 & B1 & 108 & 141 & $\mathrm{C} 22$ & 116 & 111 & D9 & 102 & 137 \\
\hline A17 & 111 & 178 & B15 & 112 & 195 & $\mathrm{C} 2$ & 118 & 132 & D20 & 103 & 156 \\
\hline A20 & 114 & 186 & B13 & 126 & 177 & $\mathrm{C} 26$ & 121 & 146 & D29 & 108 & 134 \\
\hline A9 & 121 & 150 & B2 & 127 & 194 & C19 & 123 & 137 & D24 & 119 & 159 \\
\hline A29 & 123 & 146 & B6 & 127 & 182 & $\mathrm{C} 24$ & 127 & 95 & D25 & 121 & 123 \\
\hline A11 & 124 & 171 & B14 & 129 & 184 & C12 & 134 & 138 & D15 & 124 & 138 \\
\hline A18 & 124 & 194 & B18 & 132 & 180 & $\mathrm{C} 23$ & 134 & 192 & D4 & 125 & 162 \\
\hline A19 & 129 & 121 & B7 & 136 & 153 & C13 & 135 & 146 & D19 & 127 & 125 \\
\hline A21 & 130 & 189 & B29 & 148 & 228 & C15 & 138 & 125 & D7 & 134 & 177 \\
\hline A25 & 130 & 169 & B28 & 149 & 214 & $\mathrm{C} 25$ & 143 & 124 & D26 & 141 & 122 \\
\hline A5 & 132 & 188 & B3 & 150 & 222 & C7 & 153 & 107 & D16 & 144 & 124 \\
\hline A8 & 153 & 235 & B10 & 153 & 202 & C16 & 160 & 151 & D17 & 145 & 149 \\
\hline A24 & 157 & 222 & B16 & 155 & 217 & C3 & 163 & 119 & D21 & 152 & 131 \\
\hline A14 & 163 & 171 & B22 & 157 & 182 & C18 & 169 & 137 & D13 & 157 & 171 \\
\hline A6 & 165 & 160 & B21 & 161 & 190 & & & & D28 & 158 & 162 \\
\hline A3 & 167 & 238 & B23 & 181 & 200 & & & & D5 & 159 & 161 \\
\hline A13 & 173 & 194 & B12 & 183 & 185 & & & & D27 & 174 & 143 \\
\hline A7 & 174 & 180 & B20 & 198 & 201 & & & & & & \\
\hline A15 & 177 & 237 & & & & & & & & & \\
\hline
\end{tabular}




\section{APPENDIX V}

Initial scores (IS), final scores (FS) and increases (I) in oral reading for all groups in the second experiment

\begin{tabular}{|c|c|c|c|c|c|c|c|c|c|c|c|c|c|c|c|}
\hline $\mathrm{P}$ & IS & FS & I & $\mathrm{P}$ & IS & FS & I & $\mathrm{P}$ & IS & FS & I & $\mathrm{P}$ & IS & FS & I \\
\hline A16 & 159 & 196 & 37 & B27 & 105 & 142 & 37 & $\mathrm{C} 4$ & 167 & 189 & 22 & D17 & 163 & 183 & 20 \\
\hline A15 & 185 & 218 & 33 & B22 & 221 & 255 & 35 & $\mathrm{C} 20$ & 155 & 175 & 20 & D19 & 128 & 148 & 20 \\
\hline A27 & 175 & 200 & 25 & B4 & 226 & 251 & 25 & $\mathrm{C} 1$ & 137 & 154 & 16 & D9 & 179 & 198 & 19 \\
\hline A25 & 166 & 188 & 22 & B17 & 175 & 196 & 22 & C19 & 126 & 140 & 15 & D16 & 173 & 187 & 14 \\
\hline A31 & 135 & 156 & 21 & B3 & 201 & 221 & 20 & C13 & 199 & 209 & 10 & D10 & 140 & 152 & 13 \\
\hline A12 & 199 & 216 & 17 & B6 & 173 & 192 & 19 & $\mathrm{C} 24$ & 196 & 206 & 10 & D3 & 155 & 167 & 12 \\
\hline A23 & 161 & 179 & 17 & B18 & 163 & 179 & 16 & $\mathrm{C} 12$ & 160 & 169 & 9 & D8 & 179 & 188 & 10 \\
\hline A30 & 191 & 209 & 17 & B16 & 142 & 156 & 14 & C5 & 150 & 159 & 9 & D20 & 181 & 189 & 8 \\
\hline A6 & 131 & 148 & 17 & B11 & 181 & 194 & 13 & C9 & 187 & 194 & 7 & D21 & 168 & 177 & 8 \\
\hline A17 & 154 & 169 & 16 & B29 & 201 & 213 & 12 & C14 & 196 & 201 & 5 & D26 & 148 & 153 & 6 \\
\hline A5 & 157 & 169 & 12 & B20 & 187 & 198 & 11 & $\mathrm{C} 2$ & 161 & 166 & 4 & D4 & 194 & 200 & 6 \\
\hline A20 & 191 & 202 & 11 & B10 & 156 & 166 & 10 & C3 & 183 & 187 & 4 & D7 & 198 & 204 & 6 \\
\hline A8 & 226 & 236 & 11 & B7 & 149 & 158 & 9 & C17 & 179 & 181 & 3 & D24 & 151 & 156 & 5 \\
\hline A9 & 171 & 183 & 11 & B14 & 194 & 201 & 7 & $\mathrm{C} 10$ & 153 & 155 & 2 & D5 & 173 & 178 & 5 \\
\hline A28 & 136 & 146 & 10 & B28 & 206 & 213 & 7 & $\mathrm{C} 15$ & 189 & 190 & 1 & D15 & 142 & 146 & 3 \\
\hline A14 & 206 & 214 & 8 & B1 & 170 & 175 & 5 & C7 & 189 & 188 & -1 & D23 & 168 & 171 & 3 \\
\hline A2 & 153 & 161 & 8 & B15 & 169 & 175 & 5 & C18 & 153 & 151 & -2 & D14 & 152 & 155 & 2 \\
\hline A19 & 189 & 196 & 7 & B23 & 124 & 129 & 5 & C6 & 183 & 181 & -2 & D29 & 181 & 183 & 2 \\
\hline A13 & 185 & 189 & 5 & B21 & 179 & 183 & 3 & $\mathrm{C} 23$ & 188 & 183 & -6 & D1 & 164 & 166 & 1 \\
\hline A1 & 145 & 149 & 4 & B30 & 204 & 206 & 3 & C16 & 168 & 161 & -8 & D2 & 164 & 166 & 1 \\
\hline A7 & 186 & 189 & 3 & B2 & 134 & 136 & 2 & $\mathrm{C} 25$ & 201 & 192 & -9 & D22 & 183 & 183 & 0 \\
\hline A22 & 156 & 158 & 2 & B12 & 155 & 156 & 1 & $\mathrm{C} 22$ & 157 & 148 & -10 & D25 & 223 & 223 & 0 \\
\hline A26 & 150 & 151 & 1 & B26 & 154 & 155 & 1 & $\mathrm{C} 26$ & 185 & 175 & -10 & D27 & 129 & 129 & 0 \\
\hline A29 & 158 & 159 & 1 & B24 & 206 & 204 & -3 & $\mathrm{C} 21$ & 189 & 178 & -11 & D18 & 247 & 246 & -1 \\
\hline A18 & 196 & 196 & 0 & B8 & 185 & 181 & -4 & $\mathrm{C} 8$ & 185 & 166 & -19 & D12 & 217 & 209 & -9 \\
\hline A4 & 166 & 166 & 0 & B19 & 190 & 185 & -5 & $\mathrm{C} 11$ & 259 & 234 & -25 & D11 & 150 & 137 & -13 \\
\hline A10 & 216 & 214 & -1 & B25 & 178 & 173 & -5 & & & & & D13 & 196 & 183 & -13 \\
\hline A11 & 171 & 163 & -8 & B5 & 173 & 167 & -6 & & & & & D28 & 194 & 181 & -13 \\
\hline A3 & 137 & 129 & -9 & B9 & 204 & 196 & -8 & & & & & D6 & 207 & 185 & -22 \\
\hline A 21 & 145 & 134 & -11 & B13 & 201 & 192 & -9 & & & & & & & & \\
\hline \multirow[t]{2}{*}{ A24 } & 199 & 185 & -14 & & & & & & & & & & & & \\
\hline & 171 & 180 & 9 & & 177 & 185 & 8 & & 177 & 178 & 1 & & 174 & 177 & 3 \\
\hline
\end{tabular}




\section{APPENDIX W}

Initial scores (IS), final scores (FS) and increases (I) in memory span for all participants in the second experiment

\begin{tabular}{|c|c|c|c|c|c|c|c|c|c|c|c|c|c|c|c|}
\hline $\bar{P}$ & IS & FS & I & $P$ & IS & FS & I & $P$ & IS & FS & I & $P$ & IS & FS & $\mathrm{I}$ \\
\hline A11 & 8 & 7 & -1 & B12 & 8 & 8 & 0 & $\mathrm{C} 25$ & 13 & 8 & -5 & D5 & 18 & 5 & -13 \\
\hline A2 & 10 & 9 & -1 & B26 & 14 & 15 & 1 & C10 & 9 & 5 & $\begin{array}{l}-4 \\
\end{array}$ & D17 & 17 & 10 & -7 \\
\hline A10 & 17 & 18 & 1 & B27 & 3 & 4 & 1 & C12 & 13 & 9 & $\begin{array}{l}-4 \\
\end{array}$ & D3 & 13 & 6 & $\begin{array}{l}-7 \\
\end{array}$ \\
\hline A12 & 16 & 18 & 2 & B3 & 15 & 16 & 1 & $\mathrm{C} 24$ & 13 & 9 & -4 & D10 & 12 & 8 & -4 \\
\hline A30 & 12 & 15 & 3 & B18 & 15 & 17 & 2 & C22 & 13 & 10 & -3 & D2 & 14 & 12 & -2 \\
\hline A8 & 14 & 17 & 3 & B4 & 13 & 15 & 2 & C11 & 14 & 12 & -2 & $\mathrm{D} 24$ & 8 & 7 & -1 \\
\hline A9 & 13 & 16 & 3 & $\mathrm{~B} 10$ & 11 & 14 & 3 & $\mathrm{C} 1$ & 12 & 11 & $\begin{array}{l}-1 \\
\end{array}$ & D11 & 13 & 13 & 0 \\
\hline $\mathrm{A} 1$ & 12 & 16 & 4 & B19 & 9 & 12 & 3 & C14 & 15 & 14 & -1 & D18 & 13 & 13 & 0 \\
\hline A17 & 9 & 13 & 4 & B20 & 11 & 14 & 3 & $\mathrm{C} 2$ & 11 & 10 & -1 & D19 & 13 & 13 & 0 \\
\hline A22 & 12 & 16 & 4 & B5 & 12 & 15 & 3 & $\mathrm{C} 4$ & 9 & 8 & -1 & D20 & 12 & 12 & 0 \\
\hline A31 & 11 & 15 & 4 & B23 & 11 & 15 & 4 & C8 & 8 & 8 & 0 & D6 & 12 & 12 & 0 \\
\hline A6 & 11 & 15 & 4 & B30 & 9 & 13 & 4 & C13 & 8 & 9 & 1 & D7 & 11 & 11 & 0 \\
\hline A14 & 9 & 14 & 5 & B1 & 10 & 15 & 5 & C17 & 11 & 12 & 1 & D13 & 11 & 12 & 1 \\
\hline A19 & 13 & 18 & 5 & B11 & 10 & 15 & 5 & $\mathrm{C} 18$ & 5 & 6 & 1 & D14 & 8 & 9 & 1 \\
\hline A25 & 10 & 15 & 5 & B14 & 9 & 14 & 5 & C9 & 5 & 6 & 1 & D22 & 7 & 9 & 2 \\
\hline A18 & 7 & 13 & 6 & B16 & 9 & 14 & 5 & C6 & 12 & 14 & 2 & D4 & 11 & 13 & 2 \\
\hline A23 & 13 & 19 & 6 & B22 & 7 & 12 & 5 & C5 & 11 & 14 & 3 & D8 & 9 & 11 & 2 \\
\hline A29 & 9 & 15 & 6 & $\mathrm{~B} 25$ & 12 & 17 & 5 & C20 & 8 & 12 & 4 & D26 & 14 & 17 & 3 \\
\hline A3 & 8 & 14 & 6 & B8 & 10 & 15 & 5 & C21 & 13 & 17 & 4 & $\mathrm{D} 28$ & 10 & 14 & 4 \\
\hline A7 & 5 & 11 & 6 & B13 & 8 & 14 & 6 & C26 & 10 & 14 & 4 & D12 & 13 & 18 & 5 \\
\hline A16 & 9 & 16 & 7 & B15 & 6 & 12 & 6 & C3 & 7 & 12 & 5 & D27 & 8 & 13 & 5 \\
\hline A20 & 8 & 16 & 8 & B17 & 8 & 14 & 6 & C7 & 5 & 10 & 5 & $\mathrm{D} 29$ & 5 & 10 & 5 \\
\hline A24 & 9 & 17 & 8 & B29 & 9 & 15 & 6 & C19 & 8 & 14 & 6 & D1 & 9 & 15 & 6 \\
\hline A26 & 7 & 15 & 8 & B9 & 10 & 16 & 6 & $\mathrm{C} 15$ & 8 & 16 & 8 & D15 & 7 & 13 & 6 \\
\hline A28 & 8 & 16 & 8 & B21 & 10 & 17 & 7 & $\mathrm{C} 23$ & 7 & 15 & 8 & D21 & 10 & 16 & 6 \\
\hline A5 & 5 & 13 & 8 & B24 & 6 & 14 & 8 & C16 & 3 & 12 & 9 & D9 & 3 & 9 & 6 \\
\hline A21 & 8 & 17 & 9 & B28 & 3 & 11 & 8 & & & & & D16 & 3 & 11 & 8 \\
\hline A27 & 6 & 15 & 9 & B7 & 4 & 12 & 8 & & & & & $\mathrm{D} 23$ & 3 & 14 & 11 \\
\hline A4 & 7 & 16 & 9 & B6 & 7 & 16 & 9 & & & & & $\mathrm{D} 25$ & 3 & 14 & 11 \\
\hline A13 & 3 & 13 & 10 & B2 & 7 & 19 & 12 & & & & & & & & \\
\hline A15 & 5 & 15 & 10 & & & & & & & & & & & & \\
\hline
\end{tabular}




\section{APPENDIX X}

Means and standard deviations of slowest speeds, fastest speeds and mean difference in the speed reading course for all groups in the first experiment

\begin{tabular}{cclcccc}
\hline Measure & Methods & & Group 2 & Group 1 & Group 4 & Group 3 \\
\hline \multirow{3}{*}{ Slowest } & \multirow{2}{*}{ Extreme method } & Mean & 122.68 & 130.55 & 118.44 & 132.11 \\
& & SD & 20.61 & 30.07 & 19.92 & 25.94 \\
\cline { 2 - 6 } & Three extremes & Mean & 132.52 & 139.22 & 134.27 & 150.22 \\
& method & SD & 22.02 & 27.32 & 22.19 & 30.87 \\
\hline \multirow{2}{*}{ Fastest } & \multirow{2}{*}{ Extreme method } & Mean & 212.94 & 225.66 & 238.00 & 274.33 \\
\cline { 2 - 6 } speed(s) & Three extremes & Mean & 204.89 & 214.44 & 225.77 & 251.94 \\
& method & SD & 28.27 & 40.47 & 48.76 & 68.29 \\
\hline \multirow{3}{*}{ Mean } & \multirow{2}{*}{ Extreme method } & Mean & 90.26 & 95.22 & 119.55 & 142.22 \\
\cline { 2 - 7 } & Three extremes & MD & 31.57 & 31.84 & 40.60 & 82.15 \\
& Mean & 73.36 & 75.11 & 91.50 & 101.72 \\
& method & SD & 22.68 & 26.79 & 34.70 & 52.70 \\
\hline
\end{tabular}

Means and standard deviations of slowest speeds, fastest speeds and mean difference in the speed reading course for treatment groups in the second experiment

\begin{tabular}{|c|c|c|c|c|}
\hline & & & Group A & Group B \\
\hline & The slowest & Mean & 113.35 & 115.50 \\
\hline \multirow[t]{4}{*}{ Slowest speed(s) } & & SD & 21.22 & 21.84 \\
\hline & Average of the 3 slowest & Mean & 119.77 & 121.63 \\
\hline & & SD & 22.61 & 22.47 \\
\hline & The fastest & Mean & 211.03 & 203.33 \\
\hline \multirow[t]{4}{*}{ Fastest speed(s) } & & SD & 48.73 & 41.88 \\
\hline & Average of the 3 fastest & Mean & 200.12 & 194.96 \\
\hline & & $\mathrm{SD}$ & 39.38 & 38.90 \\
\hline & Extreme method & Mean & 97.67 & 87.83 \\
\hline \multirow[t]{3}{*}{ Mean difference } & & SD & 45.10 & 36.43 \\
\hline & Three extremes method & Mean & 80.38 & 73.16 \\
\hline & & SD & 32.99 & 30.62 \\
\hline
\end{tabular}




\section{APPENDIX Y}

Means and standard deviations of in-course increases as measured by the $20^{\text {th }}$ minus $1^{\text {st }}$ scoring method for the treatment groups in the first experiment

\begin{tabular}{lrrrc}
\hline & Group 2 & Group 1 & Group 4 & Group 3 \\
\hline Mean & 59.57 & 60.38 & 78.38 & 83.55 \\
SD & 44.16 & 32.85 & 52.62 & 51.64 \\
\hline
\end{tabular}

Means and standard deviations of in-course increases as measured by the $20^{\text {th }}$ minus $1^{\text {st }}$ scoring method for the treatment groups in the second experiment

\begin{tabular}{lcc}
\hline & Group A & Group B \\
\hline Mean & 61.03 & 51.03 \\
SD & 48.14 & 38.44 \\
\hline
\end{tabular}

